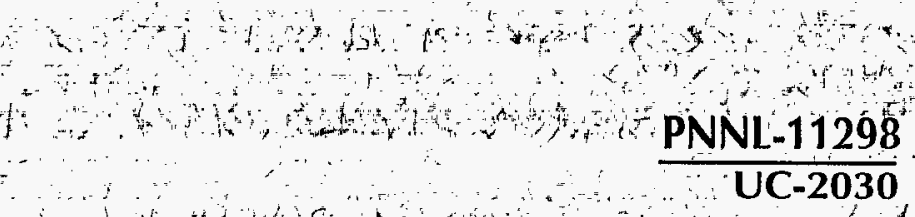

RECEIVED

OCT 041996

\title{
OSTI
}

Mechanisms of Gas Bubble

Retention and Release: Results

for Hanford Waste Tanks

241-S-102 and 241-SY-103 and

Single-Shell Tank Simulants
P. A. Gauglitz
S. D. Rassat
J. H. Konynenbelt
P. R. Bredt
S. M. Tingey
D. P. Mendoza

September 1996

Prepared for the U.S. Department of Energy under Contract DE-AC06-76RLO 1830

Pacific Northwest National Laboratory Operated for the U.S. Department of Energy by Battelle 


\section{Mechanisms of Gas Bubble Retention and Release: Results for Hanford Waste Tanks 241-S-102 and 241-SY-103 and Single-Shell Tank Simulants}
P. A. Gauglitz
J. H. Konynenbelt
S. D. Rassat
S. M. Tingey
P. R. Bredt
D. P. Mendoza

September 1996

Prepared for the U.S. Department of Energy under Contract DE-AC06-76RLO 1830

Pacific Northwest National Laboratory Richland, Washington 99352 


\section{DISCLAIMER}

Portions of this document may be illegible in electronic image products. Images are produced from the best available original document. 


\section{Executive Summary}

Research at Pacific Northwest National Laboratory (PNNL) ${ }^{(a)}$ has probed the physical mechanisms and waste properties that contribute to the retention and release of flammable gases from radioactive waste stored in underground tanks at Hanford. This study was conducted for Westinghouse Hanford Company as part of the PNNL Flammable Gas Project. The wastes contained in the tanks are mixes of radioactive and chemical products, and some of these wastes are known to generate mixtures of flammable gases, including hydrogen, nitrous oxide, and ammonia. Because these gases are flammable, their retention and episodic release pose a number of safety concerns.

Previous investigations of bubble retention focused on bubbles retained in settled solids that are submerged beneath a supernatant liquid layer. This configuration is typical of waste stored in double-shell tanks (DSTs). In this situation, when the retention of bubbles causes the solids to become buoyant, the waste undergoes a buoyancy-induced rollover. While the rollover gas release mechanism in DSTs is well documented, the mechanism of bubble retention is not as well understood. In single-shell tanks (SSTs), in contrast, the settled solids are often not completely submerged, and buoyant rollovers similar to those in DSTs are not possible. For SST waste, neither the mechanisms of bubble retention nor those of bubble release are well understood.

The objective of this study is to quantify the pertinent mechanisms of bubble retention and release by measuring and observing bubble retention both in actual waste samples and in simulated wastes. Maximum gas retention and release data were obtained from actual waste samples from the SST 241-S-102 (S-102) and the DST 241-SY-103 (SY-103), both of which are on the Flammable Gas Watch List. In addition to the retention/release studies, the ability of waste particles to armor and stabilize gas bubbles was investigated using an SY-103 waste sample.

The simulants studied in this work were chosen to mimic the behavior of actual SST waste. SST wastes have a wide range of physical properties that range from clay-like, plastic sludges to hard salt cake. In this work, experiments focused on fine-particle simulants composed of bentonite clay and water, because these are believed to mimic the sludge-like waste contained in SSTs. Because the actual properties of SST waste are not well-known, simulants with a wide range of strengths were prepared and tested. The experimental results quantified the ability of these simulants to retain gas and indicated how the gas is released. For comparison with these simulants, some previously reported results for particulate simulants were reevaluated. In addition, new gas retention results were obtained for partially drained particulate simulants to aid in our understanding of gas retention in SSTs that have been salt-well pumped. Together, the actual and simulated waste results improve our understanding of SST waste behavior.

(a) Pacific Northwest National Laboratory is operated for the U.S. Department of Energy by Battelle under Contract DE-AC06-76RLO 1830. 
Actual waste gas retention experiments were conducted using a new apparatus and method. Waste samples contained in transparent plastic retention vessels in a hot cell facility were subjected to high doses of gamma radiation to promote an accelerated generation of gas (soluble and bubbles) within the waste. Subsequently, a vacuum was applied to the sample to nucleate and grow bubbles. The vacuum pressure was changed in a controlled manner and recorded electronically throughout the experiment. Simultaneously, both close-up and wide-angle video images were obtained. The close-up view provided information on the shapes of retained bubbles, and the wide-angle view was used to follow changes in the sludge volume and to observe release mechanisms.

In the SY-103 waste samples, gas was retained primarily in nearly round bubbles, and the experimental results suggest that the thickness of the supernatant liquid layer affects both the magnitude of the maximum retention relative to that predicted for a buoyancy-induced rollover and the mechanism of gas release (rollover or other). In four SY-103 experiments, two from the current work and two conducted earlier, samples with thick convective layers (liquid layer $>25 \%$ of sample) were observed to roll over. However, the samples with thin liquid layers (liquid layer $<10 \%$ of sample) did not roll over, but instead, gas was released through an erosional process in which the convective liquid infiltrated the gaseous waste and provided a path for gas release. For the samples with thick liquid layers, the measured maximum retention results were slightly less than those predicted for neutral buoyancy in the waste based on estimated initial waste sample densities. For example, an SY-103 whole tank composite sample having a liquid layer comprising $25 \%$ of the sample had a measured maximum growth of $9.2 \%$, while $12 \%$ growth was calculated for retention to buoyancy. On the other hand, the samples with thin convective layers retained gas well beyond the theoretical neutral buoyancy point. An SY-103 nonconvective composite sample containing 4\% free liquid had $30 \%$ growth, but it was only expected to grow $18 \%$ to become neutrally buoyant. As might be expected, some minimum amount of convective liquid is required over gas-trapping waste to support a buoyancy-induced rollover.

As with the SY-103 nonconvective samples, the S-102 salt cake waste samples had insufficient convective liquid to support a buoyancy-induced rollover, and the maximum growth far exceeded the predicted neutral buoyancy fraction. The two replicate sample analyses gave maximum growth of $47 \%$ and $50 \%$ void, whereas the predicted growth to neutral buoyancy was less than $30 \%$. In both samples, the initial liquid layer was less than $10 \%$ of the sample volume.

An important result of the S-102 retention studies is that the soft sludge-like sample, which appeared to be considerably weaker than the stiff sludge-like sample, retained about $10 \%$ more gas at maximum growth (33 and $20 \%$ growth, respectively). Furthermore, the somewhat more granular and possibly still weaker salt cake samples retained even more gas ( $50 \%$ growth). These results are consistent with observations made on bentonite clay samples of varying strength. The mechanisms of gas release from the S-102 sludges are also analogous to those in the clays. In particular, the stiff S-102 sludge developed a connected path structure whereby gas was continuously released from the waste at its maximum retention. The softer sludge released some of its retained gas episodically; gas retention to peak values was followed by rapid partial gas releases. 
Bentonite clay simulants were studied to probe the effects of SST-like waste strength on gas retention and release. Additionally, it was anticipated that the size of the bubble retention apparatus would affect the experimental results, and therefore tests were performed in vessels with diameters ranging from 2.5 to $30 \mathrm{~cm}$ and initial sludge heights ranging from 15 to $90 \mathrm{~cm}$.

Experimental results show that the strength of the simulant affects 1) the shape of retained bubbles, 2) the void fraction at maximum retention, and 3) the release mechanisms. For strong simulants (shear strength of about $1000 \mathrm{~Pa}$ ), bubbles were observed to grow as slit-shaped entities, and maximum void fractions of about 0.3 were measured. Most importantly, no mechanism was found that gave a large and rapid gas release for these strong simulants in the absence of a liquid layer. Instead, gas bubbles connected and formed a continuous path that allowed gas to release continuously as it was generated. Accordingly, we anticipate that strong sludge-like materials in tanks probably will not have gas release events that pose flammable gas safety concerns.

For bentonite clays with moderate strengths (shear strength of about $100 \mathrm{~Pa}$ ), bubbles maintained a more round shape as they grew; and in the small-diameter vessel; these bubbles eventually connected, allowing continual release of gas or retention followed by small periodic releases. In larger-diameter vessels $(15.2$ and $30.5 \mathrm{~cm})$, however, $67-\mathrm{Pa}$ clay suddenly released a large fraction of its retained gas, and the simulant was almost completely disturbed by the release event. This rapid release mechanism was never observed for 200-Pa simulants, even in test vessels up to $90 \mathrm{~cm}$ in diameter. The maximum retention for moderate-strength sludge-like materials was about 0.4 void fraction for an initial depth of $30 \mathrm{~cm}$, and this intermediate range of strength gave the largest retention of all the simulants tested. Additionally, the maximum retention increased with increasing initial sludge height, and a void fraction of 0.5 was observed in the experiment with the largest initial height $(90 \mathrm{~cm})$.

For weak bentonite clays (in the range of about $5 \mathrm{~Pa}$ shear strength), the retained bubbles were also nearly round. However, in even the smallest-diameter vessels, before the bubbles could connect to allow continual release of gas, the sludge lost its ability to retain the bubbles, and essentially all of the retained gas was released. It appeared that once a bubble began to rise it disturbed the surrounding sludge, causing the subsequent release of other retained bubbles. For extremely weak sludges (less than about $3 \mathrm{~Pa}$ shear strength), round bubbles grew to a small size and then rose individually. Typically, the void fraction of retained bubbles was small, and the release of these bubbles was continuous.

The clay simulant study focused on bubble retention and release from materials without an overlying liquid layer. However, many SSTs contain salt cake waste that has particle sizes sufficiently large to behave more like a permeable medium than a clay-like sludge. Much of the salt cake waste has had, or will have, the interstitial liquid drained by salt-well pumping, and little is known about the ability of drained salt cake waste to retain bubbles. Accordingly, bubble retention experiments were conducted on particulate simulants (1-mm glass bead packs and water) that were partially or fully drained of the interstitial liquid. The studies show, as previously postulated, that as liquid is drained from the waste, the ability of the waste to retain gas is reduced. The data indicate that the volume of retained gas at maximum retention is roughly proportional to the fractional 
liquid saturation within the bead pack. These results suggest that SST waste that has been drained, presumably by salt-well pumping, is not likely to retain gas bubbles in the drained regions of the waste.

While there are a number of differences between retained bubbles in the actual waste samples and the simulants, there is also reasonable similarity between observed bubble shapes and maximum retention. This similarity, however, requires that the waste materials and concomitant bubble retention mechanisms be classified into different regimes. Three dimensionless groups are used as the basis of this classification scheme. Because of the similarities between bubble retention in actual wastes and equivalent simulants, we believe this classification scheme is valid for quantifying the bubble retention mechanisms. While the results currently available support this classification scheme, there are a number of actual waste types that have not been studied. Accordingly, this classification scheme should be considered preliminary; and as additional results become available on retained bubbles in different waste materials (types), it should be refined. 


\section{Acknowledgments}

A number of PNNL researchers contributed to this work, and the authors would like to thank these individuals for their important contributions. Michael R. Powell provided access to and operated the apparatus for measuring sludge shear strengths and assisted in the interpretation of those data. He was also instrumental in developing the bubbly clay simulants used in this work. Todd L. Gervais conducted several clay gas retention experiments in our laboratory. Lenna A. Mahoney contributed to and organized the figure summarizing bubble retention mechanisms. Finally, Garry M. Richardson and Donald Reinhart helped conduct some of the hot cell operations.

The authors would like to thank Lawrence L. Fritts and Robert F. Eggers of Westinghouse Hanford Company (WHC) for their efforts to deliver samples and data from Tank 241-S-102. The authors also wish to thank Steve A. Barker and W. Blaine Barton of WHC for providing estimates of the gas void fraction in all of the Hanford waste tanks: 


\section{Quality Assurance}

All the actual waste results reported in Section 5 of this report have been conducted and reviewed to meet PNNL Impact Level II standards. The data used to create the figures in this section are reported in Appendix B. The remaining results reported here have been performed to meet PNNL Good Practices Standards. 


\section{Contents}

Executive Summary $\ldots \ldots \ldots \ldots \ldots \ldots \ldots \ldots \ldots \ldots \ldots \ldots \ldots \ldots \ldots \ldots$

Acknowledgments $\ldots \ldots \ldots \ldots \ldots \ldots \ldots \ldots \ldots \ldots \ldots \ldots \ldots \ldots \ldots \ldots \ldots \ldots$ vii

Quality Assurance $\ldots \ldots \ldots \ldots \ldots \ldots \ldots \ldots \ldots \ldots \ldots \ldots \ldots \ldots \ldots \ldots$ viii

1.0 Introduction $\ldots \ldots \ldots \ldots \ldots \ldots \ldots \ldots \ldots \ldots \ldots \ldots \ldots \ldots \ldots \ldots \ldots \ldots \ldots \ldots$

2.0 Flammable Gas Retention in Hanford Waste Tanks . . . . . . . . . . . . . . 2.1

3.0 Gas Bubble Retention Mechanisms $\ldots \ldots \ldots \ldots \ldots \ldots \ldots \ldots \ldots \ldots \ldots \ldots \ldots$

3.1 Effect of Waste Strength on Bubble Retention $\ldots \ldots \ldots \ldots \ldots \ldots \ldots \ldots \ldots$

3.2 Effect of Waste Strength on Bubble Release $\ldots \ldots \ldots \ldots \ldots \ldots \ldots \ldots$

4.0 Simulant Gas Bubble Retention and Release $\ldots \ldots \ldots \ldots \ldots \ldots \ldots \ldots \ldots \ldots \ldots$

4.1 Experimental Methods and Materials $\ldots \ldots \ldots \ldots \ldots \ldots \ldots \ldots \ldots \ldots \ldots .1$

4.1.1 Materials - Bubbly Clay Simulants . . . . . . . . . . . . . 4.1

4.1.2 Clay Simulant Gas Retention Apparatus $\ldots \ldots \ldots \ldots \ldots \ldots \ldots .2$

4.1.2.1 Clay Strength and Initial Height Experiments . . . . . . . . 4.3

4.1.2.2 Vessel Diameter Experiments . . . . . . . . . . 4.4

4.1.2.3 Visual Observation Apparatus . . . . . . . . . . . 4.6

4.1.3 Glass Bead Simulant Experiments . . . . . . . . . . . . 4.6

4.2 Results and Discussion $\ldots \ldots \ldots \ldots \ldots \ldots \ldots \ldots \ldots \ldots \ldots \ldots \ldots \ldots \ldots \ldots$

4.2.1 Effect of Clay Strength on Retained Bubble Shape .......... 4.8

4.2.2 Maximum Retention $\ldots \ldots \ldots \ldots \ldots \ldots \ldots \ldots \ldots \ldots \ldots . \ldots \ldots$

4.2.2.1 Effect of Clay Strength on Maximum Retention . . . . . . . 4.19

4.2.2.2 Effect of Initial Clay Height on Maximum Retention . . . . . 4.20 
4.2.2.3 Effect of Vessel Diameter on Maximum Retention . . . . . . 4.21

4.2.2.4 Effect of Particle Size on Maximum Retention . . . . . . . 4. 4.22

4.2.2.5 Effect of Draining Liquid on Maximum Retention . . . . . . 4.23

4.2 .3 Gas Release Mechanisms . . . . . . . . . . . . . . 4.26

4.2.3.1 Effect of Clay Strength on Gas Release . . . . . . . . . 4.27

4.2.3.2 Effect of Initial Height on Gas Release . . . . . . . 4.32

4.2.3.3 Effect of Vessel Diameter on Gas Release . . . . . . . . . 4.33

5.0 Actual Waste Bubble Retention Mechanisms $\ldots \ldots \ldots \ldots \ldots \ldots \ldots \ldots \ldots \ldots \ldots$

5.1 Actual Waste Samples $\ldots \ldots \ldots \ldots \ldots \ldots \ldots \ldots \ldots \ldots \ldots \ldots \ldots \ldots \ldots \ldots \ldots \ldots$

5.1.1 Tank 241-SY-103 Sample Summary . . . . . . . . . . . 5.1

5.1 .2 Tank $241-$ S-102 Sample Summary $\ldots \ldots \ldots \ldots \ldots \ldots . \ldots \ldots$

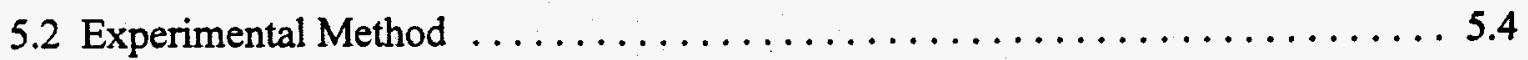

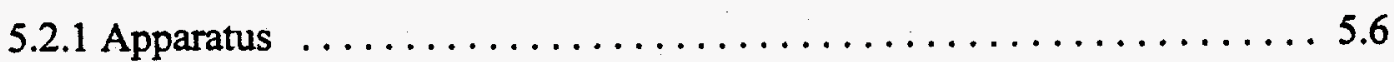

5.2 .2 Techniques and Validation $\ldots \ldots \ldots \ldots \ldots \ldots \ldots \ldots \ldots \ldots$

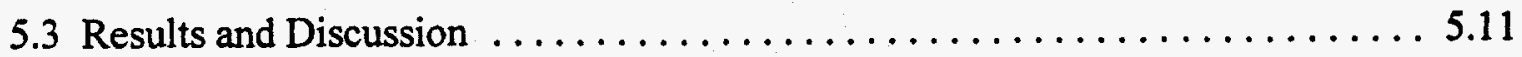

5.3.1 Bubble Shapes in Actual Waste $\ldots \ldots \ldots \ldots \ldots \ldots \ldots \ldots . \ldots \ldots$

5.3 .2 Maximum Gas Retention $\ldots \ldots \ldots \ldots \ldots \ldots \ldots \ldots . \ldots \ldots$

5.3 .2 .1 S-102 Results .................... 5.22

5.3.2.2 SY-103 Results $\ldots \ldots \ldots \ldots \ldots \ldots \ldots \ldots \ldots \ldots \ldots \ldots . \ldots \ldots$

6.0 Bubble Retention Mechanisms: Summary and Comparison of Results $\ldots \ldots \ldots . \ldots 6.1$

7.0 Conclusions $\ldots \ldots \ldots \ldots \ldots \ldots \ldots \ldots \ldots \ldots \ldots \ldots \ldots \ldots \ldots \ldots \ldots \ldots \ldots \ldots$

8.0 References $\ldots \ldots \ldots \ldots \ldots \ldots \ldots \ldots \ldots \ldots \ldots \ldots \ldots \ldots \ldots \ldots \ldots \ldots \ldots \ldots .1$ 
Appendix A: Simulant Bubble Retention Data $\ldots \ldots \ldots \ldots \ldots \ldots \ldots \ldots \ldots \ldots$ A.1

Appendix B: Actual Waste Bubble Retention Data $\ldots \ldots \ldots \ldots \ldots \ldots \ldots \ldots \ldots$ B.1 


\section{Figures}

3.1 Schematic of Bubble Displacing Particles and a Dendritic Bubble Fingering Between Waste Particles .............................. 3.2

3.2 Bubbles Displacing Sludge when Surface Tension Dominates $(\mathrm{N}<<1)$ and when

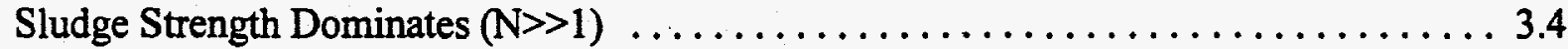

3.3 Plot Showing the Location of Different Bubble Retention Regimes ............ 3.4

3.4 Bubble Growth and the Formation of a Connected Pathway of Bubbles $\ldots \ldots \ldots \ldots . .5$

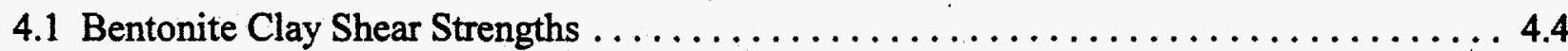

4.2 Gas Retention Apparatus for Small Diameter Tubes $\ldots \ldots \ldots \ldots \ldots \ldots \ldots \ldots . .5$

4.3 Apparatus for Measuring Bubble Retention and Release in Large Diameter Vessels . . . . 4.5

4.4 Wide-Angle Image of Bubbles Retained in a Bentonite Clay Simulant Composed of $18.75 \mathrm{wt} \%$ Bentonite in Water; Initial Shear Strength $1040 \mathrm{~Pa} . \ldots \ldots \ldots \ldots \ldots . . .2 .9$

4.5 Close-up Image of Bubbles Retained in a Bentonite Clay Simulant Composed of $18.75 \mathrm{wt} \%$ Bentonite in Water; Initial Shear Strength $1040 \mathrm{~Pa} \ldots \ldots \ldots \ldots \ldots . .10$

4.6 Wide-Angle Image of Bubbles Retained in a Bentonite Clay Simulant Composed of $13.75 \mathrm{wt} \%$ Bentonite in Water; Initial Shear Strength $67 \mathrm{~Pa} \ldots \ldots \ldots \ldots \ldots \ldots .11$

4.7 Close-up Image of Bubbles Retained in a Bentonite Clay Simulant Composed of $13.75 \mathrm{wt} \%$ Bentonite in Water; Initial Shear Strength $67 \mathrm{~Pa} . \ldots \ldots \ldots \ldots \ldots . \ldots .12$

4.8 Wide-Angle Image of Bubbles Retained in a Bentonite Clay Simulant Composed of $10.00 \mathrm{wt} \%$ Bentonite in Water; Initial Shear Strength $6.4 \mathrm{~Pa} \ldots \ldots \ldots \ldots \ldots . .13$

4.9 Close-up Image of Bubbles Retained in a Bentonite Clay Simulant Composed of $10.00 \mathrm{wt} \%$ Bentonite in Water; Initial Shear Strength $6.4 \mathrm{~Pa}$

4.10 Wide-Angle Image of Bubbles Releasing from a Bentonite Clay Simulant Composed of $10.00 \mathrm{wt} \%$ Bentonite in Water; Initial Shear Strength $6.4 \mathrm{~Pa} \ldots \ldots \ldots \ldots . . .15$

4.11 Wide-angle Image of Bubbles Retained in a Bentonite Clay Simulant Composed of $9.01 \mathrm{wt} \%$ Bentonite in Water; Initial Shear Strength less than $3 \mathrm{~Pa}$ 
4.12 Close-up Image of Bubbles Retained in a Bentonite Clay Simulant Composed of $9.01 \mathrm{wt} \%$ Bentonite in Water; Initial Shear Strength less than $3 \mathrm{~Pa} \ldots \ldots \ldots \ldots . .17$

4.13 Volumes of Gas Generated, Retained, and Released $\ldots \ldots \ldots \ldots \ldots \ldots \ldots \ldots 4.18$

4.14 Effect of Clay Strength on Maximum Void Fraction $\ldots \ldots \ldots \ldots \ldots \ldots \ldots . \ldots \ldots$

4.15 Effect of Initial Clay Height on Maximum Void Fraction $\ldots \ldots \ldots \ldots \ldots \ldots . . .21$

4.16 Effect of Column Diameter on the Maximum Void Fraction $\ldots \ldots \ldots \ldots \ldots \ldots .22$

4.17 Maximum Void Fractions of Glass Bead Slurries .................. 4.23

4.18 Generated and Trapped Gas Volumes in a 17\% Initially Saturated Bead Pack ...... 4.25

4.19 Maximum Void Fractions in Partially Saturated Bead Packs .............. 4.26

4.20 Void Fractions in $3.4-\mathrm{Pa}$ Clay $\ldots \ldots \ldots \ldots \ldots \ldots \ldots \ldots \ldots \ldots \ldots \ldots \ldots \ldots \ldots \ldots .28$

4.21 Void Fractions in $6.4-\mathrm{Pa}$ Clay $\ldots \ldots \ldots \ldots \ldots \ldots \ldots \ldots \ldots \ldots \ldots \ldots \ldots \ldots \ldots \ldots \ldots \ldots .28$

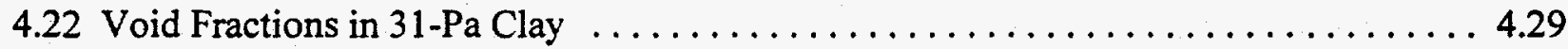

4.23 Void Fractions in $67-\mathrm{Pa}$ Clay $\ldots \ldots \ldots \ldots \ldots \ldots \ldots \ldots \ldots \ldots \ldots \ldots \ldots \ldots \ldots \ldots \ldots . .29$

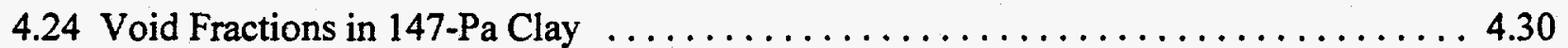

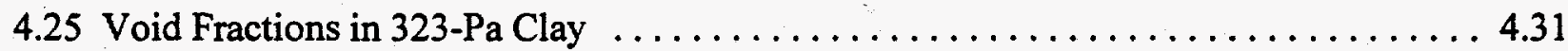

4.26 Void Fractions in $656-\mathrm{Pa}$ Clay $\ldots \ldots \ldots \ldots \ldots \ldots \ldots \ldots \ldots \ldots \ldots \ldots \ldots \ldots \ldots \ldots \ldots \ldots$

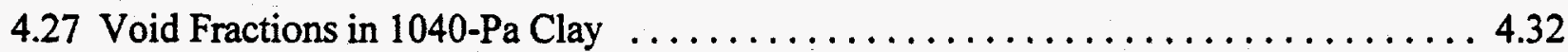

4.28 Void Fractions for Two Initial Heights of $67-\mathrm{Pa}$ Clay $\ldots \ldots \ldots \ldots \ldots \ldots \ldots \ldots .33$

4.29 Void Fractions in 67-Pa Clay in a 2.5-cm-Diameter Vessel $\ldots \ldots \ldots \ldots \ldots \ldots \ldots . . \ldots 44$

4.30 Void Fractions in-Pa Clay in a $5.1-\mathrm{cm}$ Diameter Vessel $\ldots \ldots \ldots \ldots \ldots \ldots . \ldots .34$

4.31 Void Fractions in 67-Pa Clay in a 5.1-cm-Diameter Vessel (duplicate) $\ldots \ldots \ldots \ldots .4 .35$

4.32 Void Fractions in 67-Pa Clay in a 10.2-cm-Diameter Vessel $\ldots \ldots \ldots \ldots \ldots \ldots . .35$ 
4.34 Void Fractions in 67-Pa Clay in a 15.2-cm-Diameter Vessel $\ldots \ldots \ldots \ldots \ldots \ldots . .36$

4.35 Void Fractions in 67-Pa Clay in a 30.5-cm-Diameter Vessel $\ldots \ldots \ldots \ldots \ldots \ldots .37$

4.36 Void Fractions in 200-Pa Clay in a 30.5-cm Diameter Vessel ............. 4.38

4.37 Void Fractions in 200-Pa Clay in a 30.5-cm-Diameter Vessel (duplicate) . . . . . . . 4.39

4.38 Void Fractions in 200-Pa Clay in a 91.4-cm-Diameter Vessel . . . . . . . . . . . . 4.39

5.1 Actual Waste Gas Retention Vessel $\ldots \ldots \ldots \ldots \ldots \ldots \ldots \ldots \ldots \ldots \ldots . \ldots . \ldots$

5.2 Schematic of Standard Actual Waste Gas Retention Experimental Apparatus . . . . . . 5.8

5.3 Effect of Depressurization Rate on Gas Retention in a 67-Pa Bentonite Clay ........5.11

5.4 Retained Bubbles in S-102 Salt Cake Sample (Vessel 6) at Void Fraction 0.26 . . . . 5.13

5.5 Retained Bubbles in S-102 Salt Cake Sample (Vessel 5) at Void Fraction 0.30 . . . 5.14

5.6 Retained Bubbles in S-102 Salt Cake Sample (Vessel 5) at Void Fraction 0.45 . . . . 5.15

5.7 Retained Bubbles in Stiff S-102 Sludge Sample (Vessel 7) at Void Fraction 0.17 . . . 5.16

5.8 Retained Bubbles in Soft S-102 Sludge Sample (Vessel 8) at Void Fraction $0.29 \ldots \ldots .17$

5.9 Retained Bubbles in SY-103 Nonconvective Composite (Vessel 4) at

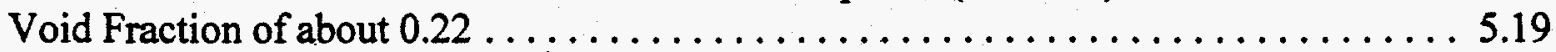

5.10 Retained Bubbles in SY-103 Waste from Video Images Collected by Bredt and Tingey (1996)

5.11 Retained Bubbles in SY-101 Waste Taken from Video Images Collected by Bredt et al. (1995) ................................... 5.21

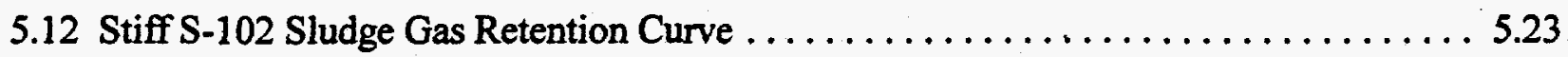

5.13 Soft S-102 Sludge Gas Retention Curve $\ldots \ldots \ldots \ldots \ldots \ldots \ldots \ldots \ldots \ldots . \ldots . \ldots . \ldots . \ldots$

5.14 Duplicate S-102 Growth Fraction Results ..................... 5.25

5.15 SY-103 Nonconvective Composite Gas Retention Curve $\ldots \ldots \ldots \ldots \ldots \ldots \ldots .27$ 
5.16 SY-103 Whole Tank Composite Gas Retention Curve $\ldots \ldots \ldots \ldots \ldots \ldots . . \ldots . . . .27$

5.17 Summary of SY-103 Maximum Gas Retention Results ................ 5.29

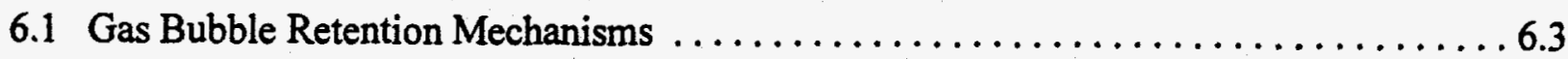

6.2 Comparison of Maximum Retention in Actual Waste Samples with Results for Bentonite Clay Simulants ....

\section{Tables}

2.1 Void Fraction Estimates for Flammable Gas Watch List Tanks $\ldots \ldots \ldots \ldots \ldots \ldots 2.3$

2.2 Void Fraction Estimates for the Additional 25 Tanks Recommended for Addition to the Flammable Gas Watch List . . . . . . . . . . . . . . . . . . . . . . . . . 2.4

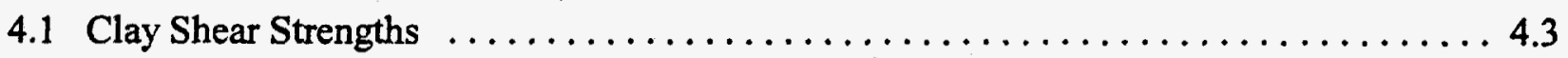

4.2 Results of Partially Drained Bead Pack Experiments .................. 4.24

5.1 Composition of Nonconvective Composites Homogenized at 222-S $\ldots \ldots \ldots \ldots \ldots .2$

5.2 Core 62 Material Used to Prepare Tank Composite $\ldots \ldots \ldots \ldots \ldots \ldots \ldots . . \ldots . . \ldots$

5.3 Samples Received for Bubble Retention Testing $\ldots \ldots \ldots \ldots \ldots \ldots \ldots \ldots \ldots .5$

5.4 Composition of Core 125 Composite Prepared for Bubble Retention Tests ........ 5.6

5.5 Summary of Actual Waste Samples Used in Gas Retention Experience . . . . . . . 5.12

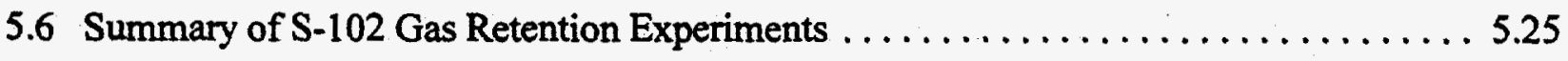




\subsection{Introduction}

The Hanford Site has 149 single-shell tanks (SSTs) and 28 double-shell tanks (DSTs) containing radioactive wastes that are complex mixes of radioactive and chemical products. Some of these wastes are known to generate mixtures of flammable gases, including hydrogen, nitrous oxide, and ammonia. Nineteen of these SSTs and six of the DSTs have been placed on the Flammable Gas Watch List (FGWL) because they are known or suspected, in all but one case, to retain these flammable gases (Hanlon 1995). Because these gases are flammable, their retention and episodic release pose a number of safety concerns. Understanding the physical mechanisms and waste properties that contribute to the retention and release of these gases will help to resolve the safety issues.

The retention and release of bubbles from tank waste, while closely tied, are two distinct physical processes. While SSTs and DSTs have similar gas-bubble retention mechanisms, the release mechanisms in SSTs differ markedly from the common buoyancy-induced rollover release mechanism in DSTs. In tanks with a layer of settled particles beneath a relatively deep supernatant liquid layer, which is the typical waste configuration in DSTs, the settled solids become buoyant when a sufficient void volume of gas is retained. Once the settled material is essentially buoyant, it will rise in what is described as a rollover (Allemann 1990; Stewart et al. 1995). The rollover mechanism, which is a common, dominant release mechanism in DSTs, does not appear to be likely in SSTs, because in SSTs a thick supernatant layer typically does not lie above a settled layer of waste. (a) $^{(2)}$

Recent studies have begun to elucidate the most likely mechanisms that could result in large, rapid releases of flammable gases from SSTs, ${ }^{(2)}$ and additional studies have estimated the probability of specific release events (LANL 1996; Spore 1996). While a number of potential release mechanisms from SSTs have been postulated, little experimental evidence or historical tank-farm data exist to confirm or refute them. In addition, while DSTs have frequent and periodic gas release events (GREs) large enough to yield measurable surface level drops, SSTs generally do not show surface level drops that indicate GRE behavior. Still, there is evidence that the SSTs are retaining gas in amounts that, if released rapidly compared with the mixing and dilution within the dome space of the tanks, could lead to a flammable condition in the tank dome space (Hodgson et al. 1995; Whitney 1995). Accordingly, understanding the release mechanism(s) from SST waste (or simulants) is pivotal for quantifying situations that could potentially give flammable conditions in the dome space of tanks.

(a) A variety of plausible gas release mechanisms were discussed by $R$. T. Allemann et al. in a letter report entitled, A Discussion of Some Release Mechanisms for Sudden Gas Release from Single-Shell Tanks at Hanford (PNL-WTS-101095, October 1995). 
A number of previous studies have investigated bubble retention in both simulated waste (Gauglitz et al. 1994, 1995; Walker et al. 1994; Rassat and Gauglitz 1995) and actual tank.waste (Bredt et al. 1995; Bredt and Tingey 1996). In all of these studies except Walker et al., the bubbles were retained in settled solids that were submerged beneath a liquid supernatant layer. The presence of a liquid layer in these experiments allowed for buoyancy-induced rollovers, although on a very small scale. Accordingly, these experiments did not investigate the ability of the waste to retain gas beyond neutral buoyancy. In one experiment reported by Bredt and Tingey (1996) with Tank 241SY-103 (SY-103) waste, very little supernatant liquid was present. In this situation, the supernatant liquid was observed to sink downward as the bubbly sludge rose. While this is a buoyancy-induced exchange of the settled sludge and the supernatant, it is a very lethargic process. ${ }^{(a)}$ The strength of the waste also delayed the onset of a rollover in these small vessels. It is expected that the presence of a supernatant liquid layer did not play an important direct role in the mechanism of bubble retention but simply allowed a mechanism whereby the bubbles could be released. In the study by Walker et al. (1994), bubble retention and release experiments were conducted in three similar salt cake simulants and a Tank 241-SY-101 (SY-101) simulant. In these small-scale (1-cm-diameter) experiments, rollovers were not observed and the salt cake retained bubbles beyond neutral buoyancy. In one experiment with salt cake, bubble growth continued to the point at which gas bubbles continually released. While these experiments provide valuable information, only a limited understanding can be gleaned from the four tests reported. Accordingly, studies are needed to investigate the retention of bubbles in situations in which the supernatant liquid layer is absent and retention progresses beyond the point of buoyancy, which is the typical waste configuration in many SSTs.

A great variety of waste is stored in Hanford tanks, and it is expected that the bubble retention and release mechanism will vary depending on the waste material and its properties. However, the only existing data on bubble retention in actual waste are limited to experiments on Tank SY-101 and SY-103 waste (Bredt et al. 1995; Bredt and Tingey 1996), which are similar waste types. Accordingly, studies are needed on bubble retention and release in other actual wastes to quantify the pertinent mechanisms and to test the expected behavior based on the previous studies.

The focus of this study was to quantify the pertinent mechanisms of gas bubble retention and release. The study has two major components: studies of bubble retention in simulants mimicking the behavior of actual SST sludge-like waste, and bubble retention studies in actual waste materials. In addition to these major components, this report includes a theoretical discussion of how waste physical properties affect the bubble retention mechanisms. The report begins with a discussion of flammable gas retention in waste tanks (Section 2). Then the mechanisms of bubble retention are discussed, and a plot of three scaling factors is presented as a method of classifying the bubble retention mechanisms (Section 3). The results for bubble retention and release from simulants are

(a) In a recent letter report entitled, An Energy Criterion for Predicting Gas Release During Rollover in Double- and Single-Shell Hanford Wast Tanks (TWS96.2, April 1996), PA Meyer (PNNL) quantified the role of the liquid layer thickness as the rollover dynamics. 
then presented (Section 4), followed by the results for the actual waste materials (S-102 and SY-103) in Section 5. The results for actual waste and simulants include detailed visual observation of retained bubbles to determine the retention mechanisms, measurements of the maximum void fraction above which gas is released, and measurements qualifying how the gas is released. Following this presentation of results, Section 6 is devoted to comparing all the existing bubble retention results with an emphasis on a unifying scheme to classify the bubble retention mechanisms. 


\subsection{Flammable Gas Retention in Hanford Waste Tanks}

Tank waste has a range of physical properties. For SSTs, the waste is typically classified as sludge, salt cake, or supernatant liquid (Hanlon 1995). Hanlon describes sludges as solids (insoluble) that were formed (precipitated) during sodium hydroxide additions to the waste. Sludges typically have very small particle sizes, generally below 1 micron, and are generally described as clay-like and plastic materials. Salt cake waste resulted from crystallization and precipitation after concentration of liquid waste and is composed of precipitated salt crystals. Generally, salt cake waste has a noticeable particulate character that varies from gravel-sized chunks to fine particles, but generally the particles are larger than the colloidal size of about 1 micron. Double-shell tank waste also has a range of physical properties, and the waste is also grouped into general waste types (Hanlon 1995). For the bubble retention studies with actual waste, samples were received from SST S-102, which contains primarily salt cake and a very small fraction of sludge (Hanlon 1995). This SST, which is a FGWL tank, was considered the most interesting SST in a recent prioritization study. ${ }^{(a)}$ The second actual waste sample was from DST SY-103, which is also a FGWL tank.

While a large amount of information is available on the FGWL tanks (see Brager 1994, for example), there is essentially no direct information on the quantity or fraction of gas retained in SSTs. In comparison, in situ measurements of void fraction have been collected for six DSTs (Shepard et al. 1995; Stewart et al. 1995, 1996). ${ }^{(b)}$ Although direct data do not exist on the void fraction in SSTs, a number of studies have made estimates of retained gas volumes. Whitney (1995) has screened Hanford tanks for trapped gas by correlating the changes in waste level with barometric pressure fluctuations due to gas bubbles compressing and expanding. Hopkins (1995) has presented a methodology for evaluating trapped gas in Hanford waste tanks that includes both the barometric pressure evaluation and level increases in the waste. Hodgson et al. $(1995,1996)$ presented an evaluation of a number of tanks based on the methodology described by Hopkins (1995).

The evaluation by Hodgson, et al.,(1995, 1996) focused on determining the largest potential flammable gas concentration in the dome space of the tanks. While retained void fractions are not

(a) ME Brewster and BJ Palmer placed Tank S-102 at the top of their prioritized list in a recent letter report entitled, Prioritization of Single Shell Tanks for Study of Gas Retention and Episodic Release (PNL-WTS122295) (December 1995).

(b) Void fraction results for three of these six tanks have been reported in letter reports by CW Stewart, JM Alzheimer, CL Shepard, G Terrones, G Chen, and NE Wilkins entitled, In Situ Determination of Rheological Properties and Void Fraction: Hanford Waste Tank 241-AW-101 (PNL-MTT-110195, October 1995), In Situ Determination of Rheological Properties and Void Fraction: Hanford Waste Tank 241-AN-105 (PNL-MTT-021696, February 1996), and In Situ Determination of Rheological properties and Void Fraction: Hanford Waste Tank 241-AN-104 (TWSMIT:060796, June 1996). Measurements of in situ void fraction in 241-AN-103 will be reported soon. 
directly reported in the evaluation, the results can be used to directly calculate the void fraction in the settled solids layer in the tanks. It should be emphasized that the method of Hopkins (1995) and the evaluation of Hodgson et al. $(1995,1996)$ used data and tank parameters that had a large uncertainty associated with them. Still, the estimates of void fraction are useful.

Table 2.1 shows the estimated percent of gas-occupied voids in the tanks on the FGWL. The estimates are based on the barometric pressure evaluation (50th percentile) using the data in the appendixes of Hodgson et al. (1996) together with the methodology presented by Hopkins (1995). The barometric pressure estimates represent "best" estimates and are reasonable estimates of the actual gas fraction in the tank waste (we have only included those estimates based on FIC or Enraf level data). For example, an average in situ void fraction of 0.069 (percent void of 6.9) was measured with the void fraction instrument in SY-103 (Shepard et al. 1995), and Table 2.1 gives an estimate of 0.05 . The void fraction results in Table 2.1 show that a number of tanks, both SSTs and DSTs, retain a substantial void fraction.

Table 2.2 gives the estimated void fraction for an additional 25 tanks that were added to the flammable gas unreviewed safety question (USQ) in January 1996. These estimates were obtained with the same methodology as the results presented in Table 2.1. These results show, again, that a number of additional tanks appear to be retaining gas bubbles with substantial void fractions. The purpose of showing these estimates for the void fraction is to indicate the range of bubble retention occurring in the actual tanks. 
Table 2.1. Void Fraction Estimates for Flammable Gas Watch List Tanks ${ }^{(a)}$

\begin{tabular}{|c|c|}
\hline Tank & $\begin{array}{c}\text { Void Fraction (\%) Based on 50th } \\
\text { Percentile Barometric Pressure } \\
\text { Evaluation Results }\end{array}$ \\
\hline \multicolumn{2}{|c|}{ Single-Shell Tanks } \\
\hline \multicolumn{2}{|l|}{ A-101 } \\
\hline \multicolumn{2}{|l|}{$A X-101$} \\
\hline \multicolumn{2}{|l|}{ AX-103 } \\
\hline$S-102$ & 19 \\
\hline$s-111$ & 14 \\
\hline \multicolumn{2}{|l|}{$S-112$} \\
\hline \multicolumn{2}{|l|}{$S X-101$} \\
\hline \multicolumn{2}{|l|}{ SX-102 } \\
\hline \multicolumn{2}{|l|}{$s X-103$} \\
\hline \multicolumn{2}{|l|}{ SX-104 } \\
\hline \multicolumn{2}{|l|}{ SX-105 } \\
\hline \multicolumn{2}{|l|}{ SX-106 } \\
\hline \multicolumn{2}{|l|}{ SX-109 } \\
\hline \multicolumn{2}{|l|}{$T-110$} \\
\hline \multicolumn{2}{|l|}{ U.103 } \\
\hline \multicolumn{2}{|l|}{ U-105 } \\
\hline \multicolumn{2}{|l|}{ U-107 } \\
\hline \multicolumn{2}{|l|}{ U-108 } \\
\hline \multicolumn{2}{|l|}{ U-109 } \\
\hline \multicolumn{2}{|c|}{ Double-Shell Tanks } \\
\hline AN-103 & 20 \\
\hline AN-104 & 8 \\
\hline AN-105 & 8 \\
\hline$A W-101$ & 7 \\
\hline SY-101 & 10 \\
\hline$S Y-103$ & 5 \\
\hline
\end{tabular}

(a) Hopkins (1995) presented a methodology for evaluating trapped gas in Hanford waste tanks, and Hodgson et al. $(1995,1996)$ presented an evaluation of a number of tanks based on this methodology. The 50th percentile barometric pressure estimates were obtained from the data reported in Hodgson et al. (1996), and we include here only those void fractions based on FIC or Enraf dU/dP results. 
Table 2.2. Void Fraction Estimates for the 25 Tanks Added to the Flammable Gas USQ in January $1996^{(a)}$

\begin{tabular}{|c|c|}
\hline Tank & $\begin{array}{l}\text { Void Fraction (\%) Based on 50th } \\
\text { Percentile Barometric Pressure } \\
\text { Evahuation Results }\end{array}$ \\
\hline \multicolumn{2}{|c|}{ Siagle-Shell Tanks } \\
\hline A-103 & 5 \\
\hline BX-107 & 6 \\
\hline \multicolumn{2}{|l|}{ BY-101 } \\
\hline \multicolumn{2}{|l|}{ BY-102 } \\
\hline \multicolumn{2}{|l|}{ BY-103 } \\
\hline \multicolumn{2}{|l|}{ BY-105 } \\
\hline \multicolumn{2}{|l|}{ BY-106 } \\
\hline \multicolumn{2}{|l|}{ BY-109 } \\
\hline C-104 & 3 \\
\hline$C-107$ & 1 \\
\hline$S-101$ & 6 \\
\hline S-103 & 18 \\
\hline \multicolumn{2}{|l|}{ S-105 } \\
\hline S-106 & 30 \\
\hline S-107 & 4 \\
\hline \multicolumn{2}{|l|}{ S-109 } \\
\hline \multicolumn{2}{|l|}{ TX-102 } \\
\hline \multicolumn{2}{|l|}{ TX-111 } \\
\hline \multicolumn{2}{|l|}{$\mathrm{TX}-112$} \\
\hline \multicolumn{2}{|l|}{ TX-113 } \\
\hline \multicolumn{2}{|l|}{ TX-115 } \\
\hline \multicolumn{2}{|l|}{ U-102 } \\
\hline U-106 & 4 \\
\hline \multicolumn{2}{|c|}{ Double-Shell Tanks } \\
\hline AW-104 & 7 \\
\hline AY-101 & 6 \\
\hline \multicolumn{2}{|c|}{$\begin{array}{l}\text { (a) Hopkins (1995) presented a methodology for evahuating trapped gas in } \\
\text { Hanford waste tanks, and Hodgson et al. ( } 1995,1996) \text { presented an } \\
\text { evaluation of a number of tanks besed on this methodology. The } 50 \text { th } \\
\text { percentile barometric pressure estimates were obtained from the data reported } \\
\text { in Hodgson et al. (1996), and we include here only those void fractions based } \\
\text { on FIC or Enraf dUdP results. }\end{array}$} \\
\hline
\end{tabular}




\subsection{Gas Bubble Retention Mechanisms}

Retained bubbles are the primary mechanism for storing large quantities of flammable gases that could be released rapidly from waste within tanks. The principal mechanisms of bubble retention were discussed previously by Gauglitz et al. $(1994,1995)$. These retention mechanisms can be grouped into three categories: bubbles retained by the strength of the waste material, bubbles retained by capillary forces, and bubbles retained via direct attachment to particles (armored bubbles, bubble attachment, and aggregates). In layers of materials, bubble retention is dominated by the waste strength and capillary forces with armored bubbles playing a minor role. ${ }^{(a)}$ In this section, we first summarize the previous work that quantified the transition between bubbles retained by the strength of the material and by capillary forces and then present a new dimensionless parameter that further refines the range of bubble behavior for strength-related retention.

The previous work showed that the distinction between yield strength and capillary force retention depends on a Bond number (Gauglitz et al. 1994, 1995). This dimensionless group contained two parameters, a ratio of gravitational force to surface tension force and a ratio of waste strength force to surface tension force, that are shown below.

$$
\begin{aligned}
& \frac{\text { Gravitational Force }}{\text { Surface Tension Force }}=\frac{\Delta \rho g h D_{\text {particle }}}{4 \gamma} \\
& \frac{\text { Strength Force }}{\text { Surface Tension Force }}=\frac{\tau_{s} D_{\text {particle }}}{4 \gamma}\left(\frac{A_{2}}{A_{1}}\right)
\end{aligned}
$$

The surface tension $(\gamma)$ force in these dimensionless groups reflects the resistance the bubble experiences as it seeks to move between particles, so the appropriate length scale is the pore-throat diameter. For beds of packed particles, the pore-throat diameter is roughly the particle diameter (Dullien 1992) so we approximate the pore-throat diameter as the particle diameter $D_{\text {paricle. }}$ In the first dimensionless parameter, $\Delta \rho$ is the density difference between the settled solids and the liquid, $\mathrm{g}$ is the gravitational acceleration, and $\mathrm{h}$ is the depth below the top of the settled solids. In the second parameter the constant $A_{2} / A_{1}$ is a ratio of areas that resulted from the original scaling analysis, and $\tau_{\mathrm{s}}$ represents the shear strength of the material. Although it is expected that both the

(a) In a companion study, frothing tests of SY-103 waste were conducted to probe the ability of waste particles to armor bubbles. In waste tanks, this effect potentially leads to smaller, shielded bubbles, which are not easily released to the tank headspace. 
tensile and shear strengths are important in the growth of bubbles, the two measures of strength are commonly directly related (see Gauglitz et al. 1995 for a discussion of tensile and shear strength measurements). The two parameters shown above define the transition between two regimes of bubble retention: particle-displacing bubbles that are retained by yield strength forces and interstitial-liquid-displacing bubbles that finger between the particles composing the particulate media. Figure 3.1 depicts these two situations.

In the previous studies, the range of behavior that could be expected for particle-displacing bubbles was not addressed. Many actual waste materials, particularly SST sludges, have very fine particles where the primary mechanism of bubble growth is bubbles displacing the waste particles. In the following section, we discuss the forces affecting the retention of particle-displacing bubbles.

\subsection{Effect of Waste Strength on Bubble Retention}

When bubbles grow in a deformable material such as a bentonite clay or actual waste sludge, the dominant factors controlling their growth are surface tension forces, which seek to keep the bubbles round, and the strength of the material that the bubble must overcome to displace the particles. Simple scaling of the relative importance of sludge strength to surface tension gives the following dimensionless group that governs bubble growth in deformable materials:

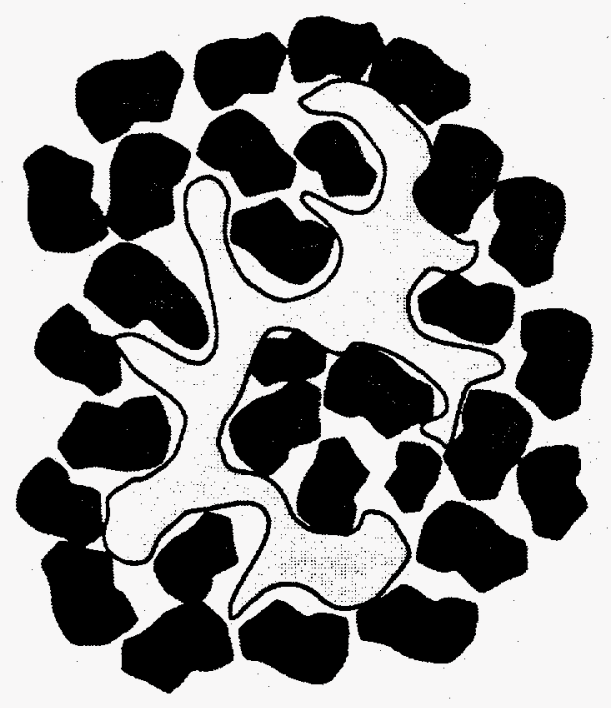

Dendritic-Shaped Bubble Fingering Between Particles

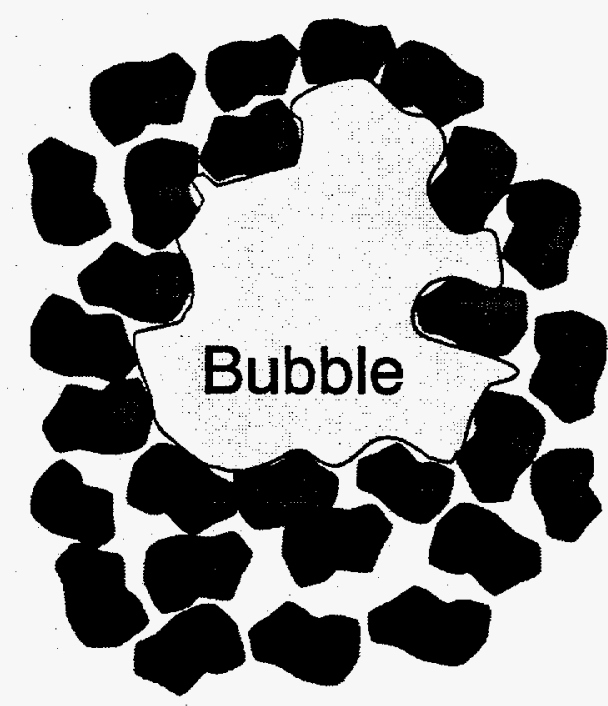

Bubble Displacing Particles

Figure 3.1. Schematic of Bubble Displacing Particles and a Dendritic Bubble Fingering Between Waste Particles 


$$
\frac{\text { Strength Force }}{\text { Surface Tension Force }}=\frac{\tau_{s} D_{\text {bubble }}}{\gamma}
$$

where $D_{\text {bubble }}$ is the bubble diameter. In this case, the surface tension $(\gamma)$ force is related to the bubble size, so the bubble diameter, $D_{b u b b l e}$ is the appropriate length scale. Again, for this scaling, we have chosen the strength of the material to be represented by the shear strength. This simple scaling assumes that the particles composing the waste are sufficiently small (small Bond number) that the bubbles never finger between the particles. As reported previously (Gauglitz et al. 1995), the shear and tensile strengths of bentonite clay sludges decrease with increasing gas bubble content, a detail this simple scaling analysis neglects.

Figure 3.2 shows the bubble shapes that are expected in fine-particulate materials where surface tension or waste strength dominates. When surface tension dominates, the bubble shape is round. When the waste strength dominates, the bubbles grow by displacing the weakest material adjacent to the bubble. In this case, if any small nonuniformity exists in the material, the bubbles will follow that path and evolve into some dendritic shape. While the overall shape may be dendritic, surface tension will dominate on a sufficiently small scale, and the interface between the gas and waste should be smoothly curved.

Figure 3.3 summarizes the different regimes of bubble retention on a plot using the three dimensionless groups described above. The solid curve denotes the transition between interstitialliquid-displacing bubbles and particle-displacing bubbles as defined by Equations 3.1 and 3.2. The particle-displacing bubbles are retained by yield strength forces and the interstitial liquid-displacing bubbles are retained by capillary forces. The particle-displacing region, within the solid curve of Figure 3.2, is further subdivided according to the bubble shape and the associated parameter given by Equation 3.3. The figure also shows the characteristic shape of bubbles in the different areas of the plot. In Section 6, the experimental results for retained bubble shapes will be summarized by arranging and comparing the different shapes on this plot.

\subsection{Effect of Waste Strength on Bubble Release}

As retained bubbles grow, and in the absence of large episodic gas releases, they will eventually connect and provide a flow path for gas to be continuously released. Figure 3.4 depicts the two situations of individual bubbles and connected bubbles. When the void fraction is small, the bubbles are separated. As the individual bubbles grow or more bubbles nucleate between previously existing bubbles, a connected path will eventually form. This pathway is likely to be very tortuous, particularly when considering the three-dimensional character of the connections. While many aspects of the bubble growth process will affect the connection between bubbles, percolation theory offers a framework to understand the minimum void fraction above which bubbles begin to connect (Stauffer 1985). 

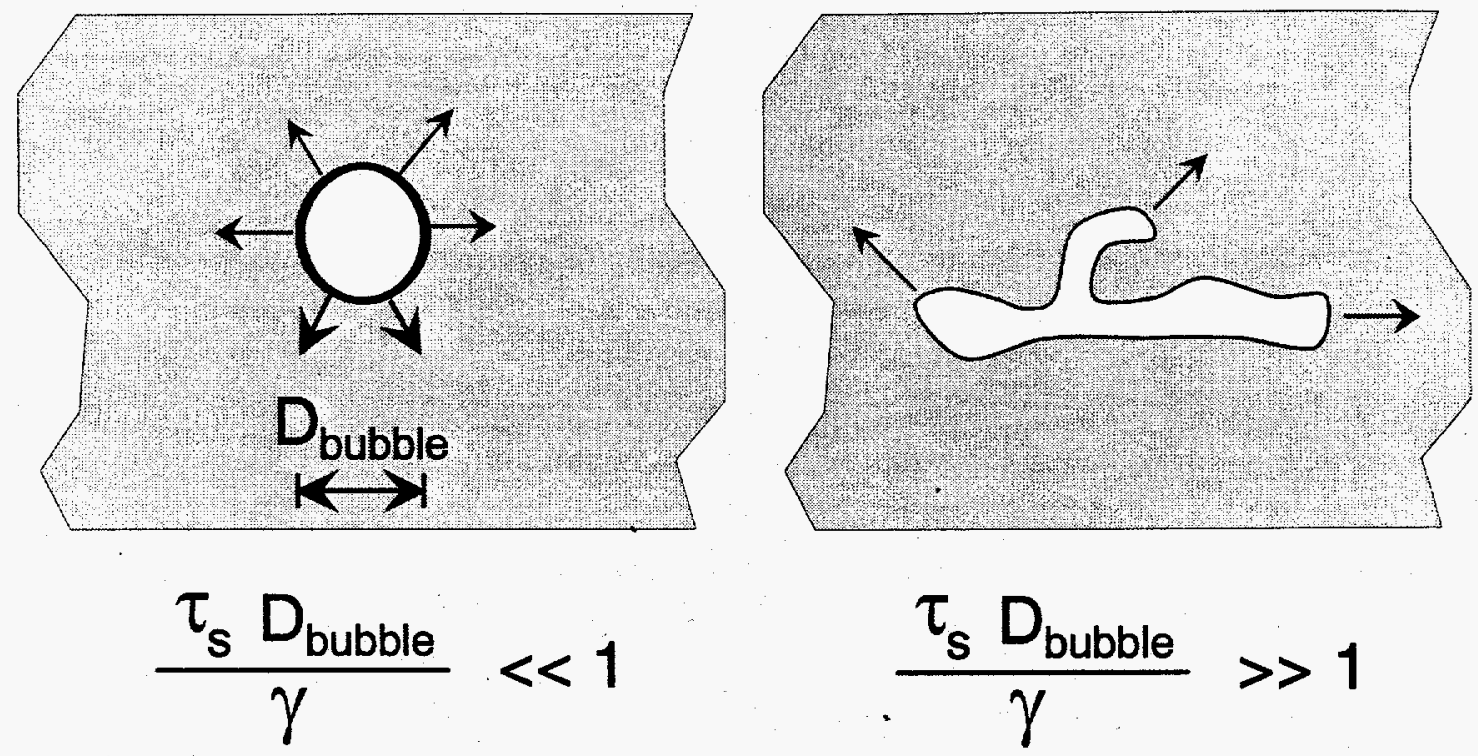

Figure 3.2. Bubbles Displacing Waste when Surface Tension Dominates $\left(\tau_{\mathrm{s}} \mathrm{D}_{\mathrm{bubble}} / \gamma<<1\right)$ and when the Waste Strength Dominates $\left(\tau_{\mathrm{s}} \mathrm{D}_{\text {bubble }} / \gamma>>1\right)$

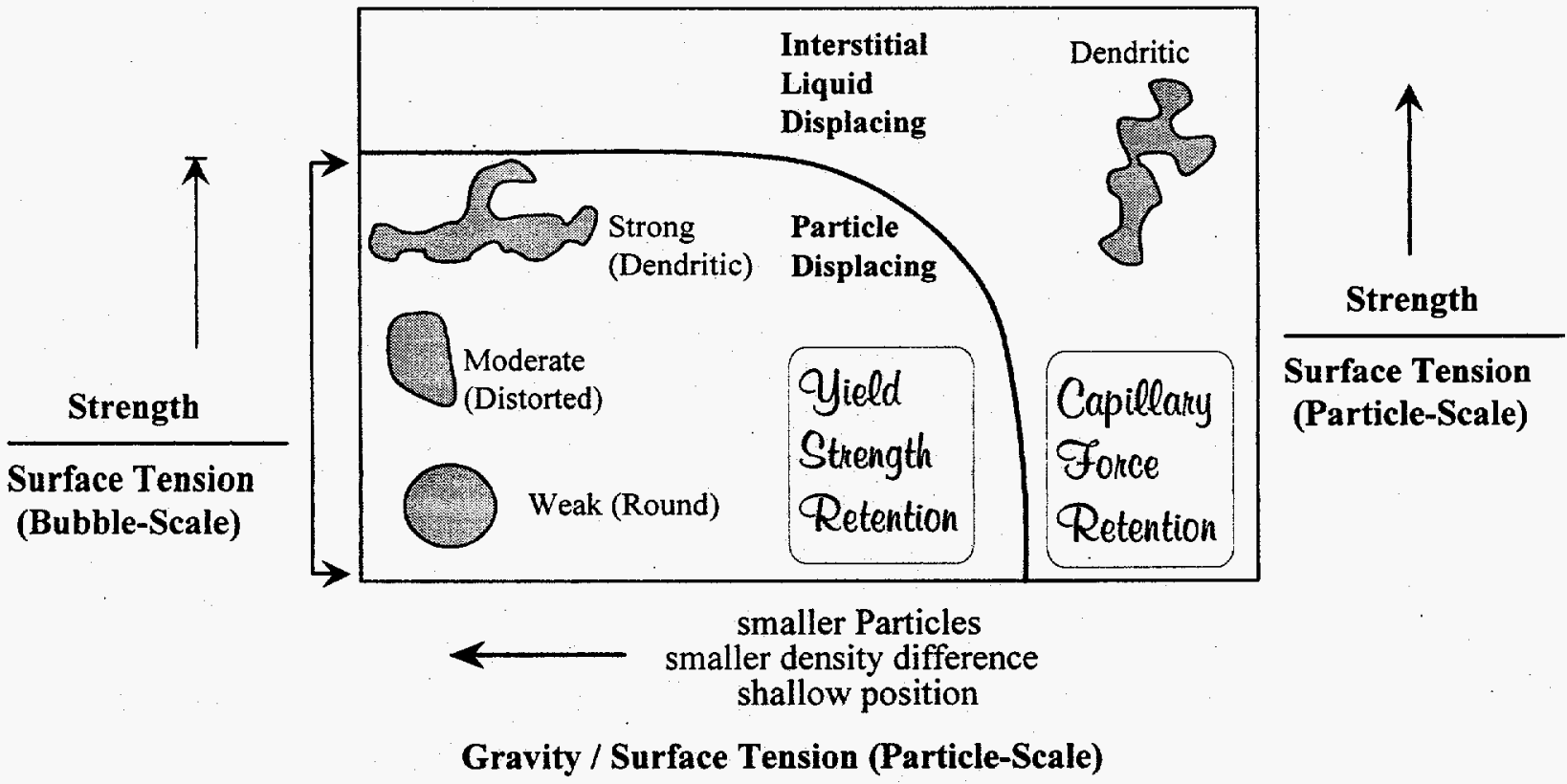

Figure 3.3. Plot Showing the Location of Different Bubble Retention Regimes 
The connecting of separate objects and the conductivity of the connected paths have been studied with percolation theory (Stauffer 1985). The situation of growing round bubbles is most closely associated with site percolation, which describes connection of objects that occupy volume, such as bubbles. The alternative percolation process is bond percolation, but this represents things that essentially connect at points (specifically, resistors between nodes of a lattice). The percolation threshold, which occurs at a specific fraction of an occupied site, represents the void fraction above which a continuous path forms.

The percolation threshold has been calculated for a number of three-dimensional lattices, and values have been reported as follows: diamond, 0.428 ; simple cubic, 0.312 ; and body centered cubic, 0.245 (Stauffer 1985). These values are equivalent to the void fraction of bubbles above which a continuous path exists. While a range of values has been reported, they suggest that the bubbles will not connect until a moderate void fraction has been reached. Finally, it is expected that bubbles of different shape will form a percolating path at different void fractions. The more long and slender bubbles shown in Figure 3.1 are expected to connect at a lower void fraction because long and skinny objects connect more easily.

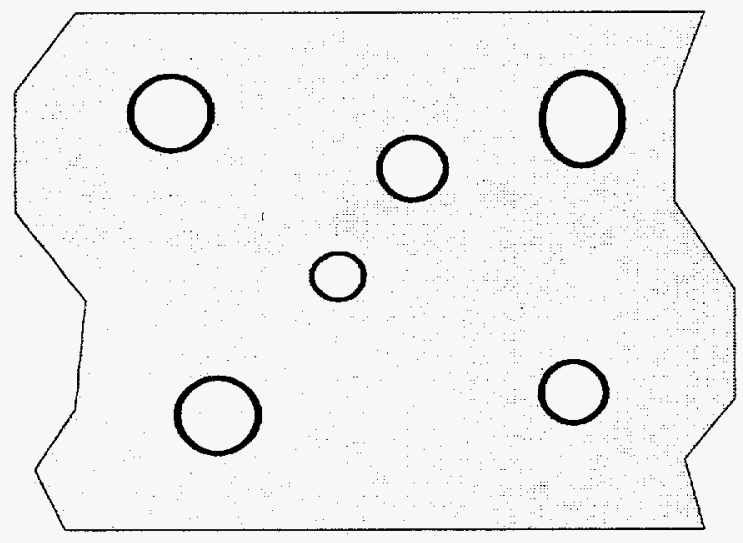

Individual Bubbles

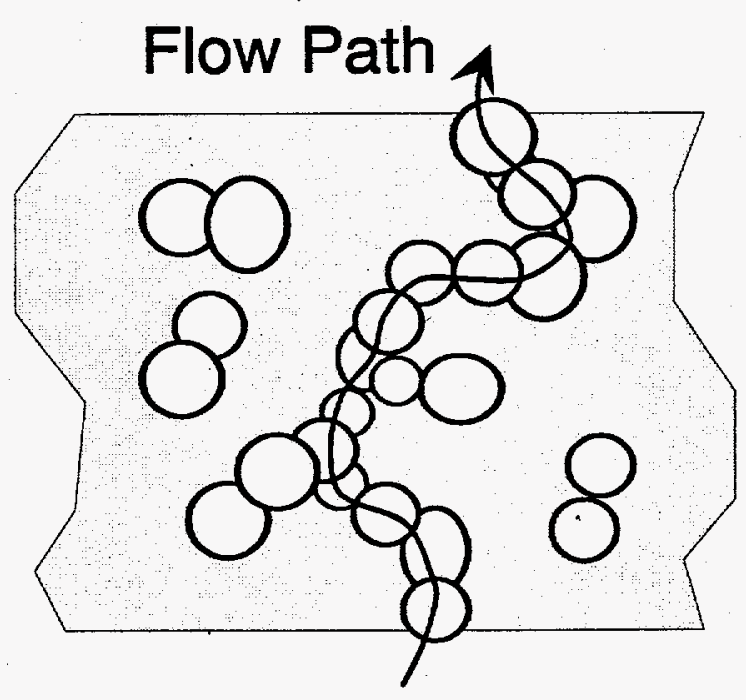

Connected Bubbles

Figure 3.4. Bubble Growth and the Formation of a Connect Pathway of Bubbles 


\subsection{Simulant Gas Bubble Retention and Release}

To prepare for the studies on actual waste and to probe the bubble retention behavior over a wide range of physical parameters, bubble retention and release studies were conducted for a range of simulants. In previous studies, the bubble retention behavior in particulate simulants was emphasized (Gauglitz et al. 1994, 1995). In this work, the studies focused on simulants that mimic SST sludges and sludge-like wastes. This section describes the experimental methods and results for these studies

\subsection{Experimental Methods and Materials}

Gas retention data are presented in this section for two types of simulants. The majority of experiments were conducted using bentonite clay simulants mixed with a small amount of hydrogen peroxide $\left(\mathrm{H}_{2} \mathrm{O}_{2}\right)$. The peroxide decomposes via interaction with the clay, and oxygen $\left(\mathrm{O}_{2}\right)$ gas is generated within the simulant at atmospheric pressure over several hours. The clay simulants represent sludge-like wastes. To mimic particulate DST waste or saturated salt cake SST waste, Gauglitz et al. (1995) used glass bead packs saturated with water. In these earlier studies, a partially soluble gas, carbon dioxide $\left(\mathrm{CO}_{2}\right)$, was dissolved in the simulant water under pressure, and gas bubbles were subsequently nucleated and grown in the bead pack by depressurization of the retention vessel. Maximum gas retention data from those studies are reevaluated here. To mimic partially drained salt cake waste, the hydrogen peroxide decomposition reaction was used in conjunction with unsaturated glass bead packs. The methods and materials used in the clay and glass bead simulant retention studies are described in more detail in the following sections.

\subsubsection{Materials - Bubbly Clay Simulants}

Fresh bubbly clay simulants were prepared for each gas retention experiment. The batch process consisted of weighing water into the mixer bowl and slowly adding a weighed amount of clay (Bighom bentonite) to the water while mixing. The clay and water was mixed until consistent, typically 30-60 minutes, and then a weighed aliquot of $3 \mathrm{wt} \% \mathrm{H}_{2} \mathrm{O}_{2}$ solution (drugstore quality) was added. The peroxide was mixed into the hydrated clay an additional 10 to 30 minutes (typically) before the clay was transferred to the gas retention vessel. The proportion of hydrogen peroxide was selected such that a maximum void fraction of 0.6 could be achieved, assuming all the $\mathrm{O}_{2}$ gas generated by the peroxide decomposition reaction was retained in the sludge. The "as-is" weight fraction of clay (see Table 4.1) was computed from the weights of clay, water, and hydrogen peroxide solution, treating the $\mathrm{H}_{2} \mathrm{O}_{2}$ as an additional source of water.

The void fraction or gas content of the clay is calculated from density information. The theoretical gas-free density is determined from the densities and weight fractions of the clay and water. For the clay, the oven-dry clay mass and density $(2.72 \pm 0.02 \mathrm{~g} / \mathrm{mL}$; Lambe and Whitman 1969 ) is used. For the water weight fraction, the water mass includes direct addition, hydrogen 
peroxide equivalent, and clay moisture. The void fraction of a bubbly clay is determined by comparing the apparent bulk sludge density at a given time with the calculated gas-free density, neglecting the mass of the gas. For each gas retention experiment, an initial gas fraction at some arbitrarily defined time zero must be determined. Two methods were used to measure this initial void fraction: 1) the mass of sludge in the retention vessel is weighed, and an initial volume is determined from the sludge height and tube diameter, giving the apparent bulk density; or 2) a fraction of the clay batch is weighed into a graduated cylinder and its volume read directly. Subsequent void fractions can then be computed from changes in the bulk density of the clay in the retention vessel as determined from the change in sludge height. An error analysis of this void fraction measurement method, based on the expected accuracies of the measurements (sample length, mass, particle density, etc.) used to calculate gas fractions, showed the technique to be accurate to better than $\pm 2 \%$ void using one-inch-diameter retention vessels.

The strength of bentonite clay simulants was controlled through the clay/water weight ratio. The shear strengths of numerous gas-free clays (no hydrogen peroxide) were measured using a shear vane attached to a Haake Rotovisco model M5 viscometer; these results are presented in Table 4.1. Each reported shear strength value is the mean of four measurements from the same batch of clay, and the $95 \%$ confidence intervals for each set of measurements is also shown in the table. The shear strength values for the very weak materials $(<15 \mathrm{~Pa})$ are more suspect because measured torque values were less than $1 \%$ of full scale using the largest available shear vane. Also, bentonite clay strengths are dynamic, and the duration between batch preparation and strength evaluation was not precisely controlled. While some uncertainty in sludge strength may be expected, the measured shear strength values shown graphically in Figure 4.1, along with the best fit curves through the data, show an acceptable degree of scatter. Also, as discussed in Section 4.2.2.1, replicate bubble retention experiments gave consistent results. For clays greater than $16.25 \mathrm{wt} \%$, the shear strengths are best represented by a linear function (curved on the log plot). The weaker clays $(\leq 16.25 \mathrm{wt} \%)$ show an exponential increase in strength as clay content increases (straight line on the log plot, Figure 4.1). The curve fit shear strength values are also tabulated in Table 4.1. Strength values reported elsewhere in this report are shear strengths for gas-free materials obtained from the fit curves shown in Figure 4.1.

\subsubsection{Clay Simulant Gas Retention Apparatus}

Four different gas retention studies were conducted using bubbly clay simulants. One type of apparatus was employed to investigate both the effects of clay strength and initial height on gas retention and release. Another apparatus was used to evaluate the effect of retention vessel diameter on gas retention, and some additional equipment was used for collecting visual observations of bubble growth. The three experimental systems are described in the following subsections. 
Table 4.1. Clay Shear Strengths

\begin{tabular}{|c|c|c|c|}
\hline $\begin{array}{l}\text { As Is Weight } \\
\text { Fraction Clay }\end{array}$ & $\begin{array}{c}\text { Measured Shear } \\
\text { Strength, } \mathrm{Pa}\end{array}$ & $\begin{array}{l}\text { 95\% Confidence } \\
\text { Interval, } \mathrm{Pa}\end{array}$ & $\begin{array}{c}\text { Curve Fit Shear } \\
\text { Strength, } \mathrm{Pa}\end{array}$ \\
\hline 5.0 & & & 0.3 \\
\hline 7.5 & & & 1.3 \\
\hline 9.0 & 1.9 & 1.1 & 3.4 \\
\hline 10.0 & 6.3 & 0.6 & 6.4 \\
\hline 11.25 & 12 & 1 & 14 \\
\hline 12.5 & 51 & 4 & 31 \\
\hline 12.5 & 26 & 2 & 31 \\
\hline 13.75 & 51 & 2 & 67 \\
\hline 15.0 & 163 & 7 & 147 \\
\hline 16.25 & 315 & 9 & 323 \\
\hline 17.5 & 720 & 30 & 656 \\
\hline 17.5 & 520 & 30 & 656 \\
\hline 18.75 & 1130 & 70 & 1040 \\
\hline 20.75 & 1380 & 70 & 1660 \\
\hline 24.0 & 3050 & 120 & $2660^{\circ}$ \\
\hline 27.25 & 3500 & 70 & 3670 \\
\hline
\end{tabular}

\subsubsection{Clay Strength and Initial Clay Height Experiments}

Figure 4.2 shows the apparatus for conducting gas retention experiments using clay simulants. The retention vessel consists of a transparent rigid plastic tube into which the clay simulant is loaded, a ruler to measure the sludge height, and a sealed top with a fitting through which displaced gas is passed. The gas is transferred to a volume measurement device through $1.6 \mathrm{~mm}(1 / 16 \mathrm{in}$.) i.d. nylon tubing. The effluent end of the transfer tube is located at the bottom of an inverted graduated cylinder filled with water and submerged a short distance into a water reservoir. The volume of gas generated in the retention vessel is determined from the volume of water displaced from the graduated cylinder $(250 \mathrm{~mL})$. In measuring the generated volume, the effect of the slight vacuum on the collected gas was neglected because it affected the measured volumes by no more than a few percent. 


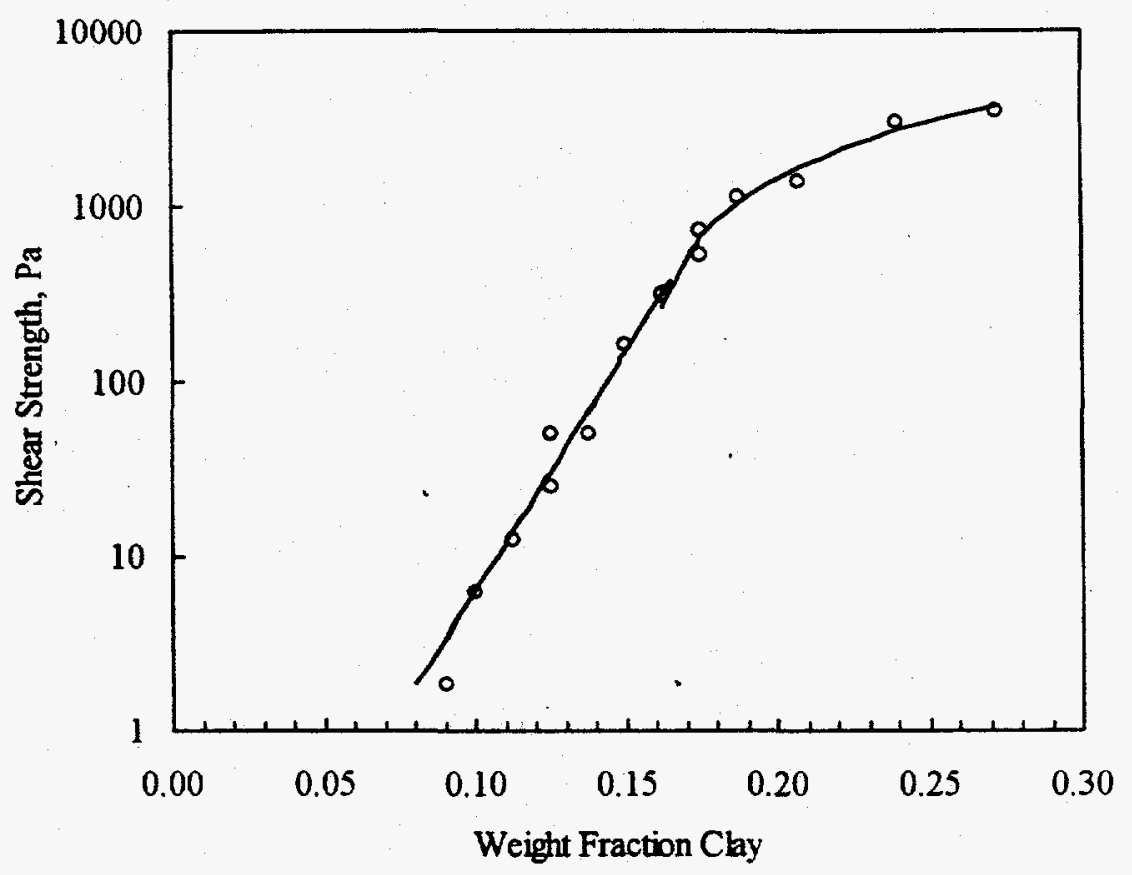

Figure 4.1. Bentonite Clay Shear Strengths

Investigations of gas retention as a function of sludge strength were conducted in 1 -in. schedule 40 clear PVC tubes (26.4 mm i.d.). Other experiments to study the effect of initial sludge height were carried out in 1-in. $(25.4 \mathrm{~mm})$-diameter clear acrylic tubes.

\subsubsection{Vessel Diameter Experiments}

Figure 4.3 shows the apparatus for investigating the effect of test vessel diameter on bubble retention and release. The primary difference between this apparatus and the one shown in Figure 4.2 is the gas collection system. For these larger-diameter tests, a flow rate meter was used to monitor the gas leaving the vessel rather than a direct measurement of cumulative volume. The apparatus consists of a 30-in.-long clear PVC tube with a range of diameters, a blinded-off slip-flange on the bottom, and a plastic pipe cap sealed with vacuum grease on the top. One-sixteenth-inch i.d. tubing carries the gas generated within the test vessel to a digital flow meter (J\&W Scientific, ADM 1000); the tubing was attached to the pipe cap with a tube fitting. Vessel diameters of 2.54, 5.1, 10.2, 15.2, and $30.5 \mathrm{~cm}$ were investigated with this apparatus. A 91.4-cm-diameter flat-bottom plastic tank with accompanying lid was used in place of the clear PVC tubes for the largest vessel diameter investigated. 


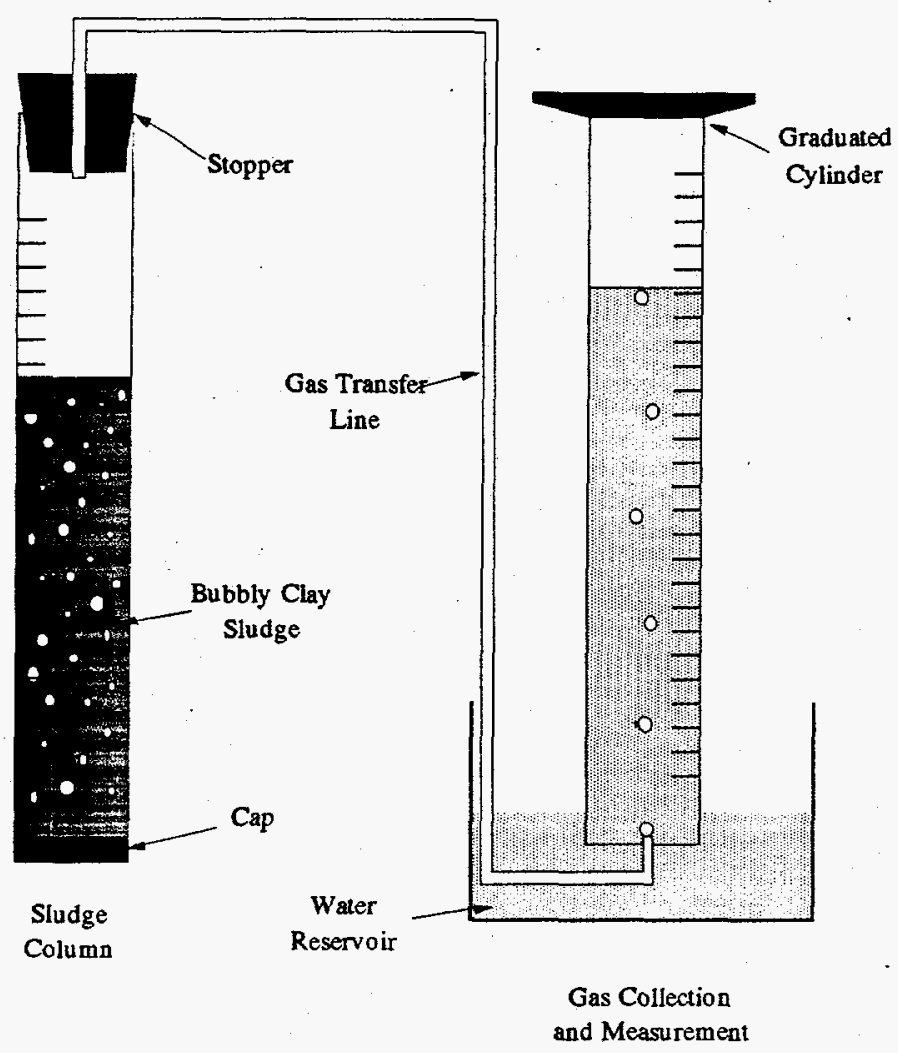

Figure 4.2. Gas Retention Apparatus for Small-Diameter Tubes

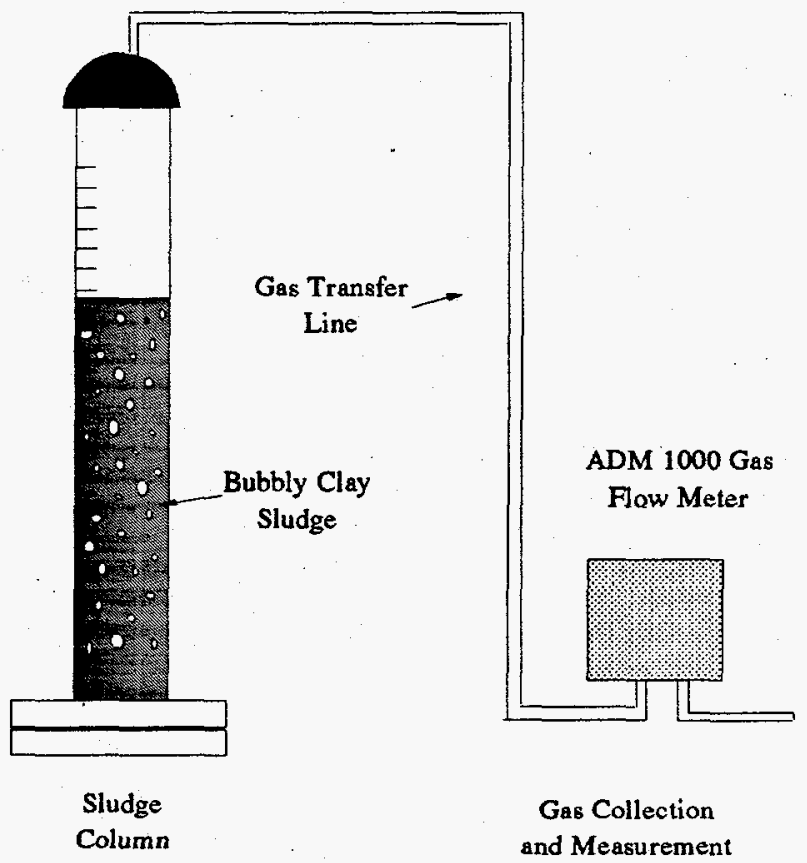

Figure 4.3. Apparatus for Measuring Bubble Retention and Release in Large-Diameter Vessels 
For all these experiments, 67-Pa (13.75 wt\%, Table 4.1) and 200-Pa (15.5 wt\%) bentonite clay was prepared by following the method described in Section 4.1.1. Small batches of the clay were mixed in a bench top mixer, and larger batches were mixed in a cement ribbon-type mixer. Sufficient clay was prepared to fill the column to an initial depth of $30 \mathrm{~cm}$. After the clay was mixed it was poured into the vertical column, and a small sample was collected in a 100-mL graduated cylinder for an initial void fraction determination. Immediately after the sample was collected, the top cap was placed on the retention vessel, and the initial height was recorded. Both the height of the clay and the volumetric flow rate through the flow meter were recorded at 2 to 5-minute intervals. After the clay height reached a maximum, the flow of gas was monitored for a period of time to show that gas generation had not ceased.

\subsubsection{Visual Observation Apparatus}

The apparatus for observing and collecting video images of the bubbles as they grew was essentially the same as the apparatus in Figure 4.2. The differences are that a larger diameter sample vessel was used $(10 \mathrm{~cm}$ diameter, $13 \mathrm{~cm}$ deep) and that the gas collection system was not used. To have an approximate value for the void fraction, the height of the clay was measured as a function of time. For these visual observation experiments, the initial void fraction in the simulant was not determined, so the void fractions reported with video images in Section 4.2.2.1 are simply estimates to allow qualitative comparison with other experiments.

Both close-up and wide-angle video images were collected. A video microscopy system composed of Leica MZ6 Zoom stereomicroscope with a $0.32 \mathrm{X}$ objective lens attached gave the close-up images. A phototube (Leica HV) with a $0.63 \mathrm{X}$ coupler split the image between the eyepieces and a video camera that was attached to the phototube. The video images were generated by a color micro CCD video camera (CV-735, AIMS Technology, New York) that produced an image with S-VHS resolution ( 450 horizontal TV lines). The wide-angle view was captured with a color zoom video camera (Sekai ISC-800A) which also generated high-resolution color video images (460 horizontal TV lines). These video images were then recorded on either a S-VHS recorder (Mitsubishi HS-S5600) or a Betacam-SP recorder (Sony UVW-1400A). In some cases, the experiments were more easily understood by viewing the video at faster than actual time. The SVHS recorder is capable of recording in a range of time-lapse modes, and many of the recorded images were edited tape-to-tape and recorded in time-lapse mode to allow viewing at up to about 120 times real speed. A series of still images was taken from the video recordings with a Sony UP$5600 \mathrm{MD}$ color video printer.

\subsubsection{Glass Bead Simulant Experiments}

Gauglitz et al. (1995) used a technique whereby $\mathrm{CO}_{2}$ gas was dissolved under pressure into glass bead/water slurries and depressurized in a controlled manner to investigate gas retention mechanisms in particulate slurries/sludges. Some of these data have been reevaluated to determine the effect of nominal glass bead size (five sizes, from 0.03 to $1 \mathrm{~mm}, \rho=2.55 \mathrm{~g} / \mathrm{mL}$ ) on the maximum void fraction. In each experiment, an approximately $15-\mathrm{cm}$ initial bead pack was submerged under 
water to a total height of $\sim 17 \mathrm{~cm}$ in rigid $1-$ in. $(2.54-\mathrm{cm})$ diameter tubes. These retention vessels were pressurized with $\mathrm{CO}_{2}$ gas, which was dissolved and mixed into the slurry liquid either by gently rocking the vessel or recirculating through the bead pack using a diaphragm metering pump (Rassat and Gauglitz 1995). For these data, equilibrium $\mathrm{CO}_{2}$ pressures of $2.4 \times 10^{5}$ to $3.4 \times 10^{5} \mathrm{~Pa} \mathrm{(20}$ to $34 \mathrm{psig}$ ) were used. In all cases, the vessels were depressurized at a rate of $\sim 6900 \mathrm{~Pa} / \mathrm{min}$ ( $1 \mathrm{psi} / \mathrm{min}$ ). The supernatant liquid and bead pack layer heights were monitored during and after depressurization. The maximum void fraction was determined as the change in supernatant liquid height (= maximum initial) divided by the maximum sludge-layer height, where the growth in supernatant liquid reflects the total amount of gas retained (dendritic, round, and fracture bubbles) in the sludge layer.

Partially drained salt cake wastes were simulated using glass beads and dilute hydrogen peroxide solutions. A capped $\sim 105-\mathrm{cm}(3.5-\mathrm{ft})$ long and 2.54-cm-i.d. Lexan (polycarbonate) cylinder was used as the gas retention device in a configuration similar to that in Figure 4.2. In each experiment, about $725 \mathrm{~g}$ of nominally $1 \mathrm{~mm}$ glass beads, corresponding to about $440 \mathrm{~mL}$ of porous media, were added to the $1-\mathrm{m}$ column containing a weighed excess of $3 \mathrm{wt} \%$ hydrogen peroxide solution. Bubbles entrained during the bead addition were removed by gently rocking the cylinder and tapping the assembly on a hard surface. . Initially, the liquid level exceeded the bead pack height, and both initial heights (volumes) were recorded and used to determine the bead pack porosity. The porosity ranged from 37.9 to $39.3 \%$ and averaged $38.6 \%$. Subsequently, liquid was drained from a valve attached to the bottom cap in the cylinder to the desired initial liquid saturation level. The top cap of the cylinder was then connected to the gas flow measurement device. As $\mathrm{O}_{2}$ gas was generated by hydrogen peroxide decomposition, the movement of the liquid capillary fringe within (or above) the bead pack was monitored visually, and the volume of gas generated was measured. Determination of the location of the capillary fringe within a bead pack is subject to greater uncertainty $(\sim \pm 1 \mathrm{~cm})$ than reading a free liquid level $(< \pm 0.1 \mathrm{~cm})$. This translates into an error in retained gas volume of approximately $2 \mathrm{~mL}$, or less than $0.5 \%$ void when based on the total bead pack volume.

\subsection{Results and Discussion}

Experimental results are presented in this section for gas retention and release studies using bentonite clay and glass bead particulate simulants. Results of visual observations of retained bubble shapes are presented in Section 4.2.1; then the maximum gas retention of the simulants and the mechanisms of gas release are addressed in Section 4.2.2 and 4.2.3, respectively. Within each topic (retention and release), the effect of bentonite clay strength on the observed gas properties is discussed. Also, the role of the test vessel height-to-diameter aspect ratio on retention and release is probed in two sets of experiments using the same clay recipe. In one group of experiments the initial clay height is varied, and in the other set the vessel diameter is manipulated. Maximum gas retention in glass bead simulated DST wastes is also probed. 


\subsubsection{Effect of Clay Strength on Retained Bubble Shape}

The clay strength was observed to affect the shape of the bubbles retained in the sludge and the maximum void fraction. As described in Section 3.1, bubble growth is dictated by the forces acting on the bubbles, including the strength of the waste being displaced by the bubbles and the surface tension force, which seeks to keep the bubbles round. These visual experiments were performed for clay ranging from $\sim 3$ to $1040 \mathrm{~Pa}$. The primary data were video recordings of the bubbles. A series of still images from these videos highlight the different bubble retention behavior for the range of simulants studied (Figures 4.4 to 4.9). A condensed and edited version of the videos from these experiments is available; it shows the transient growth of bubbles and their release.

Figures 4.4 and 4.5 show the character of gas bubbles retained in a sludge with a shear strength of $1040 \mathrm{~Pa}$; the void fraction was about 0.25 when these images were taken. The bubbles appear to be slit-shaped and/or long curving cylinders. Figure 4.4 shows a large-scale view of the retained bubbles (scale in $\mathrm{cm}$ ) that appear as wide horizontal slits. The close-up image (scale in $\mathrm{mm}$ ) in Figure 4.5 again shows a larger slit-shaped bubble as well as smaller bubbles that are long and slender. This image also shows that, on a small scale, the interfaces between the bentonite simulant and gas bubbles are smoothly curved, implying that, at this small scale, surface tension dominates the interfacial shape.

During this experiment, which lasted a few hours, bubble growth was recorded on video. The video of the large-scale image was edited into a time-lapse format, which showed the slit-shaped bubbles expanding and contracting as the bubbles grew. This breathing indicates that the slit-shaped bubbles were at times connected, and gas migrated between bubbles. While we could not observe gas exiting from the top of the sludge, gas was continually released. The height of the sludge did not grow beyond a void fraction of about 0.25 even though sufficient hydrogen peroxide was added to achieve 0.6 void fraction.

Figures 4.6 and 4.7 show retained bubbles in a 67-Pa simulant when the void fraction was 0.45. In both the large-scale image (Figure 4.6, scale in $\mathrm{cm}$ ) and the close-up image (Figure 4.7, scale in $\mathrm{mm}$ ), the retained bubbles are essentially round, quite different from the shape of those in the strong clay (Figures 4.4 and 4.5). For this 67-Pa clay, surface tension appears to dominate the shape of the bubbles. In the close-up image, bubbles smaller than $\sim 0.5 \mathrm{~mm}$ are certainly round, while bubbles larger than $\sim 1 \mathrm{~mm}$ appear slightly distorted from a spherical shape.

Figures 4.8 and 4.9 show bubbles retained in a weak clay simulant with a shear strength of 6.4 Pa. For clays this weak, surface tension again dominates the shape of the bubbles as they grow, so the bubbles are essentially round. The void fraction was about 0.3 . A few moments after these images were taken, the bubbles released. Figure 4.10 shows the sample vessel during the release event. The larger bubbles in the center swirled both upward and downward as the gas was being released. A more detailed discussion of this release event and others is given in Section 4.2.3. 


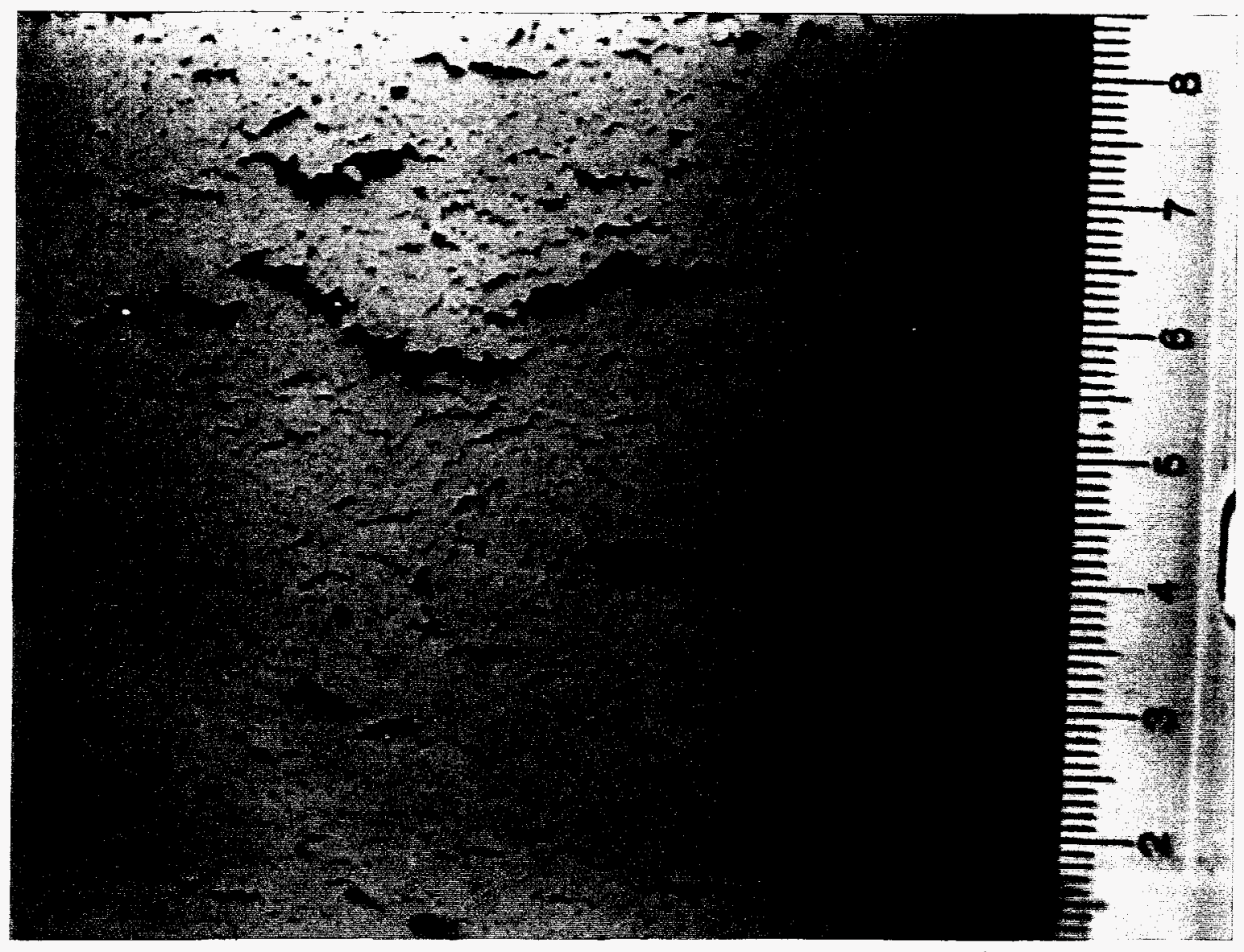

Figure 4.4. Wide-Angle Image of Bubbles Retained in a Bentonite Clay Simulant Composed of $18.75 \mathrm{wt} \%$ Bentonite in Water with an Initial Shear Strength of $1040 \mathrm{~Pa}$ (numbers on the scale are in $\mathrm{cm}$; image was taken when the void fraction was about 0.25 ) 


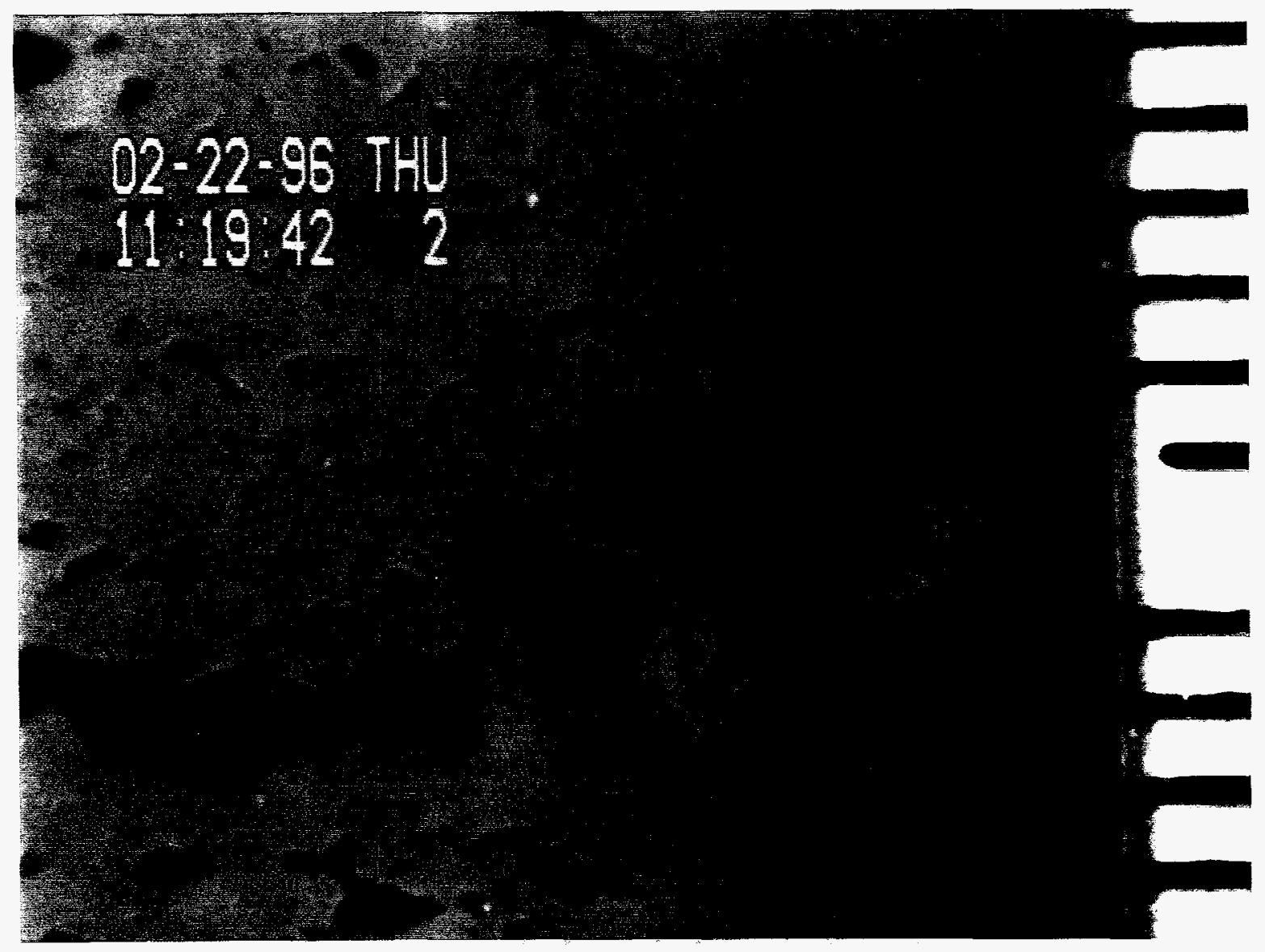

Figure 4.5. Close-up Image of Bubbles Retained in a Bentonite Clay Simulant Composed of $18.75 \mathrm{wt} \%$ Bentonite in Water and Having an Initial Shear Strength of $1040 \mathrm{~Pa}$ (markings on the scale in mm; image taken when the void fraction was about 0.25 ) 


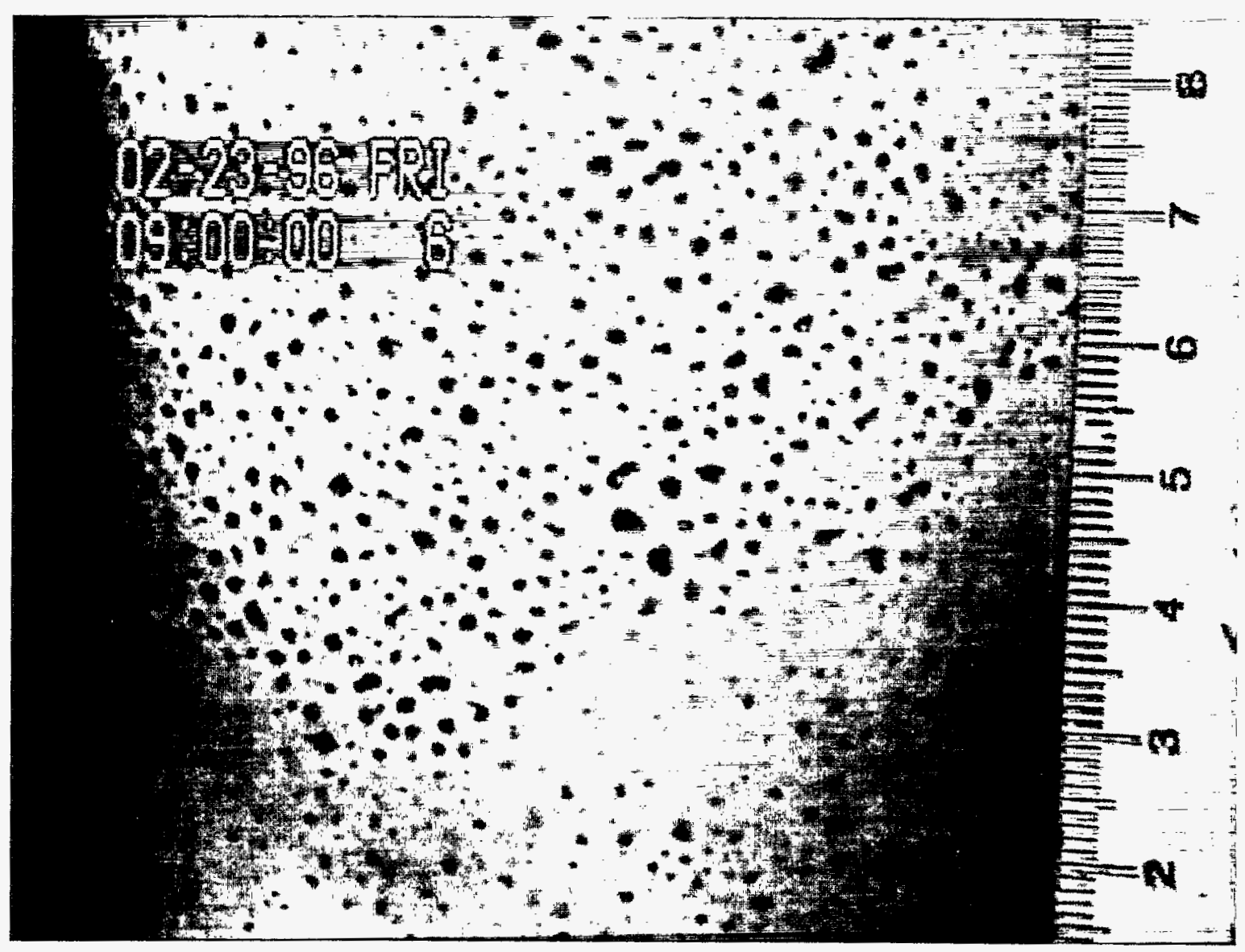

Figure 4.6. Wide-Angle Image of Bubbles Retained in a Bentonite Clay Simulant Composed of $13.75 \mathrm{wt} \%$ Bentonite in Water and Having an Initial Shear Strength of $67 \mathrm{~Pa}$ (numbers on scale are in $\mathrm{cm}$; image taken when the void fraction was about 0.45 ) 


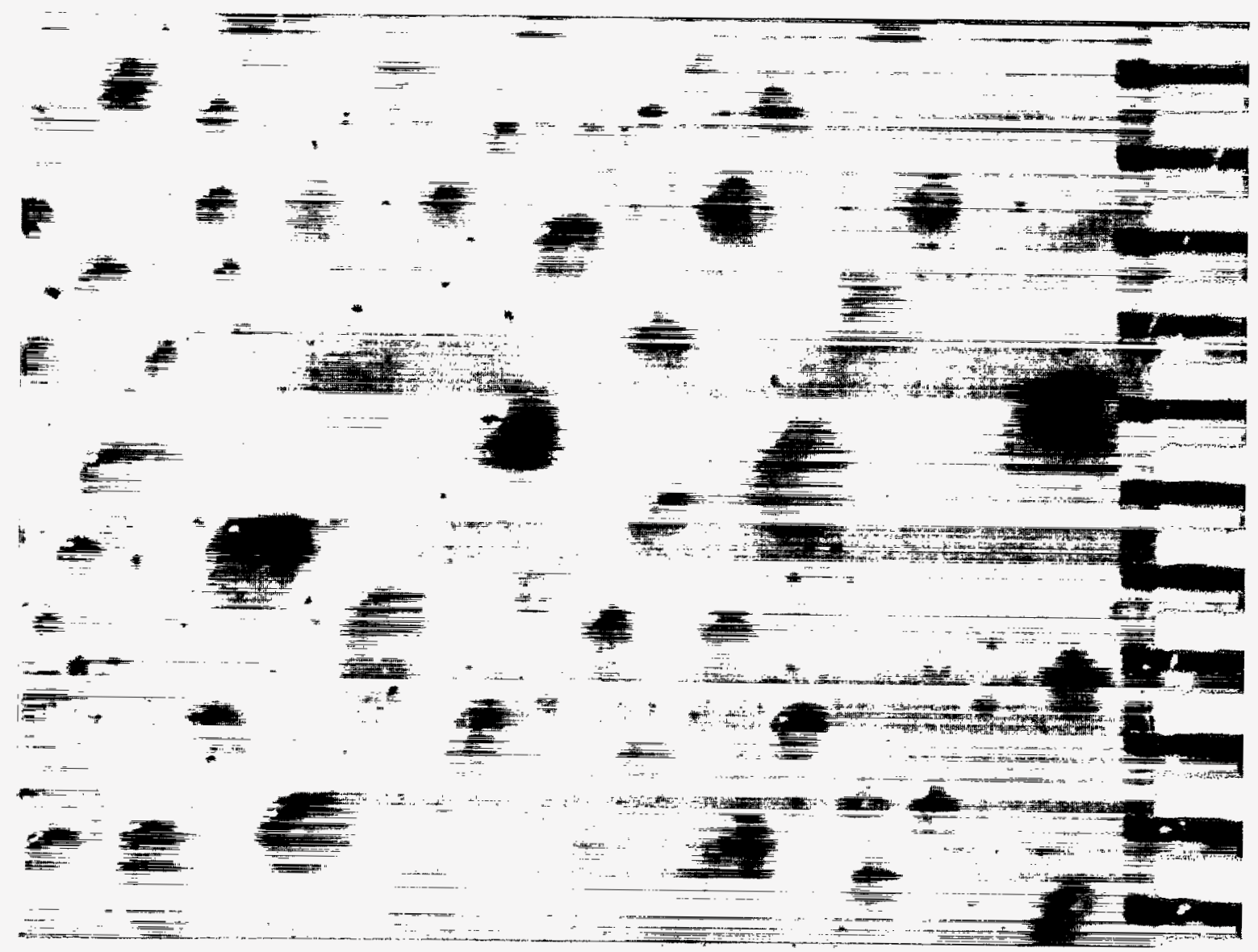

Figure 4.7. Close-up Image of Bubbles Retained in a Bentonite Clay Simulant Composed of $13.75 \mathrm{wt} \%$ Bentonite in Water with an Initial Shear Strength of $67 \mathrm{~Pa}$ (markings on the scale are in $\mathrm{mm}$; image was taken when the void fraction was about 0.45 ) 


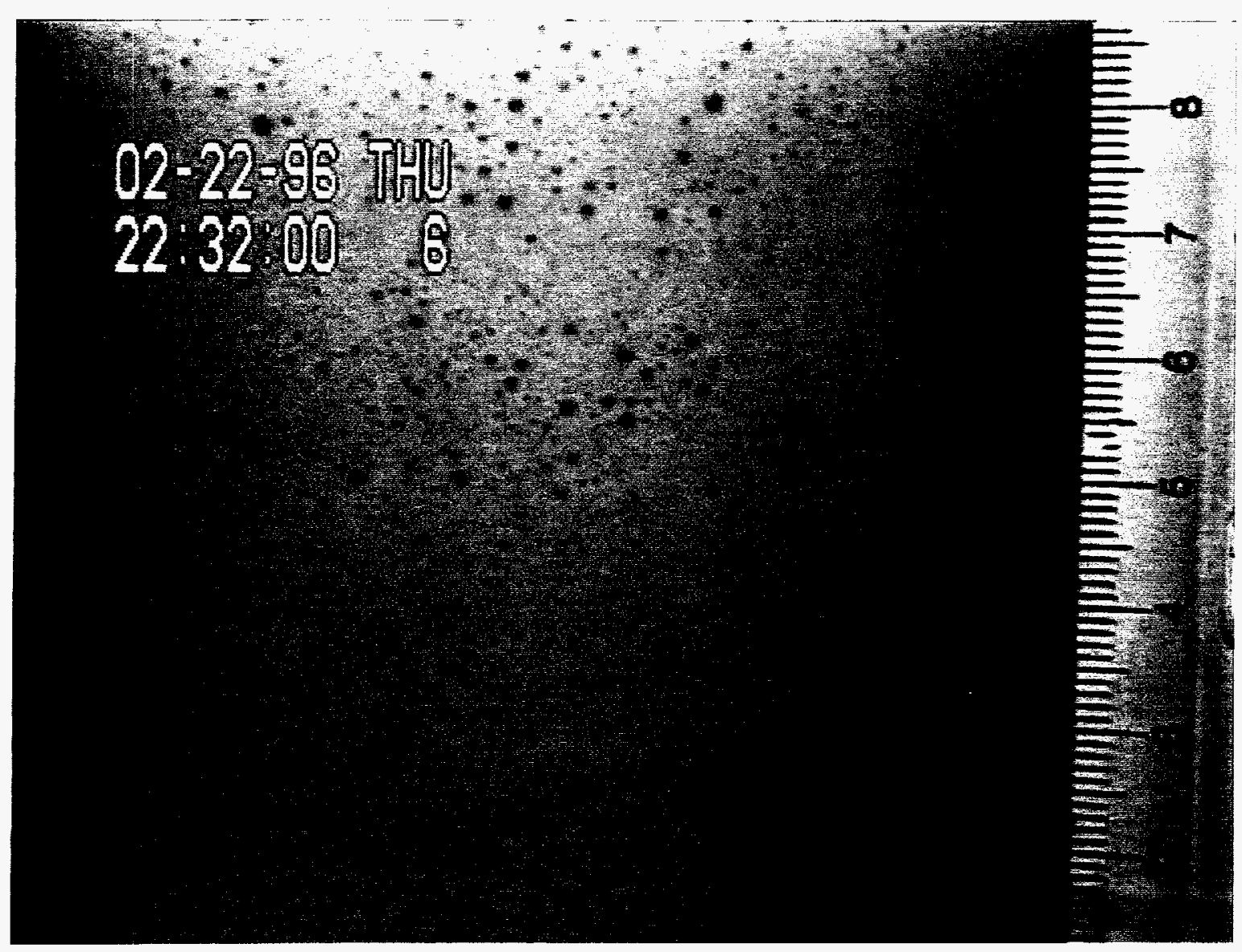

Figure 4.8. Wide-Angle Image of Bubbles Retained in a Bentonite Clay Simulant Composed of $10.00 \mathrm{wt} \%$ Bentonite in Water and Having an Initial Shear Strength of $6.4 \mathrm{~Pa}$ (numbers on the scale are in $\mathrm{cm}$; image was taken when void fraction was $\sim 0.30$ ) 


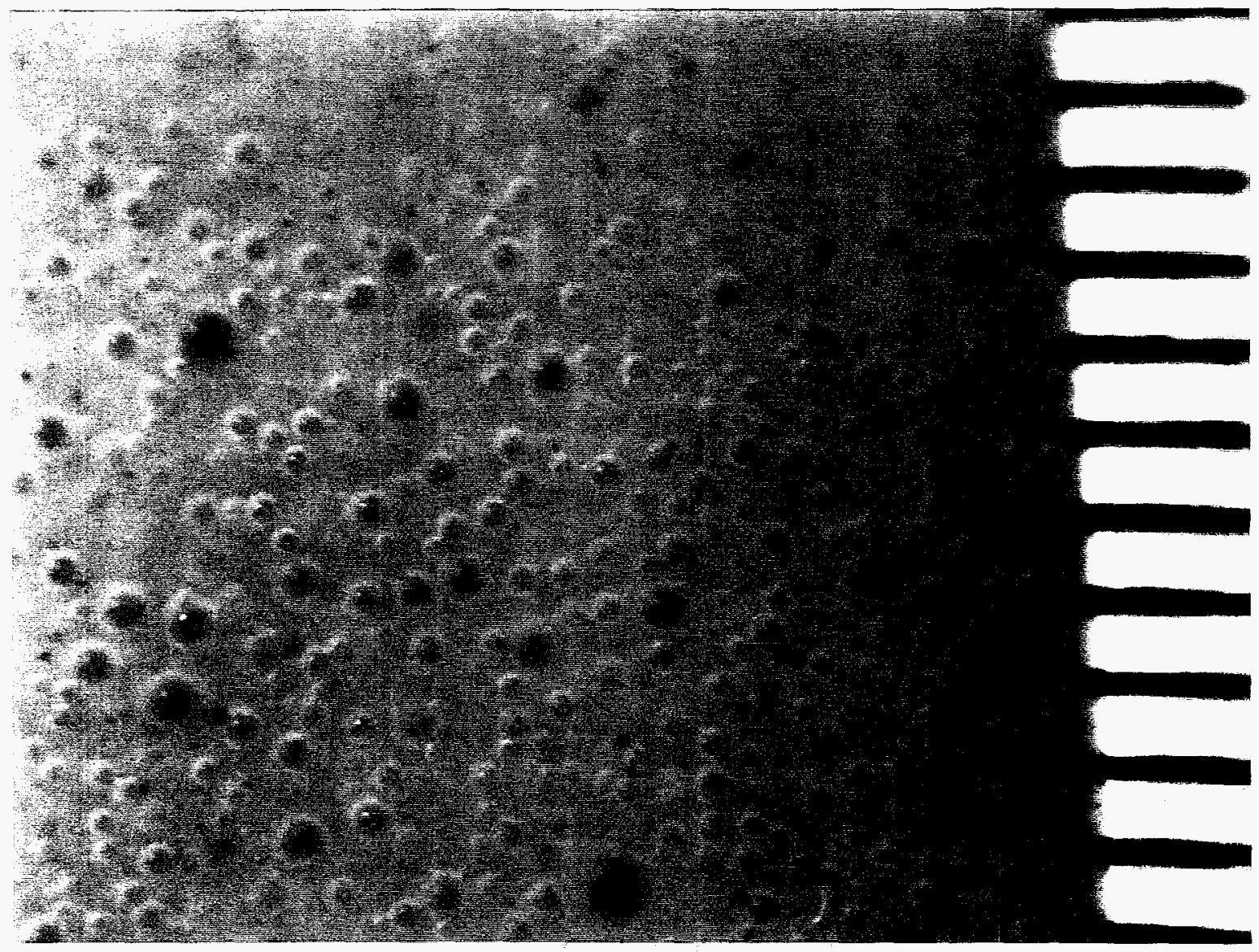

Figure 4.9. Close-up Image of Bubbles Retained in a Bentonite Clay Simulant Composed of $10.00 \mathrm{wt} \%$ Bentonite in Water and Having an Initial Shear Strength of $6.4 \mathrm{~Pa}$ (markings on scale are in $\mathrm{mm}$; image was taken when void fraction was $\sim 0.30$ ) 


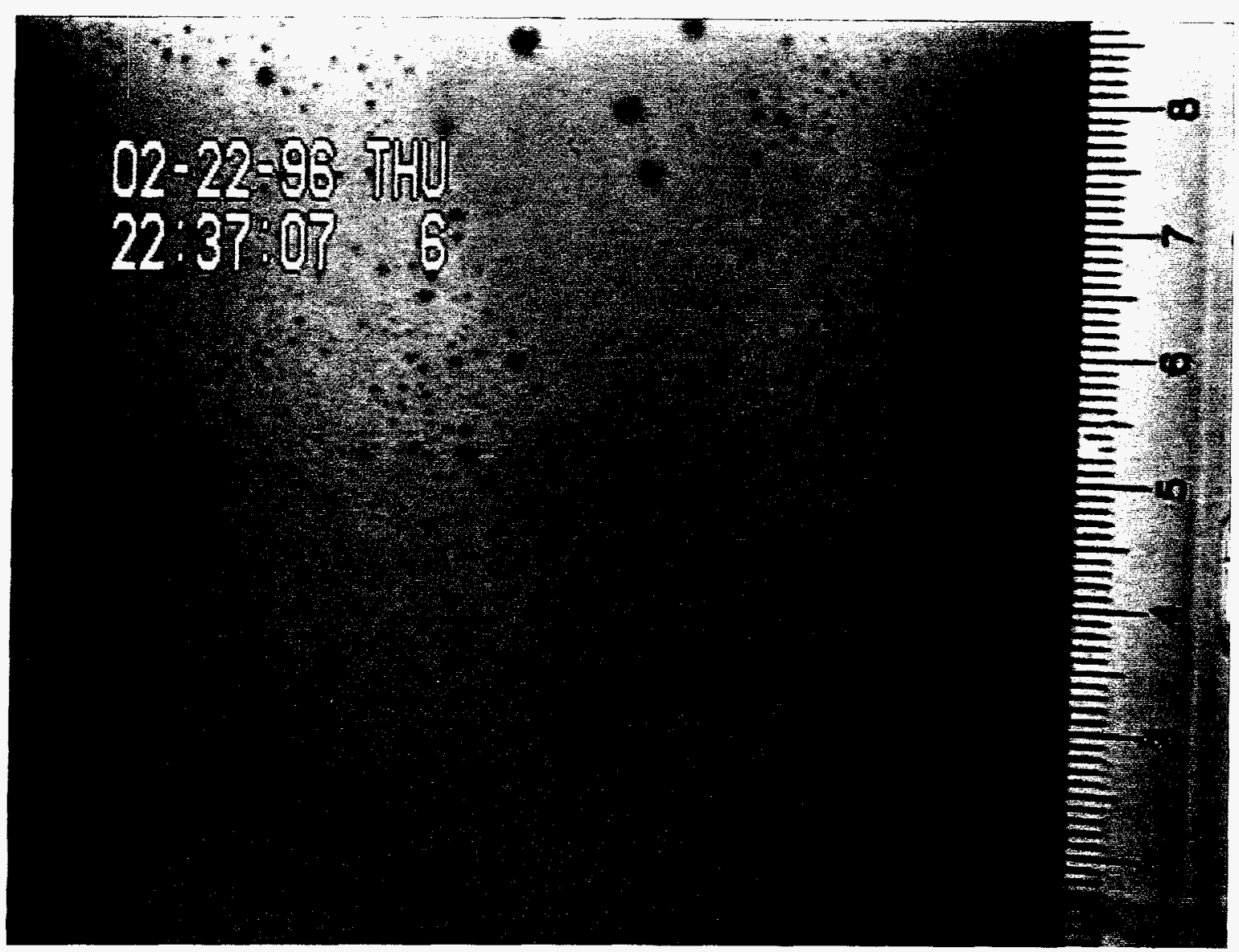

Figure 4.10. Wide-Angle Image of Bubbles Releasing from a Bentonite Clay Simulant Composed of $10.00 \mathrm{wt} \%$ Bentonite in Water and Having an Initial Shear Strength of $6.4 \mathrm{~Pa}$ (numbers on the scale in $\mathrm{cm}$; image taken when void fraction was about 0.30 ). The large dark objects in the center are bubbles that were swirling in an energetic release.

Retained bubbles in an extremely weak clay simulant with a shear strength less than $3 \mathrm{~Pa}$ are shown in Figures 4.11 and 4.12. In this simulant very few bubbles were actually retained, and even very small bubbles, on the order of $1 \mathrm{~mm}$ and larger, were continually rising through the simulant. The void fraction in these images is less than about 0.05 . In the large-scale view shown in Figure 4.11 (scale in $\mathrm{cm}$ ), the small dark items in the image are bubbles with diameters of about $0.1 \mathrm{~cm}$. Figure 4.12 shows a close-up view of these bubbles (scale in $\mathrm{mm}$ ). The largest bubbles in this image were about $1 \mathrm{~mm}$, and bubbles smaller than about $0.05 \mathrm{~cm}$ were essentially stationary, indicating that these smallest bubbles were being retained by the yield strength of the simulant. 


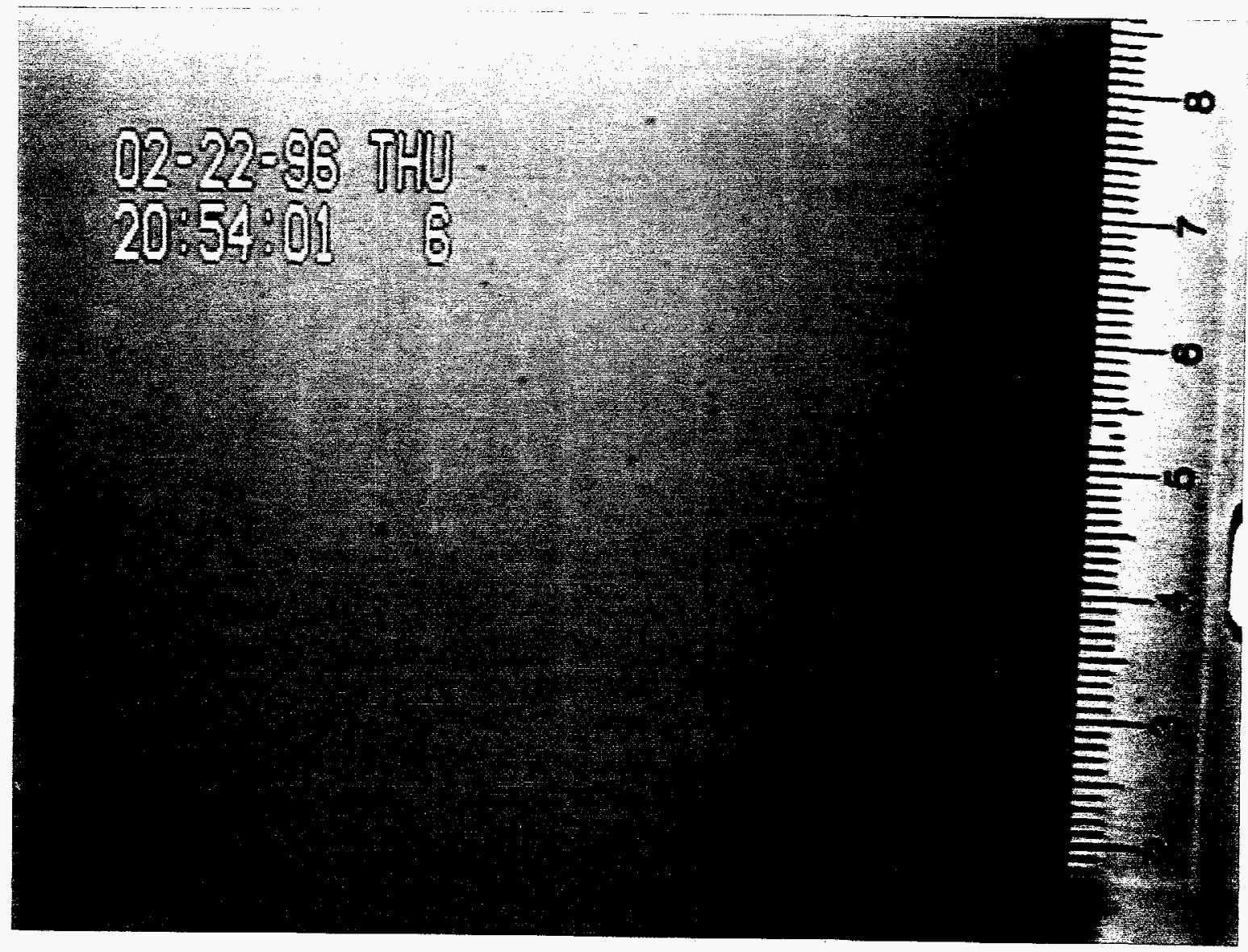

Figure 4.11. Wide-Angle Image of Bubbles Retained in a Bentonite Clay Simulant Composed of 9.01 wt\% Bentonite in Water with an Initial Shear Strength of less than $3 \mathrm{~Pa}$ (numbers on scale in $\mathrm{cm}$; image taken when void fraction was less than about 0.05 ) 


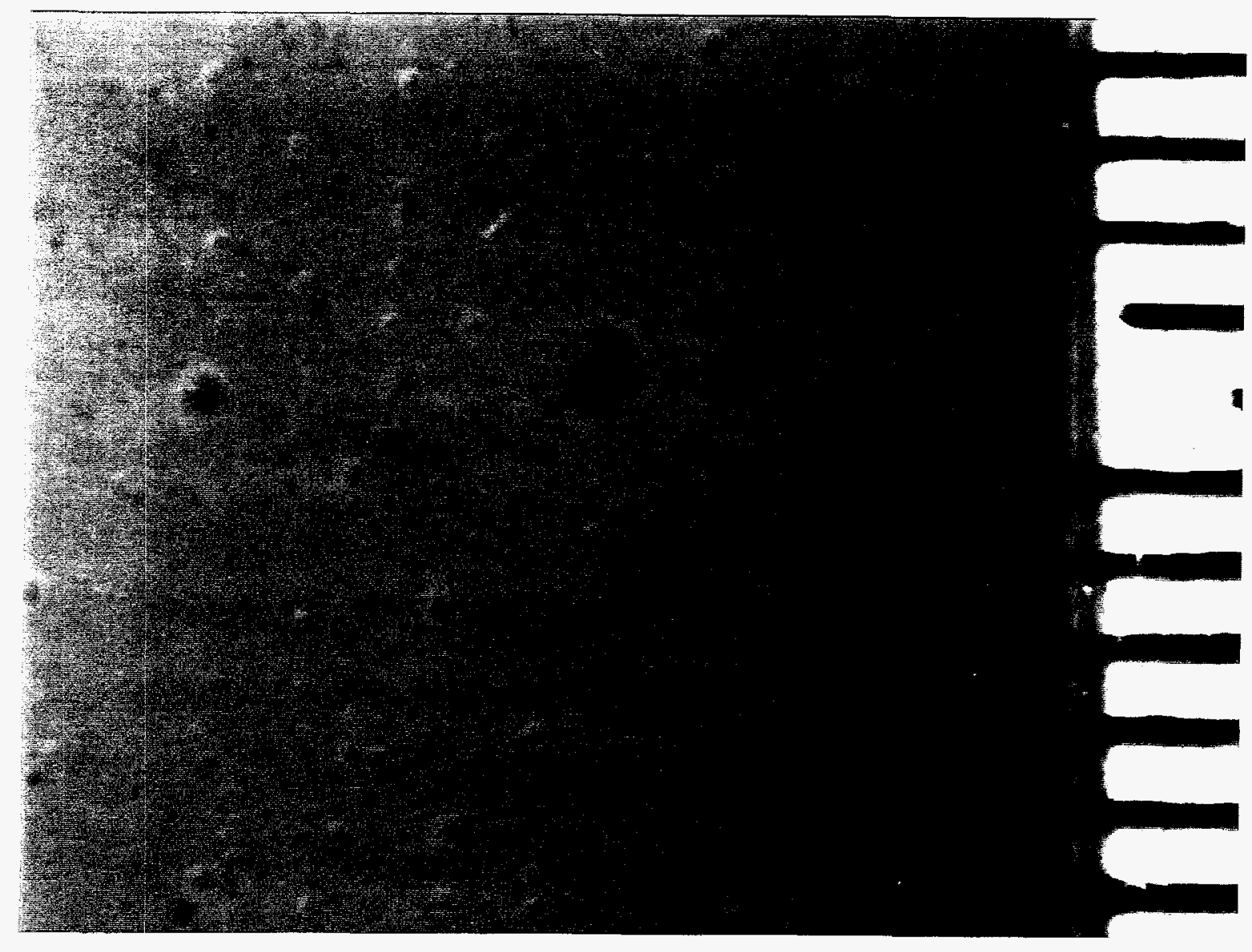

Figure 4.12. Close-up Image of Bubbles Retained in a Bentonite Clay Simulant Composed of $9.01 \mathrm{wt} \%$ Bentonite in Water with an Initial Shear Strength of less than $3 \mathrm{~Pa}$ (markings on scale are in $\mathrm{mm}$; image was taken when void fraction was less than $\sim 0.05$ ) 


\subsubsection{Maximum Retention}

A key safety issue for flammable gases is the maximum gas volume retained in the waste. Knowledge of the maximum gas fraction that can be retained in waste defines a bound that can be used in the investigation of various gas release scenarios. In this section, the results for the effect of clay strength and test vessel geometry (height and diameter) on the measured maximum void fraction are presented. Also, the maximum retention of fully saturated glass bead/water/CO $\mathrm{C}_{2}$ slurries (DST simulants) of varying particle diameter are reported, and the maximum retention of partially drained bead packs is presented.

Figure 4.13 shows the volumetric gas generation and retention data for a typical experiment. In this example, the bentonite clay had a 31-Pa shear strength and was contained in a 1-in.-diameter PVC tube with the apparatus depicted in Figure 4.2. The gas generated curve represents the total amount of gas produced in the clay by $\mathrm{H}_{2} \mathrm{O}_{2}$ decomposition as measured in the water-filled graduated cylinder. The gas retained values shown in the figure are calculated from the change in sludge height with time. Subsequently, these data were converted to void fraction values for direct comparison with other gas retention experiments. In Figure 4.13, all gas generated in the clay is retained up to an elapsed time of 90 minutes. At that point of maximum gas retention, a rapid gas release was observed. Following the gas release, the clay retained additional gas to reach essentially the same maximum retention.

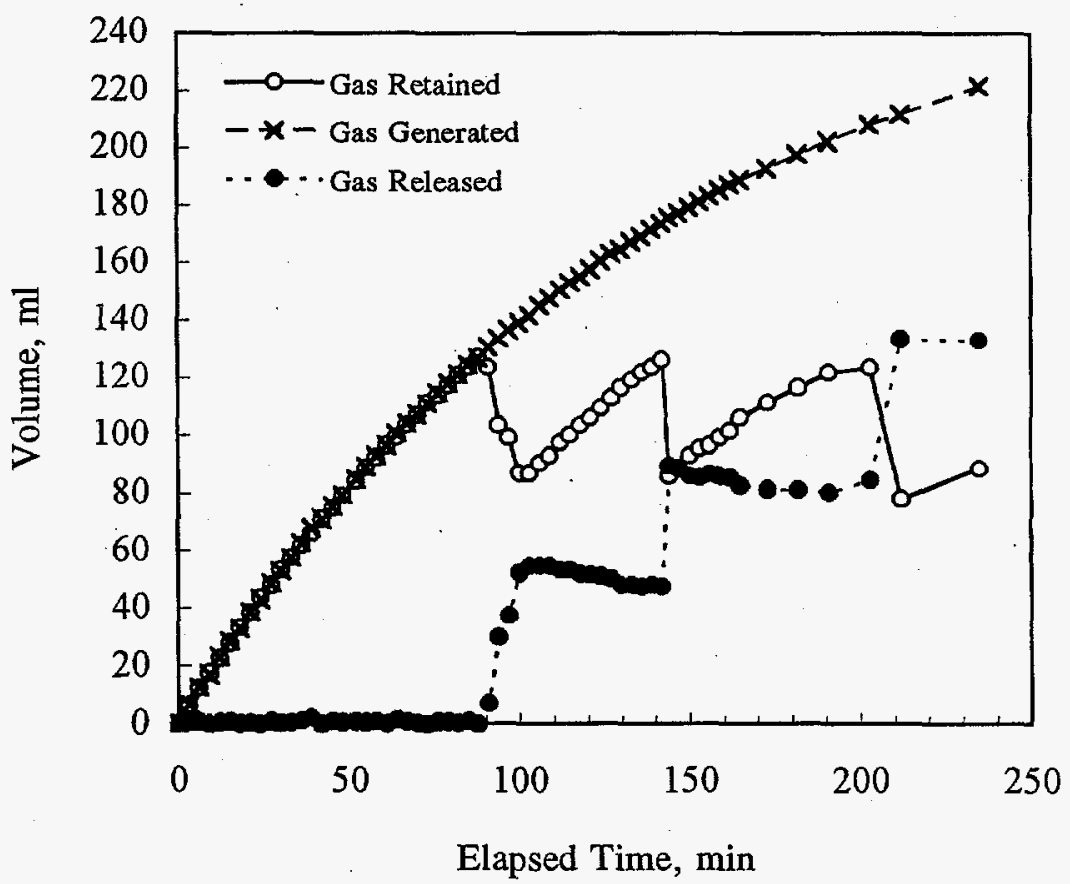

Figure 4.13. Volumes of Gas Generated, Retained, and Released 


\subsubsection{Effect of Clay Strength on Maximum Retention}

Figure 4.14 shows the measured maximum void fractions for a series of clay sludges of varying strengths contained in a $2.64-\mathrm{cm}$-diameter tube. The curve through the data represents an eye-fit of the data. In these experiments, the initial sludge height was essentially constant, ranging from 31.4 to $33.3 \mathrm{~cm}$. The results show that the retention is negligible for vanishingly small strengths, increases to a peak value for intermediate strengths, and then decreases slightly at the highest strengths. In the limit of a zero-strength, it is expected that no gas would be retained and bubbles would freely rise due to buoyancy. The results for a 1.3-Pa clay, as shown in Figure 4.14, confirm this expectation. As the simulant strengthens, gas retention increases. Even for very weak sludges of 3.4 and $6.4 \mathrm{~Pa}$, moderate gas retention of 0.095 and 0.20 void fraction, respectively, was observed. As described in Section 4.2.1, the retained bubbles were round at these strengths. These very weak clays, with the consistency of thin maple syrup, are readily pourable. As shown in Figure 4.14, a peak in measured maximum void fraction was found for clays of weak-to-moderate strength. A maximum void fraction of 0.404 was determined for a 31-Pa sludge, and a 67-Pa sludge had a 0.379 maximum void fraction. These sludges were the consistency of latex wall paints, and retained bubbles were round in shape but tended to become more oblong in the stronger material, and their volumes are included in the void fraction results. (As discussed in Section 4.2.2.3 on vessel diameter effects, the presence of vessel spanning bubbles did not appear to have a large affect on maximum retention.) Also, vessel-spanning bubbles were observed in these sludges. The gas retention in moderate to strong clays $(>100 \mathrm{~Pa})$ decreases from the peak values near $40 \%$ void to about $30 \%$ near $1000 \mathrm{~Pa}$.

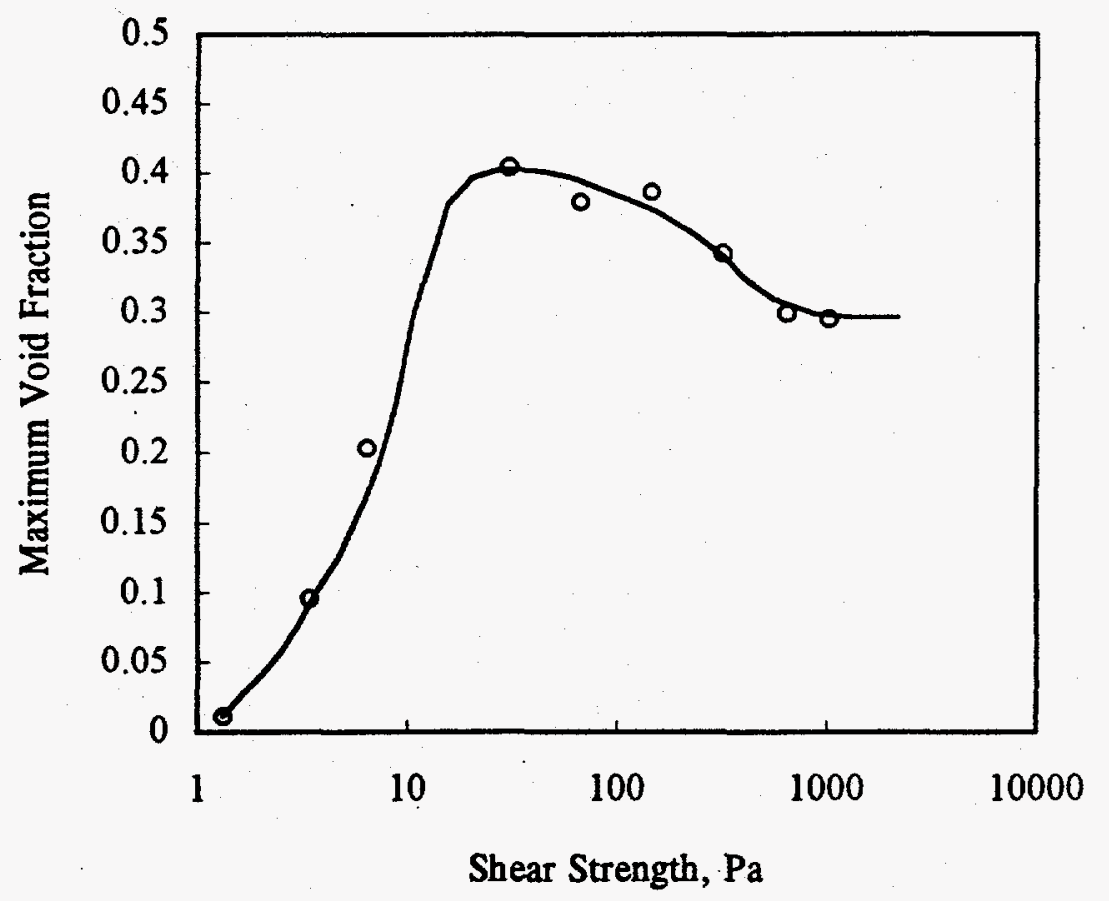

Figure 4.14. Effect of Clay Strength on Maximum Void Fraction 
In these strongest sludges, gas was retained primarily in fingering, slit-shaped bubbles, and fracture bubbles also developed. Plots showing changes in void fraction with time, for the individual experiments from which the Figure 4.14 data points were obtained, are presented in Section 4.2.3.1. These data are also tabulated in Appendix A, Tables A.2-A.9.

As discussed in Section 3.2, percolation theory suggests that a substantial void fraction must be retained before the bubbles connect. The results in Figure 4.14 give maximum void fractions of order 0.3 to 0.4 , which agrees with this expectation. In addition, it was expected that slit-shaped bubbles formed in very strong sludges would connect at a lower void fraction. For the strongest sludges, the maximum retention is slightly less than the peak value, which supports this explanation.

Three replicate experiments were conducted using 67-Pa sludge and an essentially constant initial height ranging from 31.4 to $37.8 \mathrm{~cm}$. The measured maximum void fractions for these cases were $0.379,0.378$, and 0.366 in order of increasing sludge height. The reproducibility of these results is unexpectedly good. From the data, a $95 \%$ confidence interval of $37.4 \pm 1.8 \%$ void is calculated. For comparison, the estimated error associated with determining void fraction in a single measurement using the density estimation method is also about $\pm 2 \%$ void. The gas retention experimental results for the three replicate cases are tabulated in Appendix A, Tables A.9-A.11.

\subsubsection{Effect of Initial Clay Height on Maximum Retention}

A moderately weak 67-Pa bentonite clay was used to probe the effect of initial clay height on maximum gas retention in $2.54-\mathrm{cm}$-diameter clear acrylic tubes. Figure 4.15 shows the maximum void data for a series of experiments in which the initial height was varied from 13.3 to $91.0 \mathrm{~cm}$. The results indicate an essentially linear trend (straight line fit by eye through the data) of increasing maximum void fraction with increasing initial height. In the limit of zero initial height, which more closely represents the height-to-diameter aspect ratio in real tank waste, the best fit line extrapolates to $39 \%$ void. The datum for the $91.0-\mathrm{cm}$ initial sludge height shown in Figure 4.15 should be specially noted. In this experiment, the sludge eclipsed the top of the retention vessel, so the maximum void measured is actually $251.1 \%$ void. The increase in maximum retention with sludge length may be indicative of vessel wall contributions affecting gas retention. This is reflected in differences in the number of vessel-spanning bubbles (fractures) where gas is accumulated within the sludge column. In the shorter sludge columns, one or two fractures were detected in an isolated area. However, in the longer sludge columns, five or more fractures were observed starting as low as 10 $\mathrm{cm}$ from the bottom of the vessel upward about every $25 \mathrm{~cm}$. These data support the need to investigate gas retention for similar in larger-diameter vessels, which is described in the following section.

Wall effects may also be implicated in the gas retention results for clays of about $30-\mathrm{cm}$ initial height. As shown in subsection 4.2.2.1, three replicate experiments using 67-Pa clay, 31.4-37.8-cm initial heights, and a 2.64-mm-diameter PVC tube resulted in an average $37.4 \pm 1.8 \%$ maximum void. The tube used in the initial height studies was a $2.54-\mathrm{mm}$-diameter acrylic. With this vessel a maximum void of $42.2 \%$ was measured for a $29.2-\mathrm{cm}$ initial height. Three reasonable explanations may be postulated: 1) it is an effect due to vessel diameter; 2) it is a function of the plastic 


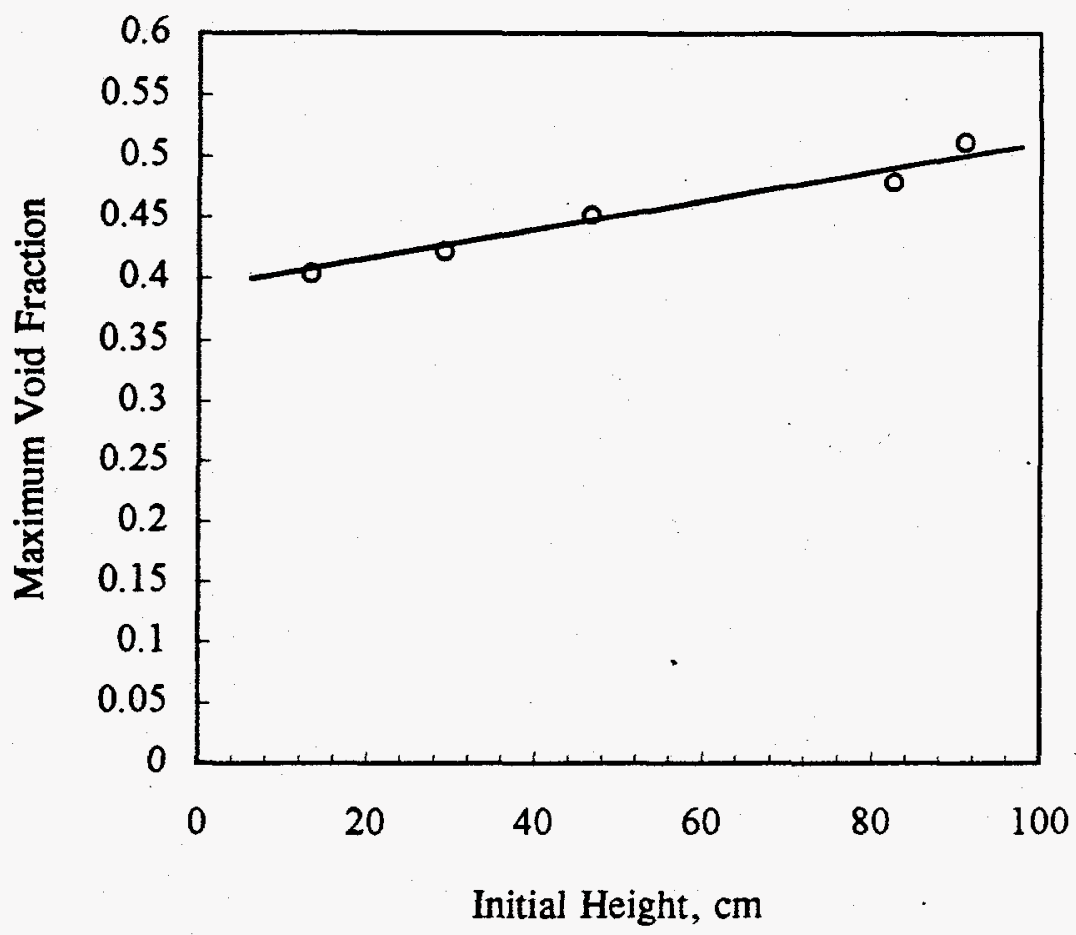

Figure 4.15. Effect of Initial Clay Height on Maximum Void Fraction

composition; or 3) it reflects a change in a raw material (e.g., bentonite clay) or some other random error, which broadens considerably the confidence interval for reproducibility of maximum void fraction results. The $95 \%$ confidence interval for all four gas retention results in nominally 1 -in.-diameter tubes becomes $38.6 \pm 3.9 \%$ void.

\subsubsection{Effect of Vessel Diameter on Maximum Retention}

The results for the retention and release of gas obtained with the apparatus for large-diameter vessels were similar to the results collected in the 2.5 -cm-diameter columns. The clay retained gas up to a maximum and then released gas both with and without level drops. In all the experiments with this apparatus, the flow rate meter confirmed that gas continued to be generated and released after the clay had attained its maximum retention. The complete data for level and gas generation rate and cumulative volume are provided in Appendix A, Tables A.17 to A.26.

Figure 4.16 shows the maximum retention results for the range of vessel diameters studied for clays with strengths of 67 and $200 \mathrm{~Pa}$. The results show that vessel diameter appears to have little effect on the maximum, and the single line through the data was fit by eye. Figure 4.16 also shows acceptable repeatability for the duplicate experiments conducted in the $5.1-\mathrm{cm}, 10.2-\mathrm{cm}$, and $30.5-$ $\mathrm{cm}$-diameter vessels. While the vessel diameter had only a minor effect on the maximum retention, it played a major role in the release behavior, as discussed in Section 4.2.3.3. As also noted in 


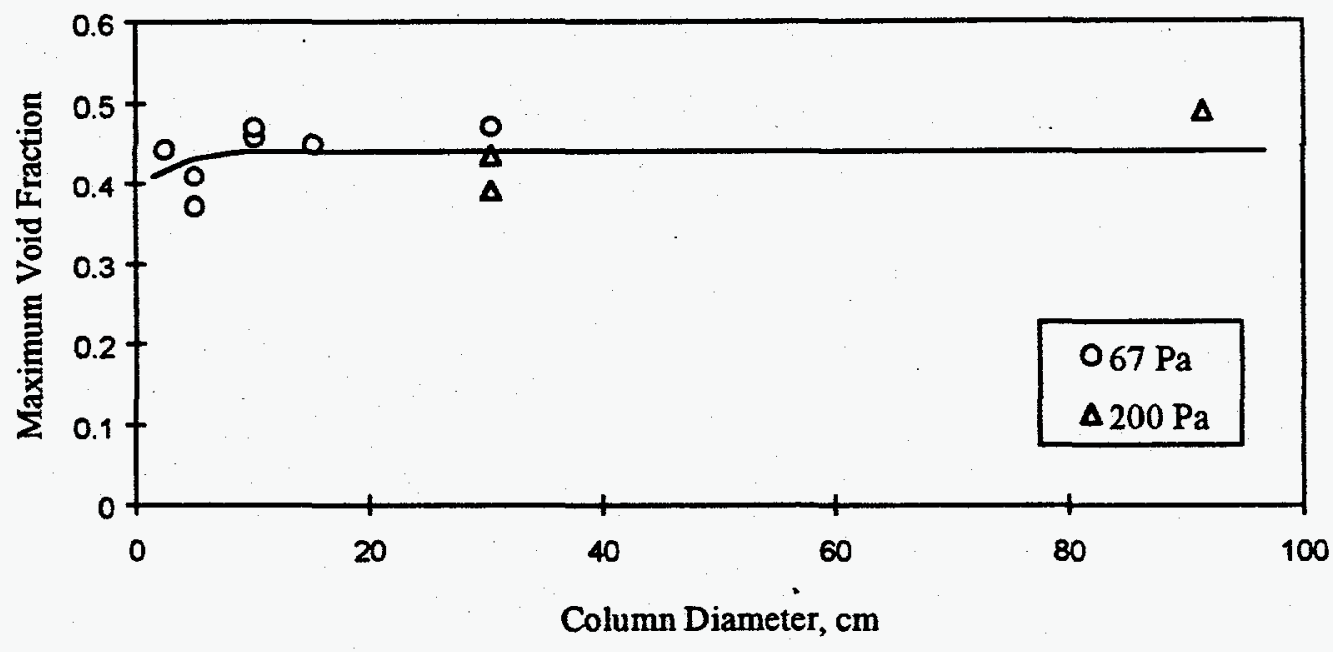

Figure 4.16. Effect of Column Diameter on the Maximum Void Fraction (results obtained for 67 and 200-Pa bentonite clay sludges)

subsections 4.2.2.1 and 4.2.2.2, careful observation showed some retained bubbles spanning the entire-cross section of the smallest diameter vessel $(2.5 \mathrm{~cm})$. In this test vessel, it appeared that the small diameter of the apparatus clearly affected the retention of bubbles. In vessels of $5.1 \mathrm{~cm}$ diameter and larger, apparatus-spanning bubbles were not observed. Still, the results in Figure 4.16 show that, overall, the vessel diameter had only a slight effect on maximum retention.

In these experiments, the total gas volume leaving the vessel was determined by integrating the flow rate measurements over time. While the flow rate measurements clearly showed continual gas release without sludge growth when the maximum retention was attained, a number of experimental issues confounded the flow rate data. In some cases, leaks caused problems; in other situations, the flow rate fluctuated, often deviating $50 \%$ about some average value. Accordingly, the retained gas volumes and total generated gas volumes reported in Appendix A do not match one another as well as the results shown in Figure 4.13. This discrepancy is a reflection of the experimental measurements and is not an indication of different behavior in larger-diameter vessels.

\subsubsection{Effect of Particle Size on Maximum Retention}

Figure 4.17 shows the maximum void fractions for settled particulate slurries of glass beads, water, and $\mathrm{CO}_{2}$ gas for a range of particle (glass) sizes. In general, the maximum void fraction increases with decreasing particle diameter, as suggested by the line drawn through the data. For 1$\mathrm{mm}$ nominal diameter beads, a maximum void of $8.3 \%$ was measured, and for $0.06-\mathrm{mm}$ beads the maximum was $22.5 \%$ void. However, the apparent downturn in maximum retention (17.5\%) for the 


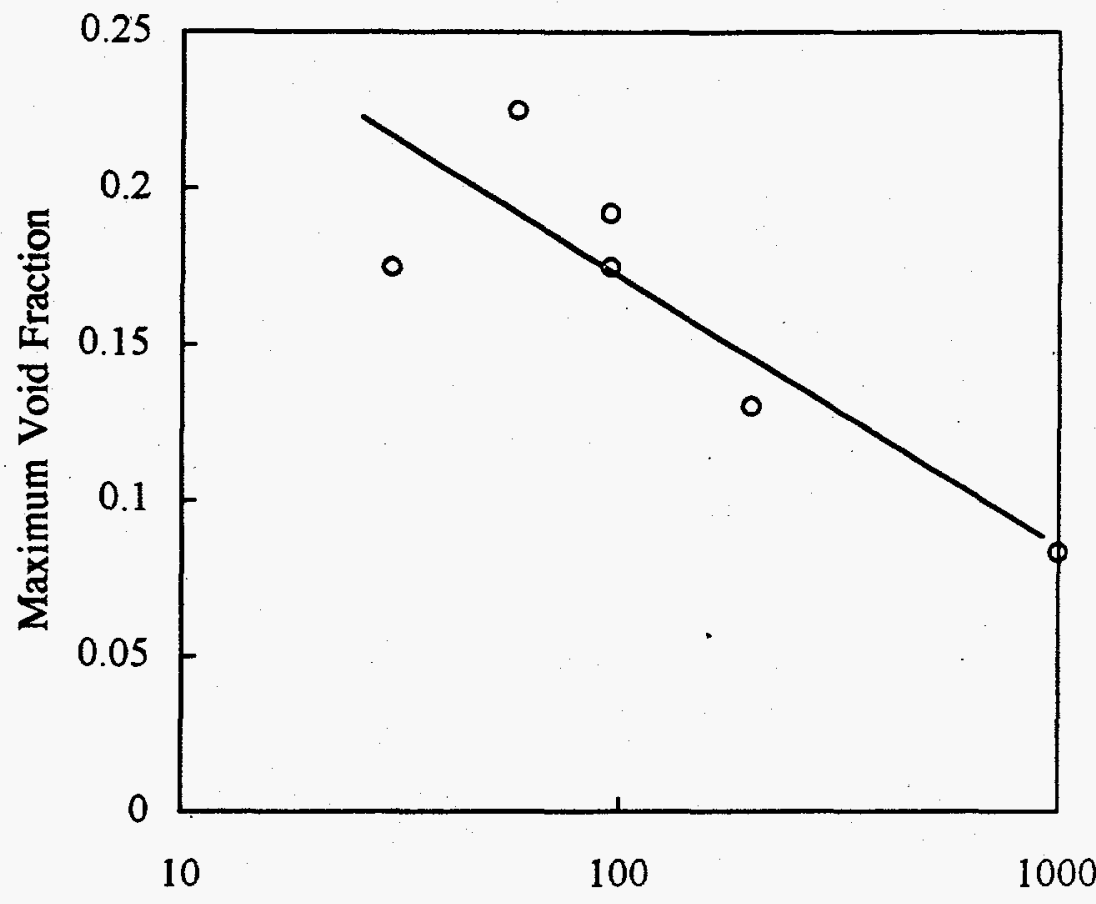

Nominal Bead Size, microns

Figure 4.17. Maximum Void Fractions of Glass Bead Slurries

smallest beads ( $0.03 \mathrm{~mm}$ nominal diameter) is unexplained. Replicate experiments are needed to confirm the maximum void values. Two maximum void values for $0.09-\mathrm{mm}$ nominal diameter beads, in relatively good agreement, are shown in Figure 4.17 . The lower maximum value $(17.5 \%)$ was obtained using an initial $\mathrm{CO}_{2}$ pressure of $3.4 \times 10^{5} \mathrm{~Pa}(34 \mathrm{psig})$; a higher void $(19.2 \%)$ was observed when the initial $\mathrm{CO}_{2}$ pressure was lower $\left(2.5 \times 10^{5} \mathrm{~Pa}\right.$ [ $\left.\left.22 \mathrm{psig}\right]\right)$. In both experiments, sudden GREs were observed. These data suggest that, provided sufficient gas is dissolved to reach a discernable maximum retention point (gas being released), the initial $\mathrm{CO}_{2}$ pressure does not control the maximum void fraction. Although not directly comparable, the trend of increasing maximum void with decreasing particle size shown in Figure 4.17 is consistent with the bentonite clay (very fine particulate) gas retention results. For example, a 13-cm-high (initial) column of 67-Pa bentonite clay in a 1 -in.-diameter $(2.54-\mathrm{cm})$ tube was found to have a maximum $40 \%$ void.

\subsubsection{Effect of Liquid Removal on Maximum Retention}

Gas retention in partially drained $1-\mathrm{mm}$ glass bead packs was measured for five initial saturation levels. From the mass of the liquid retained in the bead pack and the estimated porosity, a theoretical initial saturation level was computed assuming all liquid was completely drained to the saturated zone. Table 4.2 shows the theoretical and measured initial saturation levels for the five 
experiments. In all but the completely saturated system, the observed capillary fringe or saturated zone was less than the theoretical value, indicating that liquid was retained by capillary forces above the saturation level, as expected. The difference between the measured and theoretical initial fraction saturated is a measure of the liquid retained in the upper drained regions of the bead pack. There are two key effects associated with this retained liquid. First, the measured saturation level in the bead pack will advance as the liquid continues to drain, giving falsely high trapped gas volumes. This effect is expected to be more pronounced in highly drained systems. Second, the retained liquid in films, pendular rings, and small pores also generates gas, but this gas is not easily trapped within the porous bead structure. As a result, it is possible to have measured gas generation rates exceeding the rate of gas retention within the highly saturated region even if all gas generated within the lower layer is retained.

Figure 4.18 shows the volumes of gas generated and retained for a system having a measured initial liquid saturation level of $17 \%$. After about 40 minutes elapsed time, the rate of gas generation exceeds the rate of gas retention. However, since gas is generated in the both the saturated and unsaturated zones, it impossible to discern whether gas is being released from the saturated zone. In spite of this difficulty, Figure 4.18 clearly shows that the volume of gas retained plateaus well before gas generation ceases. Thus, the measured maximum retention is not limited by the gas source. It should also be noted that, using this simple measurement technique, one cannot distinguish between gas retained by imbibition as the liquid advances and gas generated and retained within the saturated zone.

The peak retained gas volume $(27 \mathrm{~mL})$ shown in Figure 4.18 for the $17 \%$ initial saturation case corresponds to a trapped void content of $6.2 \%$ of the total bead pack volume and is equivalent to $18.5 \%$ void within the saturated region. These data and the analogous data for the other initial

Table 4.2. Results of Partially Drained Bead Pack Experiments

\begin{tabular}{|c|c|c|c||}
\hline \multicolumn{2}{|c|}{$\begin{array}{c}\text { Fraction of Bead Pack } \\
\text { Saturated }\end{array}$} & \multicolumn{2}{c|}{ Maximum Void Fraction } \\
\hline $\begin{array}{c}\text { Measured } \\
\text { Initial }\end{array}$ & $\begin{array}{c}\text { Theoretical } \\
\text { Initial }\end{array}$ & $\begin{array}{c}\text { Entire } \\
\text { Bead Pack }\end{array}$ & Sat. Zone \\
\hline \hline 0.015 & 0.11 & 0.003 & -- \\
\hline 0.17 & 0.27 & 0.062 & 0.185 \\
\hline 0.31 & 0.40 & 0.097 & 0.173 \\
\hline 0.54 & 0.60 & 0.151 & 0.164 \\
\hline 1.0 & 1.0 & 0.154 & 0.154 \\
\hline
\end{tabular}




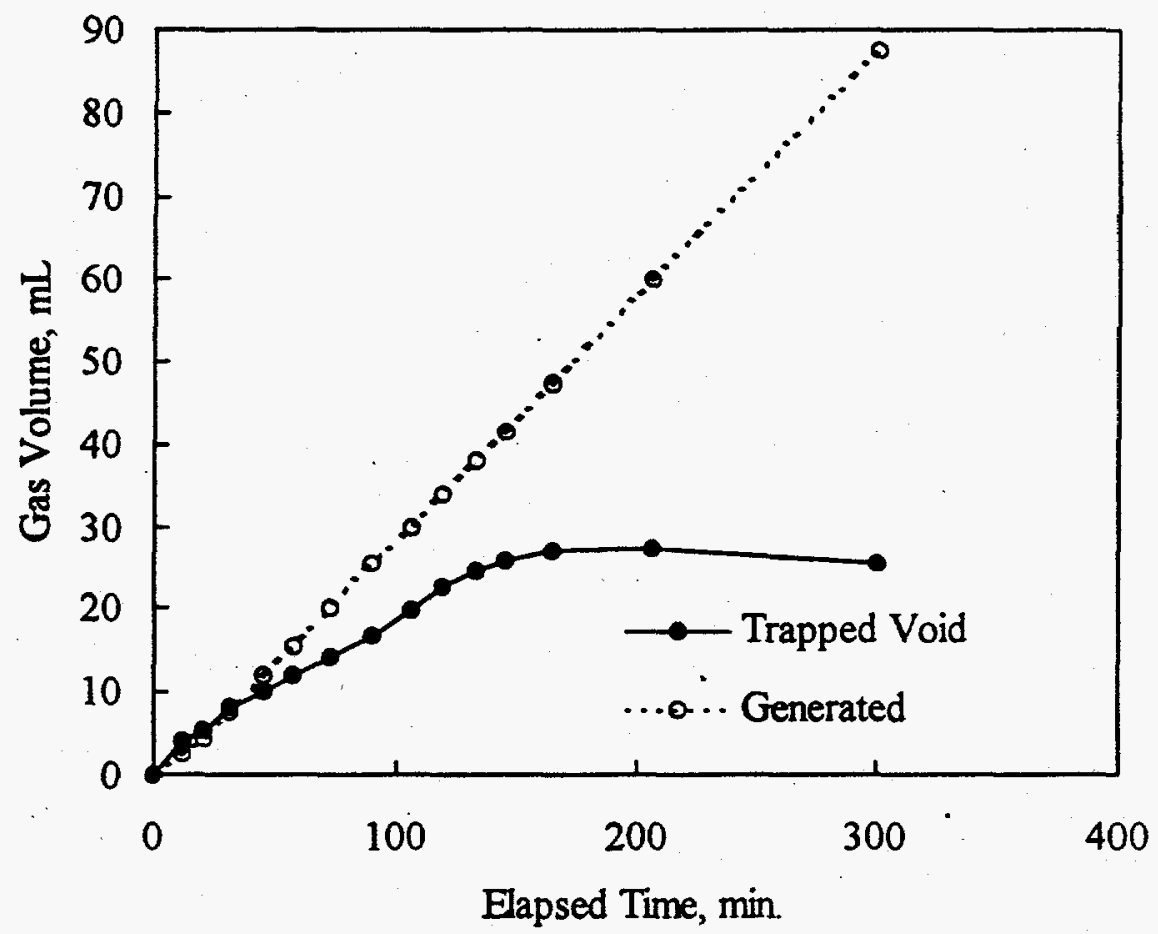

Figure 4.18. Generated and Trapped Gas Volumes in a 17\% Initially Saturated Bead Pack

saturation cases are tabulated in Table 4.2, and the void fraction data are plotted in Figure 4.19. As expected, the trapped void fraction within the total bead pack volume decreases as the initial saturation level decreases. A minimum retained void fraction of $0.3 \%$ was attained for the almost completely drained case ( $1.5 \%$ initial liquid saturation), and a maximum retention of $15.4 \%$ void was measured for the initially saturated system.

It is also of value to compare the maximum void fractions within the saturated regions. Here, the retained gas volume is compared with the peak volume of the saturated zone (where gas bubbles are captured) rather than with the entire bead pack volume. These data are also presented in Figure 4.19. Note that the values range from $15.4 \%$ void (saturated case) to $18.5 \%$ void (17\% initial liquid saturation). No datum is presented for the initially unsaturated case because the error is large due to the small changes in volume. Overall, the data indicate roughly equivalent maximum gas retention within the saturated zone independent of initial saturation level. This shows that the mechanism of gas retention, predominantly as dendritic bubbles, is relatively consistent throughout the bead packs over a wide range of liquid saturation conditions. It is unclear whether the slight trend of increasing maximum saturated zone void with decreasing initial saturation level noted in Figure 4.19 is real or an artifact. One could argue that continued liquid draining during the course of the experiment gives rise to higher reported saturation levels. This effect is expected to be more pronounced in the less saturated cases as more liquid is retained in the drained zone, and volume measurement errors play a more critical role. 


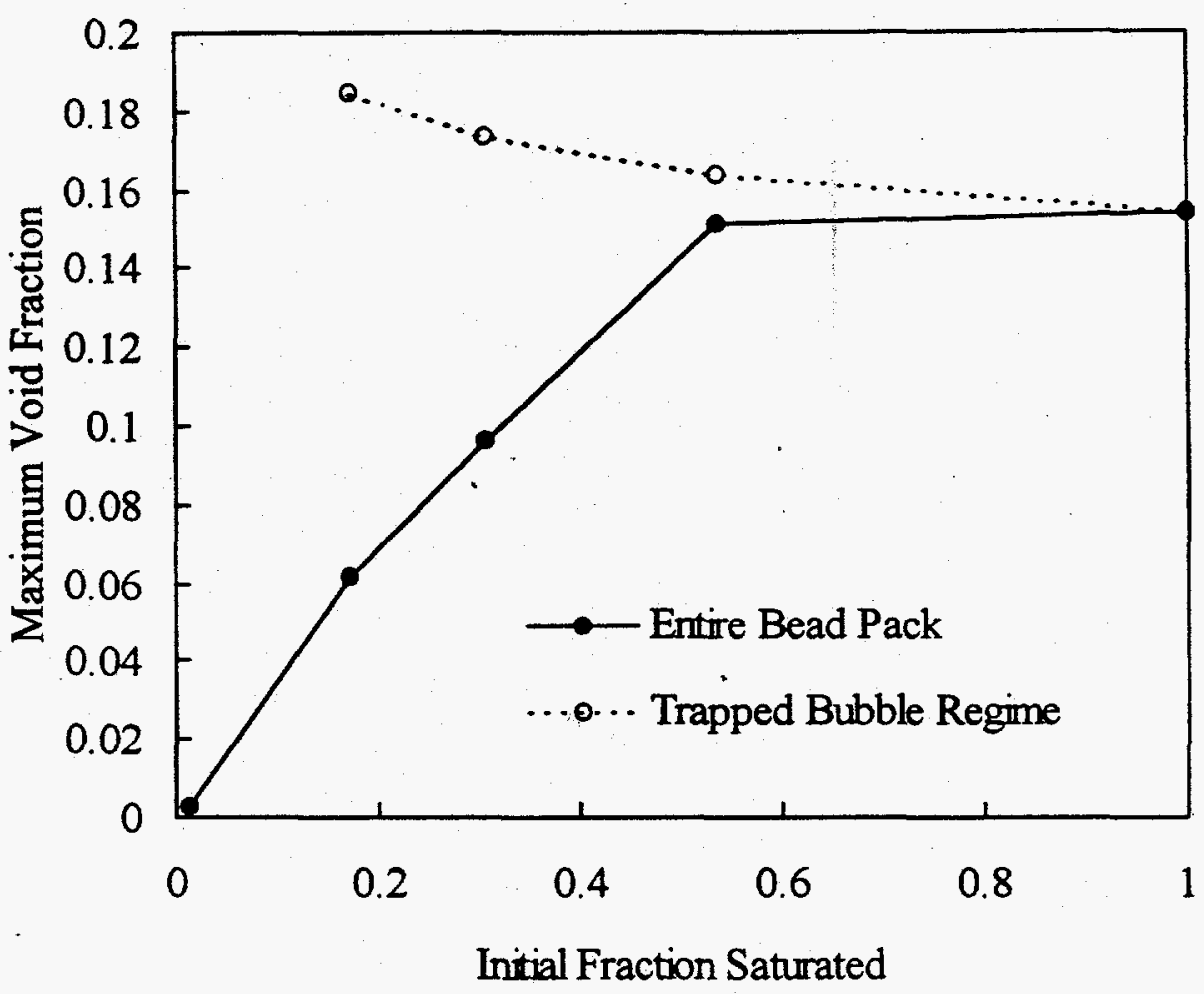

Figure 4.19. Maximum Void Fractions in Partially Saturated Bead Packs

The results of these partially drained bead pack experiments are of particular importance to the understanding of flammable gas retention in single shell tanks. These results show that SST waste that has been drained, presumably by salt well pumping, is not likely to retain gas bubbles in the drained regions of the waste. While this effect has been postulated previously, these results confirm this expectation, and they also show that the mechanism of retention is consistent with previous studies.

\subsubsection{Gas Release Mechanisms}

Figure 4.13 in Section 4.2.2 shows typical gas release results, which in this case were from an experiment with a 31-Pa sludge. At an elapsed time of about 90 minutes, the figure shows a rapid decrease in the retained gas volume and a corresponding increase in the volume of gas released. The gas release data were calculated from the difference of gas generated and gas retained volumes. Figure 4.13 shows a sawtooth cycling effect-after the initial release, the clay grows anew to reach essentially the same volume of retained gas before it again collapses. The periodic level increases and drops, and the associated gas releases are analogous to the level changes and gas releases in actual waste tanks. With this weak clay ( $31 \mathrm{~Pa}$ ), the relatively fluid clay appears to heal after a release event. As seen in the relatively flat gas release profiles of Figure 4.13, essentially all gas generated after a gas release event is retained until the next release event. In fact, the slight negative slope of 
some portions of the gas release curve suggests either a small gas leak in the total gas generated measurement system or a slight overestimation of the sludge volumes (height measurement errors due to clay-streaked walls following a release).

The effects of clay strength and sample geometry on the mechanism of gas release are discussed in more detail in this section, where we show the release characteristics for a range of clays in which each has been characterized by a single physical property, the initial shear strength. In some cases, the clay exhibits level drops, which are dynamic processes, and the dynamic properties of the clay, such as its viscosity, are also important. While we have not measured the rheology of the clay simulants, they are shear-thinning suspensions, and increasing the bentonite fraction increases the viscosity as well as the shear strength.

\subsubsection{Effect of Clay Strength on Gas Release}

The void fractions measured as function of time for several strengths of clay are shown in Figures 4.20 to 4.27 and are also tabulated in Appendix A, Tables A.2 to A.9. As noted previously, each of these experiments was conducted in 2.54-cm-diameter clear PVC tubes, and initial clay heights were about $30 \mathrm{~cm}$. The shapes of the void fraction versus time curves indicate the nature of gas release from the various clays. For example, Figures 4.20 and 4.21 , for 3.4 and $6.4 \mathrm{~Pa}$ clays, respectively, show periodic and rapid release of nearly all the retained gas. In the 6.4-Pa sludge, the gas retained decreases from the maximum void $(20.3 \%)$ to about $2 \%$ void over a nine-minute period. In these very weak clays it appears that a critical gas content is reached, at which point a release is initiated and nearly all the retained round bubbles are carried to the surface. As the clay strength increased, the ability of the clay to release all retained gas decreased. Figure 4.22 shows the release behavior of the 31-Pa clay in terms of void fraction. (These data are also shown in volumetric form in Figure 4.13.) The gas releases from the 31-Pa clay coincide with the collapse of vessel-spanning bubbles within the column. As noted in the introduction to Section 4.2.3, essentially all generated gas was retained in the 31-Pa clay during the retention phase of the retention-release cycles.

Although the magnitudes of the gas release events in the 31-Pa clay are smaller in terms of the fractional volume released ( $40 \%$ maximum void down to $31 \%$ void), the absolute volume of gas released is comparable to that released from the 6.4-Pa clay. In both cases, about $40 \mathrm{~mL}$ of gas was typically expelled; and these releases were larger than release events observed for the stronger and weaker clays in this study. Furthermore, the durations of the releases were comparable for the two sludges, ranging from 2 to 15 minutes in both. Also note in Figures 4.21 and 4.22 that the retention and release cycle, once initiated, appears to be repeated every 50 to 70 minutes over the course of the four-hour experiment.

As the clay strength was increased further, the relative magnitude and frequency of gas release events decreased. Figure 4.23 shows the retention behavior for the 67-Pa sludge. In this case, an initial maximum void of $35.3 \%$ decays to $32.0 \%$ void over about 40 minutes, and the overall retention-release cycle time increased to about 90 minutes. At this strength, vessel-spanning bubbles did not completely release from the sludge during a release event; rather, gas that collected near the 


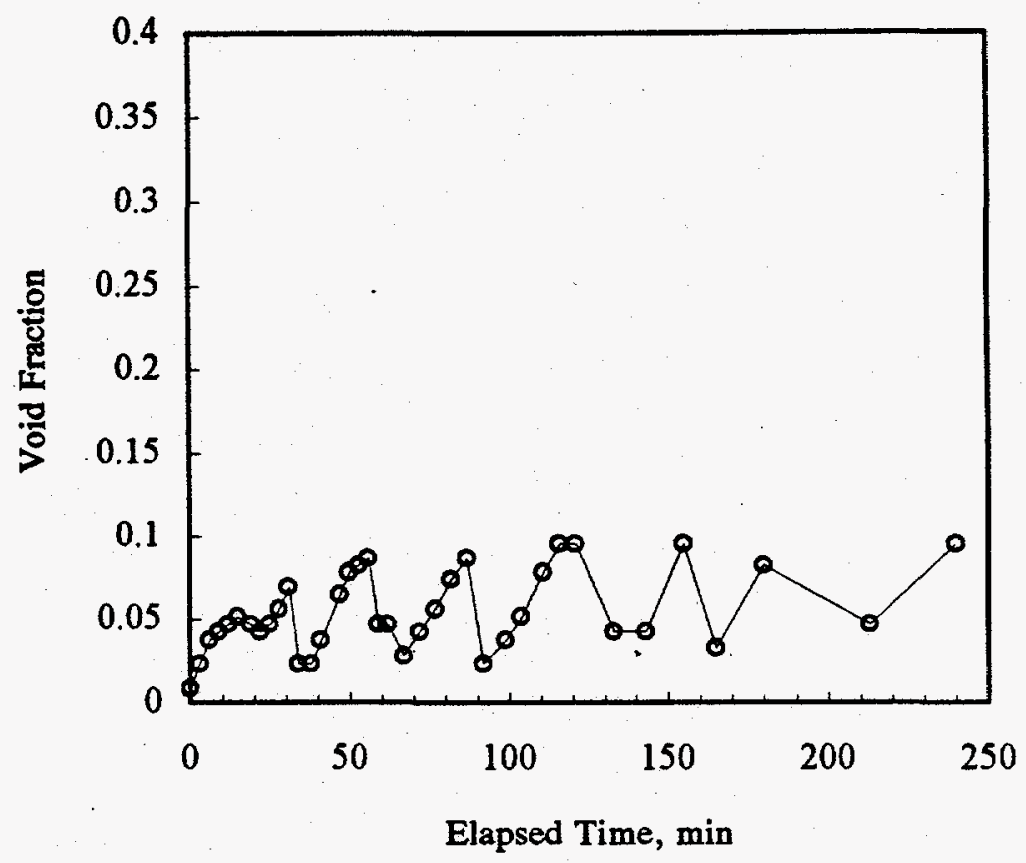

Figure 4.20. Void Fractions in 3.4-Pa Clay

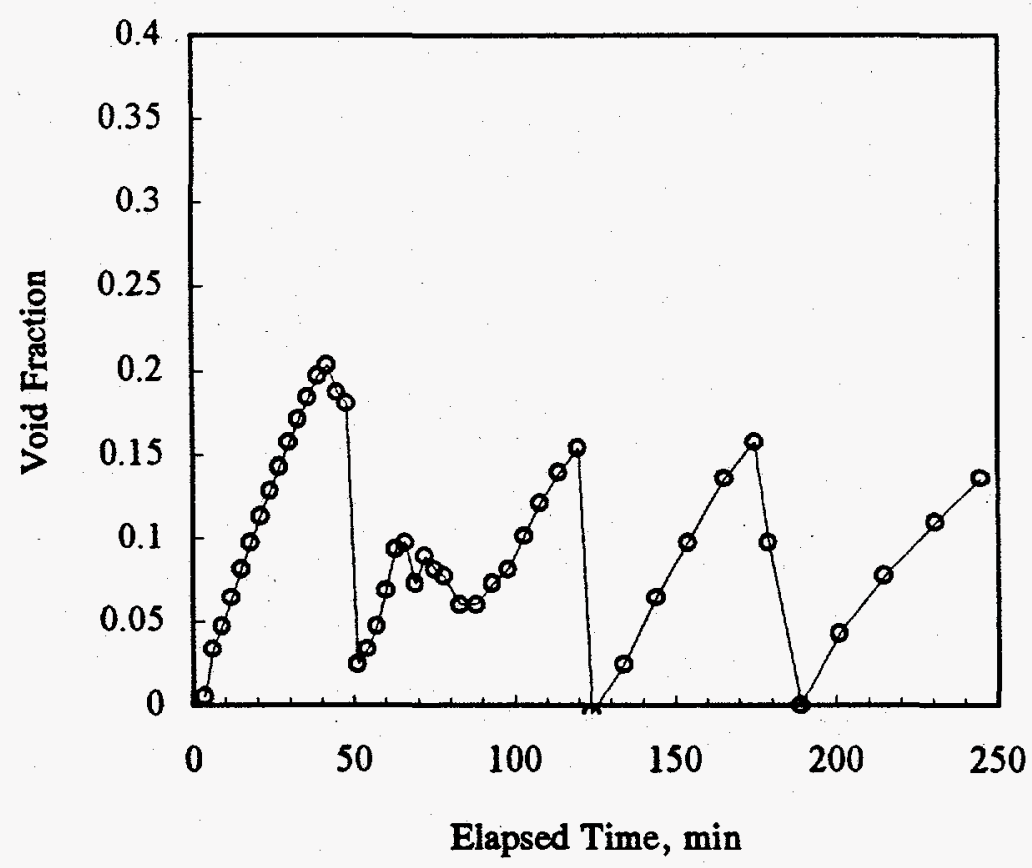

Figure 4.21. Void Fractions in 6.4-Pa Clay 


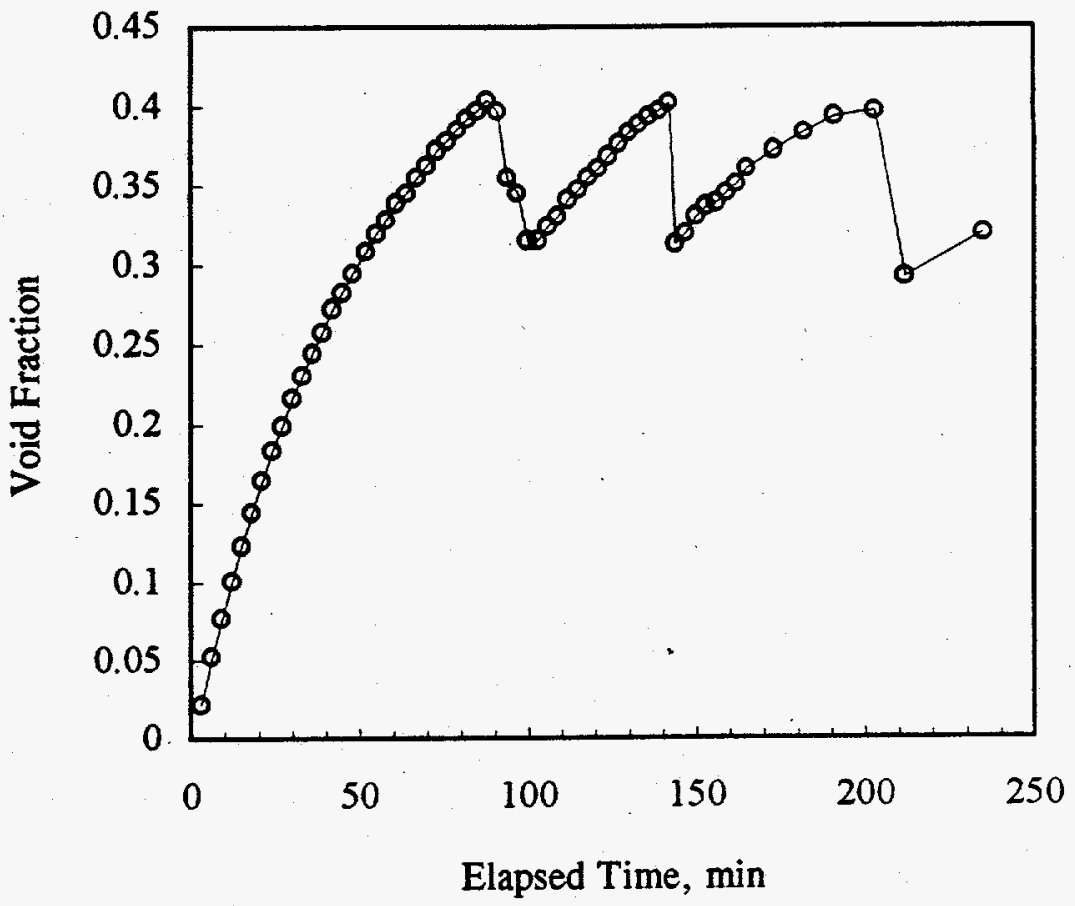

Figure 4.22. Void Fractions in $31-\mathrm{Pa}$ Clay

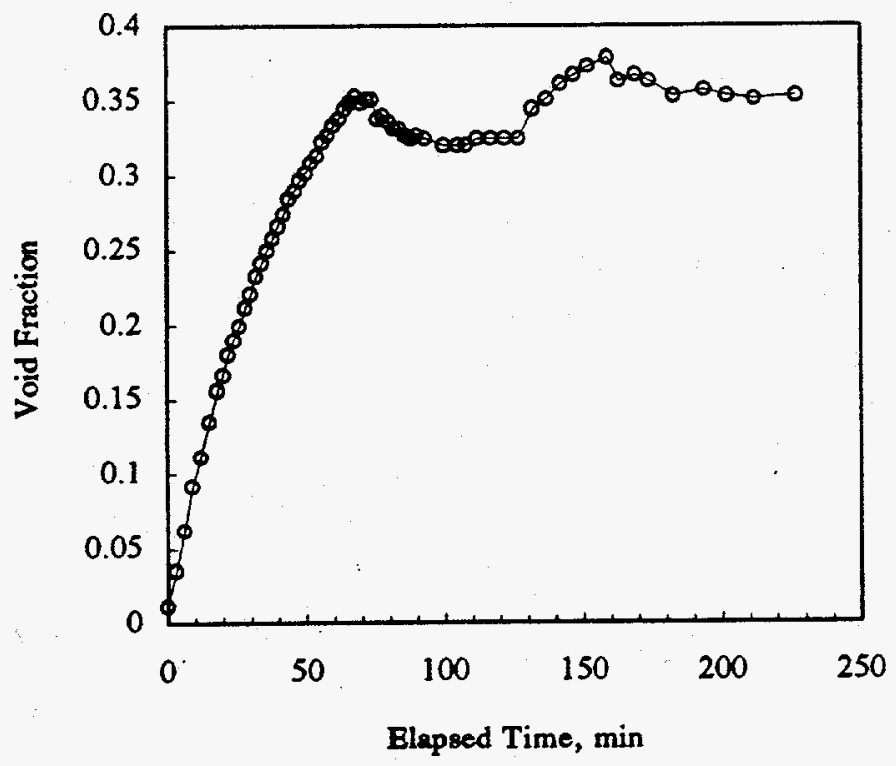

Figure 4.23. Void Fractions in 67-Pa Clay 
sludge surface (foam and/or larger bubbles) released relatively slowly and continuously after the first retention maximum was attained ( -68 minutes elapsed time). It is interesting to note that the second retention maximum ( $37.9 \%$ void) is slightly higher than the first peak ( $35.3 \%$ void).

Clays ranging in strength from 147 to $1040 \mathrm{~Pa}$ show comparable gas retention and release characteristics. The behavior is depicted in Figures $4.24-4.27$ for four clay strengths. The void fraction curve in Figure 4.24 for a 147-Pa clay demonstrates the effect. During the phase where the void fraction is increasing, intermediate plateaus are reached where the height neither increases or decreases, and any generated gas is released continuously. See, for example, the data just prior to an elapsed time of 100 minutes in Figure 4.24. Eventually the maximum void fraction plateau is reached, and any subsequently generated gas is continuously released through established channels in the sludge. These channels are formed from a network of connected round and vessel-spanning bubbles. The sludge/wall interaction appears to be strong enough to prevent the collapse of these fractures. As noted in subsection 4.2.2.3, vessel diameter and the associated presence or absence of vessel spanning bubbles did not appear to have a measurable impact on the maximum gas retention. For even stronger sludges, the release behavior is similar, but the retained bubble shape changes from round to slit-shaped.

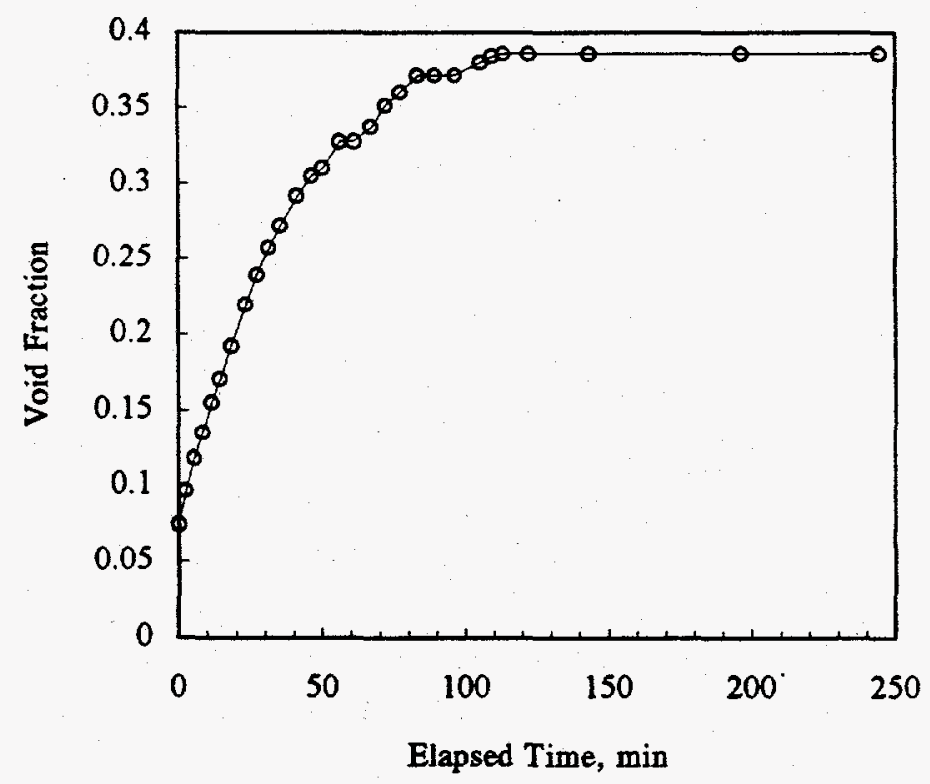

Figure 4.24. Void Fractions in 147.Pa Clay 


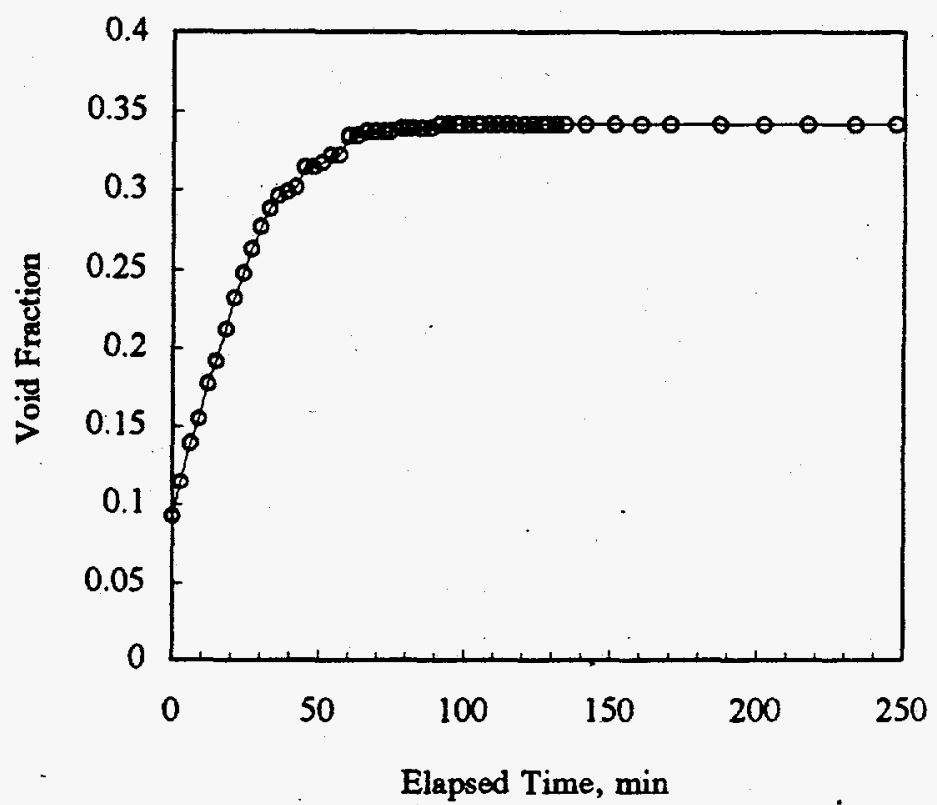

Figure 4.25. Void Fractions in 323-Pa Clay

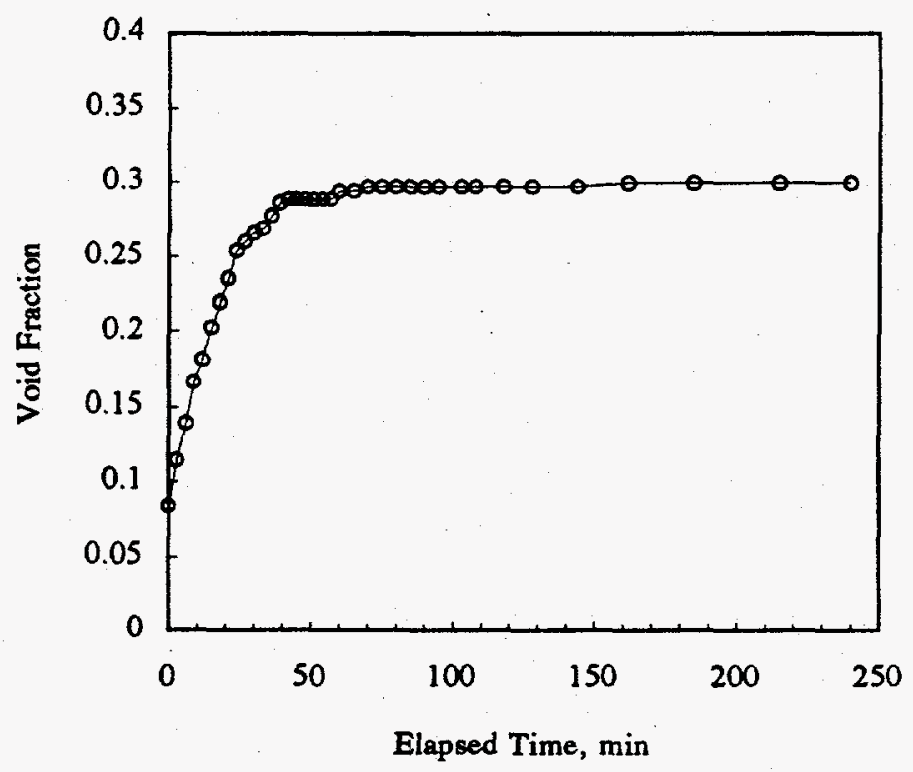

Figure 4.26. Void Fractions in 656-Pa Clay 


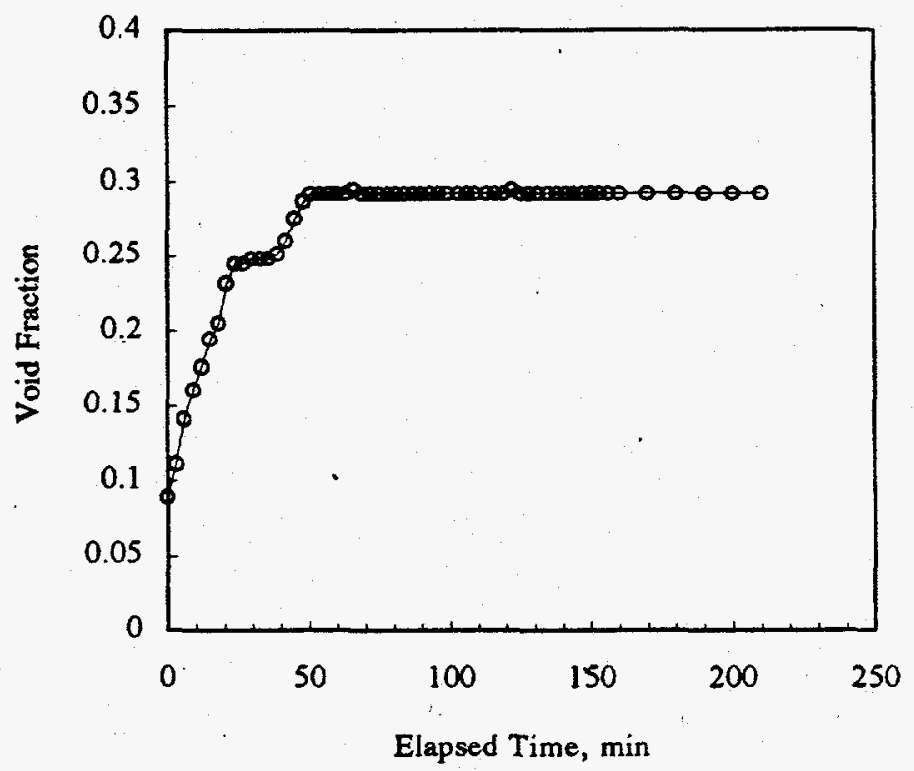

Figure 4.27. Void Fractions in 1040-Pa Clay

\subsubsection{Effect of Initial Height on Gas Release}

Figure 4.28 shows the gas retention characteristics for two initial heights, 29.2 and $82.7 \mathrm{~cm}$. In both cases, the clay was $67-\mathrm{Pa}$ bentonite and the retention vessel was a $2.54-\mathrm{cm}$-diameter clear acrylic tube. The two data sets display almost identical retention characteristics up to the points of first release at about 85 minutes elapsed time. The shorter column released relatively more gas, and the release was quite sudden. The void fraction in the longer column briefly plateaued in the same time frame; and shortly thereafter, a relatively small and rapid release was observed. Both columns grew again and reached a second release point near 175 elapsed minutes. Here again, the release from the shorter column was more pronounced. Although the later data are not available, the $29.2-\mathrm{cm}$ column appeared to have reached its maximum retention in the second peak ( $42.2 \%$ void). However, the longer column continued to grow, with occasional small releases, attaining a maximum void of $47.8 \%$ at about 280 minutes. The distinction in the release behavior for these two systems is likely related to the greater number of vessel-spanning bubbles in longer columns and the greater distance the gas in the lower of these bubbles must migrate before release can occur. In both cases, gas release events appeared to correspond to at least partial collapse of fracture bubbles near the surface of the clay. Because the fraction of gas retained in the near surface vessel-spanning bubbles of longer columns is relatively small, the change in void fraction associated with the release of those bubbles is also relatively small. The magnitudes of releases from the two columns were comparable in absolute volume terms; the first release from the shorter column was $32 \mathrm{~mL}$, the second, $22 \mathrm{~mL}$; in the longer column, the rapid release at about 120 minutes elapsed time was also about $22 \mathrm{~mL}$, the slower release, around 215 minutes, was $27 \mathrm{~mL}$. 


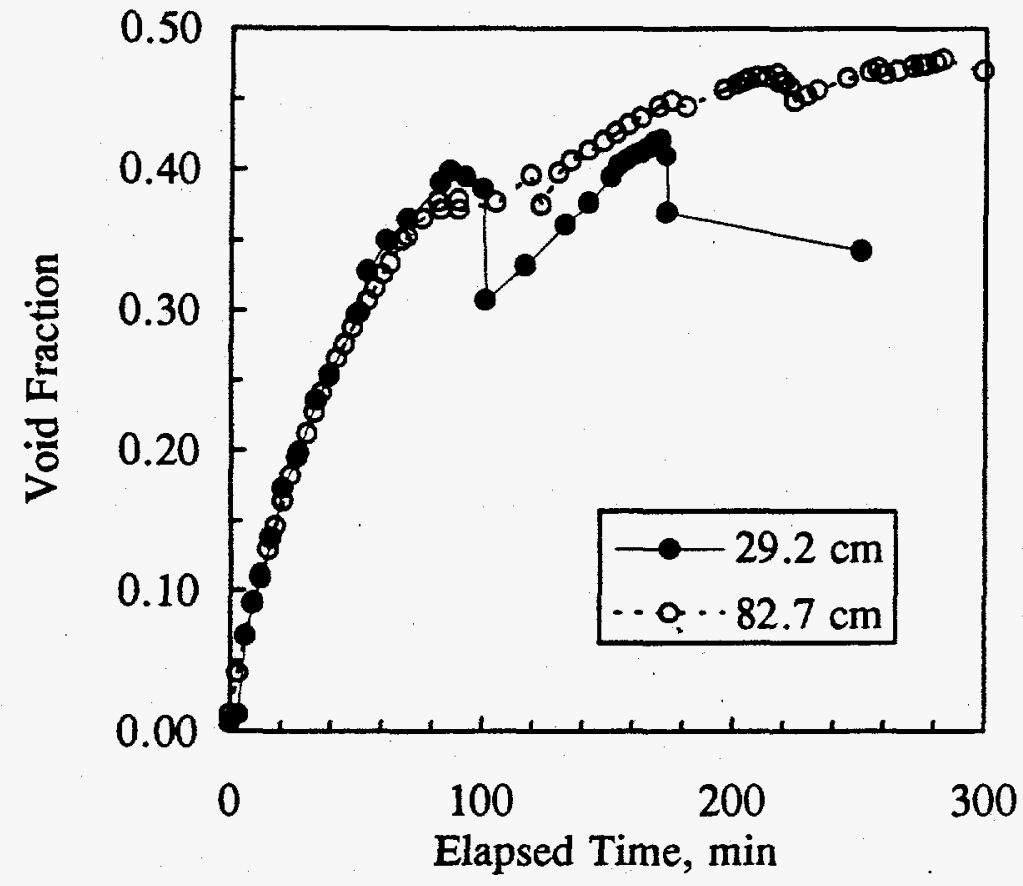

Figure 4.28. Void Fractions for Two Initial Heights of 67-Pa Clay

\subsubsection{Effect of Vessel Diameter on Gas Release}

The vessel diameter was found to affect the mechanism of gas release for the 67-Pa clay but not for the 200-Pa sludge. For the 67-Paclay in small-diameter vessels, gas released continuously and some moderate level drops indicated that larger releases were also occurring. In contrast, once the maximum void fraction had been reached in the larger-diameter vessels, it was consistently observed that, as bubbles began to release, the entire test vessel would become involved, and the majority of the gas bubbles would be released from the sludge. In this situation, large and rapid level drops were observed. Figures 4.29 to 4.35 show the retained void fraction as a function of time for the vessel diameters studied. In the 2.5-cm-diameter vessel shown in Figure 4.29, the void fraction increased to about 0.45 . At this point gas began continuously releasing, and a small drop in void fraction (level drop) occurred as groups of bubbles were released. In Figure 4.35, for the 30.5-cm-diameter vessel, the void fraction also increased to about 0.45 , but a large decrease in void fraction followed. In this case, the void fraction decreased from 0.47 to 0.14 . A similar large release was observed in the 15.2-cm-diameter vessel as shown in Figure 4.34, where the void fraction decreased from 0.44 to 0.13 . In both these cases the release was complete in less than one minute. Observation of the release while it was occurring was only made in the $15.2-\mathrm{cm}$ vessel, and it occurred in less than 15 seconds. In contrast, the releases from 10.2-cm-diameter and smaller vessels were slow and minor, as can be seen in Figures 4.29 to 4.33 . 


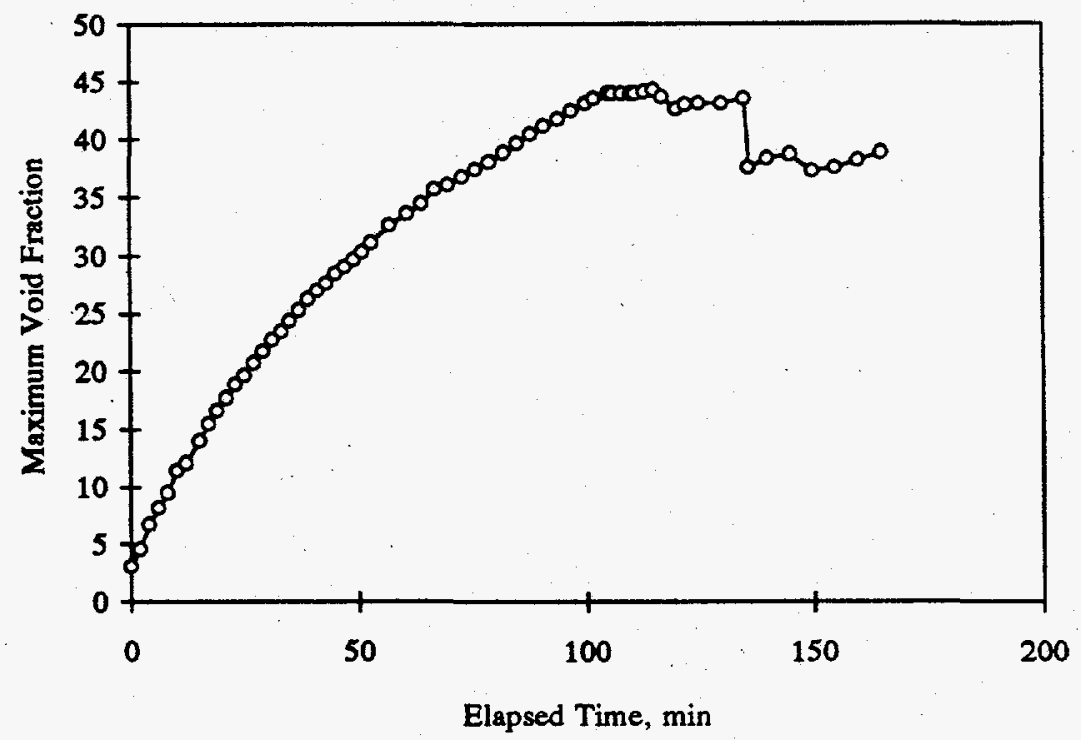

Figure 4.29. Void Fractions in 67-Pa Clay in a $2.5-\mathrm{cm}-D i a m e t e r$ Vessel

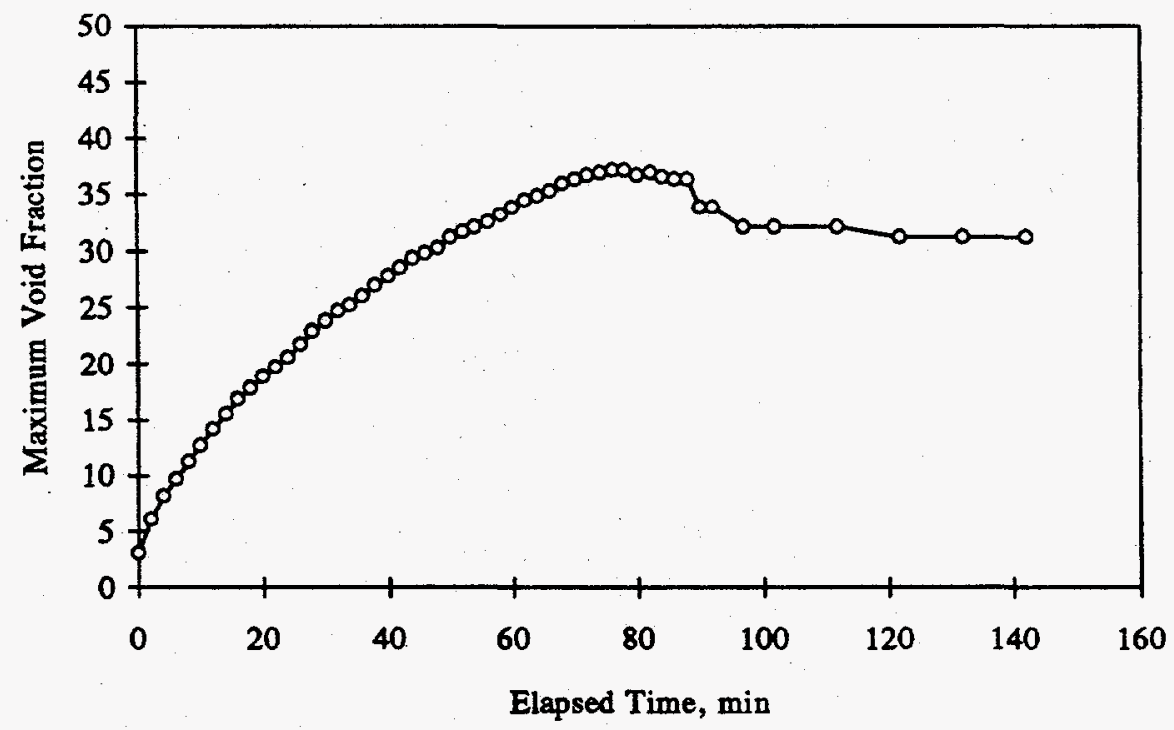

Figure 4.30. Void Fractions in 67-Pa Clay in a 5.1-cm-Diameter Vessel 


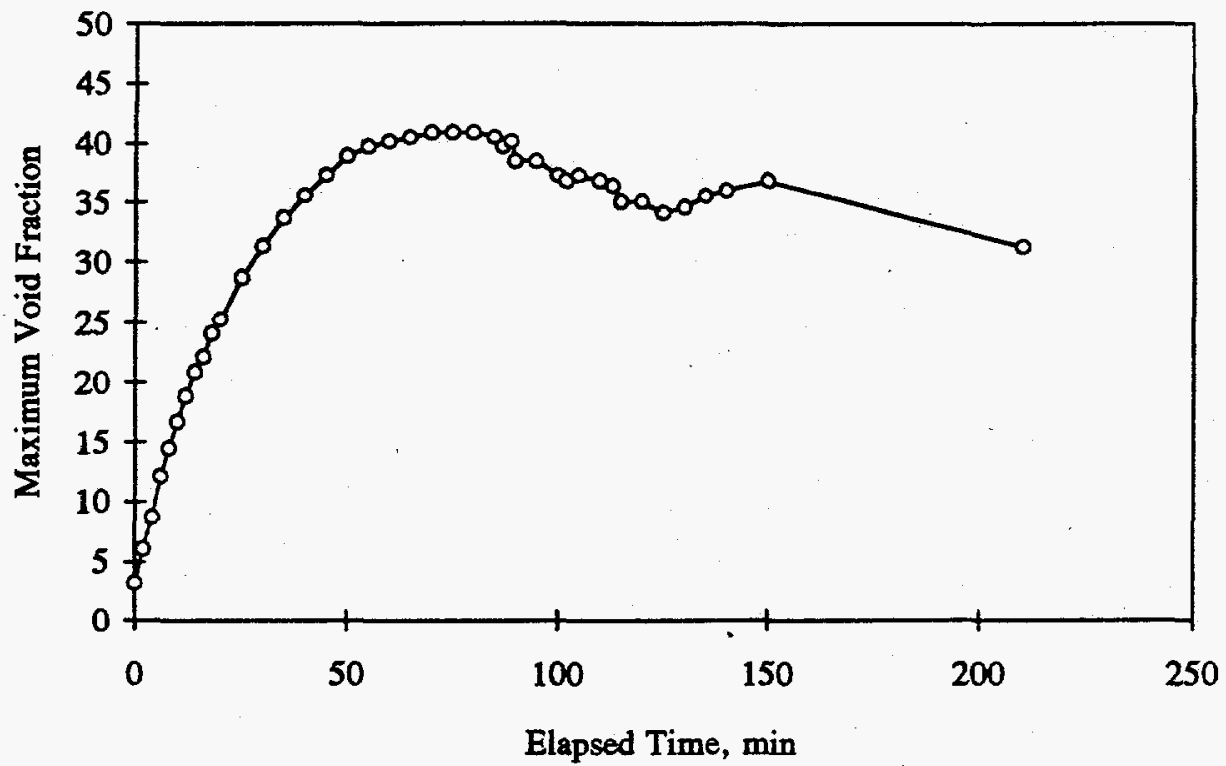

Figure 4.31. Void Fractions in 67-Pa Clay in a 5.1-cm-Diameter Vessel (duplicate)

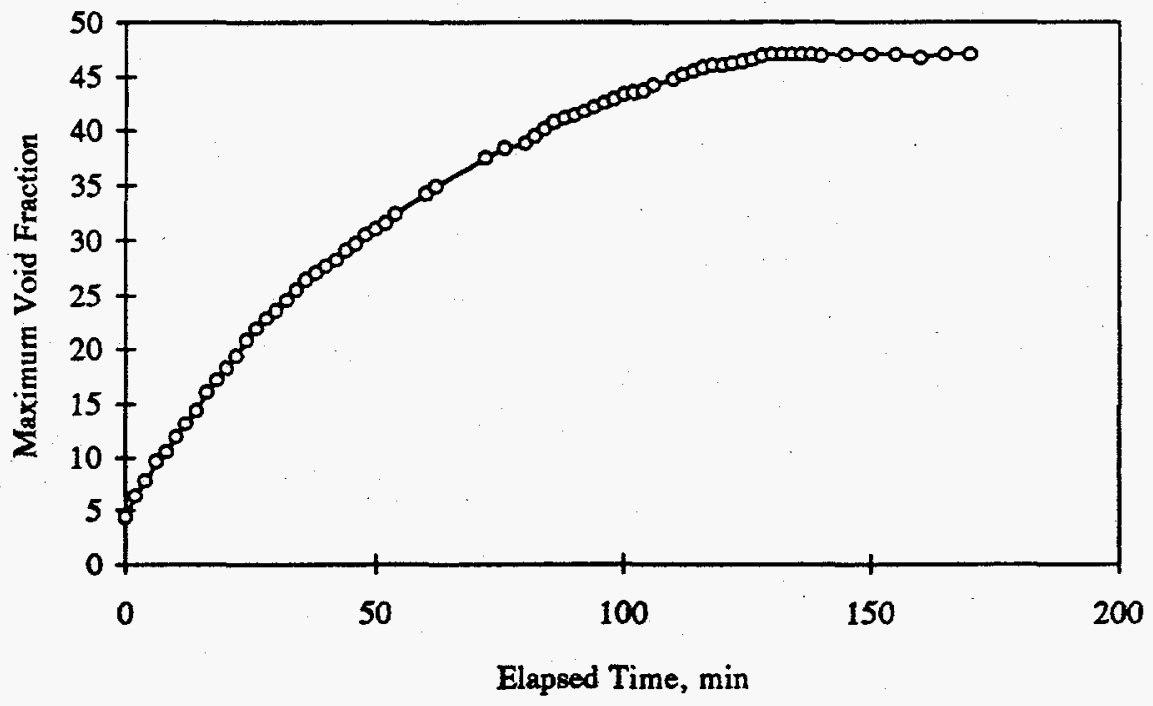

Figure 4.32. Void Fractions in 67-Pa Clay in a 10.2-cm-Diameter Vessel 


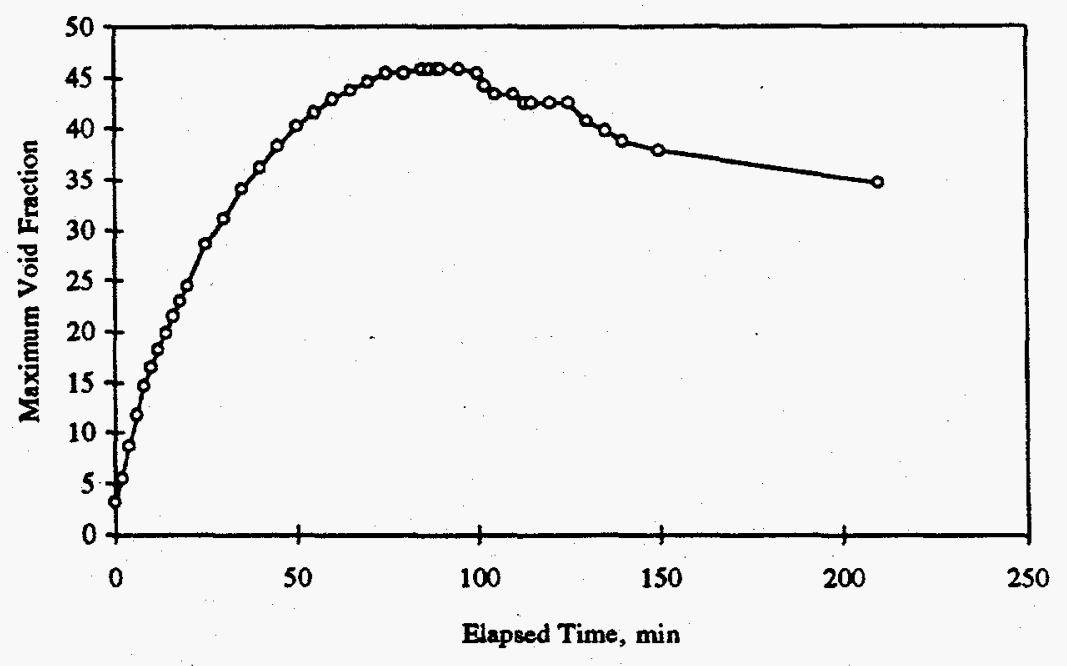

Figure 4.33. Void Fractions in 67-Pa Clay in a 10.2-cm-Diameter Vessel (duplicate)

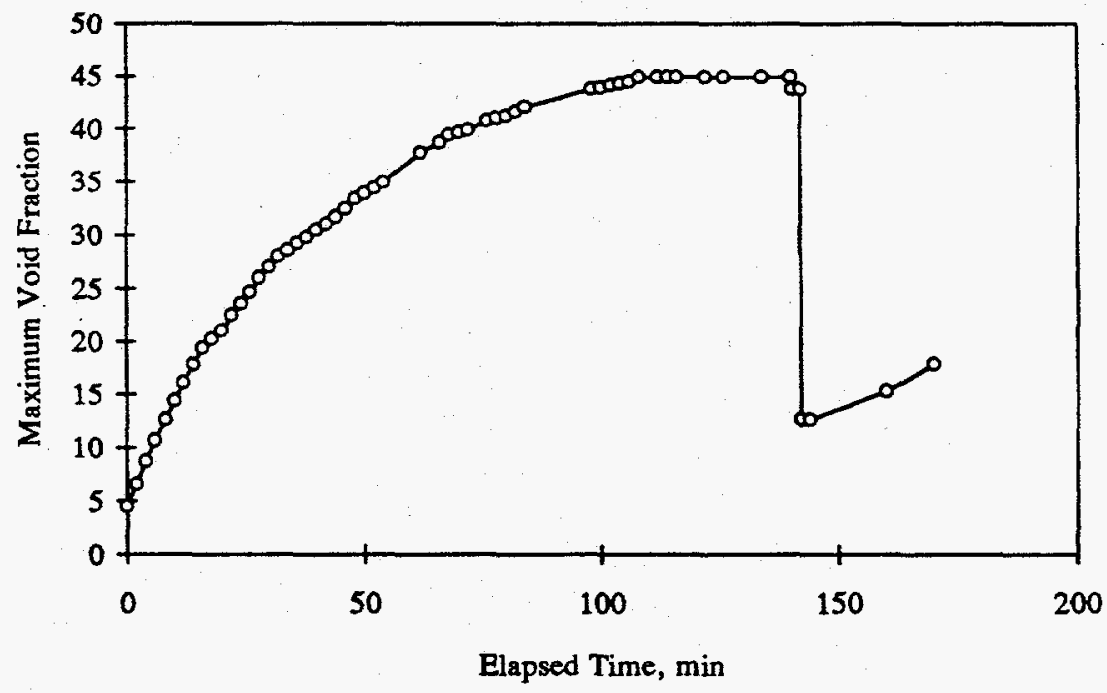

Figure 4.34. Void Fractions in 67-Pa Clay in a 15.2-cm-Diameter Vessel 


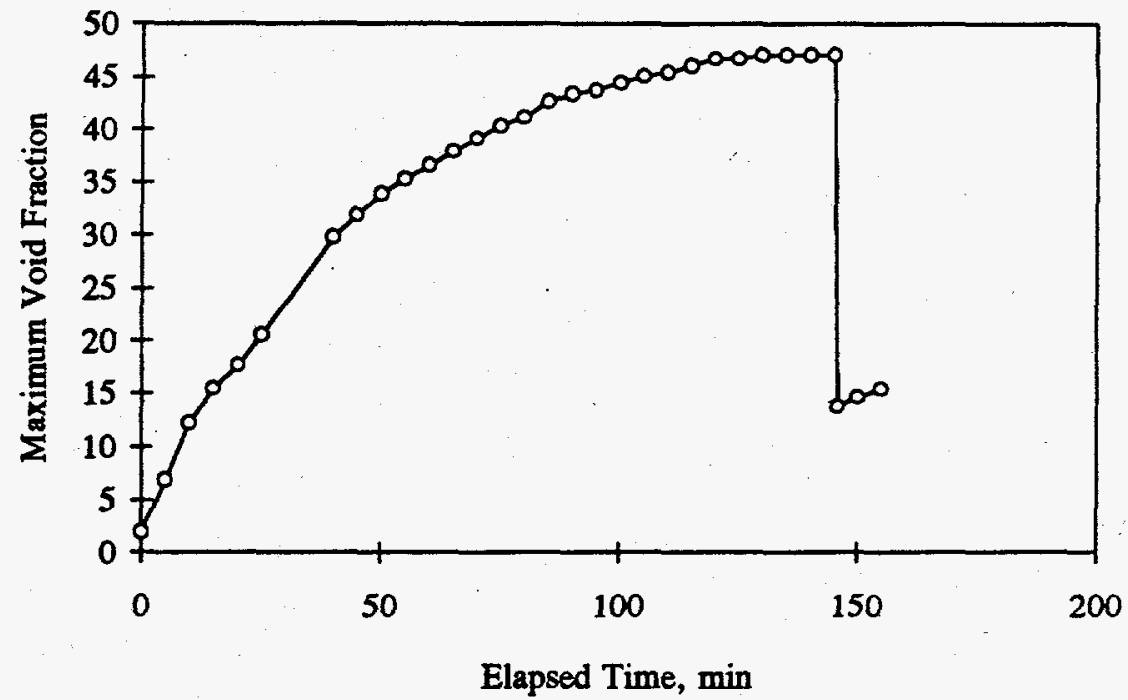

Figure 4.35. Void Fractions in 67-Pa Clay in a 30.5-cm-Diameter Vessel

While it is not clear why larger-diameter vessels encourage larger releases, one theory is that bubbles connect to form a network that feeds a few very large bubbles. When the large bubbles become sufficiently buoyant and rise, they greatly disturb the surrounding clay, and this allows other retained bubbles to be released. In the series of experiments in $2.5-\mathrm{cm}$-diameter columns described in Section 4.2.3.1, this type of large release was observed, but only for a weaker clay with a strength of about $6.7 \mathrm{~Pa}$. A second explanation is that the vessel wall holds the clay in place and inhibits the release mechanism.

It also appears that, as the void fraction increases, the ease of triggering substantial release increases. Attempts were made to initiate a release in the $30.5-\mathrm{cm}$-diameter vessel by bumping the column after the clay had returned to approximately a $25 \%$ void following an initial release. Limited releases occurred as a result of the bumping, and the release was not self-sustaining.

From the results with the 67-Pa strength material it was not clear whether stronger simulants would exhibit large releases if the test vessel were sufficiently large. To experimentally bound the release mechanism, a second set of experiments was conducted using 200-Pa strength material in vessels with diameters of 30.5 and $91.4 \mathrm{~cm}$. Results from the 200-Pa material showed that gas released continuously after the maximum void fraction had been reached. The experiments were conducted for approximately 2 hours after the maximum void fraction had been reached, in an effort to observe a large release. Also, a final void fraction check was made at least 12 hours after the maximum void fraction had been reached. 
Figures 4.36 to 4.38 show the retained void fraction as a function of time for the stronger (200 Pa) clays. Two experiments were conducted with the $30.5 \mathrm{~cm}$-diameter vessel for repeatability. In the first $30.5 \mathrm{~cm}$-diameter vessel, shown in Figure 4.36, the void fraction increased to 0.43 , then gradually decreased to 0.36 over the next 19 hours. In the second run conducted in the $30.5-\mathrm{cm}-$ diameter vessel, shown in Figure 4.37, the void fraction increased to 0.39 then gradually decreased to 0.34 over the next 16 hours. A similar slow release was observed in the $91.4-\mathrm{cm}$ vessel, where the void fraction decreased from 0.49 to 0.47 in 17 hours. Although not included in the figures, a similar release behavior was observed for $\sim 200 \mathrm{~Pa}$ strength material in a $15.0 \mathrm{~cm}$-diameter vessel. This data supports the described in Section 4.2.3.1.

The most probable explanation for the observed slow release behavior in the 200-Pa strength clay is the formation of surface cracks which allowed the gas to continually vent after the maximum retention had been reached. Unlike the weaker 67-Pa strength clay which "self-healed" after minor releases, cracks and surface holes that formed in the 200-Pa clay remained throughout the duration of the test.

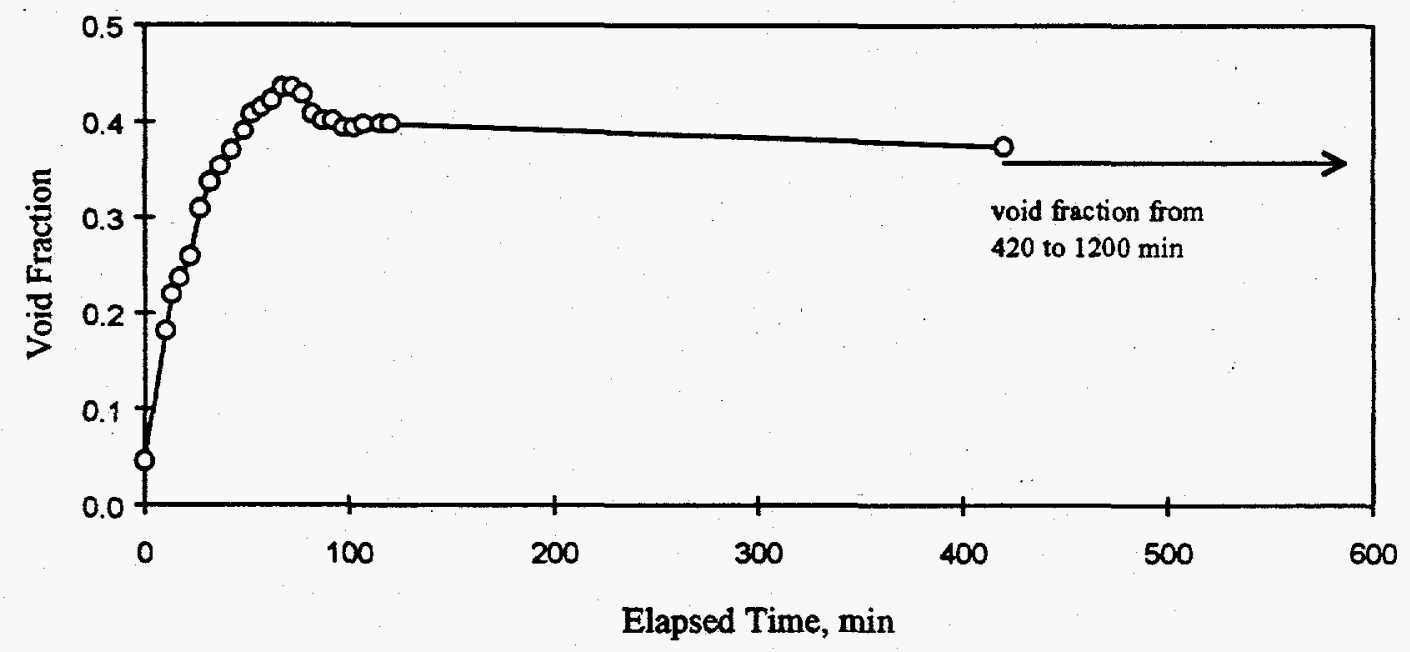

Figure 4.36. Void Fractions in 200-Pa Clay in a 30.5-cm-Diameter Vessel 


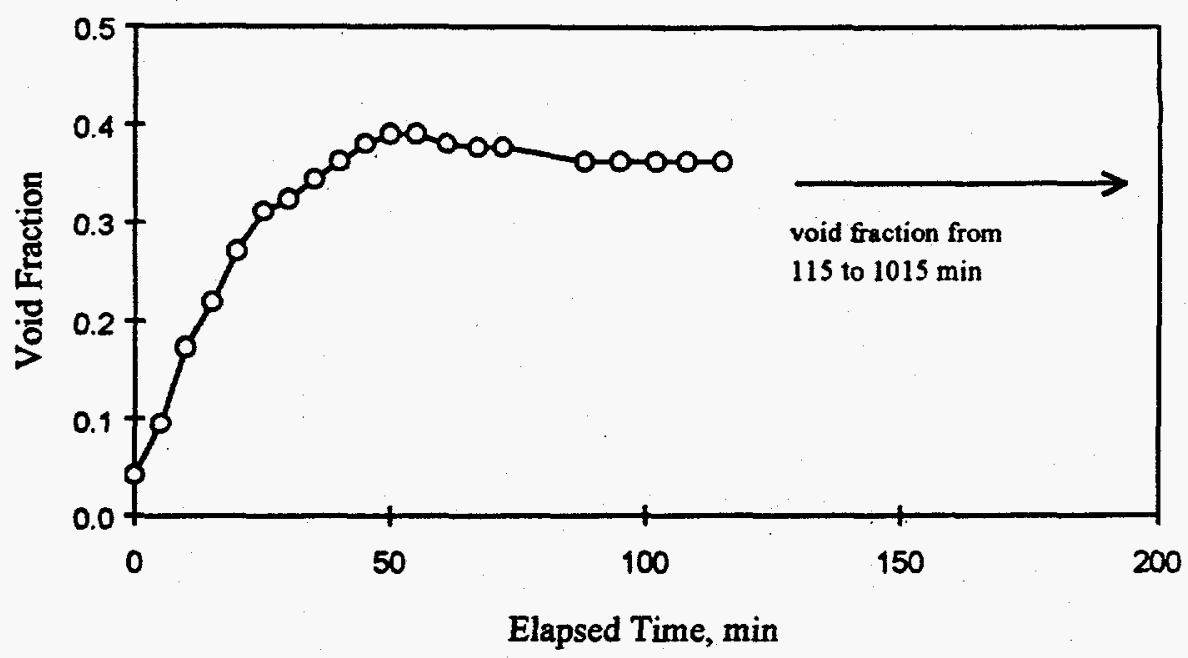

Figure 4.37. Void Fractions in 200-Pa Clay in a 30.5-cm-Diameter Vessel (duplicate)

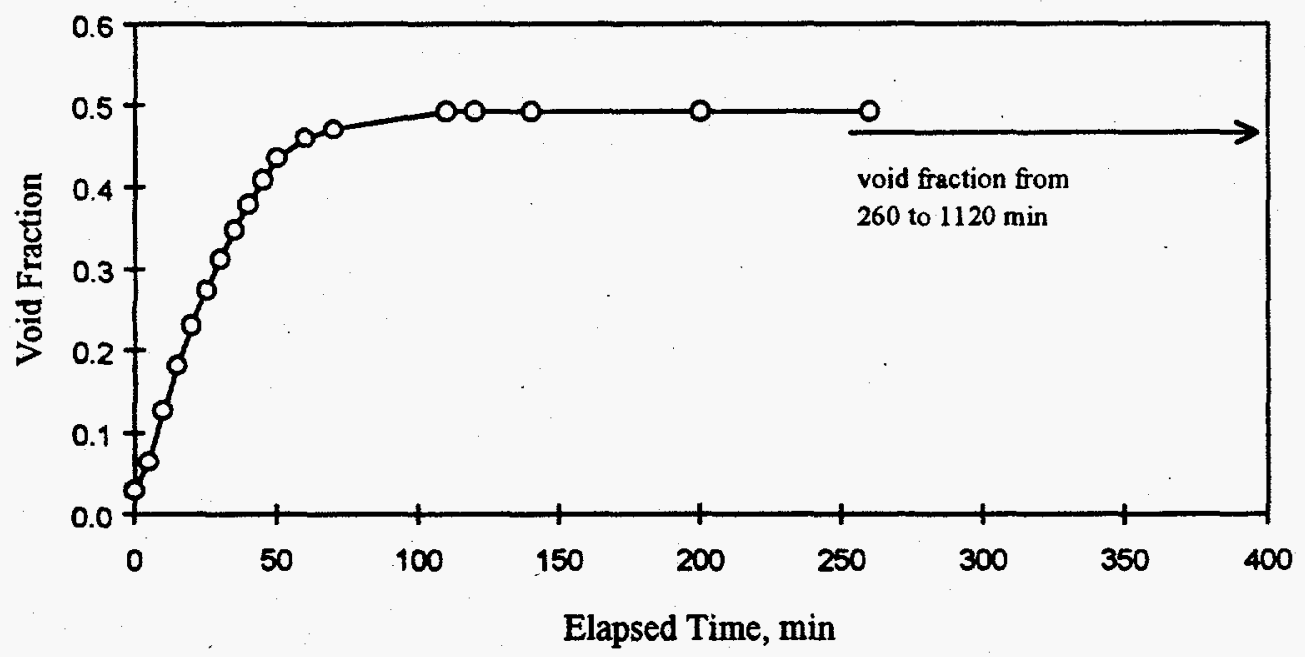

Figure 4.38. Void Fractions in 200-Pa Clay in a 91.4-cm-Diameter Vessel 


\subsection{Actual Waste Bubble Retention Mechanisms}

Gas retention experiments were conducted on waste samples from two tanks, SY-103 and S-102. These tests were performed using a standard gas retention experimental procedure in which gas bubbles within the settled waste are nucleated and grown by reducing the pressure within the sample vessel and changes in the waste structure and volume are observed simultaneously. The details of the method are described in this section. The technique was applied to two samples of the SY-103 DST waste, one a nonconvective composite and the other a whole tank composite. The results of these experiments are compared with results obtained previously for SY-103 samples by Bredt and Tingey (1996). Four samples of S-102 waste were evaluated by the standard gas retention method: two replicate analyses on an S-102 salt cake composite were conducted, and experiments on two individual S-102 sludge samples were performed. The results are presented below, following a detailed description and history of the actual waste samples used in this study.

\subsection{Actual Waste Samples}

Waste samples were obtained from two tanks for this study. The first pair of samples was from the DST 241-SY-103 (SY-103). In previous studies experiments had been conducted with these samples, so they were undoubtedly different from their original in-tank state. The second group of samples came from SST 241-S-102 (S-102). These samples only experience hand mixing prior to being received and were closer to their in-tank state.

\subsubsection{Tank 241-SY-103 Sample Summary}

Tank 241-SY-103 contains approximately 2.8 million liters of waste at a height of $689 \mathrm{~cm}$ (Hanlon 1996). A heel of concentrated complexant waste, 466 kiloliters, remained after transfers in and out of the tank between 1977 and 1980. In 1980, 1.6 million liters of double-shell slurry were added on top of the heel. The last major addition was the transfer of 500 kiloliters of interstitial liquid and water from Tank 241-SX-104 in 1988. Except for that addition, the Tank 241-SY-103 fill history is chemically similar to that of Tank 241-SY-101. Fox (1993) lists minor additions between June 1985 and May 1993 that include uranium sludge and other smaller waste streams.

In August 1994, samples were taken from Tank 241-SY-103. This sampling event, referred to as Core 62 , contained 15 segments, each 19 inches in height. Results of the sample analysis indicate a stratification of waste in the tank with a total height of $686 \mathrm{~cm}$ (Hansen et al. 1995). The nonconvective layer extends from the bottom of the tank to a height of approximately $333 \mathrm{~cm}$; the convective layer extends from $333 \mathrm{~cm}$ to $673 \mathrm{~cm}$; and the crust, located on top of the convective layer, has a thickness of no more than $13 \mathrm{~cm}$. This stratification is similar to the conditions existing in Tank 241-SY-101 prior to mixer pump operations. In Core 62, the convective layer was contained in segments 1 through 9 and the nonconvective layer in segments 10 through 14 . The crust was not sampled. Segment 15 was found to contain hydrostatic fluid, a $0.3 \mathrm{M} \mathrm{LiBr}$ solution used in the sampling process to prevent waste from traveling up the drill string; therefore, it was not a valid sample and was not used in any testing (Wilkins 1995). 


\section{Sample Preparation and Testing History}

A total of seven samples from core 62 were received at PNNL's High-Level Radiochemistry Facility (325A HLRF). Samples included one nonconvective layer composite, one supernatant composite, and five undisturbed nonconvective layer samples; one each from segments 10 through 14. The undisturbed samples were extruded from the samplers and placed in $125 \mathrm{~mL}$ jars without any homogenization.

The sludge composite used for bubble retention testing reported in this work was subsampled from the nonconvective layer composite, which was prepared at the WHC 222-S laboratory in the 200 West area using hand mixing. The ratio of segments used to make the composite are listed in Table 5.1.

The density of the nonconvective composite varied with the measurement technique and sample history. (a) The density of the bulk $222-\mathrm{S}$ prepared nonconvective composite was measured three times: upon receipt, during settling studies, and after high-speed centrifuging. Upon receipt, the sample density was measured by centrifuging at $1000 \mathrm{~g}$ for two hours to remove voids. During settling studies, the composite was allowed to settle for three days at 60,80 and then $28^{\circ} \mathrm{C}$ to separate liquids and solids. High-speed centrifugation $(1500 \mathrm{~g})$ for one hour was used to separate liquids and solids. The resulting bulk densities were $1.57,1.59$, and $1.62 \mathrm{~g} / \mathrm{mL}$, respectively. ${ }^{(a)}$ Foam was observed on the top of these samples during the last two techniques; this, along with the increase in density, indicates a release of gas retained by the solids. The density of the 325A HLRF prepared nonconvective composite was measured once. This sample was centrifuged at $1000 \mathrm{~g}$ for two hours, and the measured density for this composite was $1.63 \mathrm{~g} / \mathrm{mL}$.

Table 5.1. Composition of Nonconvective Composite Homogenized at 222-S

\begin{tabular}{|c|c|}
\hline Segment & Weight Percent \\
\hline \hline 10 & 18.3 \\
\hline 11 & 24.6 \\
\hline 12 & 16.7 \\
\hline 13 & 24.0 \\
\hline 14 & 164 \\
\hline
\end{tabular}

(a) Bredt, PR, JD Hudson, and JM Tingey. 1995. Effects of Dilution on the Physical, Rheological and Chemical Properties of Tank 241-SY-103 Waste. PNLMIT 092995, Pacific Northwest Laboratory, Richland, Washington. 
A supernatant liquid composite was prepared at 222-S using equal volumes of liquid from each convective layer segment. The density of the supernatant composite upon receipt was $1.44 \mathrm{~g} / \mathrm{mL}$.

The whole tank composite used in this work was prepared from the convective composite, material from the undisturbed segments, and the material from the 222-S prepared nonconvective composite. The undisturbed samples were subjected to shear stresses resulting from shear stress versus shear rate analysis prior to being added to the composite. The shear stress versus shear rate analysis was run between 1 and $-450 \mathrm{~s}^{-1}$. Table 5.2 lists the masses of material used in the composite, which was hand-stirred to combine the material. The composite was then exposed to approximately $7 \times 10^{6} \mathrm{R}$ from a $500-\mathrm{Ci}^{137} \mathrm{Cs}$ source by Bredt and Tingey (1995) as part of gas retention testing prior to use in the current bubble retention study.

\subsubsection{Tank 241-S-102 Sample Summary}

Hanford Tank 241-S-102 was placed into service during the fourth quarter of 1953 (Brager 1994). From 1953 to approximately 1955 , the stream was 1,630 kiloliters of high-level waste from the REDOX process. This stream included "salt waste, lab waste, and hot condensate" (Brevick 1993). Tank 241-S-102 was the second tank in a cascade of three in which overflow wastes from one tank could flow into and from another tank. Waste from the REDOX process flowed from S-101 to S-102 and then to S-103. Much of the supernatant was removed and disposed of in soil columns. The next series of major changes in waste inventory began in 1973, when S-102 waste was transferred to evaporator 242-S and the tank started receiving evaporator bottoms. Between 1976 and 1977, S-102 received a combination of noncomplexed waste, partially neutralized waste, and

Table 5.2. Core 62 Material Used to Prepare Tank Composite

\begin{tabular}{|l|r|}
\hline \multicolumn{1}{|c|}{ Sample } & Mass $(\mathrm{g})$ \\
\hline \hline Segment 10 & 18.43 \\
\hline Segment 11 & 15.32 \\
\hline Segment 12 & 15.36 \\
\hline Segment 13 & 9.16 \\
\hline Segment 14 & 48.41 \\
\hline Nonconvective Composite & 157.40 \\
\hline Convective Composite & 295.69 \\
\hline
\end{tabular}


double-shell slurry feed. The waste level fluctuated between 1973 and 1980 with a high of approximately $691 \mathrm{~cm}$, the height of the cascade overflow, and a low of $183 \mathrm{~cm}$. The tank was removed from service in 1980 with a total waste height of approximately $569 \mathrm{~cm}$. The level then began to drop until December of 1982; data show the waste height has been increasing slowly since then, from approximately $502 \mathrm{~cm}$ in the first quarter of 1982 to $518 \mathrm{~cm}$ in mid 1993 (Brager 1994).

Tank 241-S-102 was core sampled between January and March of 1996. Two cores were collected, one each from risers 11 and 14. These sampling events are referred to as Core 125 and Core 130, respectively. Core 125 contained 11 segments, each $48 \mathrm{~cm}$ (19 inches) in height. Due to sampling problems, Core 130 had three duplicate segments in the entire core of 11 segments (14 total segment samples). Extrusion of these segments indicates stratification of the waste (Fritts 1996). Both cores contained salt cake in segments 2 through 8 , sludge-like material in segments 9 and 10 , and more salt cake in segment 11. Segment 1 in both cores contained one gram or less of sample. Since segments are numbered from the top of the waste down, segment 11 contains material near the bottom of the tank. Tank S-102 appears to contain a thin heel of salt cake, approximately $50 \mathrm{~cm}$, covered by a thick layer of sludge-like material, approximately $95 \mathrm{~cm}$, covered with a thicker layer of salt cake, approximately $340 \mathrm{~cm}$.

Segments from Cores 125 and 130 were extruded at WHC's 222-S laboratory. Segments 7 and 11 of Core 125 and segments 5,6A, and 10 of Core 130 contained drainable liquid. Drainable liquids were separated from the solids and handled as unique samples. Solids were subsampled into half- or quarter-segments based on general appearance. The subsamples were then homogenized by hand mixing.

A total of nine solids samples from the Core 125 and 130 sampling events were received at PNNL's 325A HLRF for gas-bubble retention studies. Table 5.3 lists the segments, core numbers, and densities of these samples.

A composite was prepared for bubble retention testing using material from Core 125 , and Table 5.4 lists its composition. The samples, which were gray and had approximately $5-10 \mathrm{~mL}$ of standing liquid, were hand mixed with a spatula prior to subsampling. The solids were firm at first but thinned after mixing. The final composite was homogenized by hand mixing with a spatula. The sludge samples studied in this work came from the lower half of segments 9 and 10 of Core 130 . These two sludge samples were noticeably different; the sample from segment 9 was stiffer than the sample from segment 10. In the discussion of the experimental results, the segment 9 sample will be referred to as the stiff S-102 sludge, and the segment 10 sample will be called the soft S-102 sludge.

\subsection{Experimental Method}

The apparatus and methods used to evaluate maximum gas retention and the mechanism of gas retention in actual wastes are described below. First, the details of the apparatus are provided, and then data evaluation techniques and lessons learned from validation experiments with a simulated waste are discussed. 
Table 5.3. Samples Received for Bubble Retention Testing

\begin{tabular}{|c|c|c|c|c|}
\hline Core & Segment & Subsegment & $\begin{array}{c}\text { Density, } \\
\mathrm{g} / \mathrm{mL}^{(\mathbf{a})}\end{array}$ & Sample Appearance (Fritts 1996) \\
\hline 125 & 4 & Lower Half & 1.71 & $\begin{array}{c}\text { Solids were light gray to gray in } \\
\text { color and resembled a salt cake }\end{array}$ \\
\hline 125 & 5 & Lower Half & 1.67 & $\begin{array}{c}\text { Solids were light gray to gray in } \\
\text { color and resembled a salt cake }\end{array}$ \\
\hline 125 & 6 & Quarter Segment C & 1.68 & $\begin{array}{c}\text { Solids were light gray and } \\
\text { resembled a salt cake. }\end{array}$ \\
\hline 125 & 7 & Lower Half & 1.62 & $\begin{array}{c}\text { Solids were gray in color and } \\
\text { resembled a damp salt cake }\end{array}$ \\
\hline 130 & $6 \mathrm{~B}$ & Lower Half & 1.67 & $\begin{array}{c}\text { Solids ranged from light gray to } \\
\text { dark gray in color and resembled } \\
\text { a damp salt cake }\end{array}$ \\
\hline 130 & 9 & Lower Half & 1.60 & $\begin{array}{c}\text { Solids were black in color and } \\
\text { resembled a sludge }\end{array}$ \\
\hline 130 & 9 & Upper Half & 1.63 & $\begin{array}{c}\text { Solids were black in color and } \\
\text { resembled a sludge }\end{array}$ \\
\hline 130 & 10 & Lower Half & 1.63 & $\begin{array}{c}\text { Solids were black in color and } \\
\text { resembled a sludge }\end{array}$ \\
\hline (a) These density data were obtained on $5 / 9 / 96 \mathrm{from} \mathrm{Lawrence} \mathrm{Fritts,} \mathrm{Westinghouse} \mathrm{Hanford}$ \\
Company, Richland, Washington.
\end{tabular}


Table 5.4. Composition of Core 125 Composite

Prepared for Bubble Retention Tests

\begin{tabular}{|c|c|}
\hline Segment & Mass (g) \\
\hline 4, Lower Half & 39.89 \\
\hline 5, Lower Half & 37.68 \\
\hline 6, Quarter Segment C & 46.27 \\
\hline
\end{tabular}

\subsubsection{Apparatus}

Figure 5.1 is a drawing of a vessel used for actual waste gas retention experiments. The vessel is assembled from machined acrylic parts. The main vessel tube is constructed of 1 in. $(2.54 \mathrm{~cm})$ i.d., $1-1 / 4$ in. $(3.18 \mathrm{~cm})$ o.d. rigid plastic tubing and 1 in. $(2.54 \mathrm{~cm})$ wide, $1 / 4 \mathrm{in} .(0.64 \mathrm{~cm})$ thick plastic sheet. As shown in the figure, a section of the cylindrical tube is cut away and replaced with the flat sheet; the tube and sheet are solvent welded to produce a leak-tight fit. The flat surface provides for improved close-up imaging of retained gas bubbles. The bottom plug is machined to fit into the flat-faced tube up to the bottom of the flat sheet and is solvent-welded to the tube assembly. The base of the bottom plug is $1-1 / 2$ in $(3.81 \mathrm{~cm})$ square. The cylindrical portion of the vessel top contains grooves for two $\mathrm{O}$-rings, which provide a vacuum seal between the top and the vessel. Straight threads are machined in the top of the cap to accept a Swagelok O-ring face seal fitting. This fitting is used to attach a vacuum line for sample evacuation. For improved radiation stability, the vessel and fitting $\mathrm{O}$-ring materials are either ethylene propylene or silicone.

The fillable portion of each vessel is just over $25 \mathrm{~cm}$ long, and the flat-faced tube is etched every $0.5 \mathrm{~cm}$ along its length. Each vessel was calibrated for volume as a function of height using deionized water. The calibration results gave an average vessel cross-sectional area $4.8 \mathrm{~cm}^{2}$. Information from individual vessel calibrations was applied in the analysis of corresponding waste sample volumes. Each actual waste sample used in gas retention experiments was loaded in a unique retention vessel, and six vessels numbered from 3 to 8 were used in the experiments discussed here.

Two potential mechanisms for generating gas in the waste samples include thermal decomposition and radiolysis. Since properties related to gas retention are affected by temperature (Tingey et al. 1994; Bredt et al. 1995), gas was generated by radiolysis. A sample rack was constructed of stainless steel to simultaneously hold up to four sample vessels and the cesium gamma radiation source $\left(500 \mathrm{Ci}^{137} \mathrm{Cs}\right.$ ). The square bases of the waste vessels fit into slightly oversized square slots in the rack, and the vessels were pinned securely in the rack by wing bolts. The gamma source, when in place, was centrally located in the rack. The source axis-to-vessel axis distance was $2 \mathrm{in} .(5.1 \mathrm{~cm})$. After the waste samples were loaded into the vessels and settled for two to four weeks, the gamma 


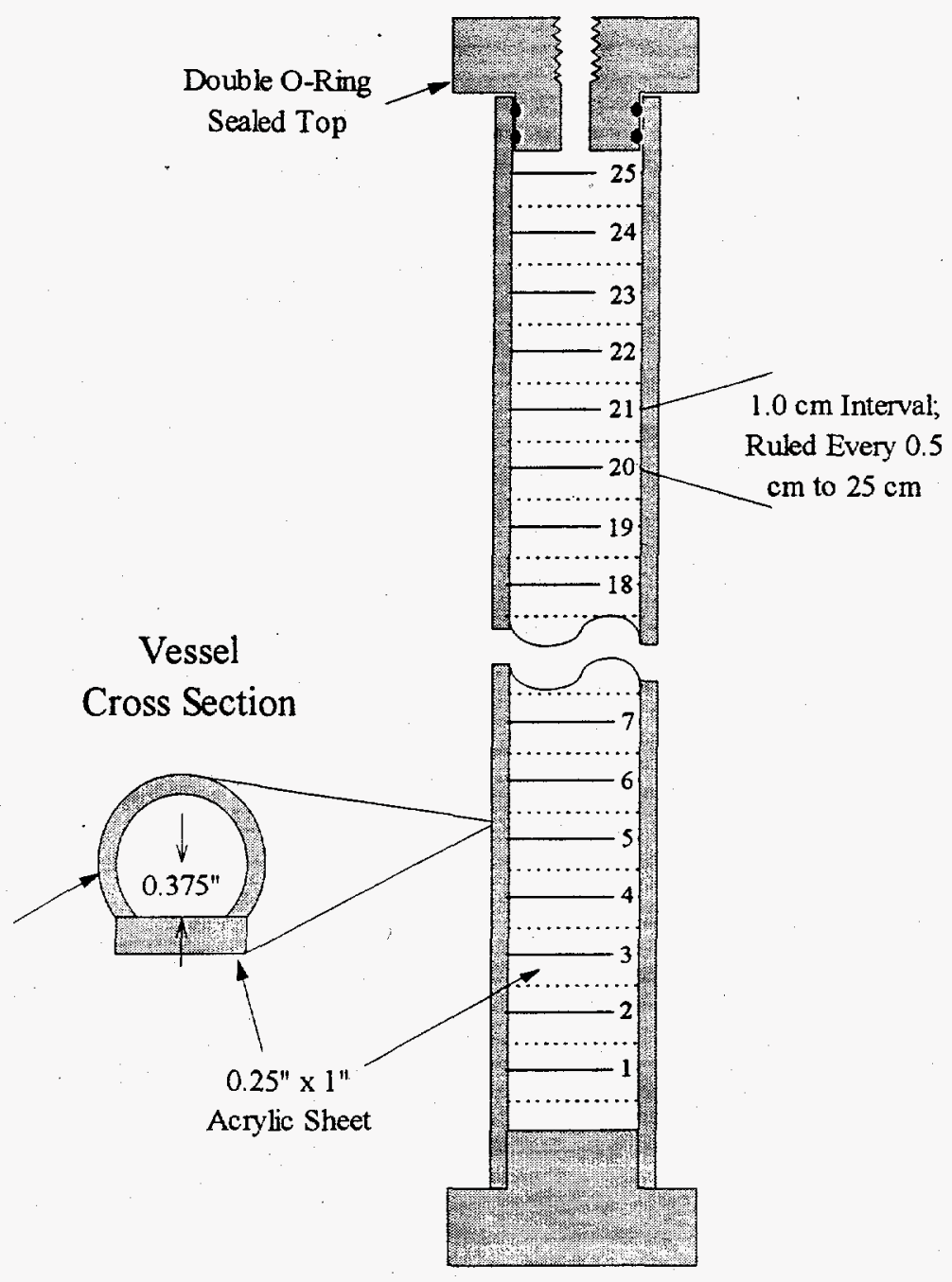

Figure 5.1. Actual Waste Gas Retention Vessel

source was placed in the sample rack. The samples were irradiated for four days and were rotated 90 degrees each day to impart more uniform radiation dose within the waste. Using the dose rate data obtained by Bredt and Tingey, ${ }^{(a)}$ the estimated gamma radiation dose rate to the samples is about $37 \mathrm{kR} / \mathrm{hr}$, giving a total dose of approximately $3500 \mathrm{kR}$.

(a) PR Bredt and JM Tingey (1996) measured and reported an $8.2 \mathrm{kR} / \mathrm{hr}$ dose rate from the same cesium-137 gamma source at a distance of 4 in. from the source. 
The experiments reported here were conducted at the ambient hot cell temperature, approximately $33^{\circ} \mathrm{C}$. This temperature is similar to actual tank conditions in 241-SY-103 (between 32 and $38^{\circ} \mathrm{C}$ in the nonconvective layer [Wilkins 1995]), and it is approximately 7 to $10^{\circ} \mathrm{C}$ below the temperature in Tank $241-\mathrm{S}-102$ (40 to $43^{\circ} \mathrm{C}$ measured using the thermocouple tree in riser 3 on April 8, 1996).

After some gas is generated within the waste sample by radiolysis, the sample vessel pressure was reduced in a controlled manner to nucleate and grow bubbles. Figure 5.2 is a schematic of the actual apparatus used to conduct and monitor these studies. The vacuum line attached to the sample vessel was a $1 / 4$ in. $(0.64 \mathrm{~cm})$ o.d., $1 / 8$ in. $(0.32 \mathrm{~cm})$ i.d. semi-rigid plastic (Nylo-seal) tube. Approximately $75 \mathrm{~cm}$ from the vessel, the tubing was joined to a stainless steel tee, which was also connected to a stainless steel diaphragm vacuum pressure transducer (Varian Vacuum Products part \# 6543-25-035) to obtain a measure of the pressure within the sample vessel. An extended length transducer cable was run through a cell penetration to the digital controller and readout (Varian Vacuum Products model DV-100). The vacuum pressure gauge has a measurement range of 1 to $1500 \mathrm{~mm} \mathrm{Hg}$, a readout resolution of $1 \mathrm{~mm} \mathrm{Hg}$, and an accuracy of better than $1 \%$ of the reading. The recorder output of the digital controller was linked to a National Instruments analog-to-digital converter in an IBM-compatible personal computer, and the vacuum pressure and time were recorded to file every five seconds during the course of an experiment using a digital chart recorder routine created with LabView (National Instruments) software.

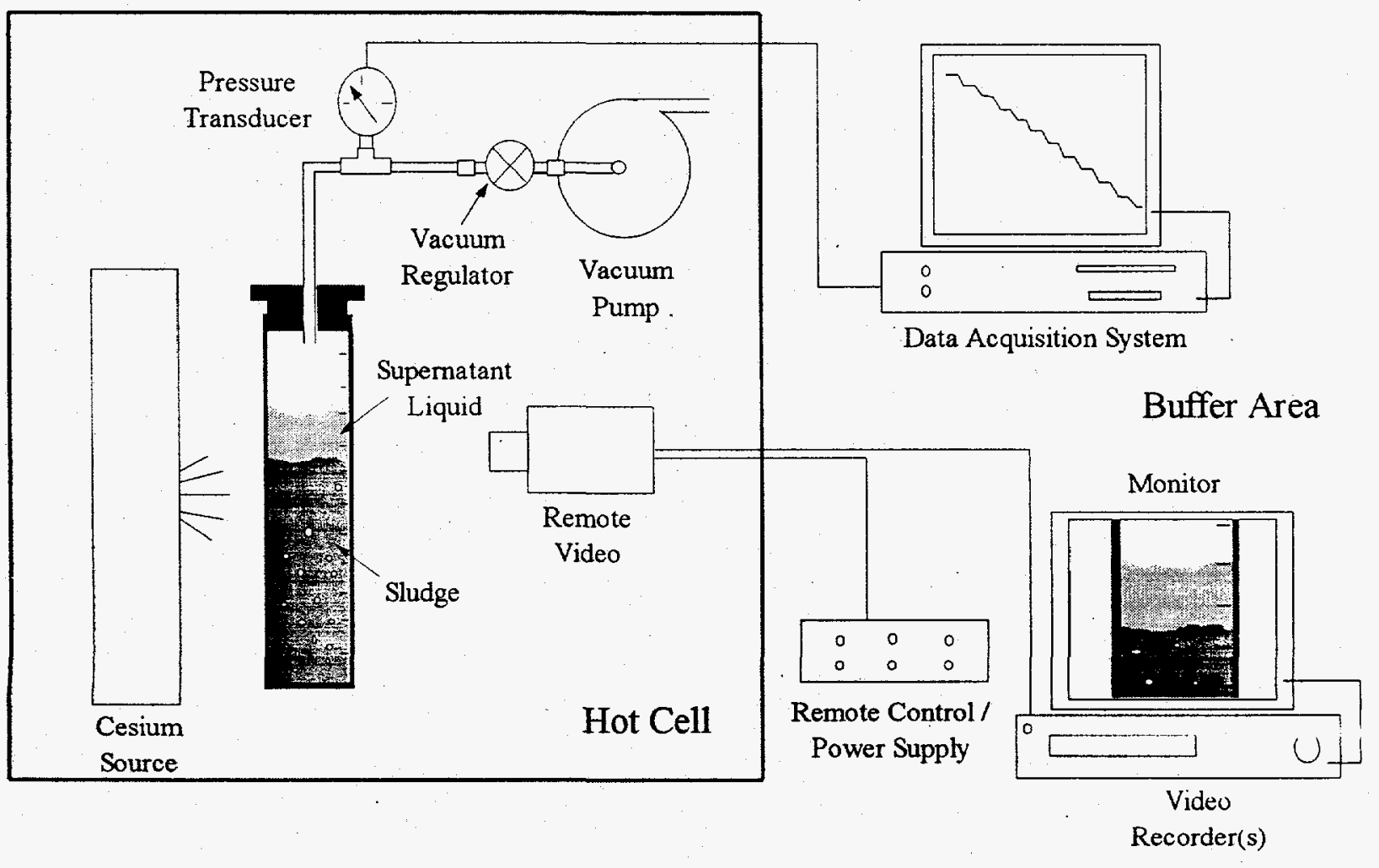

Figure 5.2. Schematic of the Standard Actual Waste Gas Retention Experimental Apparatus 
The vacuum line was continued from the pressure transducer tee to the vacuum regulator, which was attached directly to the vacuum pump. The pump was a Welch Vacuum Technology model \#8890A-55 DirectTorr gerotor type having an ultimate vacuum pressure rating of $0.1 \mathrm{~mm} \mathrm{Hg}$. The regulator, whose details are not shown in the figure, consisted of two stainless steel needle valves (Whitey, $2.0 \mathrm{~mm}$ orifice) in series between the vacuum pump and the vessel. The primary function of the valve closest to the pump was to maintain the pressure on the pump side of the valve at nearly its ultimate vacuum. This configuration was found to give better vacuum control than a single needle valve system. A ball valve was also teed to the regulator to bypass the pump and relieve the system pressure as necessary. The vacuum regulator was controlled manually by the hot cell technician using remote master-slave manipulators. In most cases, pressure changes were made stepwise every two to five minutes from ambient pressure down to vacuum pressures where gas was clearly being released from the sample. The magnitude of the pressure change varied during the course of the experiment from large increments of about $100 \mathrm{~mm} \mathrm{Hg}$ near ambient pressure to $3 \mathrm{~mm}$ $\mathrm{Hg}$ or less below $80 \mathrm{~mm} \mathrm{Hg}$ absolute pressure. The variation in step size was employed to give more uniform changes in retained gas volume, and the height change in any step was typically much less than $0.5 \mathrm{~cm}$.

During a gas retention experiment, two remote controlled video camera systems (Sekac ISC$800 \mathrm{~A}$ ) were used to record waste growth and gas bubble shapes. One camera was used primarily for close-up shots taken through the flat face of the retention vessel. The other camera, set on a side of the vessel, was used to observe the heights of the waste samples throughout the experiment. The camera signals were output to separate video cassette recorders. The time stamps of the two recorders were synchronized to within one second of the time record of the pressure measurements (computer time) so that gas retention as a function of vacuum pressure could be evaluated after the experiment. Additional details of the video equipment are presented in subsection 4.1.2.3.

\subsubsection{Techniques and Validation}

To estimate the initial void fraction within a sample, the ideal gas law was applied to the measured pressure and volume growth data in the higher pressure range $(>300 \mathrm{~mm} \mathrm{Hg})$. For a gas expanding ideally, a plot of gas volume (or volume change) against an inverse pressure (1/P) results in a line. The slope of the line contains information on the number of moles of gas giving rise to the volume expansion, and when corrected to ambient pressure provides a measure of the gas volume initially present within the sample. However, this technique does not provide an absolute measure of initial void fraction, as two competing effects limit its accuracy. On the one hand, soluble gases dissolved within the sample liquid begin to evolve when the pressure is reduced and give an apparent increase in the initial gas volume. This effect becomes important if the time scale of mass transfer from the liquid phase to gas bubbles is short relative to the rate of pressure change. For pressure steps in three minute intervals, the diffusive mass transfer length scale is on the order of $0.5 \mathrm{~mm}$. With this range of activity, it seems likely that mass transfer will influence the initial void measurement. A competing effect may result from the yield strength of the settled solids resisting gas expansion. In this case, low estimates of the initial gas content would result. 
Unless otherwise noted, void fraction results presented here are based on growth in the waste sample occurring during sample evacuation and do not include the initial void volume calculated by the ideal gas law method described above. The growth void fraction at any time is defined as the increase in total waste volume from the start of the evacuation divided by the settled solids volume at the time (pressure) of interest. The growth in total waste volume captures gas retention by dendritic (liquid-displacing) and round (particle-displacing) bubbles in the settled solids. During the latter stages of an experiment, it often became impossible to distinguish the interface of the settled solids and liquid layers because of particulate mixing in the liquid layer. Beyond this point, the settled solids volume was estimated assuming uniform growth in the total waste sample and the solids layer. This assumption, which is equivalent to assuming gas retention by particle-displacing bubbles only, is supported by the gas retention data obtained up to the point where the levels became indistinguishable.

The ideal gas law was also employed to evaluate the point of gas release from the samples, particularly for those in which sudden gas releases were not visually observed. The estimated retained gas volume (growth volume) within the sample, $V_{i}$, at some initial pressure, $P_{i}$, is known. After a pressure change to the next pressure, $P_{f}$, the new retained gas volume is expected to be given by the following ideal gas law relationship:

$$
V_{f}=P_{i} V_{i} / P_{f}
$$

If the measured retained gas volume following a pressure change is less than the ideal gas law estimated volume $V_{f}$, it suggests that the sample has ceased retaining all the gas during the expansion; thus gas was released.

A gas retention experimental apparatus and methods similar to those described above were tested using simulated wastes. Figure 5.3 shows the measured void fractions as a function of pressure for three samples of $67-\mathrm{Pa}$ bentonite clay. Three rates of pressure change, $3 \mathrm{~mm} \mathrm{Hg} / \mathrm{min}, 13 \mathrm{~mm}$ $\mathrm{Hg} / \mathrm{min}$, and $50 \mathrm{~mm} \mathrm{Hg} / \mathrm{min}$, were used to evaluate the effect of pressure change rate on the measured maximum void fraction. As shown in the figure, the maximum measured void fraction (total void) in the samples ranged from about 0.35 to 0.43 . This range is consistent with the maximum void fractions observed in other 67-Pa clay simulants where gas bubbles were grown at ambient pressure by the decomposition of hydrogen peroxide (see subsections 4.2.2.1 and 4.2.2.2). No clear relationship was observed between the rate of depressurization and maximum void fraction for the range studied. Also apparent in Figure 5.3 is the increase in void content of each sample at ambient pressure; this results from the pre-evacuation decomposition of small amounts of hydrogen peroxide that was added to the samples as a source of initial gas.

The validation experiments depicted in Figure 5.3 showed several things. First and most importantly, gas bubble growth induced by depressurization gave results similar to those obtained at ambient pressure with hydrogen peroxide decomposition. The pressure regulation system used in these preliminary experiments gave poor pressure control, and substantial pressure swings about the set point resulted in cyclic expansion/compression of the simulant sample. The effect of these pressure variations on the maximum retention results is unclear, but the need for an improved 


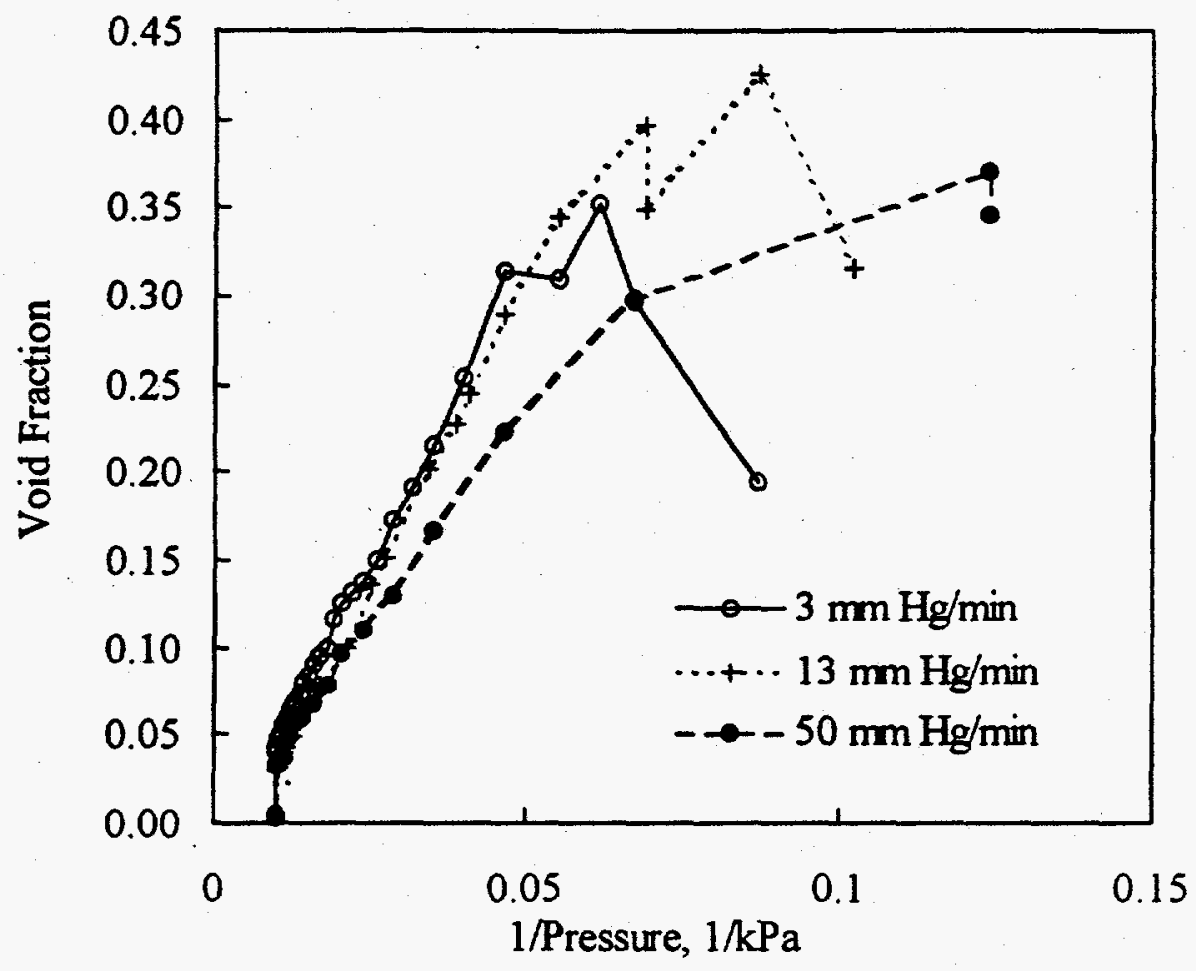

Figure 5.3. Effect of Depressurization Rate on Gas Retention in a 67-Pa Bentonite Clay

pressure regulator was clear. As a result of these experiments, it was decided to use progressively smaller pressure steps as the absolute pressure decreased to achieve more uniform waste sample growth. As seen in Figure 5.3, single uniform pressure steps at lower pressure gave rise to sudden increases in void of greater than $5 \%$. Ideally, a pressure program linear in $1 /$ pressure would be applied to the sample. Furthermore, the $50 \mathrm{~mm} \mathrm{Hg} / \mathrm{min}$ depressurization rate was found to be much too fast to control manually in a hot cell operation. The actual waste samples were typically evacuated over 60 to 90 minutes, which corresponds to an average depressurized rate in the range of 8 to $13 \mathrm{~mm} \mathrm{Hg} / \mathrm{min}$.

\subsection{Results and Discussion}

The results of actual waste gas retention experiments for two tank wastes are presented here. Of primary interest in these studies are the ability of the waste to retain gas, or maximum retention, and the mechanism of gas retention, which is determined to a great extent by the shapes of retained bubbles. Both topics are discussed in the following sections. As detailed in Section 5.1, waste samples from Tanks 241-SY-103 and 241-S-102 were evaluated. The six samples used in these standard gas retention experiments cover a broad range of waste types, including SST and DST wastes, sludge, and salt cake. To aid in the discussion of the actual waste results, the sample descriptions and associated vessel numbers are summarized in Table 5.5. 
Table 5.5. Summary of Actual Waste Samples Used in Gas Retention Experiments

\begin{tabular}{|c|c|l|l||}
\hline $\begin{array}{c}\text { Vessel } \\
\text { Number }\end{array}$ & Waste Tank & \multicolumn{1}{|c|}{ Core/Segments } & Description \\
\hline \hline 3 & 241 -SY-103 & $\begin{array}{l}62 / \text { composite of all convective layer } \\
\text { segments and nonconvective segments } 10, \\
11,12,13, \text { and 14 }\end{array}$ & $\begin{array}{l}\text { whole tank } \\
\text { composite }\end{array}$ \\
\hline 4 & $241-$ SY-103 & $\begin{array}{l}62 / \text { composite of segments 10,11,12,13, } \\
\text { and 14 }\end{array}$ & $\begin{array}{l}\text { nonconvective } \\
\text { composite }\end{array}$ \\
\hline 5 & $241-$ S-102 & $\begin{array}{l}125 / \text { composite of segments 4-lower half, } \\
5 \text {-lower half, and 6-quarter segment C }\end{array}$ & salt cake composite \\
\hline 6 & $241-$ S-102 & $\begin{array}{l}125 / \text { composite of segments 4-lower half, } \\
5-\text { lower half, and 6-quarter segment C }\end{array}$ & salt cake composite \\
\hline 7 & $241-$ S-102 & $\begin{array}{l}130 / 9 \text {-lower half } \\
\text { stiff sludge }\end{array}$ \\
\hline 8 & $241-$ S-102 & soft sludge \\
\hline
\end{tabular}

\subsubsection{Bubble Shapes in Actual Waste}

The shape of retained bubbles varied considerably depending on the waste material studied. In this work, the waste material ranged from the stiff sludge-like material from two segments of SST S-102 to a weak sludge-like material from SY-103. In addition, the salt cake from S-102 provided a good example of a waste material with a distinctly particulate character. As described in Section 2.1, bubble growth is dictated by the forces acting on the bubbles, which include those arising from gravity, surface tension, and the strength of the waste being displaced. In this section, we present video images that highlight the range of observed behavior for these waste materials with widely different characters.

The S-102 salt cake samples (both vessels 5 and 6) had a distinctly particulate character. Figure 5.4 shows retained bubbles in S-102 salt cake (vessel 6) at a void fraction of 0.26 . This image shows that the retained bubbles displaced the salt cake particles. Figures 5.5 and 5.6 show retained bubbles in S-102 salt cake (vessel 5) at later stages of the bubble growth experiment where the void fraction was higher $(0.30$ and 0.45$)$. It is apparent in these images that the bubbles displaced the salt cake particles and the bubbles were certainly distorted from spherical.

Bubble retention in S-102 samples from the segments that contained sludge-like material gave clearly different results. Figure 5.7 shows retained bubble in the stiff S-102 sludge (vessel 7) when the void fraction was about 0.17 . In this case, the bubbles were slit-shaped and displaced the waste particles. As described in Section 4.2, when the waste material is quite strong, the retained bubbles 


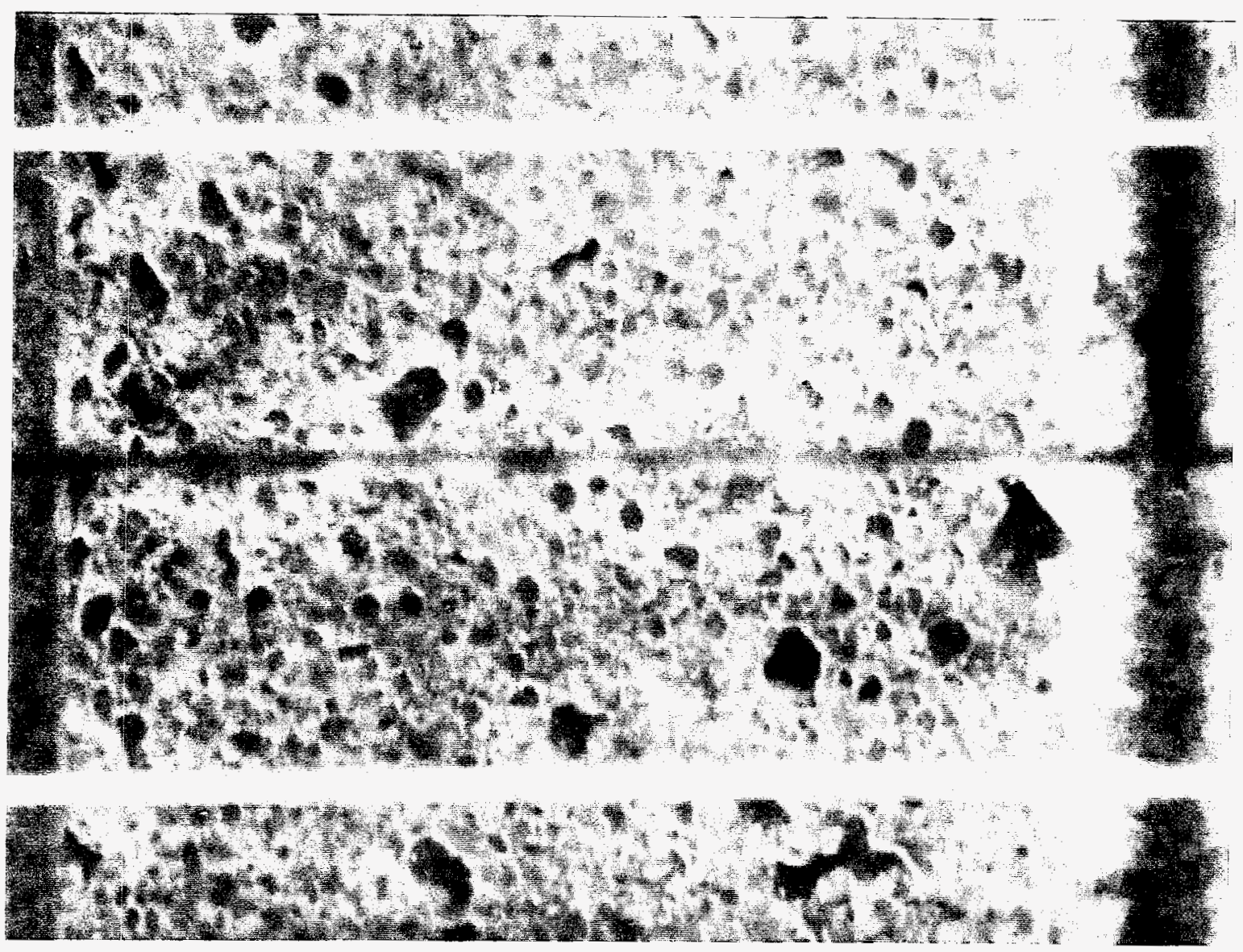

Figure 5.4. Retained Bubbles in S-102 Salt Cake Sample (Vessel 6) at a Void Fraction of 0.26 (horizontal lines are $0.5 \mathrm{~cm}$ apart)

are greatly distorted and tend to grow into slit-shaped bubbles. Figure 5.8 shows the behavior of retained bubbles in the soft S-102 sludge when the void fraction was about 0.29 . While the retained bubbles were distorted from spherical, they were not as slit-shaped as bubbles in the stiff S-102 sludge. The distorted bubbles observed for soft S-102 sludge samples also conform to bentonite clay results shown in Section 4.2. That is, sludge with moderate strength will distort bubbles from spherical, but the bubbles will not grow into more the extreme situation of slit-shaped bubbles. 


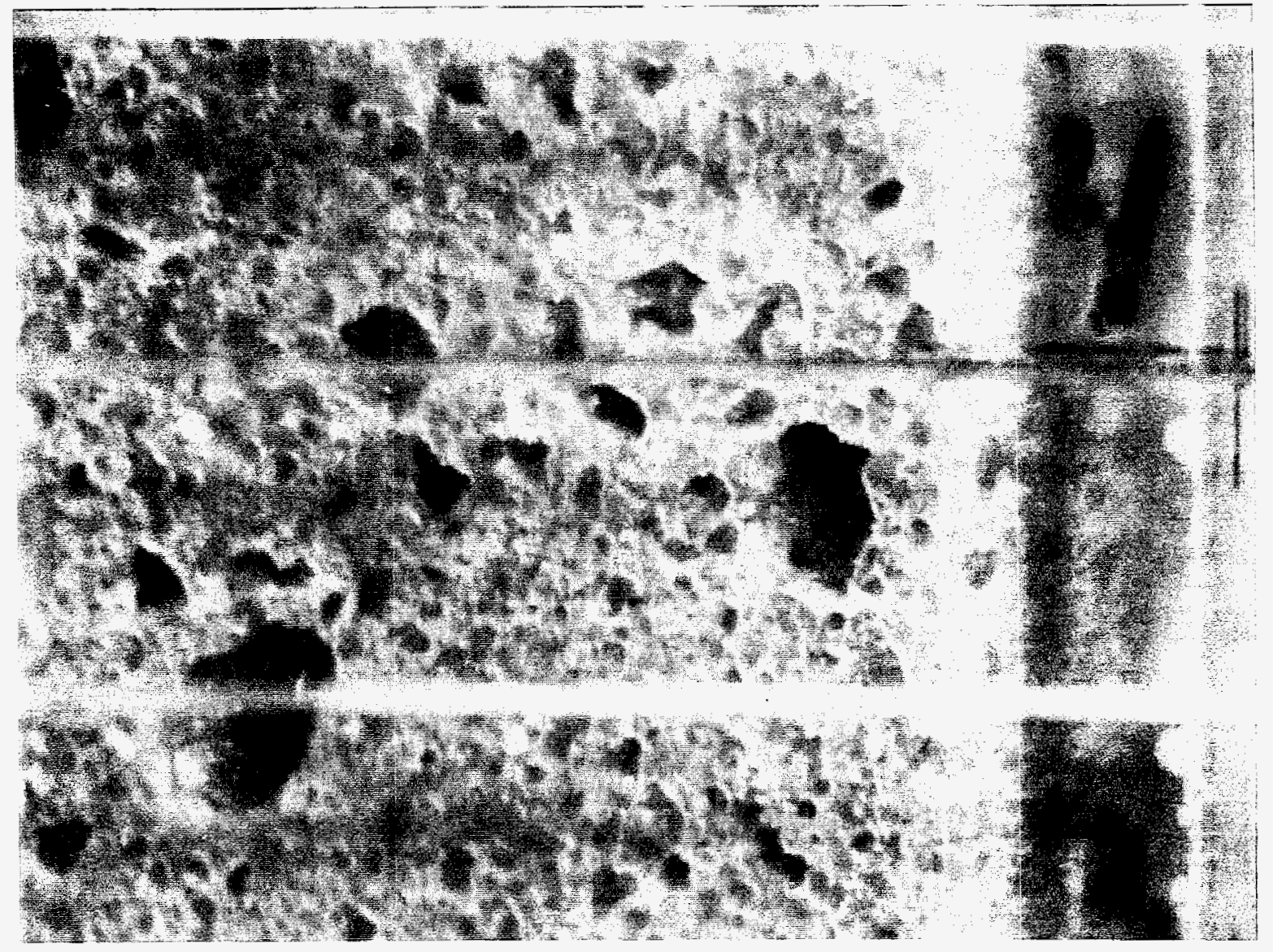

Figure 5.5. Retained Bubbles in S-102 Salt Cake Sample (Vessel 5) at a Void Fraction of 0.30 (horizontal lines are $0.5 \mathrm{~cm}$ apart) 


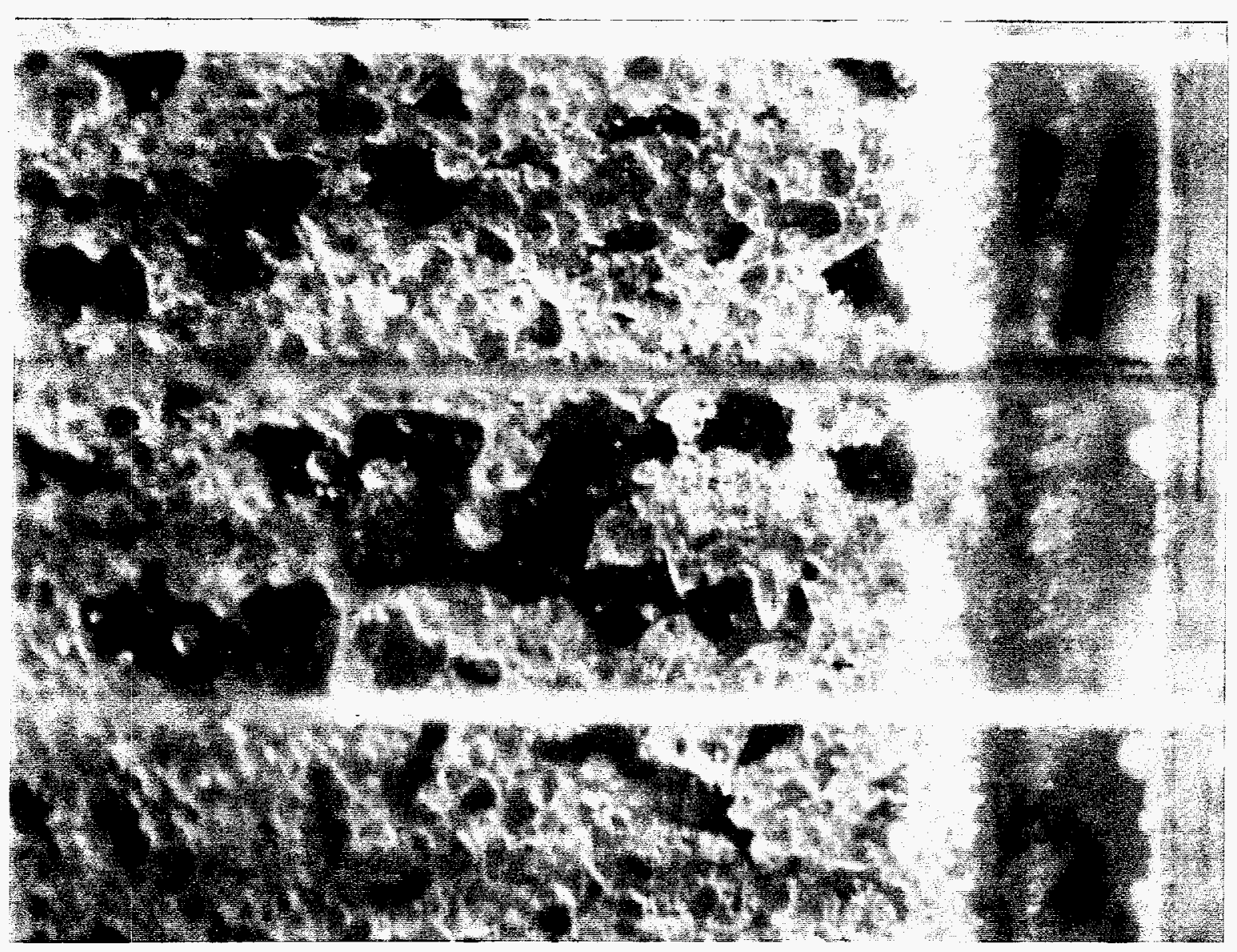

Figure 5.6. Retained Bubbles in S-102 Salt Cake Sample (Vessel 5) at a Void Fraction of 0.45 (horizontal lines are $0.5 \mathrm{~cm}$ apart) 


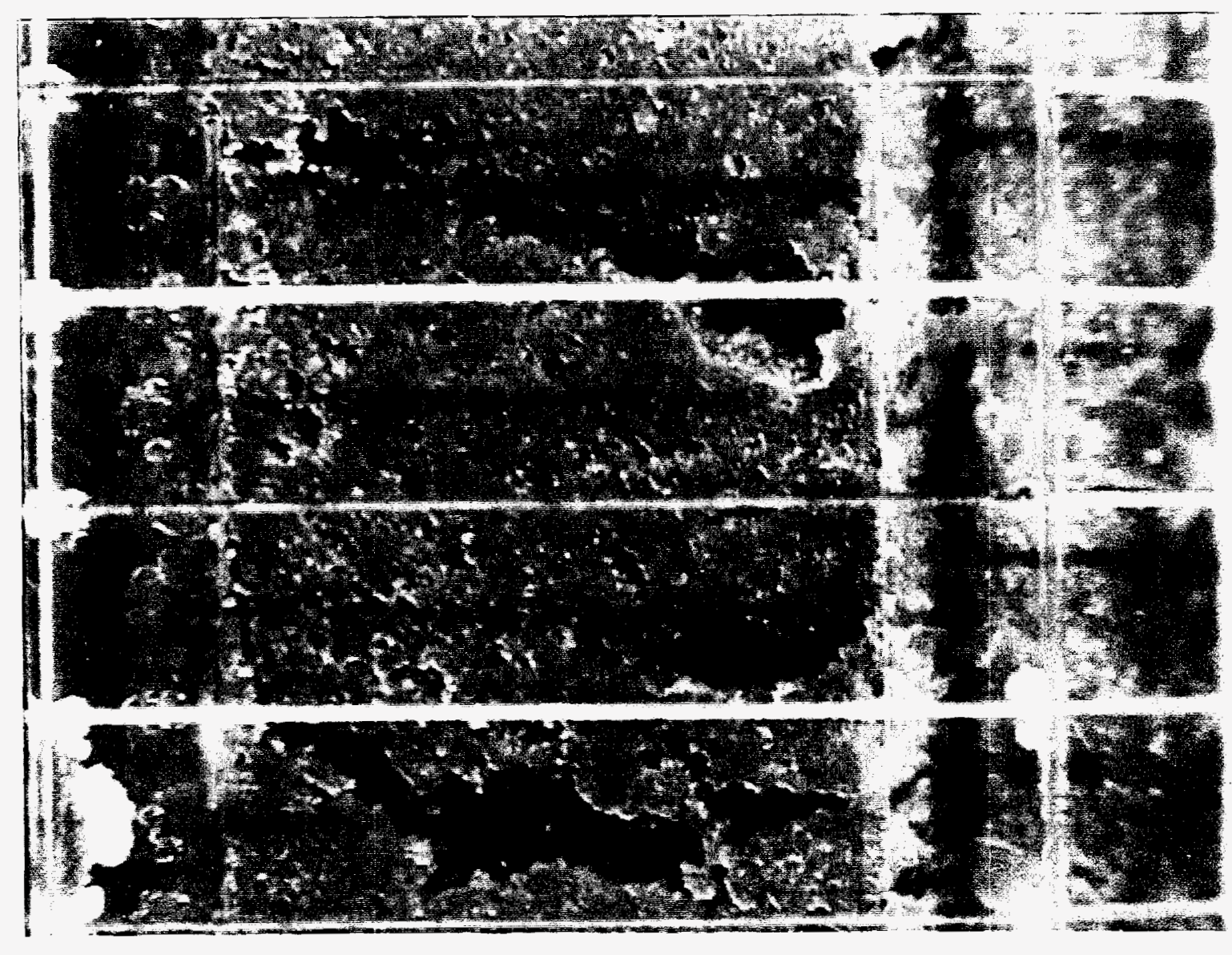

Figure 5.7. Retained Bubbles in the Stiff S-102 Sludge Sample (Vessel 7) at a Void Fraction of 0.17 (horizontal lines are $0.5 \mathrm{~cm}$ apart) 


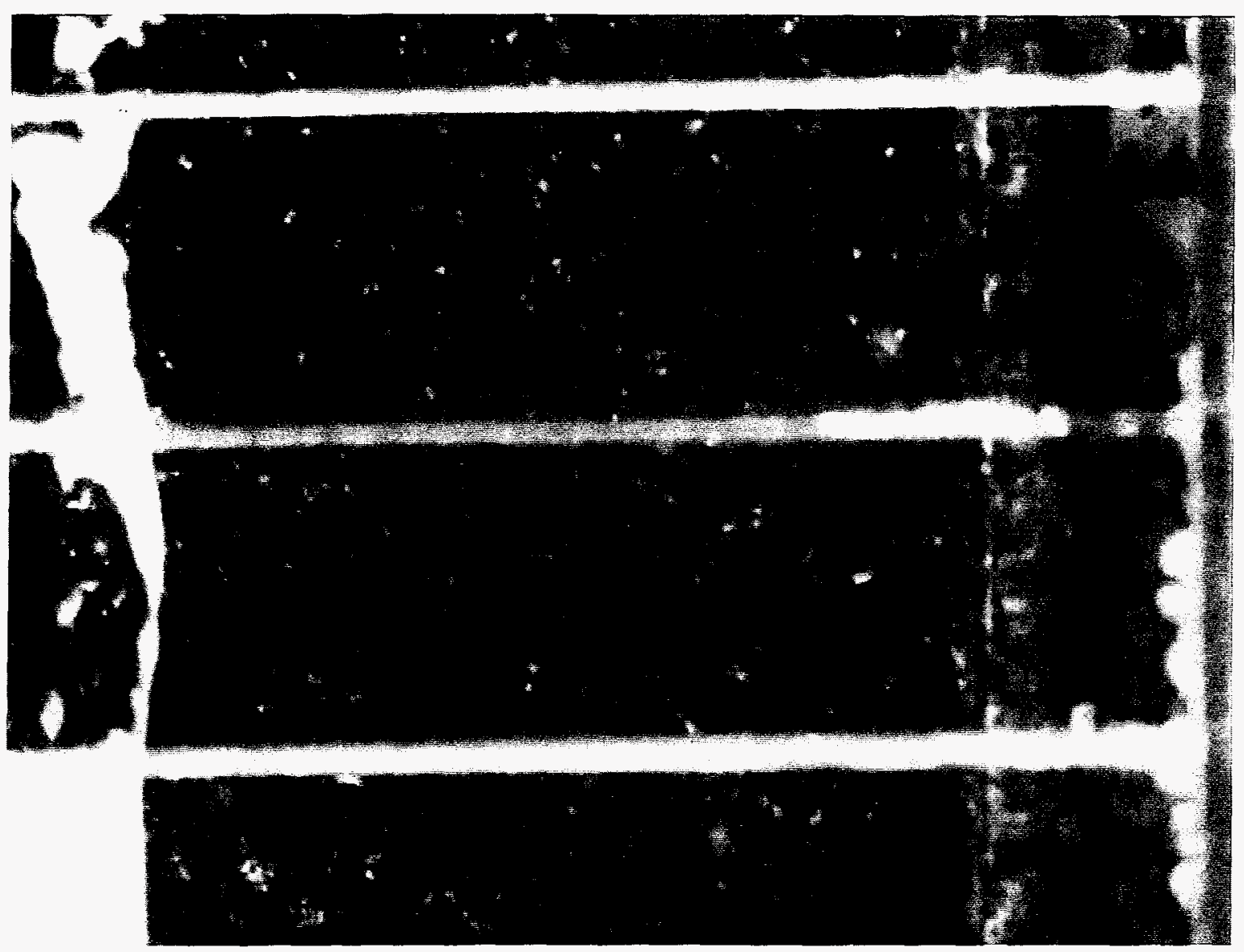

Figure 5.8. Retained Bubbles in the Soft S-102 Sludge Sample (Vessel 8) at a Void Fraction of 0.29 (horizontal lines are $0.5 \mathrm{~cm}$ apart) 
Retained bubbles in the SY-103 nonconvective composite appeared essentially round, as shown in Figure 5.9. The void fraction was about 0.22 at the time this image was taken. The SY-103 sample studied in this work was weak, having been previously composited and tested. The observed bubbles were round, most likely because surface tension forces were the most dominant force acting on the bubbles.

The bubble shapes observed in this study agree in most ways with the limited number of previous observations reported by Bredt et al. (1995) and Bredt and Tingey (1996) on bubble retention in actual waste. Bredt and Tingey (1996) and Bredt et al. (1995) collected video images of retained bubbles in SY-103 and SY-101 waste as part of a dilution mitigation study. In this current work, we reviewed these videos with an emphasis on observing the bubble shapes in actual waste. ${ }^{(a)}$ Figure 5.10 shows retained bubbles in the settled solids of a whole-tank composite made from SY-103 core material. Prior to taking this image, the bubbles were expanded by applying a vacuum to the test vessel. The bubbles appear to be essentially round. Figure 5.11 shows retained bubbles in the settled solids of a mixture of SY-101 core material studied by Bredt et al. (1995). Similar to those retained in the SY-103 material, the bubbles were expanded by applying a vacuum to the test vessel and again the bubbles appear to be essentially round. In both of these images, the bubbles appear similar to those we observed in the SY-103 waste and those retained in the bentonite clay sludges that had moderate strengths.

While the images in Figures 5.10 and 5.11 appear similar to the retained bubbles we observed in SY-103 waste and in bentonite-clay simulants, Bredt and Tingey (1996) reported behavior we did not observe in our actual waste experiments or in the simulants. Before applying the vacuum to expand them, small round bubbles were observed in SY-103 waste (Bredt and Tingey 1996). These bubbles appeared to have displaced the waste, similar to our observations. The first difference was that small liquid-filled voids were observed in the actual waste; the second observation was that bubbles may have migrated a short distance (a few $\mathrm{mm}$ ), as suggested by liquid-filled cracks adjacent to the bubbles. This suggests that over long periods of time ( 30 days or more) other mechanisms of bubble release, which would reduce the maximum retention, may be important. Details of experiments and procedures are reported in Bredt and Tingey (1996).

\subsubsection{Maximum Gas Retention}

The maximum gas retention in samples of S-102 and SY-103 tank wastes were evaluated using the standard sample evacuation procedure. It should be noted that no measurable waste

(a) The video images of bubbles in SY-101 waste were taken from experiments that were a continuation of those described in Bredt et al. (1995). While generally similar, the specifics of these continuation experiments differ, and the details have not previously been reported. In the context of the bubble retention studies, the primary difference was that the SY-101 sample was maintained at the hot cell temperature rather than at the actual tank temperature. 


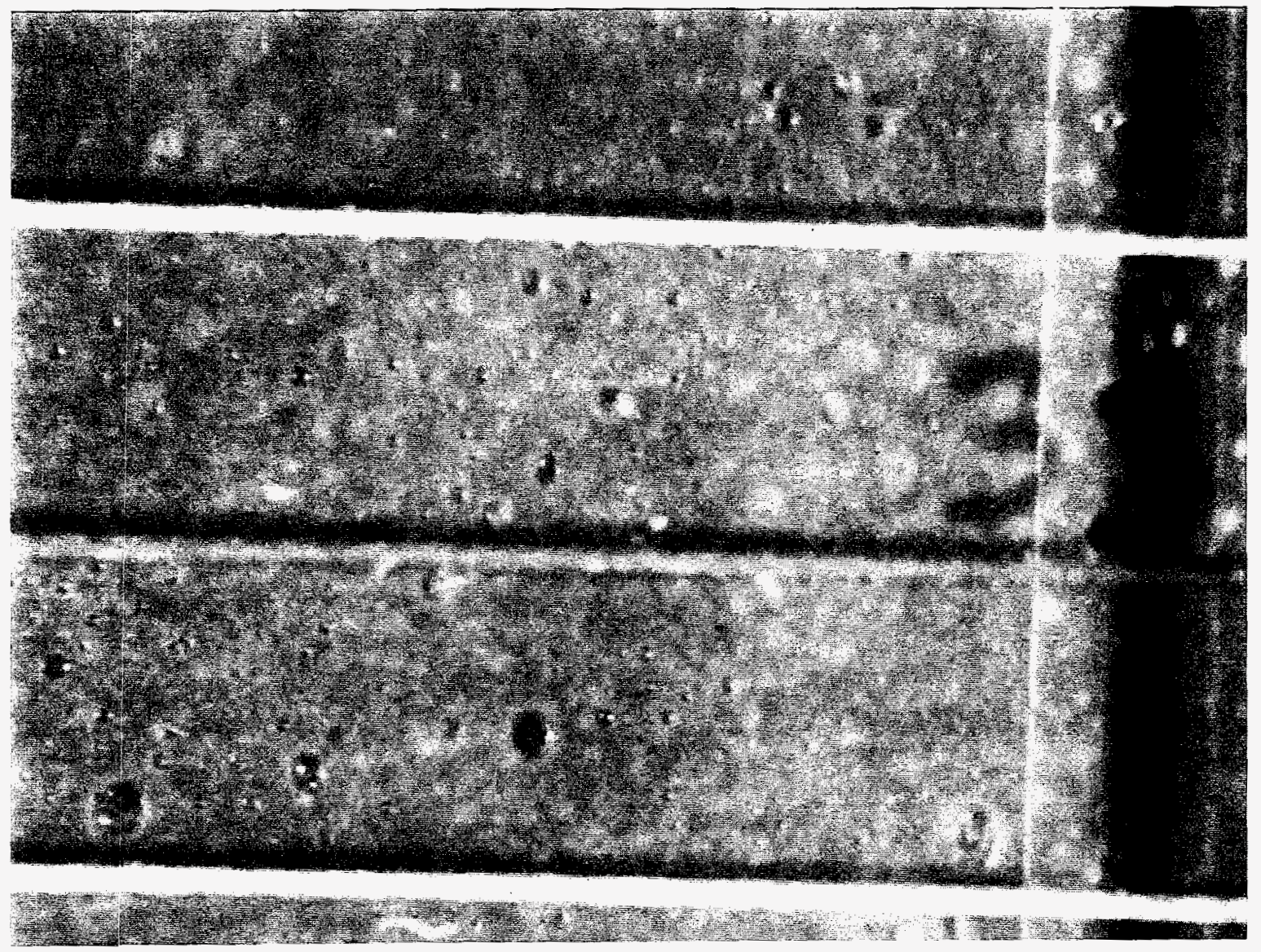

Figure 5.9. Retained Bubbles in the SY-103 Nonconvective Composite (Vessel 4) at a Void Fraction of about 0.22 (horizontal lines are $0.5 \mathrm{~cm}$ apart) 


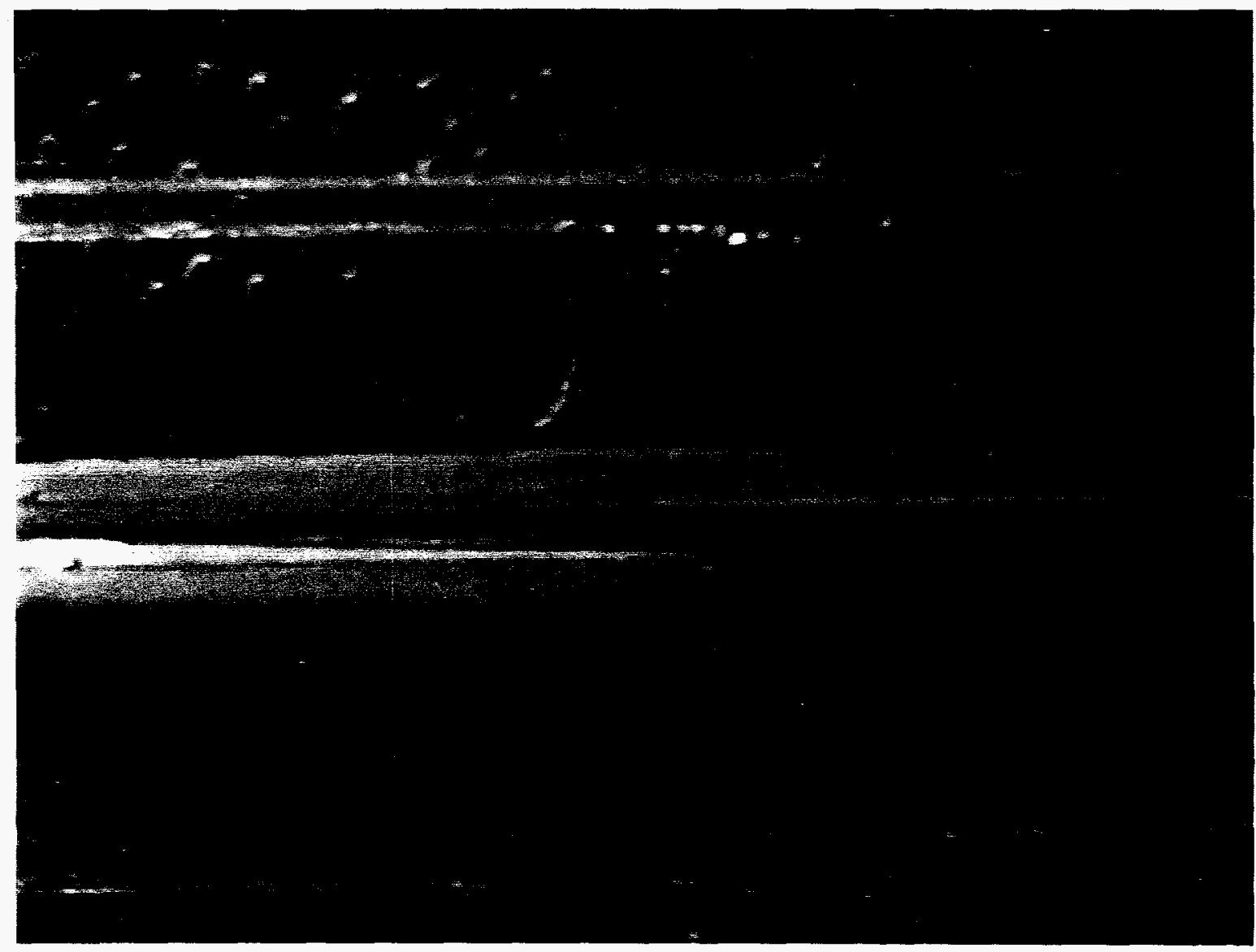

Figure 5.10. Retained Bubbles in the SY-103 Waste from Video Images Collected by Bredt and Tingey (1996) (horizontal lines are $0.5 \mathrm{~cm}$ apart) 


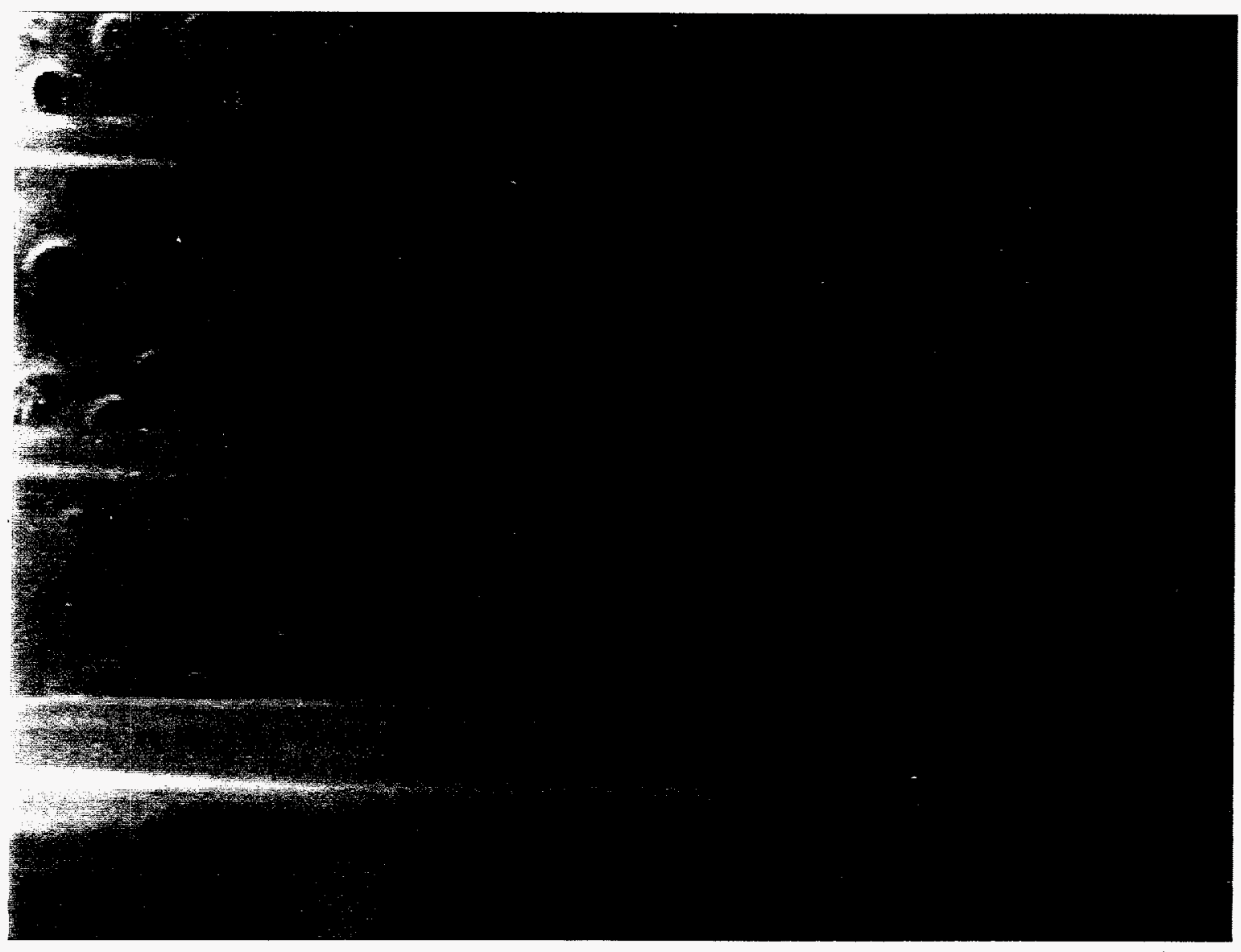

Figure 5.11. Retained Bubbles in the SY-101 Waste Taken from Video Images Collected by Bredt et al. (1995) (horizontal lines are $0.5 \mathrm{~cm}$ apart) 
sample growth resulted from the four-day irradiation process, even though bubbles were clearly observed in most samples before evacuation. The reported void fraction results are based, primarily, on level changes resulting from sample evacuation. The results for the S-102 samples are presented first, and those for SY-103 samples follow. The actual waste gas retention data are also tabulated in Appendix B.

\subsubsection{S-102 Results}

Four S-102 waste samples, two salt cake and two sludge, were tested for maximum gas retention. Of these, the segment 9 lower-half sludge was unique. This sample was very stiff and had a clay-like consistency. Unlike the other samples tested (including SY-103 samples), this stiff sludge had no discernible free liquid even after several weeks of settling. Whereas each of the other waste types tended to settle naturally, this sample had to be manually compacted with a blunt rod to reduce the number of large voids and pits entrained during vessel loading. The gas retention and release behavior of this sludge-like material, as shown in Figure 5.12, was also atypical of the other actual waste samples.

The shape of the stiff sludge gas retention curve is very similar to those presented in Section 4.2.3.1 for moderate to strong bentonite clays, where the time axis of the clay experiments is replaced with the 1/pressure abscissa. (See, for example, Figures 4.25 through 4.27 for 300-1000-Pa shear strength clays.) Each of these retention curves shows a temporary gas retention plateau at some intermediate void fraction, where gas is at least partially released. In the S-102 sludge curve, this release point occurred at about $150 \mathrm{~mm} \mathrm{Hg}\left(1 /\right.$ pressure $\left.\sim 0.05 \mathrm{kPa}^{-1}\right)$ and about $12 \%$ sample growth. This release was detected using the ideal gas law technique (Eq. 5.1) noted earlier, wherein the measured sample growth was considerably less than expected for the magnitude of the associated pressure change. The ideal gas law theoretical expansion data are shown in Figure 5.12 for comparison with the measured growth data. With continued pressure reductions, the pathway through which gas was released in this first event apparently closed up, and the sample expanded to a maximum growth of about $20 \%$. Once the maximum retention was achieved in this stiff sludge, additional pressure reductions did not further expand the sample, and gas was released continuously. This steady upper limit in the retention curve is also characteristic of the strong clay data. The behavior is consistent with a sample having a somewhat rigid structure and a system of connected pathways to the sample headspace whereby gas is released. In fact, the structure was found to be self-supporting; when the experiment was complete and pressure in the vessel allowed to come back to ambient, the sample did not collapse. Again, this is quite different from any of the other actual waste samples investigated.

The S-102 segment 10 lower half sludge sample was considerably wetter and softer than the segment 9-lower half sludge discussed above. It settled naturally after some gentle tapping of the sample vessel to remove larger voids, and a thin $0.3-\mathrm{cm}$ supernatant liquid layer formed on top of the sludge with time. The gas retention curve for the soft sludge is shown in Figure 5.13. The gas retention and release behavior in the soft S-102 sludge is somewhat analogous to that observed for weak to moderate shear strength bentonite clay samples, as can be seen by comparing Figure 5.13 


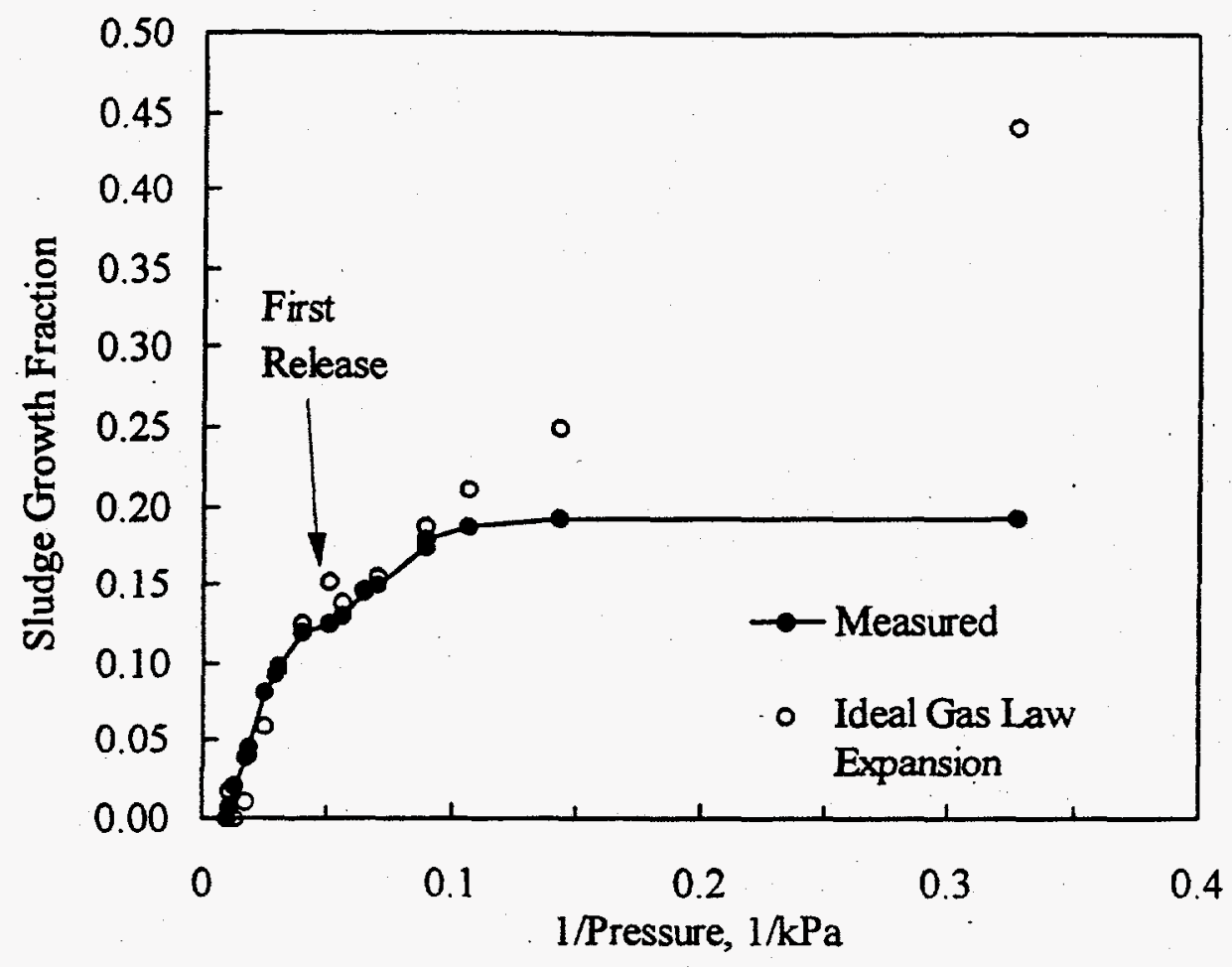

Figure 5.12. Stiff S-102 Sludge Gas Retention Curve

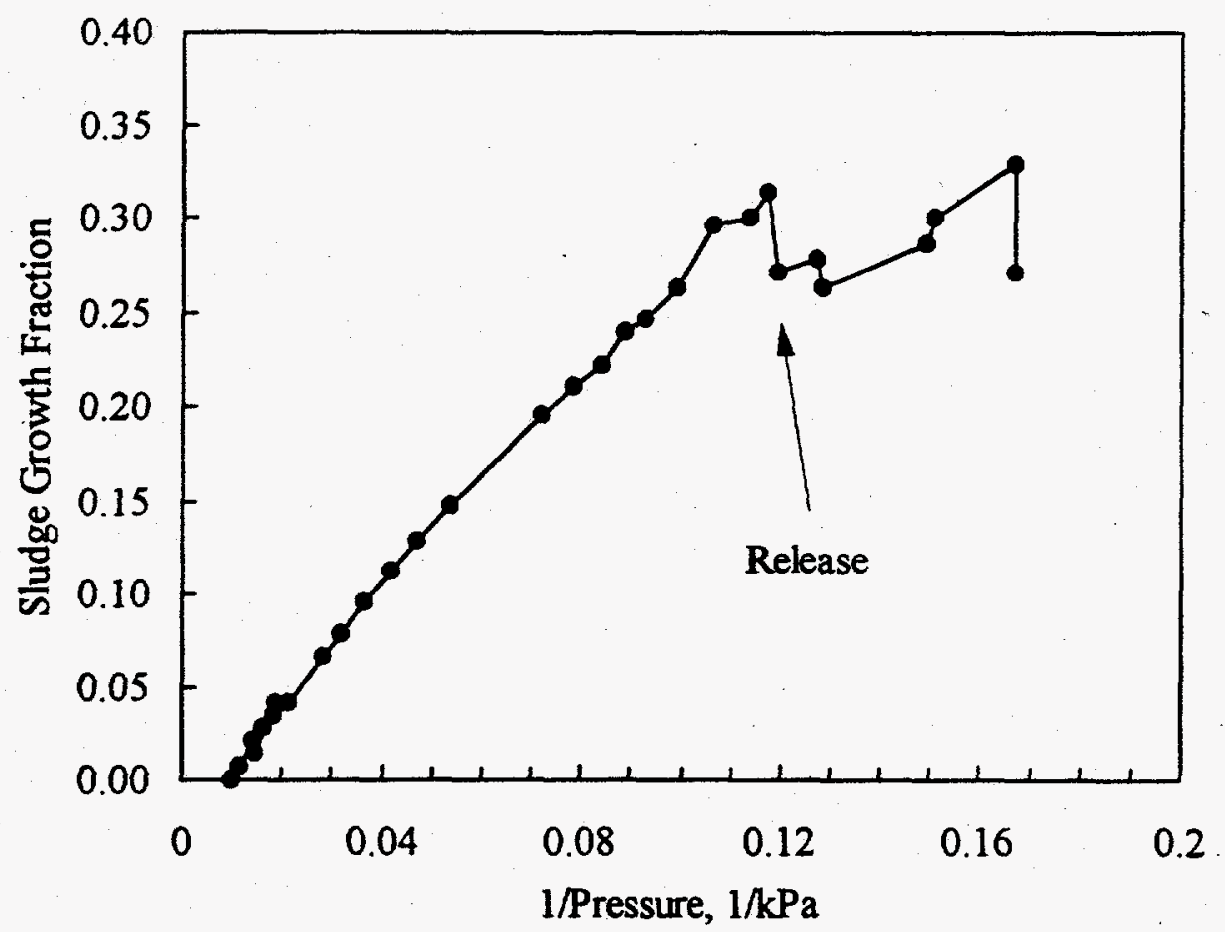

Figure 5.13. Soft S-102 Sludge Gas Retention Curve 
with Figures 4.22 and 4.23 (subsection 4.2 .3 .1 ) for 31 - and 67-Pa clays, respectively. In all three curves, gas is retained in the sample to some initial maximum where some relatively small fraction of the void ( $-5 \%$ or less) is released. Following the release event, the sample grows anew until a second maximum retention is reached, and a sudden release occurs. As with clay samples, the first maximum growth fraction in the soft sludge, 0.31 , is essentially equal to the second peak, 0.33 . The measured bulk density of this sludge prior to sample evacuation was $1.78 \mathrm{~g} / \mathrm{mL}$. Assuming a supernatant liquid density of $1.4 \mathrm{~g} / \mathrm{mL}$, it can be shown that a growth fraction of only 0.22 is needed to make the sludge neutrally buoyant in the liquid. The actual growth exceeds the neutral buoyancy point, likely due to an insufficient amount of convective liquid over the sludge. A more detailed discussion of neutral buoyancy as it relates to maximum retention in tank wastes follows in the SY103 results section.

Maximum gas retention experiments were conducted on two S-102 samples. The results of these tests provide a check on the reproducibility of the gas retention method, because the samples were drawn from the same composite mix. Figure 5.14 shows the gas retention curves for the replicate measurements. The results indicate nearly identical maximum growth values for the two experiments, $47 \%$ in vessel 5 and $50 \%$ in vessel 6 . Further testament to the reproducibility of the experiments is a comparison of the shape of the two retention curves. In both cases, small gas releases of less than $1 \%$ void reduction occurred at $\sim 90 \mathrm{~mm} \mathrm{Hg}\left(1 /\right.$ pressure $\left.\sim 0.085 \mathrm{kPa}^{-1}\right)$ and both attained maximum retention near $75 \mathrm{~mm} \mathrm{Hg}\left(1 /\right.$ pressure $\left.\sim 0.1 \mathrm{kPa}^{-1}\right)$. The mechanism of release was also similar. It appeared that large gas bubbles would collect near the surface of the gaseous waste and pop like over-expanded balloons upon reduction in pressure. Additional decreases in pressure resulted in more collected gas and further sudden small releases. Using the measured initial sample bulk densities of 1.88 and $1.92 \mathrm{~g} / \mathrm{mL}$, vessels 5 and 6 , respectively, and assuming a supernatant liquid density of $1.4 \mathrm{~g} / \mathrm{mL}$, the estimated growth to neutral buoyancy is $27 \%$ for the vessel 5 sample and $28 \%$ for the vessel 6 sample. As with the S-102 soft sludge sample, the amount of supernatant liquid on these samples ( 8 and 5 vol\% free liquid, respectively) was insufficient to support a buoyancyinduced rollover. It should also be noted that the gas retention experimental results for these salt cake samples indicate that the bubbles displaced particles (round bubbles) as opposed to fingering between particles (dendritic bubbles). This was deduced from the nearly identical growths in the gaseous salt cake layer and the free liquid layer of the samples.

The results of the four S-102 gas retention experiments are summarized in Table 5.6. An important result is that the soft sludge sample, which appeared to be considerably weaker than the stiff sludge, retained about $10 \%$ more gas at maximum growth. Furthermore, the somewhat more granular, and possibly still weaker, salt cake samples retained even more gas. These results are consistent with observations made on bentonite clay samples; this issue will be discussed in more detail in the next section. The table also contains estimates of the initial void fractions in each sample as determined by the ideal gas law extrapolation method described in Section 5.2.2. The salt cake samples gave higher initial void content estimates (10-12\%) than the sludge samples (4-5\%). Using these initial estimates, one calculates somewhat higher values for the maximum void fraction retained in the wastes as shown in Table 5.6. The table shows the measured initial bulk sample densities and the associated estimated growth fraction to neutral buoyancy assuming a liquid density of $1.4 \mathrm{~g} / \mathrm{mL}$. In the two salt cake samples and the soft sludge, the maximum growth far exceeded the predicted neutral buoyancy fraction, most likely due to the small amount of convective liquid in each case. 


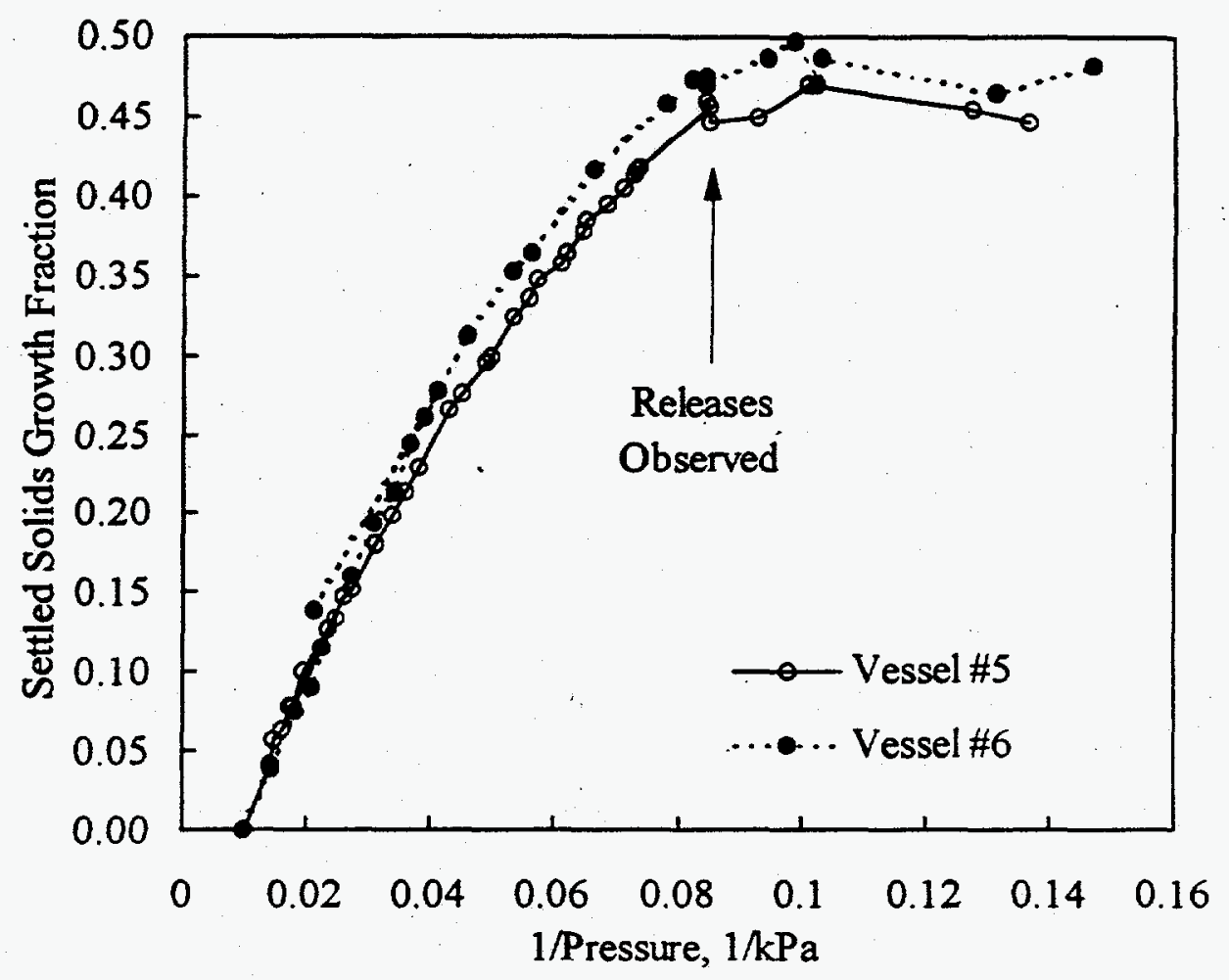

Figure 5.14. Duplicate S-102 Growth Fraction Results

Table 5.6. Summary of S-102 Gas Retention Experiments

\begin{tabular}{|c|c|c|c|c|c|l||}
\hline \multirow{2}{*}{$\begin{array}{c}\text { Vessel } \\
\text { Number }\end{array}$} & Description & $\begin{array}{c}\text { Measured } \\
\text { Maximum } \\
\text { Growth }\end{array}$ & $\begin{array}{c}\text { Calculated } \\
\text { Initial }\end{array}$ & $\begin{array}{c}\text { Maximum } \\
\text { Including } \\
\text { Initial }\end{array}$ & $\begin{array}{c}\text { Estimated } \\
\text { Growth to } \\
\text { Buoyancy }\end{array}$ & $\begin{array}{c}\text { Bulk Density } \\
\text { (Initial) g/mL }\end{array}$ \\
\hline \hline 5 & composite & 0.47 & 0.12 & 0.53 & 0.27 & 1.88 \\
\hline 6 & composite & 0.50 & 0.10 & 0.54 & 0.28 & 1.92 \\
\hline 7 & stiff sludge & 0.20 & 0.053 & 0.24 &.- & 1.63 \\
\hline 8 & soft sludge & 0.33 & 0.044 & 0.36 & 0.22 & 1.78 \\
\hline
\end{tabular}




\subsubsection{SY-103 Results}

The maximum measured gas retention and the mechanism of gas release in the two SY-103 waste samples, a nonconvective composite and a whole tank composite, were vastly different. The differences in maximum retention are clearly shown in the gas retention curves for the nonconvective composite and the whole tank composite, Figures 5.15 and 5.16, respectively. The maximum growth fraction in the nonconvective sample, 0.30 , was about three times that of the whole tank composite growth fraction, 0.092 . The ideal gas law technique for estimating initial void content was applied to the gas retention data shown in Figures 5.15 and 5.16, and an initial void fraction of 0.016 was calculated for both nonconvective and whole tank composite samples. Correcting the maximum growth data for this apparent initial void content results in only slightly higher maximum void fractions of 0.31 for the nonconvective sample and 0.11 for the whole tank composite. The differences in maximum retention for the two waste samples is the result of the variations in the amounts of supernatant liquid present in the samples and the apparent settled solids layer densities.

Using a supernatant liquid (convective layer) density of $1.44 \mathrm{~g} / \mathrm{mL}^{(\text {(a) }}$ and the initial volume of the free liquid layer in each gas retention sample, the initial densities of the settled solids layers were computed. These densities, $1.78 \mathrm{~g} / \mathrm{mL}$ for the nonconvective composite and $1.64 \mathrm{~g} / \mathrm{mL}$ for the whole tank composite, were used to estimate the growth fraction to the point of neutral buoyancy within the solids-containing layers. For the whole tank composite, the predicted growth to buoyancyinduced rollover is $12 \%$, just slightly higher than the observed maximum growth of $9.2 \%$. It is reasonable to expect the rollover event to occur at lower void fraction than predicted as local variation of gas content could lead to partial sample buoyancy. Contradictory to this early release scenario, the nonconvective composite was expected to be buoyant after $19 \%$ growth, but the sample achieved a $30 \%$ maximum growth before gas was released. The difference in these results is due to the absence of a thick supernatant in the nonconvective sample.

In the nonconvective sample, the free liquid layer was a thin $0.2 \mathrm{~cm}$, corresponding to about $4 \%$ of the total sample volume. This liquid layer was not sufficiently thick to support a buoyancyinduced rollover event. This result is in good agreement with observations of the gas release from the sample. After retaining a large gas fraction, the supernatant liquid eroded the surface of the settled solids layer, providing a release path for gas bubbles entrapped in the waste. Ultimately, the combination of liquid infiltration, continued erosion, and gas bubble expansion resulting from pressure reductions led to a large fractional release of gas.

In the whole tank composite sample, a rollover event was clearly observed. Prior to the attainment of the maximum gas retention and the rollover event, some individual gas bubbles were seen to release at the free liquid-solids interface. This event is indicated in Figure 5.16 at a pressure of about $100 \mathrm{~mm} \mathrm{Hg}$ (1/pressure $\sim 0.07 \mathrm{kPa}^{-1}$ ). When pressure was reduced further to the point of

(a) PR Bredt and SM Tingey (1996) measured and reported this density for a SY-103 convective layer sample. 


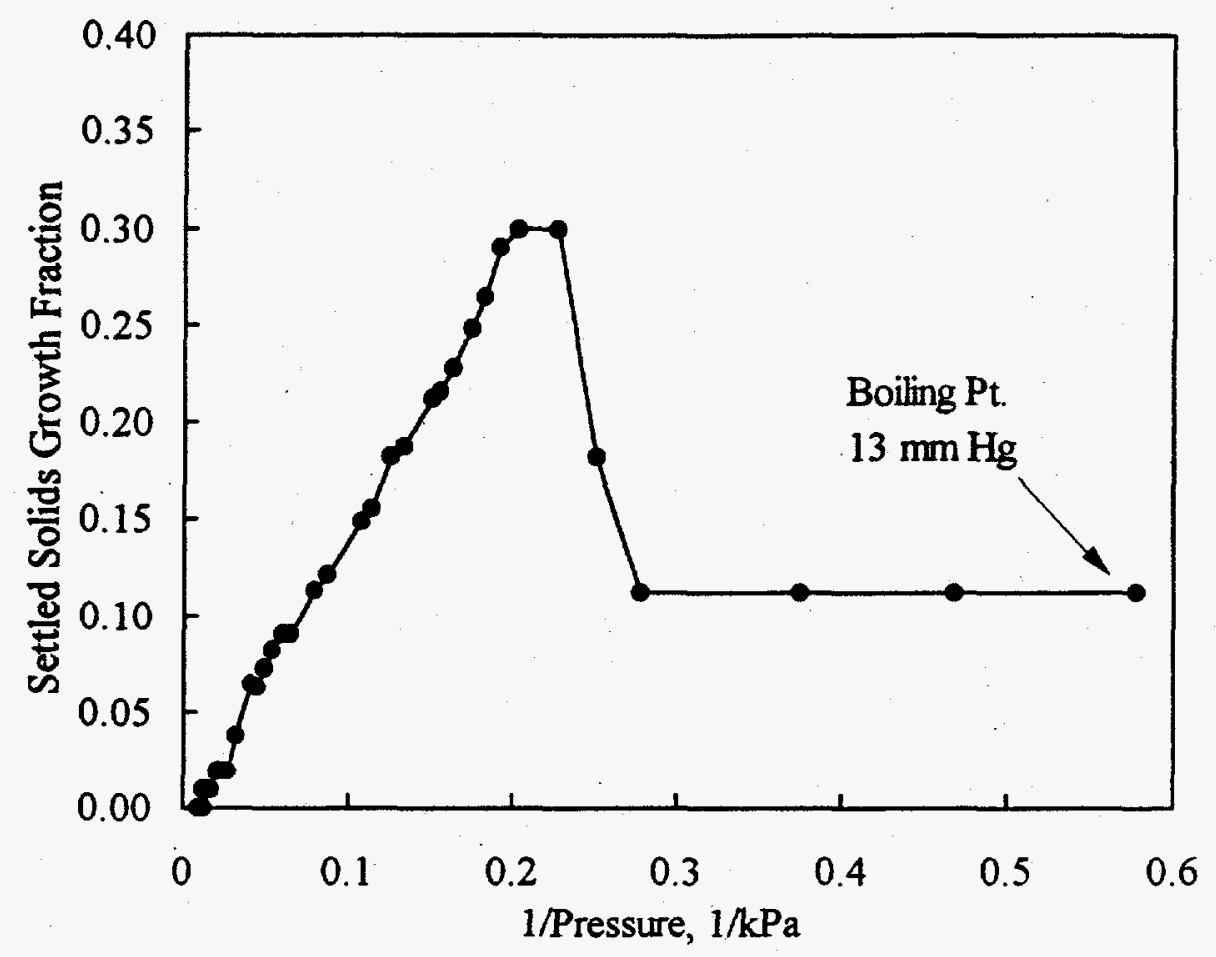

Figure 5.15. SY-103 Nonconvective Composite Gas Retention Curve

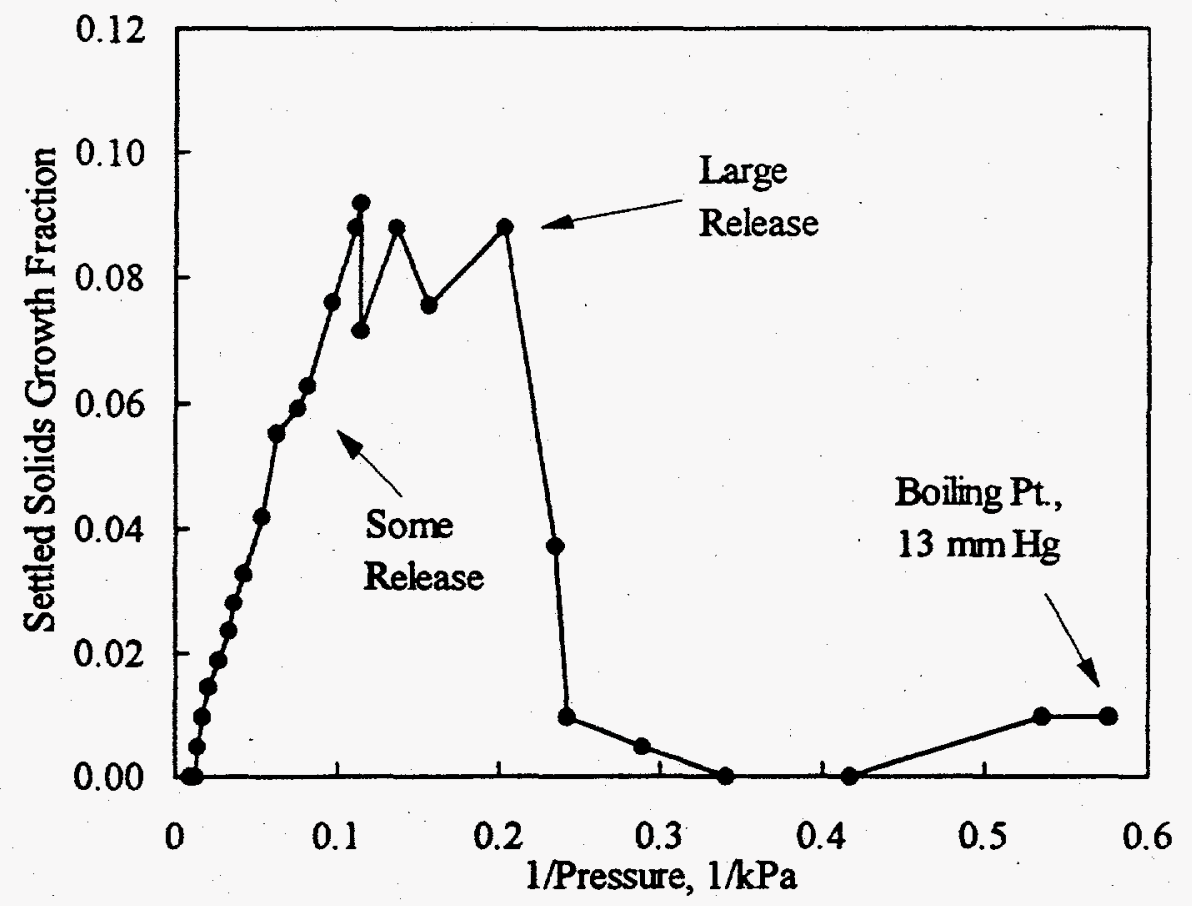

Figure 5.16. SY-103 Whole Tank Composite Gas Retention Curve 
maximum retention, a large cloud of bubbly waste released into the supernatant liquid layer, indicative of the buoyancy-induced rollover release mechanism. The free liquid layer in the whole tank composite sample was $-3.6 \mathrm{~cm}$ thick or $25 \%$ of the total sample volume, and this liquid fraction is clearly sufficient for a buoyancy-induced rollover gas release.

These data are summarized in Figure 5.17 along with data obtained in earlier experiments by Bredt and Tingey (1996) for comparable SY-103 whole tank composite samples. The definition of void fraction presented in the earlier study on the effect of dilution on gas retention is different than the settled solids growth fraction used here, so it was necessary to reevaluate the original data sources ${ }^{(t)}$ in the preparation of the figure. The figure shows good agreement between the whole tank composite results of the present (April 1996) and earlier (October 1995) work. Two whole-tank composite samples were investigated in the earlier study. One of these had a thick free liquid layer (35\% supernatant), and it was observed to roll over after reaching a maximum solids layer growth of $9.0 \%$. This is nearly equal to the predicted rollover growth of $9.8 \%$. The other whole tank composite sample in the earlier investigation had a thinner liquid layer ( $10 \%$ supernatant), and it attained more than $14 \%$ growth. (The maximum retention was not measured in this case because the vacuum system in the earlier study was not set up or intended to handle the vacuum pressures necessary to achieve gas release.) As with the nonconvective composite sample, the whole tank composite sample having a relatively thin supernatant liquid layer attained a maximum growth exceeding that predicted for buoyancy-induced rollover $(12 \%)$.

It is apparent from the results summarized in Figure 5.17 that the thickness of the supernatant liquid layer affects both the magnitude of the maximum retention relative to that predicted for a buoyancy-induced rollover and the mechanism of gas release (rollover or other). The role of settled solids layer density on maximum gas retention is not completely understood. The density is used to predict the gas retention to buoyancy, and for a given supernatant liquid there is a monotonic increase in predicted retention with increasing density. What is less clearly understood is the role of sample compaction (and its tie to strength) on the ability of the waste to retain gas beyond the rollover prediction in cases where insufficient free liquid is present to support a rollover event. Additional studies are needed to help elucidate the importance of waste settling and compaction on flammable gas retention.

(a) The data are contained in Laboratory Record Book BNW 55817, and the project record video tapes cited in Bredt and Tingey (1996). 


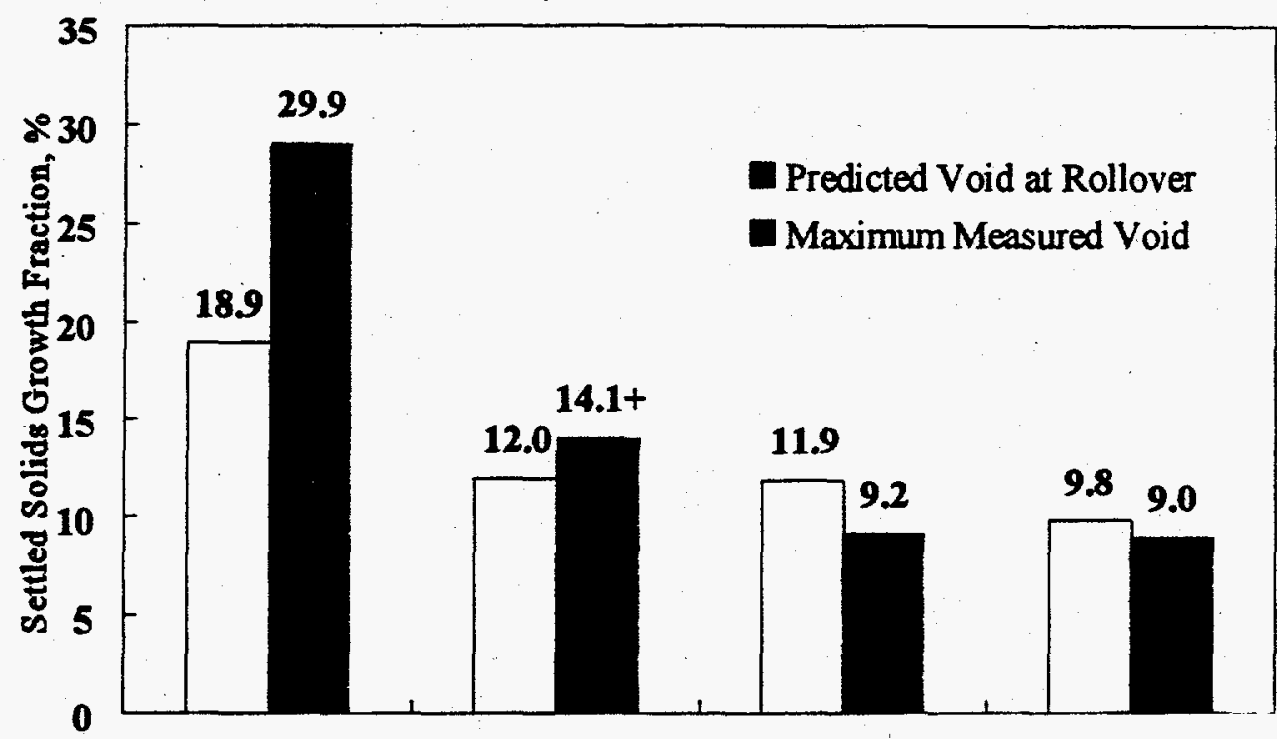

Nonconvective Whole Tank Whole Tank Whole Tank Composite, 4/96 Composite, 10/95 Composite, 4/96 Composite, 10/95 $\begin{array}{llll}1.78 & 1.64 & 1.64 & 1.60\end{array}$ Increasing Apparent Initial Settled Solids Density, $\mathrm{g} / \mathrm{mL}$
$4 \%$
$10 \%$
$25 \%$
$35 \%$
Increasing Supernatant Liquid Volume Fraction

Figure 5.17. Summary of SY-103 Maximum Gas Retention Results 


\subsection{Bubble Retention Mechanisms: Summary and Comparison of Results}

Our approach to quantifying bubble retention mechanisms in this and previous studies (Gauglitz et al. 1994, 1995) is to investigate the behavior of retained bubbles in actual waste and in a broad range of waste simulants. The studies in the waste simulants are used to provide a general picture of the range of expected behavior and how this behavior scales with waste properties. The actual waste behavior is then compared with the simulant behavior to highlight both similarities and differences. In the previous two sections, the mechanisms of bubble retention in simulants and actual waste samples have been discussed in detail. In this section, we present our current understanding of bubble retention mechanisms through a summary comparison of all currently available actual waste results and simulant results on bubble shapes and maximum retention. For the comparison of bubble shapes, we have selected results that are typical to each of a number of specific situations, rather than seeking to report all the subtle variations on the general themes. For both the bubble shapes and maximum retention, we have resorted to making approximate (order of magnitude) estimates of the actual waste physical properties to facilitate grouping of the comparisons. While we believe our estimates of physical parameters are reasonable, they are largely based on qualitative visual observations; however, these observations are independent of the bubble shape observations. The observations of retained bubble shapes will be discussed first followed by a comparison of the maximum retention results.

The shape of retained bubbles corresponds directly to the mechanisms of bubble retention. As described in Section 3, competition between the forces acting on the bubbles governs the behavior of the bubbles, their shape, and thus the retention mechanism. While the range of behavior is large, distinct regimes of bubble retention behavior occur, as described in Section 3, and we will use these regimes as a classification scheme for bubble retention mechanisms.

Figure 6.1 summarizes the bubble retention mechanisms for essentially all of the results currently available. This summary is structured around a plot with the three dimensionless groups discussed in Section 3.1 that determine the mechanism of bubble retention. The solid curve on the plot denotes the transition between particle displacing bubbles and interstitial liquid displacing bubbles. The square symbols overlaying this curve are data for the location of the transition as reported by Gauglitz et al. (1995) for glass bead simulants. Surrounding this plot are images of retained bubbles reported in this work and described in previous studies (Bredt and Tingey 1996; Bredt et al. 1995; Gauglitz et al. 1994, 1995). The bubble images are taken from experiments with simulants and with actual waste. The dimensionless groups shown on the axis of the plot contain a number of parameters. As mentioned above, it is difficult to measure all these parameters for each experiment, but it is possible to make reasonable estimates. Each retained bubble image has an arrow showing the approximate location on the plot. The axes for the plot have quantitative scales, so the plot is a quantitative expression of the bubble retention mechanisms. In most cases, the arrows point to circles on the graphs to indicate that our estimates are uncertain. 
In each location on the plot, the images of retained bubbles in actual waste and simulants are quite similar. Starting on the left side of the plot for sludges (particle displacing bubbles), the stiff S-102 sludge shows slit-shaped bubbles that are visually equivalent to the slit-shaped bubbles observed in the 1040-Pa bentonite clay. For the softer S-102 sludge, the retained bubbles were distorted from spherical, but were not as slit-shaped as the stiffer sludge; behavior that lies between that of the round bubbles seen in the 67-Pa bentonite clay and the slit-shaped bubbles observed in 1040-Pa bentonite clay. The SY-103 waste samples studies in this work and by Bredt and Tingey (1996) and the SY-101 waste sample studied by Bredt et al. $(1995)^{(a)}$ were all weak materials with very fine particles. While the original waste samples had moderate strengths, these samples were composites prepared for laboratory testing, and the strength had been degraded. These samples would pour somewhat easily, so they are located on the lower left region of the plot corresponding to weak particle-displacing bubbles. The round bubbles observed in all these actual waste samples correspond to the round bubbles observed in the weak bentonite clays $(6.7$ to $67 \mathrm{~Pa})$.

The S-102 salt cake samples allowed us to observe bubble retention in actual waste with a distinctly particulate character. The images of bubbles in the S-102 salt cake show the bubbles displacing the particles, which is expected for these small samples having a shallow depth (h). In the case of $15 \%$ void, the retained bubbles in the S-102 are distorted from spherical but are qualitatively similar to the image of bubbles displacing $0.2 \mathrm{~mm}$ beads. At the higher void fraction of $45 \%$, the bubbles in the S-102 salt cake appear more dendritic; this may result from this sample being close to the transition between particle-displacing and interstitial liquid-displacing bubbles (farther to the right on the plot), or the strength of the sample may be affecting the bubble shape (farther upward on the plot). The final image is a dendritic bubble in a $1-\mathrm{mm}$ beadpack that has displaced the interstitial liquid. While we fully believe that salt cake waste such as these S-102 samples will retain interstitial-liquid-displacing (dendritic) bubbles, the existing laboratory studies have used samples that are too small (h too small on $\mathrm{x}$-axis) to readily observe this behavior.

The maximum retention of gas bubbles also provides information on the mechanism of bubble retention. Figure 6.2 shows a comparison of the maximum retention results for the actual waste and bentonite clays. The strength of the actual waste samples was estimated independently (from waste behavior during one extrusion and in sample transfers) and the range bars for this data represent the order of magnitude span of these estimates. The S-102 sludge-like material and the SY-103 composite samples were clearly fine-particle materials and can reasonably compared to the bentonite clays. The S-102 salt cake samples, while clearly particulate in character, retained particle-displacing bubbles, so these results are included in this comparison with the sludge-like materials.

(a) The video images of bubbles in SY-101 waste were taken from experiments that were a continuation of those described in Bredt et al. (1995). While generally similar, the specifics of these experiments differ, and the details have not previously been reported. In the context of the bubble retention studies, the primary difference was that the SY-101 sample was maintained at the hot cell temperature rather than at the actual tank temperature 
Bentonite clay

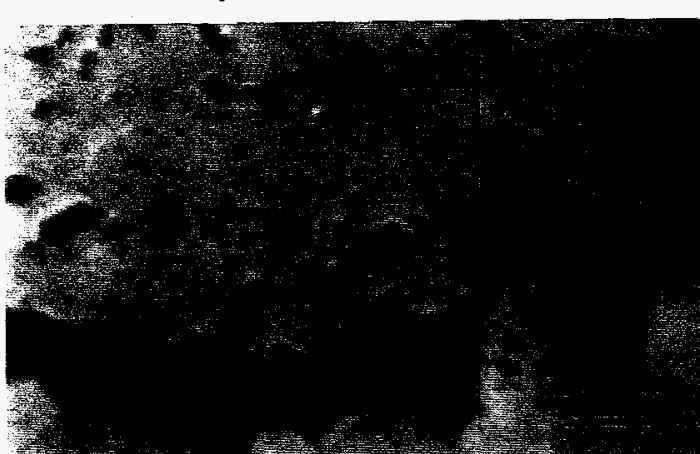

S-102 soft sludge
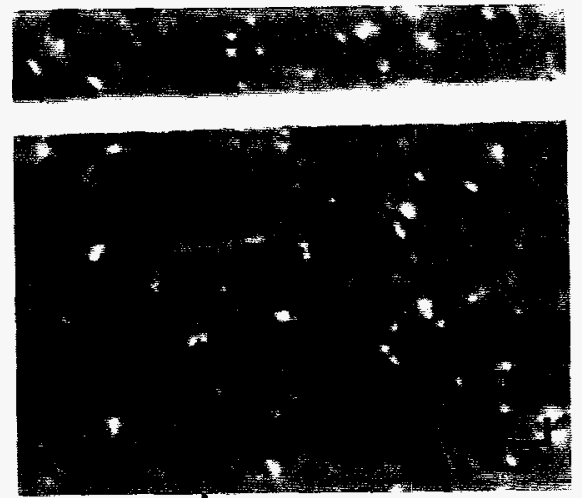

S-102 stiff sludge

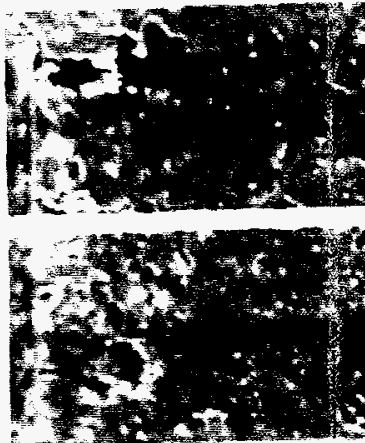

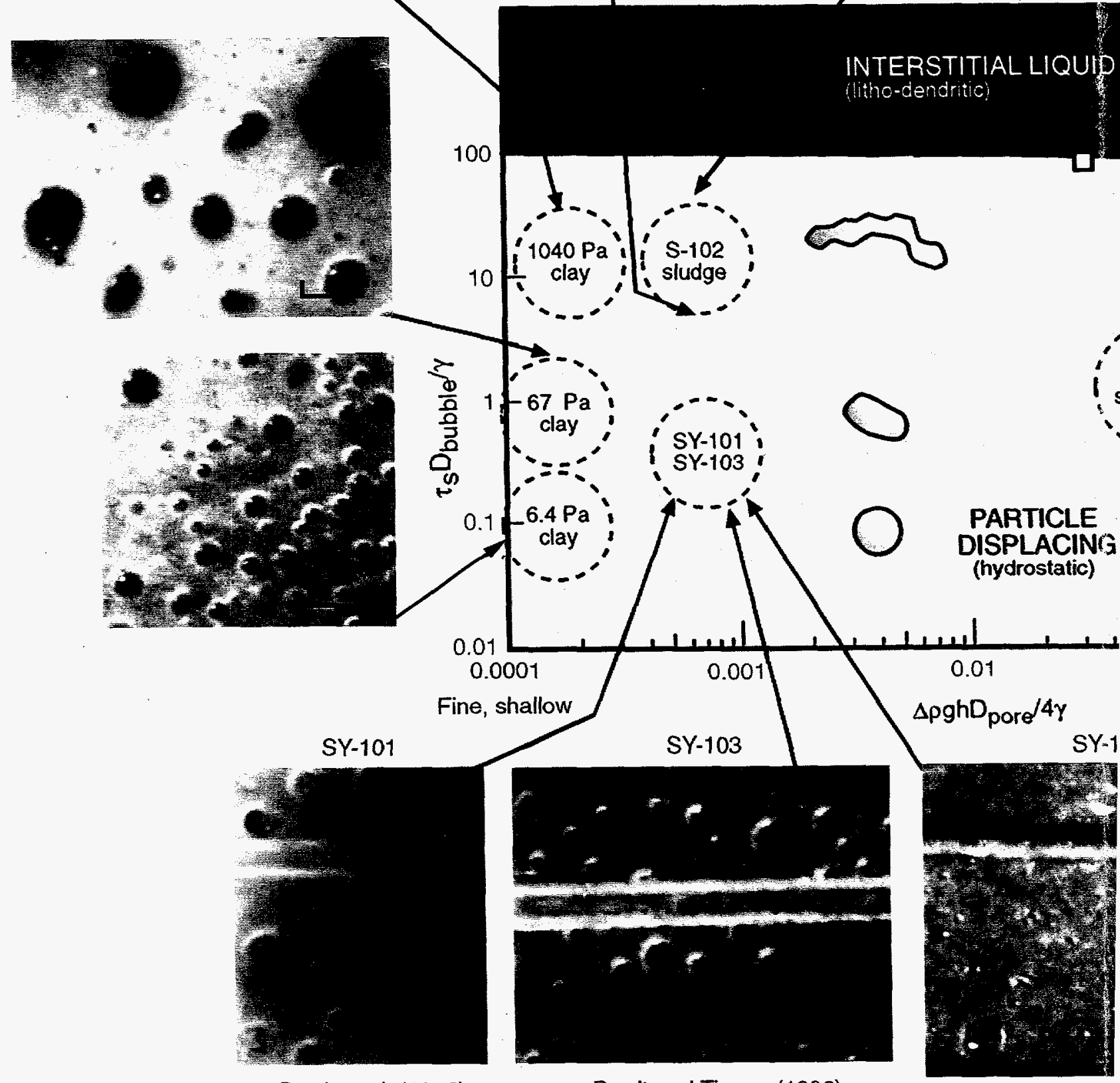

Bredt et al. (1995)

Bredt and Tingey (1996) 
crats

$+3 x^{2}$

bst. a. $b=$ $3 / y^{2}-4-4$ $+3,3+4$ 14toly
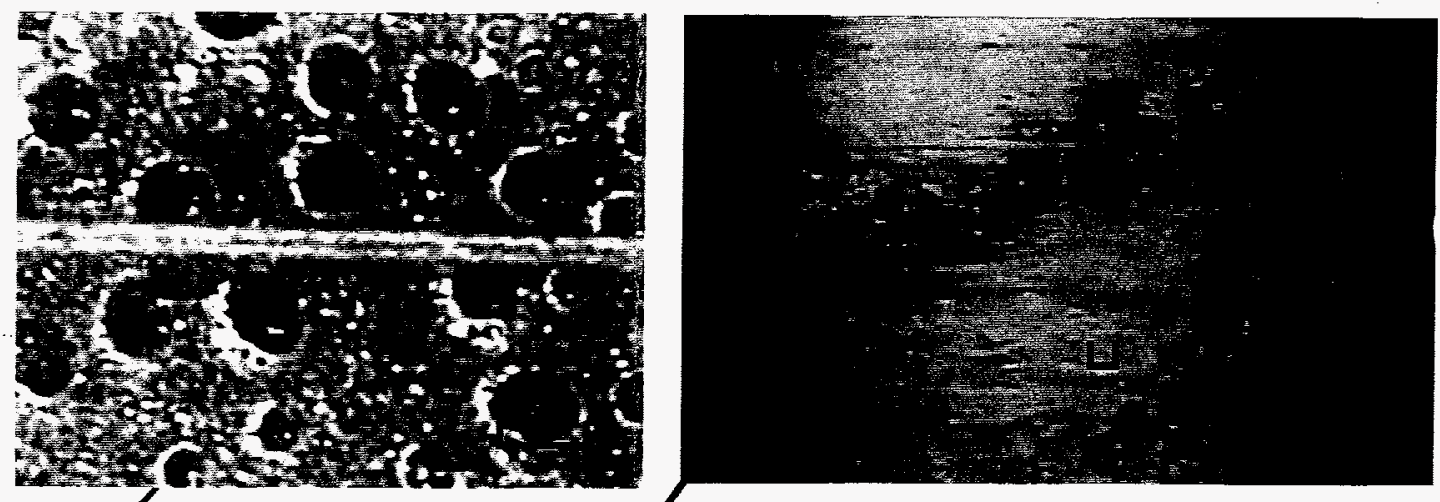

$322 \%$ void

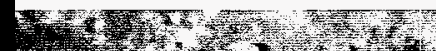

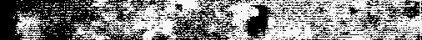

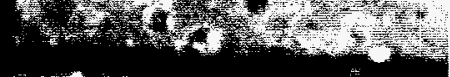

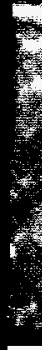

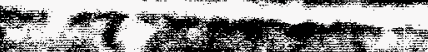
7 (3)

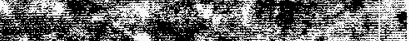

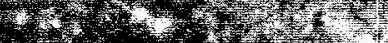

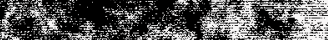

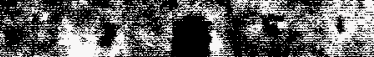

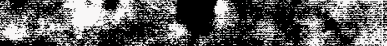

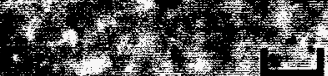

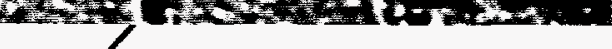

0.01 Weak

10

Coarse, deep

S-102 salt, cake $15 \%$ void

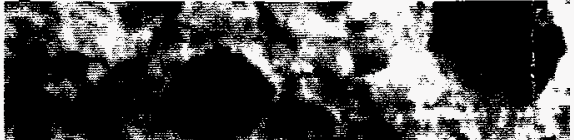

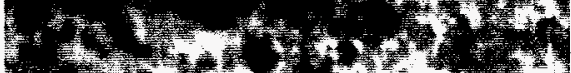
3) T.

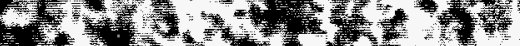

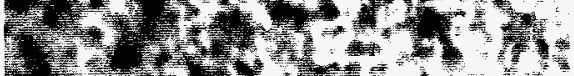

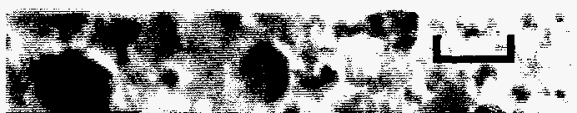

S-102 salt cake $45 \%$ void
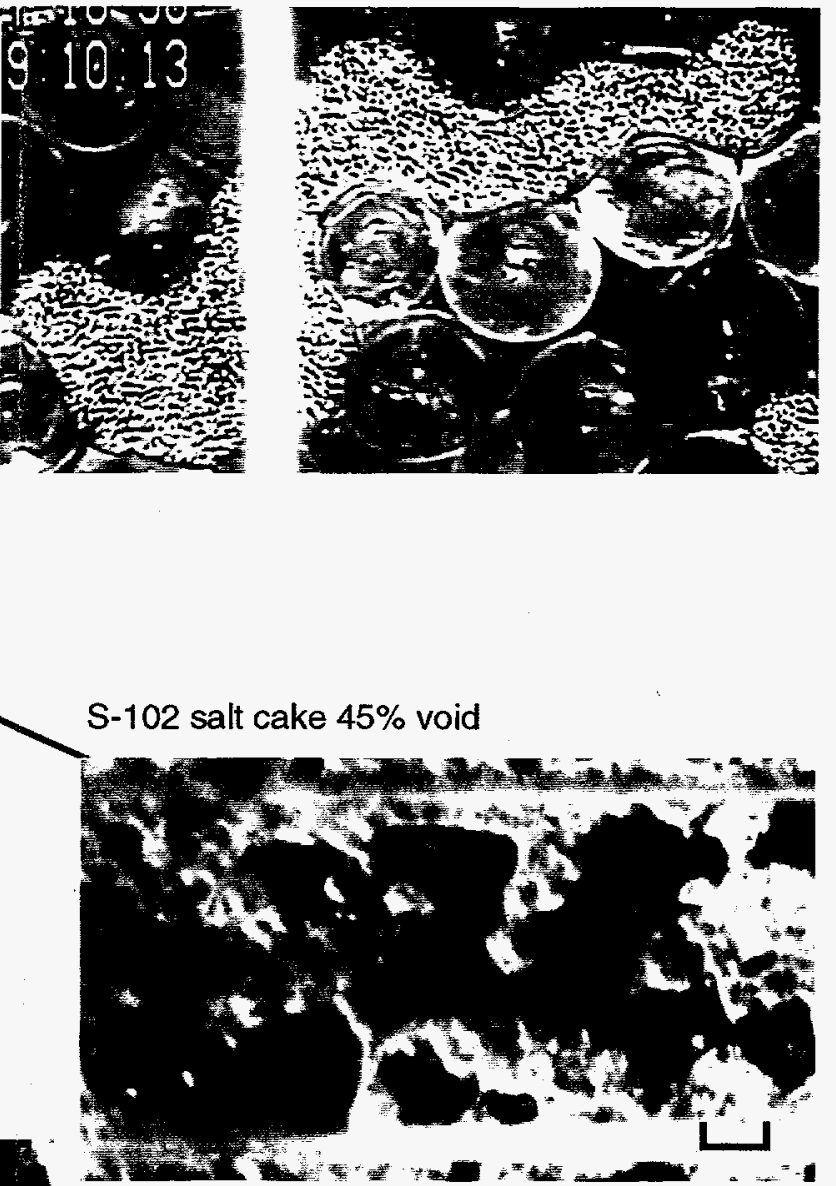

Figure 6.1

Gas-Bubble Retention Mechanisms

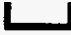

$1 \mathrm{~mm}$ 


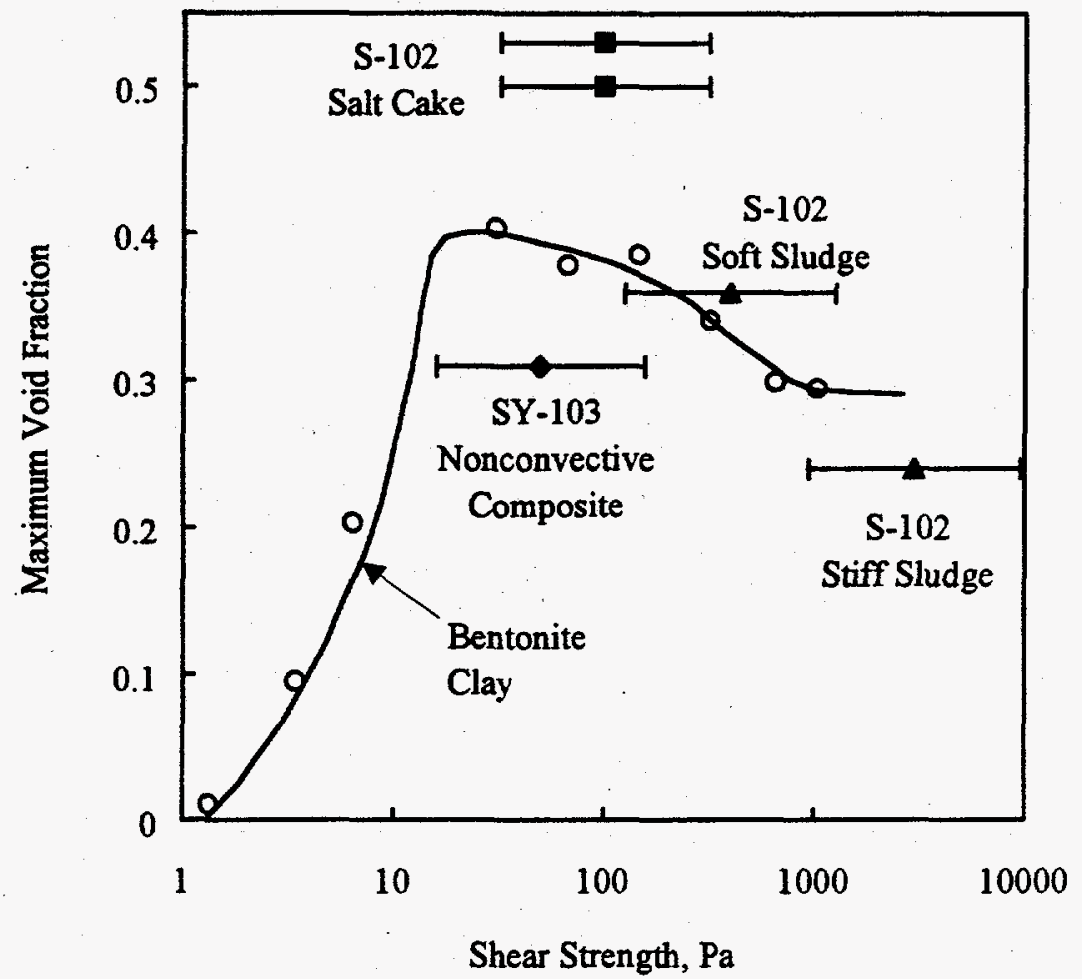

Figure 6.2. Comparison of the Maximum Retention in Actual Waste Samples with the Results for Bentonite Clay Simulants

The actual waste materials show a wide range of maximum retention, spanning from $20 \%$ void for the stiff S-102 sludge to about 50\% void for the S-102 salt cake. This range is somewhat larger than bentonite clay results. The $20 \%$ void maximum retention in the stiff S-102 sample, while lower than bentonite clay results, agrees with the trend (beyond the maximum) of decreasing maximum retention with increasing strength: As discussed in Section 3, slit-shaped bubbles are expected to form a connected path (maximum retention) at a gas fraction which is lower than when round bubbles form a connected path. Because the stiff S-102 sample retained slit-shaped bubbles, which are similar to the bubbles in the 1040-Pa bentonite clay, the lower maximum retention agrees with our expectation. The $45 \%$ to $50 \%$ maximum retention for the S-102 salt cake samples, while greater than the bentonite clay results, shows reasonable similarity between the simulant and actual waste. The bubbles retained in the salt cake samples were less round than bubbles in bentonite clay, and this is likely caused by either the strength or the particulate character of the S-102 salt cake.

These results for maximum retention for both the actual SST waste samples and the bentonite clay show higher values than are generally found in the actual waste tanks (see Tables 2.1 and 2.2). This implies that there are release mechanisms in the actual tanks (specifically those without continuing level rise) that are not represented in our relatively small and rapid laboratory experiments. 
In the actual tanks, the time scale is much longer and the size scale is much larger. It is possible that what appeared to be upward creeping of bubbles in the intermediate length (time) studies of Bredt and Tingey (1996) may be one of the release mechanisms that is important on the scale of the actual tank. Understanding the long-time-scale behavior of bubble retention and release is an area in need of further study.

In summary, while there are a number of differences between retained bubbles in the actual waste samples and in the simulants, there are also reasonable similarities between observed bubble shapes and maximum retention. These similarities, however, require that the waste materials, and concomitant bubble retention mechanisms, be classified into different regimes. The dimensionless groups that form the basis of this classification scheme were discussed in Section 3. Because of the similarities between bubble retention in actual wastes and equivalent simulants, we believe this classification scheme is a valid basis for quantifying the bubble retention mechanisms. While the results currently available support this classification scheme, there are a number of major actual waste types (Hanlon 1995) that have not been studied. Accordingly, this classification scheme should be considered preliminary, and as additional results become available on retained bubbles in different waste materials (types), should be refined. 


\subsection{Conclusions}

Several of the waste storage tanks at Hanford have been placed on the Flammable Gas Watch List because they are known or suspected, in all but one case, to retain flammable gases. Because of their flammability, the retention and episodic release of these gases pose a number of safety concerns. Understanding the physical mechanisms and waste properties that contribute to the retention and release of these gases will help to resolve the safety issues. The focus of this study was to quantify the pertinent mechanisms of gas bubble retention and release. The study has two major components: bubble retention studies in actual waste materials from S-102 and SY-103, and studies of bubble retention in simulants. Following are the major conclusions of this work:

- The mechanisms of bubble retention were quantified as a classification scheme basis on three dimensionless groups. While there are a number of differences between retained bubbles in the actual waste samples and in the simulants, there is also reasonable similarity between observed bubble shapes and maximum retention. Because of this similarity, we believe this is a valid classification scheme for quantifying the bubble retention mechanisms.

- The shapes of retained bubbles were found to depend strongly on the waste material. For fine particle materials, the bubbles transitioned from round bubbles in weak materials (SY-103 and SY-101 settled solids), to distorted bubbles in moderate strength materials (soft sludge from S-102), to slit-shaped in stiff materials (stiff sludge from S-102). Retained bubbles in S-102 salt cake displaced the waste particles and were distorted from spherical.

- The maximum retention of gas bubbles provides information on the mechanism of bubble retention. The actual waste materials show a wide range of maximum retention, spanning from $20 \%$ void for the stiff S- 102 sludge to about $50 \%$ void for the S-102 salt cake. Results for bentonite clay simulants agree with this range of maximum retention and show a similar trend of decreasing maximum retention with increasing strength for the range of materials tested.

- A variety of gas release mechanisms were observed in the actual waste samples, and the results for bentonite clay simulants generally agree with these results. With an SY-103 sample having a thick supernatant layer, a small-scale rollover event was observed. In the absence of a supernatant layer, no mechanism was found that gave large and rapid gas releases when the waste strength was sufficiently large. Instead, gas bubbles connected and formed continuous paths that allowed gas to release continuously at the same rate as it was being generated. Accordingly, we anticipate that tanks with strong sludge-like materials and little or no supernatant will probably not have GREs that pose flammable gas safety concerns. 


\subsection{References}

Allemann, RT, ZI Antoniak, JR Friley, CE Haines, LM Liljegren, and S Somasundaram. 1990. Mechanistic Analysis of Double-Shell Tank Gas Release--Progress Report, November. PNL7657, Pacific Northwest Laboratory, Richland, Washington.

Brager, HR. 1994. Summary of Information of Flammable Gas Watch List Tanks. WHC-EP-0711, Westinghouse Hanford Company, Richland, Washington.

Bredt, PR, and SM Tingey. 1996. The Effect of Dilution on the Gas Retention Behavior of Tank 241-SY-103 Waste. PNL-10893, Pacific Northwest National Laboratory, Richland, Washington.

Bredt, PR, SM Tingey, and EH Shade. 1995. The Effect of Dilution on the Gas-Retention Behavior of Tank 24I-SY-101 Waste. PNL-10781, Pacific Northwest Laboratory, Richland, Washington.

Brevic, CH. 1993. Data Collection and Analysis for Specific Single-Shell Tanks. WHC-SDWM-ER-210 Rev. 0, Kaiser Engineers Hanford, Richland, Washington.

Dullien, FAL. 1992. Porous Media: Fluid Transport and Pore Structure. Academic Press, San Diego.

Fox, GL, DD Stepnewski, and RP Anantatmula. 1993. Tank 241-SY-103 Hazard Assessment. WHC-SD-WM-SAR-061, Westinghouse Hanford Company, Richland, Washington.

Gauglitz, PA, SD Rassat, MR Powell, RR Shah, and LA Mahoney. 1995. Gas Bubble Retention and its Effect on Waste Properties: Retention Mechanisms, Viscosity, and Tensile and Shear Strength. PNL-10740, Pacific Northwest Laboratory, Richland, Washington.

Gauglitz, PA, LA Mahoney, DP Mendoza, and MC Miller. 1994. Mechanisms of Gas Bubble Retention. PNL-10120, Pacific Northwest Laboratory, Richland, Washington.

Hanlon, BM. 1995. Waste Tank Summary Report for Month Ending August 31, 1995. WHC-EP0182-89, Westinghouse Hanford Company, Richland, Washington.

Hansen, DR, SG Metcalf, and KW Johnson. 1995. Tank Characterization Report for Double-Shell Tank 241-SY-103. WHC-SD-DP-074, Westinghouse Hanford Company, Richland, Washington.

Hodgson, KM, RP Anantatmula, SA Barker, KD Fowler, JD Hopkins, JA Lechelt, and DA Reynolds. 1995. Evaluation of Hanford Tanks for Trapped Gas. WHC-SD-WM-ER-526 Rev. 0, Westinghouse Hanford Company, Richland, Washington. 
Hopkins, JD. 1994. Criteria for Flammable Gas Watch List. WHC-EP-0702 Rev. 0, Westinghouse Hanford Company, Richland, Washington.

Hopkins, JD. 1995. Methodology for Flammable Gas Evaluations. WHC-SD-WM-T1-724, Westinghouse Hanford Company, Richland, Washington.

LANL Technology and Safety Assessment Division. 1996. A Safety Assessment of Rotary Mode Core Sampling in Flammable Gas Single Shell Tanks: Hanford Site, Richland, Washington. WHCSD-WM-SAD-035 Rev. 0, Westinghouse Hanford Company, Richland, Washington.

Rassat, SD, and PA Gauglitz. 1995. Bubble Retention in Synthetic Sludge: Testing of Alternative Gas Retention Apparatus. PNL-10661, Pacific Northwest Laboratory, Richland, Washington.

Shepard, CL, CW Stewart, JM Alzheimer, TI Stokes, G Terrones, G Chen, and NE Wilkins. 1995. In Situ Determination of Rheological Properties and Void Fraction: Hanford Waste Tank 241-SY103. PNL-10865, Pacific Northwest Laboratory, Richland, Washington.

Spore, JW. 1996. Conservative Gas Releases for Tank 241-A-101. Los Alamos National Laboratory Calc-Note, TSA10-CN-WT-SA-GR-046.

Stauffer, D. 1985. Introduction to Percolation Theory. Taylor and Francis, London.

Stewart, CW, CL Shepard, JM Alzheimer, TI Stokes, and G Terrones. 1995. In Situ Determination of Rheological Properties and Void Fraction in Hanford Waste Tank 241-SY-101. PNL-10682, Pacific Northwest Laboratory, Richland, Washington.

Stewart, CW, JM Alzheimer, ME Brewster, RE Mendoza, HC Reid, CL Shepard, and G Terrones. 1996. In Situ Rheology and Gas Volume in Hanford Double-Shell Waste Tanks. PNNL-11296, Pacific Northwest National Laboratory, Richland, Washington.

Tingey, JM, PR Bredt, and EH Shade. 1994. The Effects of Heating and Dilution On the Rheological and Physical Properties of Tank 241-SY-101 Waste. PNL-10198, Pacific Northwest Laboratory, Richland, Washington.

Walker, DD, CL Crawford, and NE Bibler. 1994. "Radiolytic Bubble Formation and Level Changes in Simulated High-Level Waste Salts and Sludges - Application to HLW Storage Tanks." Proceedings of Waste Management 1994, Tucson, Arizona, pp. 393-396.

Whitney, P. 1995. Screening the Hanford Tanks for Trapped Gas. PNL-10821, Pacific Northwest Laboratory, Richland, Washington.

Wilkins, NE. 1995. Tank 241-SY-103 Core Sample: Interpretation of Results. WHC-SD-WM-TI712, Westinghouse Hanford Company, Richland, Washington. 
Appendix A

Simulant Bubble Retention Data 
Table A.1. Gas Retention Data for a 0.3-Pa Clay (33-cm initial height and 2.64-cm tube diameter)

\begin{tabular}{||c|c|c|c|c|}
\hline $\begin{array}{c}\text { Elapsed } \\
\text { Time, min }\end{array}$ & $\begin{array}{c}\text { Volume Gas } \\
\text { Generated, } \mathrm{mL}\end{array}$ & $\begin{array}{c}\text { Sludge } \\
\text { Height, cm }\end{array}$ & $\begin{array}{c}\text { Sludge } \\
\text { Volume, mL }\end{array}$ & $\begin{array}{c}\text { Sludge Gas } \\
\text { Volume Fraction }\end{array}$ \\
\hline \hline 0 & 0 & 33.0 & 180.7 & -0.0065 \\
\hline 48 & 26 & 33.3 & 182.5 & 0.0031 \\
\hline
\end{tabular}

Table A.2. Gas Retention Data for a 1.3-Pa Clay (31.6- $\mathrm{cm}$ initial height and 2.64-cm tube diameter)

\begin{tabular}{|c|c|c|c|c|}
\hline $\begin{array}{c}\text { Elapsed } \\
\text { Time, min }\end{array}$ & $\begin{array}{c}\text { Volume Gas } \\
\text { Generated, } \mathrm{mL}\end{array}$ & $\begin{array}{c}\text { Sludge } \\
\text { Height, } \mathrm{cm}\end{array}$ & $\begin{array}{c}\text { Sludge } \\
\text { Volume, } \mathrm{mL}\end{array}$ & $\begin{array}{c}\text { Sludge Gas } \\
\text { Volume Fraction }\end{array}$ \\
\hline \hline 0 & 0 & 31.6 & 172.9 & 0.001 \\
\hline 90 & 69 & 31.9 & 174.7 & 0.010 \\
\hline
\end{tabular}


Table A.3. Gas Retention Data for a 3.4-Pa Clay (31.4-cm initial height and 2.64-cm tube diameter)

\begin{tabular}{|c|c|c|c|c|}
\hline $\begin{array}{c}\text { Elapsed Time, } \\
\text { min }\end{array}$ & $\begin{array}{l}\text { Volume Gas } \\
\text { Generated, } \mathrm{mL}\end{array}$ & $\begin{array}{c}\text { Sludge Height, } \\
\mathrm{cm}\end{array}$ & $\begin{array}{c}\text { Sludge Volume, } \\
\mathrm{mL}\end{array}$ & $\begin{array}{l}\text { Sludge Gas } \\
\text { Volume Fraction }\end{array}$ \\
\hline 0 & 0 & 31.4 & 172.1 & 0.009 \\
\hline 3 & 5 & 31.9 & 174.7 & 0.023 \\
\hline 6 & 10 & 32.4 & 177.3 & 0.038 \\
\hline 9 & 14.5 & 32.5 & 178.1 & 0.042 \\
\hline 12 & 17.5 & 32.7 & 179.0 & 0.047 \\
\hline 15 & 21 & 32.9 & 179.9 & 0.052 \\
\hline 19 & 26 & 32.7 & 179.0 & 0.047 \\
\hline 22 & 30 & 32.5 & 178.1 & 0.042 \\
\hline 25 & 34 & 32.7 & 179.0 & 0.047 \\
\hline 28 & 37 & 33.0 & 180.7 & 0.056 \\
\hline 31 & 39 & 33.5 & 183.4 & 0.070 \\
\hline 34 & 42 & 31.9 & 174.7 & 0.023 \\
\hline 38 & 46 & 31.9 & 174.7 & 0.023 \\
\hline 41 & 49 & 32.4 & 177.3 & 0.038 \\
\hline 47 & 55 & 33.3 & 182.5 & 0.065 \\
\hline 50 & 58 & 33.8 & 185.1 & 0.078 \\
\hline 53 & 60.5 & 34.0 & 186.0 & 0.083 \\
\hline 56 & 64 & 34.1 & 186.8 & 0.087 \\
\hline 59 & 66 & 32.7 & 179.0 & 0.047 \\
\hline 62 & 69 & 32.7 & 179.0 & 0.047 \\
\hline 67 & 74 & 32.1 & 175.5 & 0.028 \\
\hline 72 & 78.5 & 32.5 & 178.1 & 0.042 \\
\hline 77 & 83 & 33.0 & 180.7 & 0.056 \\
\hline 82 & 87 & 33.7 & 184.2 & 0.074 \\
\hline 87 & 92 & 34.1 & 186.8 & 0.087 \\
\hline 92 & 95 & 31.9 & 174.7 & 0.023 \\
\hline 99 & 99 & 32.4 & 177.3 & 0.038 \\
\hline 104 & 103 & 32.9 & 179.9 & 0.052 \\
\hline 111 & 108 & 33.8 & 185.1 & 0.078 \\
\hline 116 & 112 & 34.5 & 188.6 & 0.095 \\
\hline 121 & 114 & 34.5 & 188.6 & 0.095 \\
\hline 133 & 122 & 32.5 & 178.1 & 0.042 \\
\hline 143 & 128 & 32.5 & 178.1 & 0.042 \\
\hline 155 & 136.5 & 34.5 & 188.6 & 0.095 \\
\hline 165 & 140.5 & 32.2 & 176.4 & 0.033 \\
\hline 180 & 150 & 34.0 & 186.0 & 0.083 \\
\hline 213 & 163 & 32.7 & 179.0 & 0.047 \\
\hline 240 & 176 & 34.5 & 188.6 & 0.095 \\
\hline
\end{tabular}


Table A.4. Gas Retention Data for a 6.4-Pa Clay $(31.6-\mathrm{cm}$ initial height and 2.64-cm tube diameter)

\begin{tabular}{|c|c|c|c|c|}
\hline $\begin{array}{c}\text { Elapsed } \\
\text { Time, min } \\
\end{array}$ & $\begin{array}{l}\text { Volume Gas } \\
\text { Generated, } \mathrm{mL}\end{array}$ & $\begin{array}{c}\text { Sludge } \\
\text { Height, } \mathrm{cm}\end{array}$ & $\begin{array}{c}\text { Sludge } \\
\text { Volume, mL }\end{array}$ & $\begin{array}{c}\text { Sludge Gas } \\
\text { Volume Fraction }\end{array}$ \\
\hline 0 & 0 & 31.6 & 172.9 & -0.025 \\
\hline 3.5 & $\overline{9.5}$ & 32.5 & 178.1 & 0.005 \\
\hline 6 & 13 & 33.5 & 183.4 & 0.034 \\
\hline 9 & 17 & 34.0 & 186.0 & 0.047 \\
\hline 12 & $\overline{21}$ & 34.6 & 189.4 & 0.065 \\
\hline$\overline{15}$ & 25 & 35.2 & 192.9 & 0.081 \\
\hline 18 & 28.5 & 35.9 & 196.4 & 0.098 \\
\hline 21 & $\overline{32.5}$ & $\overline{36.5}$ & 199.9 & 0.113 \\
\hline 24 & 35 & 37.1 & 203.3 & 0.128 \\
\hline 27 & 39 & 37.8 & 206.8 & 0.143 \\
\hline$\overline{30}$ & 42.5 & 38.4 & 210.3 & 0.157 \\
\hline$\overline{33}$ & 46.5 & 39.1 & 213.8 & 0.171 \\
\hline$\overline{36}$ & 49 & 39.7 & 217.2 & 0.184 \\
\hline$\overline{39}$ & 52.5 & 40.3 & 220.7 & 0.197 \\
\hline$\overline{42}$ & 56.5 & 40.6 & 222.5 & 0.203 \\
\hline 45 & 59 & 39.8 & 218.1 & 0.188 \\
\hline$\overline{48}$ & 62.5 & $\overline{39.5}$ & 216.4 & 0.181 \\
\hline$\overline{51}$ & 64.5 & 33.2 & 181.6 & 0.024 \\
\hline$\overline{54}$ & $\overline{67}$ & 33.5 & 183.4 & $\overline{0.034}$ \\
\hline 57 & 70.5 & 34.0 & 186.0 & 0.047 \\
\hline 60 & $\overline{74.5}$ & 34.8 & 190.3 & 0.069 \\
\hline 63 & 77 & 35.7 & 195.5 & 0.094 \\
\hline 66 & 80.5 & 35.9 & 196.4 & 0.098 \\
\hline 69 & 83 & 34.9 & 191.2 & 0.073 \\
\hline 72 & 86.5 & 35.6 & 194.7 & 0.090 \\
\hline 75 & $\overline{88.5}$ & 35.2 & 192.9 & 0.081 \\
\hline 78 & 91 & 35.1 & 192.1 & 0.077 \\
\hline 83 & 95.5 & 34.5 & 188.6 & 0.060 \\
\hline 88 & 99 & 34.5 & 188.6 & 0.060 \\
\hline 93 & 103.5 & 34.9 & 191.2 & $\overline{0.073}$ \\
\hline 98 & 107.5 & $\overline{35.2}$ & 192.9 & 0.081 \\
\hline$\overline{103}$ & 111.5 & 36.0 & 197.3 & 0.102 \\
\hline 108 & 116.5 & 36.8 & 201.6 & 0.121 \\
\hline
\end{tabular}


Table A.4 (contd)

\begin{tabular}{||c|c|c|c|c||}
\hline $\begin{array}{c}\text { Elapsed } \\
\text { Time, min }\end{array}$ & $\begin{array}{c}\text { Volume Gas } \\
\text { Generated, } \mathrm{mL}\end{array}$ & $\begin{array}{c}\text { Sludge } \\
\text { Height, cm }\end{array}$ & $\begin{array}{c}\text { Sludge } \\
\text { Volume, mL }\end{array}$ & $\begin{array}{c}\text { Sludge Gas } \\
\text { Volume Fraction }\end{array}$ \\
\hline \hline 114 & 120.5 & 37.6 & 206.0 & 0.140 \\
\hline 120 & 125 & 38.3 & 209.4 & 0.154 \\
\hline 124 & 128.5 & 32.2 & 176.4 & -0.005 \\
\hline 134 & 133.5 & 33.2 & 181.6 & 0.024 \\
\hline 144 & 140.5 & 34.6 & 189.4 & 0.065 \\
\hline 154 & 146.5 & 35.9 & 196.4 & 0.098 \\
\hline 165.5 & 153.5 & 37.5 & 205.1 & 0.136 \\
\hline 175 & 159.5 & 38.4 & 210.3 & 0.157 \\
\hline 179 & 161.5 & 35.9 & 196.4 & 0.098 \\
\hline 189 & 165 & 32.4 & 177.3 & 0.000 \\
\hline 201 & 172 & 33.8 & 185.1 & 0.043 \\
\hline 215 & 181.5 & 35.1 & 192.1 & 0.077 \\
\hline 231 & 185.5 & 36.4 & 199.0 & 0.109 \\
\hline 245 & 190.5 & 37.5 & 205.1 & 0.136 \\
\hline
\end{tabular}


Table A.5. Gas Retention Data for a 31-Pa Clay (33.3-cm initial height and 2.64-cm tube diameter)

\begin{tabular}{|c|c|c|c|c|}
\hline $\begin{array}{l}\text { Elapsed } \\
\text { Time, min }\end{array}$ & $\begin{array}{l}\text { Volume Gas } \\
\text { Generated, } \mathrm{mL}\end{array}$ & $\begin{array}{c}\text { Sludge } \\
\text { Height, } \mathrm{cm}\end{array}$ & $\begin{array}{c}\text { Sludge } \\
\text { Volume, } \mathrm{mL}\end{array}$ & $\begin{array}{c}\text { Sludge Gas } \\
\text { Volume Fraction }\end{array}$ \\
\hline 0 & 0 & 33.3 & 182.5 & -0.010 \\
\hline 3 & 6.5 & 34.5 & 188.6 & 0.022 \\
\hline 6 & 12.5 & 35.6 & 194.7 & 0.053 \\
\hline$\overline{9}$ & 17 & 36.5 & 199.9 & 0.077 \\
\hline$\overline{12}$ & $\overline{23}$ & 37.5 & 205.1 & 0.101 \\
\hline 15 & 28.5 & 38.4 & 210.3 & 0.123 \\
\hline$\overline{18}$ & $\overline{33}$ & $\overline{39.4}$ & 215.5 & 0.144 \\
\hline$\overline{21}$ & 38.5 & 40.3 & 220.7 & 0.165 \\
\hline 24 & 43 & 41.3 & 225.9 & 0.184 \\
\hline 27 & 48.5 & 42.1 & 230.3 & 0.199 \\
\hline 30 & 53 & 43.0 & 235.5 & 0.217 \\
\hline$\overline{33}$ & 57.5 & 43.8 & 239.8 & 0.231 \\
\hline 36 & 62.5 & 44.6 & 244.2 & 0.245 \\
\hline 39 & 68 & 45.4 & 248.5 & 0.258 \\
\hline$\overline{42}$ & $\overline{71}$ & 46.4 & 253.7 & 0.273 \\
\hline$\overline{45}$ & 75.5 & 47.0 & 257.2 & 0.283 \\
\hline 48 & 79.5 & 47.8 & 261.6 & 0.295 \\
\hline 52 & 85 & 48.7 & 266.8 & 0.309 \\
\hline 55 & 89 & 49.5 & 271.1 & 0.320 \\
\hline 58 & 93 & 50.2 & 274.6 & 0.328 \\
\hline 61 & 96.5 & 51.0 & 279.0 & 0.339 \\
\hline 64 & 100.5 & $\overline{51.4}$ & 281.6 & 0.345 \\
\hline 67 & 104 & $\overline{52.2}$ & 285.9 & 0.355 \\
\hline 70 & 107 & 52.9 & 289.4 & 0.363 \\
\hline 73 & $\overline{111}$ & 53.7 & 293.7 & 0.372 \\
\hline 76 & 114.5 & $\overline{54.1}$ & 296.3 & 0.378 \\
\hline 79 & 118 & 54.8 & 299.8 & 0.385 \\
\hline 82 & $\overline{121}$ & 55.4 & 303.3 & 0.392 \\
\hline 85 & 124.5 & 55.9 & 305.9 & 0.397 \\
\hline 88 & 126.5 & $\overline{56.5}$ & 309.4 & 0.404 \\
\hline 91 & 130.5 & 55.9 & 305.9 & 0.397 \\
\hline$\overline{94}$ & 133.5 & 52.2 & 285.9 & 0.355 \\
\hline 97 & 136.5 & 51.4 & 281.6 & 0.345 \\
\hline
\end{tabular}


Table A.5 (contd)

\begin{tabular}{|c|c|c|c|c|}
\hline $\begin{array}{l}\text { Elapsed } \\
\text { Time, min }\end{array}$ & $\begin{array}{l}\text { Volume Gas } \\
\text { Generated, } \mathrm{mL}\end{array}$ & $\begin{array}{c}\text { Sludge } \\
\text { Height, } \mathrm{cm}\end{array}$ & $\begin{array}{c}\text { Sludge } \\
\text { Volume, } \mathrm{mL}\end{array}$ & $\begin{array}{c}\text { Sludge Gas } \\
\text { Volume Fraction }\end{array}$ \\
\hline 100 & 139 & 49.2 & 269.4 & 0.315 \\
\hline 103 & 141.5 & 49.2 & 269.4 & 0.315 \\
\hline 106 & 145 & 49.8 & 272.9 & 0.324 \\
\hline 109 & 147.5 & 50.3 & 275.5 & 0.331 \\
\hline 112 & 150.5 & 51.1 & 279.8 & 0.341 \\
\hline 115 & 153 & $\overline{51.6}$ & 282.4 & 0.347 \\
\hline 118 & 155 & 52.2 & 285.9 & 0.355 \\
\hline 121 & 157.5 & 52.7 & 288.5 & 0.361 \\
\hline 124 & 160.5 & 53.3 & 292.0 & 0.368 \\
\hline 127 & 163 & 54.0 & 295.5 & 0.376 \\
\hline 130 & 164.5 & 54.6 & 298.9 & 0.383 \\
\hline 133 & 167 & 55.1 & 301.5 & 0.388 \\
\hline 136 & 169 & 55.6 & 304.1 & 0.394 \\
\hline 139 & 171.5 & 55.9 & 305.9 & 0.397 \\
\hline 142 & 173.5 & 56.4 & 308.5 & 0.402 \\
\hline 144 & 175.5 & 49.1 & 268.5 & 0.313 \\
\hline 147 & 177 & 49.5 & 271.1 & 0.320 \\
\hline 150 & 179 & 50.3 & 275.5 & 0.331 \\
\hline 153 & $\overline{181}$ & 50.8 & 278.1 & 0.337 \\
\hline 156 & 183 & 51.0 & 278.9 & 0.339 \\
\hline 159 & 185 & 51.4 & 281.6 & 0.345 \\
\hline 162 & 187 & 51.9 & 284.1 & 0.351 \\
\hline 165 & 188.5 & 52.7 & 288.5 & 0.361 \\
\hline 173 & 192.5 & 53.7 & 293.7 & 0.372 \\
\hline 182 & 197.5 & 54.6 & 298.9 & 0.383 \\
\hline 191 & 202 & 55.6 & 304.1 & 0.394 \\
\hline 203 & 208 & 55.9 & 305.9 & 0.397 \\
\hline 212 & 211.5 & 47.6 & 260.7 & 0.293 \\
\hline 235 & 221.5 & 49.5 & 271.1 & 0.320 \\
\hline
\end{tabular}


Table A.6. Gas Retention Data for a 147-Pa Clay (31.6-cm initial height and 2.64-cm tube diameter)

\begin{tabular}{|c|c|c|c|c|}
\hline $\begin{array}{l}\text { Elapsed } \\
\text { Time, min }\end{array}$ & $\begin{array}{l}\text { Volume Gas } \\
\text { Generated, } \mathrm{mL}\end{array}$ & $\begin{array}{c}\text { Sludge } \\
\text { Height, } \mathrm{cm}\end{array}$ & $\begin{array}{c}\text { Sludge } \\
\text { Volume, } \mathrm{mL}\end{array}$ & $\begin{array}{c}\text { Sludge Gas } \\
\text { Volume Fraction }\end{array}$ \\
\hline 0 & $\overline{0}$ & 31.6 & 172.9 & 0.074 \\
\hline 2.5 & 5 & $\overline{32.4}$ & 177.3 & 0.097 \\
\hline 5.5 & $\overline{9.5}$ & 33.2 & 181.6 & 0.119 \\
\hline 8.5 & 14.5 & 33.8 & 185.1 & 0.135 \\
\hline 11.5 & 19 & 34.6 & 189.4 & $0: 155$ \\
\hline 14.5 & $\overline{23}$ & 35.2 & 192.9 & 0.170 \\
\hline 18.5 & 29 & 36.2 & 198.1 & 0.192 \\
\hline 23.5 & 35.5 & 37.5 & 205.1 & 0.219 \\
\hline 27.5 & 41 & 38.4 & 210.3 & 0.239 \\
\hline 31.5 & 45.5 & $\begin{array}{l}39.4 \\
\end{array}$ & 215.5 & 0.257 \\
\hline 35.5 & 51 & 40.2 & 219.9 & 0.272 \\
\hline 41.5 & 59 & $4 \overline{41.3}$ & 225.9 & 0.291 \\
\hline 46.5 & $\overline{65}$ & 42.1 & 230.3 & 0.305 \\
\hline 50.5 & 69.5 & 42.4 & 232.0 & 0.310 \\
\hline 56.5 & $\overline{78}$ & 43.5 & 238.1 & 0.328 \\
\hline 61.5 & 82.5 & 43.5 & 238.1 & 0.328 \\
\hline 67.5 & 88 & 44.1 & 241.6 & 0.337 \\
\hline 72.5 & 93.5 & 45.1 & 246.8 & 0.351 \\
\hline 77.5 & 99 & 45.7 & 250.3 & 0.360 \\
\hline 83.5 & 105 & 46.5 & $254: 6$ & 0.371 \\
\hline 89.5 & 111 & 46.5 & 254.6 & 0.371 \\
\hline 96.5 & 116.5 & 46.5 & 254.6 & 0.371 \\
\hline 105.5 & 124.5 & 47.1 & 258.1 & 0.380 \\
\hline 109.5 & 128 & 47.5 & 259.8 & 0.384 \\
\hline 113.5 & 131.5 & 47.6 & 260.7 & 0.386 \\
\hline 122.5 & 137.5 & 47.6 & 260.7 & 0.386 \\
\hline 143.5 & 149.5 & 47.6 & 260.7 & 0.386 \\
\hline 196.5 & 177 & 47.6 & 260.7 & 0.386 \\
\hline 244.5 & 193 & 47.6 & 260.7 & 0.386 \\
\hline
\end{tabular}


Table A.7. Gas Retention Data for a 323-Pa Clay (32.4-cm initial height and 2.64-cm tube diameter)

\begin{tabular}{|c|c|c|c|c|}
\hline $\begin{array}{l}\text { Elapsed } \\
\text { Time, min }\end{array}$ & $\begin{array}{l}\text { Volume Gas } \\
\text { Generated, } \mathrm{mL}\end{array}$ & $\begin{array}{c}\text { Sludge } \\
\text { Height, } \mathrm{cm}\end{array}$ & $\begin{array}{c}\text { Sludge } \\
\text { Volume, } \mathrm{mL}\end{array}$ & $\begin{array}{c}\text { Sludge Gas } \\
\text { Volume Fraction }\end{array}$ \\
\hline 0 & 0 & 32.4 & 177.3 & 0.093 \\
\hline 3 & 7.5 & 33.2 & 181.6 & 0.115 \\
\hline 6 & 13 & 34.1 & 186.8 & 0.139 \\
\hline 9 & 19 & 34.8 & 190.3 & 0.155 \\
\hline$\overline{12}$ & 23.5 & 35.7 & 195.5 & 0.178 \\
\hline 15 & 28.5 & 36.4 & 199.0 & 0.192 \\
\hline 18 & 33.5 & 37.3 & 204.2 & 0.213 \\
\hline 21 & 38 & 38.3 & 209.4 & 0.232 \\
\hline 24 & 42 & 39.1 & 213.8 & 0.248 \\
\hline 27 & 47.5 & 39.8 & 218.1 & 0.263 \\
\hline 30 & 51.5 & 40.6 & 222.5 & 0.277 \\
\hline 33 & 56 & 41.3 & 225.9 & 0.288 \\
\hline 36 & $\overline{62}$ & 41.8 & 228.5 & 0.296 \\
\hline 39 & 65.5 & 41.9 & 229.4 & 0.299 \\
\hline 42 & 68 & 42.1 & 230.3 & 0.302 \\
\hline 45 & 75.5 & 42.9 & 234.6 & 0.315 \\
\hline 48 & 78 & 42.9 & 234.6 & 0.315 \\
\hline 51 & 81.5 & 43.0 & 235.5 & 0.317 \\
\hline$\overline{54}$ & $\overline{84}$ & 43.3 & 237.2 & 0.322 \\
\hline 57 & 90 & 43.3 & 237.2 & 0.322 \\
\hline 60 & 94 & 44.1 & 241.6 & 0.334 \\
\hline 63 & 97.5 & 44.1 & 241.6 & 0.334 \\
\hline 66 & 100.5 & 44.3 & 242.5 & 0.337 \\
\hline 69 & 103.5 & 44.3 & 242.5 & 0.337 \\
\hline 72 & 106 & 44.3 & 242.5 & 0.337 \\
\hline 74 & 110 & 44.3 & 242.5 & 0.337 \\
\hline 78 & 112.5 & 44.5 & 243.3 & 0.339 \\
\hline 80 & 116 & 44.5 & 243.3 & 0.339 \\
\hline 82 & 118 & 44.5 & 243.3 & 0.339 \\
\hline 85 & 120 & 44.5 & 243.3 & 0.339 \\
\hline 88 & 122.5 & 44.5 & 243.3 & 0.339 \\
\hline 91 & 127.5 & 44.6 & 244.2 & 0.341 \\
\hline 94 & 129.5 & 44.6 & 244.2 & 0.341 \\
\hline
\end{tabular}


Table A.7 (contd)

\begin{tabular}{||c|c|c|c|c||}
\hline $\begin{array}{c}\text { Elapsed } \\
\text { Time, min }\end{array}$ & $\begin{array}{c}\text { Volume Gas } \\
\text { Generated, mL }\end{array}$ & $\begin{array}{c}\text { Sludge } \\
\text { Height, cm }\end{array}$ & $\begin{array}{c}\text { Sludge } \\
\text { Volume, mL }\end{array}$ & $\begin{array}{c}\text { Sludge Gas } \\
\text { Volume Fraction }\end{array}$ \\
\hline \hline 97 & 132 & 44.6 & 244.2 & 0.341 \\
\hline 98 & 133.5 & 44.6 & 244.2 & 0.341 \\
\hline 101 & 135.5 & 44.6 & 244.2 & 0.341 \\
\hline 104 & 137.5 & 44.6 & 244.2 & 0.341 \\
\hline 105 & 139.5 & 44.6 & 244.2 & 0.341 \\
\hline 108 & 141.5 & 44.6 & 244.2 & 0.341 \\
\hline 111 & 144 & 44.6 & 244.2 & 0.341 \\
\hline 114 & 146 & 44.6 & 244.2 & 0.341 \\
\hline 117 & 148.5 & 44.6 & 244.2 & 0.341 \\
\hline 120 & 151.5 & 44.6 & 244.2 & 0.341 \\
\hline 123 & 153.5 & 44.6 & 244.2 & 0.341 \\
\hline 126 & 154.5 & 44.6 & 244.2 & 0.341 \\
\hline 128 & 157.5 & 44.6 & 244.2 & 0.341 \\
\hline 131 & 158.5 & 44.6 & 244.2 & 0.341 \\
\hline 134 & 161.5 & 44.6 & 244.2 & 0.341 \\
\hline 141 & 166 & 44.6 & 244.2 & 0.341 \\
\hline 151 & 171.5 & 44.6 & 244.2 & 0.341 \\
\hline 160 & 178 & 44.6 & 244.2 & 0.341 \\
\hline 170 & 183.5 & 44.6 & 244.2 & 0.341 \\
\hline 187 & 190.5 & 44.6 & 244.2 & 0.341 \\
\hline 202 & 196.5 & 44.6 & 244.2 & 0.341 \\
\hline 217 & 203.5 & 44.6 & 244.2 & 0.341 \\
\hline 233 & 207.5 & 44.6 & 244.2 & 0.341 \\
\hline 247 & 212 & 44.6 & 244.2 & 0.341 \\
\hline & & & & \\
\hline
\end{tabular}


Table A.8. Gas Retention Data for a 656-Pa Clay $(32.1-\mathrm{cm}$ initial height and 2.64-cm tube diameter)

\begin{tabular}{|c|c|c|c|c|}
\hline $\begin{array}{l}\text { Elapsed } \\
\text { Time, min }\end{array}$ & $\begin{array}{l}\text { Volume Gas } \\
\text { Generated, } \mathrm{mL}\end{array}$ & $\begin{array}{l}\text { Sludge } \\
\text { Height, } \mathrm{cm}\end{array}$ & $\begin{array}{c}\text { Sludge } \\
\text { Volume, mL }\end{array}$ & $\begin{array}{c}\text { Sludge Gas } \\
\text { Volume Fraction }\end{array}$ \\
\hline$\overline{0}$ & 0 & 32.1 & 175.5 & 0.084 \\
\hline$\overline{3}$ & 12.5 & $\overline{33.2}$ & 181.6 & 0.115 \\
\hline 6 & 18.5 & $\overline{34.1}$ & 186.8 & 0.139 \\
\hline 9 & 24.5 & 35.2 & 192.9 & 0.166 \\
\hline$\overline{12}$ & 29 & 35.9 & 196.4 & 0.181 \\
\hline 15 & $\overline{34}$ & 36.8 & 201.6 & 0.202 \\
\hline 18 & $\overline{39}$ & 37.6 & 206.0 & 0.219 \\
\hline$\overline{21}$ & $\overline{43}$ & $\overline{38.4}$ & 210.3 & 0.235 \\
\hline$\overline{24}$ & 48.5 & 39.4 & 215.5 & 0.254 \\
\hline 27 & $\overline{56}$ & 39.7 & 217.2 & 0.260 \\
\hline$\overline{30}$ & $\overline{59}$ & 40.0 & 219.0 & 0.266 \\
\hline 33 & 67 & 40.2 & 219.9 & 0.269 \\
\hline$\overline{36}$ & 70.5 & 40.6 & 222.5 & 0.277 \\
\hline 39 & 74.5 & 41.1 & 225.1 & 0.286 \\
\hline 42 & 81 & $\overline{41.3}$ & 225.9 & 0.288 \\
\hline 45 & $\overline{85}$ & 41.3 & 225.9 & 0.288 \\
\hline$\overline{48}$ & $\overline{90}$ & 41.3 & 225.9 & 0.288 \\
\hline 51 & $\overline{93}$ & 41.3 & 225.9 & 0.288 \\
\hline$\overline{54}$ & $\overline{95}$ & 41.3 & 225.9 & 0.288 \\
\hline 57 & $\overline{102}$ & 41.3 & 225.9 & 0.288 \\
\hline 60 & 108 & 41.6 & 227.7 & 0.294 \\
\hline$\overline{65}$ & 112.5 & 41.6 & 227.7 & 0.294 \\
\hline$\overline{70}$ & 116 & 41.8 & 228.5 & 0.296 \\
\hline$\overline{75}$ & 126 & 41.8 & 228.5 & 0.296 \\
\hline 80 & 130.5 & 41.8 & 228.5 & 0.296 \\
\hline 85 & 136 & 41.8 & 228.5 & 0.296 \\
\hline 90 & 141 & 41.8 & 228.5 & 0.296 \\
\hline 95 & 146 & 41.8 & 228.5 & 0.296 \\
\hline 103 & $\overline{152}$ & $\overline{41.8}$ & 228.5 & 0.296 \\
\hline$\overline{108}$ & 156.5 & 41.8 & $228: 5$ & 0.296 \\
\hline 118 & 164 & 41.8 & 228.5 & 0.296 \\
\hline 128 & 171 & 41.8 & 228.5 & 0.296 \\
\hline 144 & 182 & 41.8 & 228.5 & 0.296 \\
\hline
\end{tabular}


Table A.8 (contd)

\begin{tabular}{||c|c|c|c|c|}
\hline $\begin{array}{c}\text { Elapsed } \\
\text { Time, min }\end{array}$ & $\begin{array}{c}\text { Volume Gas } \\
\text { Generated, mL }\end{array}$ & $\begin{array}{c}\text { Sludge } \\
\text { Height, cm }\end{array}$ & $\begin{array}{c}\text { Sludge } \\
\text { Volume, mL }\end{array}$ & $\begin{array}{c}\text { Sludge Gas } \\
\text { Volume Fraction }\end{array}$ \\
\hline \hline 162 & 192 & 41.9 & 229.4 & 0.299 \\
\hline 185 & 202.5 & 41.9 & 229.4 & 0.299 \\
\hline 215 & 213 & 41.9 & 229.4 & 0.299 \\
\hline 240 & 220 & 41.9 & 229.4 & 0.299 \\
\hline
\end{tabular}


Table A.9. Gas Retention Data for a 67-Pa Clay (32.5-cm initial height and 2.64-cm tube diameter)

\begin{tabular}{|c|c|c|c|c|}
\hline $\begin{array}{l}\text { Elapsed } \\
\text { Time, min }\end{array}$ & $\begin{array}{l}\text { Volume Gas } \\
\text { Generated, } \mathrm{mL}\end{array}$ & $\begin{array}{c}\text { Sludge } \\
\text { Height, } \mathrm{cm}\end{array}$ & \begin{tabular}{|c|} 
Sludge \\
Volume, $\mathrm{mL}$
\end{tabular} & $\begin{array}{c}\text { Sludge Gas } \\
\text { Volume Fraction }\end{array}$ \\
\hline 0 & 0 & 32.5 & 178.1 & 0.012 \\
\hline 3 & 5 & 33.3 & 182.5 & 0.036 \\
\hline 6 & 11 & 34.3 & 187.7 & 0.062 \\
\hline 9 & 16 & 35.4 & 193.8 & 0.092 \\
\hline 12 & 21 & 36.2 & 198.1 & 0.112 \\
\hline 15 & 25.5 & 37.1 & 203.3 & 0.135 \\
\hline 18 & 31 & 38.1 & 208.6 & 0.156 \\
\hline 20 & 33 & 38.6 & 211.2 & 0.167 \\
\hline 22 & 36 & 39.2 & 214.6 & 0.180 \\
\hline 24 & 39.5 & 39.7 & 217.2 & 0.190 \\
\hline 26 & 42 & 40.2 & 219.9 & 0.200 \\
\hline 28 & 45.5 & 40.8 & 223.3 & 0.212 \\
\hline 30 & 47.5 & 41.3 & 225.9 & 0.221 \\
\hline 32 & 50.5 & 41.9 & 229.4 & 0.233 \\
\hline 34 & 53.5 & 42.4 & 232.0 & 0.242 \\
\hline 36 & 55.5 & 42.9 & 234.6 & 0.250 \\
\hline 38 & 59 & 43.3 & 237.2 & 0.258 \\
\hline 40 & 61.5 & 43.8 & 239.8 & 0.266 \\
\hline 42 & 63.5 & 44.3 & 242.5 & 0.274 \\
\hline 44 & 67 & 44.9 & 245.9 & 0.284 \\
\hline 46 & 69 & 45.2 & 247.7 & 0.289 \\
\hline 48 & 72.5 & 45.7 & 250.3 & 0.297 \\
\hline 50 & 75 & 46.0 & 252.0 & 0.302 \\
\hline 52 & 76 & 46.5 & 254.6 & 0.309 \\
\hline 54 & 77.5 & 46.8 & 256.4 & 0.314 \\
\hline 56 & 81.5 & 47.5 & 259.8 & 0.323 \\
\hline 58 & 83 & 47.8 & 261.6 & 0.327 \\
\hline 60 & 85.5 & 48.3 & 264.2 & 0.334 \\
\hline 62 & 87.5 & 48.6 & 265.9 & 0.338 \\
\hline 64 & 90 & 49.1 & 268.5 & 0.345 \\
\hline 66 & 93 & 49.4 & 270.3 & 0.349 \\
\hline 68 & 94.5 & 49.7 & 272.0 & 0.353 \\
\hline 70 & 97 & 49.4 & 270.3 & 0.349 \\
\hline 72 & 99 & 49.5 & 271.1 & 0.351 \\
\hline 74 & 101.5 & 49.5 & 271.1 & 0.351 \\
\hline
\end{tabular}


Table A.9 (contd)

\begin{tabular}{|c|c|c|c|c|}
\hline $\begin{array}{c}\text { Elapsed } \\
\text { Time, min }\end{array}$ & $\begin{array}{l}\text { Volume Gas } \\
\text { Generated, mL }\end{array}$ & $\begin{array}{c}\text { Sludge } \\
\text { Height, } \mathrm{cm}\end{array}$ & \begin{tabular}{|c|} 
Sludge \\
Volume, $\mathrm{mL}$ \\
\end{tabular} & $\begin{array}{c}\text { Sludge Gas } \\
\text { Volume Fraction }\end{array}$ \\
\hline 76 & 104.5 & 48.6 & 265.9 & 0.338 \\
\hline 78 & 106 & 48.7 & 266.8 & 0.340 \\
\hline 80 & $\overline{108}$ & 48.4 & 265.0 & 0.336 \\
\hline 82 & 111.5 & 48.1 & 263.3 & 0.332 \\
\hline$\overline{84}$ & 112 & 48.1 & 263.3 & 0.332 \\
\hline$\overline{86}$ & 114.5 & 47.8 & 261.6 & 0.327 \\
\hline$\overline{88}$ & 115.5 & 47.6 & 260.7 & 0.325 \\
\hline 90 & 116.5 & 47.8 & 261.6 & 0.327 \\
\hline$\overline{93}$ & 120.5 & 47.6 & 260.7 & 0.325 \\
\hline 100 & 126 & 47.3 & 259.0 & 0.320 \\
\hline 105 & 130.5 & 47.3 & 259.0 & 0.320 \\
\hline 108 & 132.5 & 47.3 & 259.0 & 0.320 \\
\hline 112 & 135.5 & 47.6 & 260.7 & 0.325 \\
\hline 117 & 139.5 & 47.6 & 260.7 & 0.325 \\
\hline 122 & 142.5 & 47.6 & 260.7 & 0.325 \\
\hline 127 & 146 & 47.6 & 260.7 & 0.325 \\
\hline 132 & 150 & 49.1 & 268.5 & 0.345 \\
\hline 137 & $\overline{152}$ & 49.5 & 271.1 & 0.351 \\
\hline 142 & 157.5 & 50.3 & 275.5 & 0.361 \\
\hline 147 & 158 & 50.8 & 278.1 & 0.367 \\
\hline 152 & 161 & 51.3 & 280.7 & 0.373 \\
\hline 159 & 165.5 & 51.8 & 283.3 & 0.379 \\
\hline 163 & 169 & 50.5 & 276.3 & 0.363 \\
\hline 169 & 171 & 50.8 & 278.1 & 0.367 \\
\hline 174 & 174.5 & 50.5 & 276.3 & 0.363 \\
\hline 183 & 178.5 & 49.7 & 272.0 & 0.353 \\
\hline 194 & 184 & 50.0 & 273.7 & 0.357 \\
\hline 202 & 190 & 49.7 & 272.0 & 0.353 \\
\hline 212 & 195 & 49.5 & 271.1 & 0.351 \\
\hline 227 & 199.5 & 49.7 & 272.0 & 0.353 \\
\hline 257 & 208.5 & 49.7 & 272.0 & 0.353 \\
\hline 266 & 211 & 49.7 & 272.0 & 0.353 \\
\hline
\end{tabular}


Table A.10. Gas Retention Data for a 67-Pa Clay $(37.8-\mathrm{cm}$ initial height and 2.64-cm tube diameter)

\begin{tabular}{|c|c|c|c|c|}
\hline $\begin{array}{l}\text { Elapsed } \\
\text { Time, min }\end{array}$ & $\begin{array}{l}\text { Volume Gas } \\
\text { Generated, } \dot{\mathrm{mL}}\end{array}$ & $\begin{array}{c}\text { Sludge } \\
\text { Height, } \mathrm{cm}\end{array}$ & $\begin{array}{c}\text { Sludge } \\
\text { Volume, } \mathrm{mL}\end{array}$ & $\begin{array}{c}\text { Sludge Gas } \\
\text { Volume Fraction }\end{array}$ \\
\hline 0 & 0 & 37.8 & 206.8 & 0.0197 \\
\hline 3 & 10 & 39.1 & 213.8 & 0.0515 \\
\hline 5 & 15.5 & 40.0 & 219.0 & 0.0741 \\
\hline 8 & 20.5 & 41.1 & 225.1 & 0.0992 \\
\hline 11 & 28 & $\overline{42.1}$ & 230.3 & 0.1196 \\
\hline 14 & 33.5 & 43.2 & 236.4 & 0.1422 \\
\hline 17 & 40 & 44.3 & 242.5 & 0.1637 \\
\hline 20 & 45.5 & 45.2 & 247.7 & 0.1813 \\
\hline 23 & 51.5 & 46.4 & 253.7 & 0.2009 \\
\hline 26 & 56.5 & 47.2 & 258.1 & 0.2144 \\
\hline 29 & 61.5 & 47.9 & 262.4 & 0.2274 \\
\hline 32 & 66.5 & 48.9 & 267.6 & 0.2425 \\
\hline 35 & 72 & 50.0 & 273.7 & 0.2593 \\
\hline 38 & 77.5 & 51.1 & 279.8 & 0.2754 \\
\hline$\overline{41}$ & 81.5 & 51.9 & 284.2 & 0.2865 \\
\hline 44 & 87.5 & 52.9 & 289.4 & 0.2993 \\
\hline 47 & 92.5 & 53.7 & 293.7 & 0.3097 \\
\hline 50 & $\overline{98}$ & $\overline{54.6}$ & 298.9 & 0.3217 \\
\hline 53 & 100 & 55.6 & 304.1 & 0.3334 \\
\hline 56 & 106.5 & $\overline{56.2}$ & 307.6 & 0.3409 \\
\hline 59 & 111.5 & 57.2 & 312.8 & 0.3519 \\
\hline 61 & 113.5 & 56.8 & 311.1 & 0.3483 \\
\hline 64 & 118.5 & 57.2 & 312.8 & 0.3519 \\
\hline 67 & 122.5 & 56.8 & 311.1 & 0.3483 \\
\hline 69 & 127.5 & 56.5 & 309.4 & 0.3446 \\
\hline$\overline{72}$ & 131.5 & 55.7 & 305.0 & 0.3353 \\
\hline 75 & 135.5 & 52.7 & 288.5 & 0.2972 \\
\hline 81 & 143.5 & 50.2 & 274.6 & 0.2616 \\
\hline 85 & 147.5 & 50.2 & 274.6 & 0.2616 \\
\hline 91 & 154 & 53.8 & 294.6 & 0.3117 \\
\hline 97 & 162 & 54.9 & 300.7 & 0.3257 \\
\hline 103 & 168.5 & 51.4 & $\overline{281.6}$ & 0.2799 \\
\hline 108 & 172 & 57.8 & 316.3 & 0.3590 \\
\hline
\end{tabular}


Table A.10 (contd)

\begin{tabular}{||c|c|c|c|c||}
\hline $\begin{array}{c}\text { Elapsed } \\
\text { Time, min }\end{array}$ & $\begin{array}{c}\text { Volume Gas } \\
\text { Generated, mL }\end{array}$ & $\begin{array}{c}\text { Sludge } \\
\text { Height, cm }\end{array}$ & $\begin{array}{c}\text { Sludge } \\
\text { Volume, mL }\end{array}$ & $\begin{array}{c}\text { Sludge Gas } \\
\text { Volume Fraction }\end{array}$ \\
\hline \hline 113 & 179.5 & 57.2 & 312.8 & 0.3519 \\
\hline 120 & 185.5 & 58.4 & 319.8 & 0.3660 \\
\hline 133 & 197.5 & 57.8 & 316.3 & 0.3590 \\
\hline 145 & 207.5 & 57.2 & 312.8 & 0.3519 \\
\hline 180 & 229.5 & 54.6 & 298.9 & 0.3217 \\
\hline
\end{tabular}


Table A.11. Gas Retention Data for a 67-Pa Clay (31.4-cm initial height and 2.64-cm tube diameter)

\begin{tabular}{|c|c|c|c|c|}
\hline $\begin{array}{c}\text { Elapsed } \\
\text { Time, min }\end{array}$ & $\begin{array}{l}\text { Volume Gas } \\
\text { Generated, mL }\end{array}$ & $\begin{array}{c}\text { Sludge } \\
\text { Height, } \mathrm{cm}\end{array}$ & $\begin{array}{c}\text { Sludge } \\
\text { Volume, } \mathrm{mL}\end{array}$ & $\begin{array}{c}\text { Sludge Gas } \\
\text { Volume Fraction }\end{array}$ \\
\hline 0 & 0 & 31.4 & 172.1 & 0.0043 \\
\hline 3 & 6.5 & $\overline{32.2}$ & 176.4 & 0.0288 \\
\hline 6 & 12 & 33.3 & 182.5 & 0.0612 \\
\hline 10 & $\overline{18}$ & 34.6 & 189.4 & 0.0956 \\
\hline 13 & 25 & 35.6 & 194.7 & 0.1198 \\
\hline 18 & 33 & $\overline{37.1}$ & 203.3 & 0.1574 \\
\hline 21 & 38 & 37.9 & 207.7 & 0.1751 \\
\hline 24 & 43 & $\overline{39.1}$ & 213.8 & 0.1985 \\
\hline 27 & 48 & 39.7 & 217.2 & 0.2114 \\
\hline 30 & 52 & 40.8 & 223.3 & 0.2329 \\
\hline 33 & 56.5 & 41.4 & 226.8 & 0.2446 \\
\hline 36 & 61 & 41.9 & 229.4 & 0.2532 \\
\hline 39 & 66 & 42.9 & 234.6 & 0.2698 \\
\hline$\overline{42}$ & 70 & 43.5 & 238.1 & 0.2804 \\
\hline 45 & $\overline{74}$ & 44.3 & 242.5 & 0.2934 \\
\hline 48 & $\overline{78}$ & 44.5 & 243.3 & 0.2959 \\
\hline 51 & $\overline{84}$ & 45.9 & 251.1 & 0.3178 \\
\hline 56 & 89 & 46.5 & 254.6 & 0.3271 \\
\hline 59 & $\overline{93}$ & 47.5 & 259.8 & 0.3406 \\
\hline 65 & 102 & 48.9 & 267.6 & 0.3599 \\
\hline 72 & 108 & 49.4 & 270.3 & 0.3661 \\
\hline$\overline{75}$ & 112 & 48.7 & 266.8 & 0.3578 \\
\hline 78 & 118 & 48.3 & 264.2 & 0.3515 \\
\hline$\overline{83}$ & 122 & 46.4 & 253.7 & 0.3248 \\
\hline 87 & 126 & 45.1 & 246.8 & 0.3058 \\
\hline$\overline{93}$ & 134 & 42.2 & 231.1 & 0.2588 \\
\hline 99 & 138 & 43.8 & 239.8 & 0.2857 \\
\hline 115 & 142 & 44.3 & 242.5 & 0.2934 \\
\hline 121 & 148 & 44.3 & 242.5 & 0.2934 \\
\hline 130 & $\overline{164}$ & 47.6 & 260.7 & 0.3428 \\
\hline 139 & 170.5 & 47.5 & 259.8 & 0.3406 \\
\hline 145 & 176 & 47.6 & 260.7 & 0.3428 \\
\hline 148 & 178 & 48.4 & 265.0 & 0.3536 \\
\hline
\end{tabular}


Table A.11 (contd)

\begin{tabular}{|c|c|c|c|c||}
\hline $\begin{array}{c}\text { Elapsed } \\
\text { Time, min }\end{array}$ & $\begin{array}{c}\text { Volume Gas } \\
\text { Generated, mL }\end{array}$ & $\begin{array}{c}\text { Sludge } \\
\text { Height, } \mathrm{cm}\end{array}$ & $\begin{array}{c}\text { Sludge } \\
\text { Volume, mL }\end{array}$ & $\begin{array}{c}\text { Sludge Gas } \\
\text { Volume Fraction }\end{array}$ \\
\hline \hline 160 & 186.5 & 50.0 & 273.7 & 0.3741 \\
\hline 164 & 189 & 50.3 & 275.5 & 0.3781 \\
\hline 169 & 193 & 50.2 & 274.6 & 0.3761 \\
\hline 174 & 196 & 50.2 & 274.6 & 0.3761 \\
\hline 183 & 200 & 50.2 & 274.6 & 0.3761 \\
\hline 199 & 208.5 & 50.0 & 273.7 & 0.374 \\
\hline 202 & 210 & 49.7 & 272.0 & 0.370 \\
\hline 221 & 220 & 49.5 & 271.1 & 0.368 \\
\hline 232 & 224 & 50.2 & 274.6 & 0.376 \\
\hline 243 & 227 & 50.2 & 274.6 & 0.376 \\
\hline 255 & 232 & 49.8 & 272.9 & 0.372 \\
\hline
\end{tabular}


Table A.12. Gas Retention Data for a 67 Pa-Clay (13.3-cm initial height and 2.54-cm tube diameter)

\begin{tabular}{|c|c|c|c|c|}
\hline $\begin{array}{l}\text { Elapsed } \\
\text { Time, } \min \end{array}$ & $\begin{array}{l}\text { Volume Gas } \\
\text { Generated, } \mathrm{mL}\end{array}$ & $\begin{array}{l}\text { Sludge } \\
\text { Height, } \mathrm{cm}\end{array}$ & $\begin{array}{l}\text { Sludge } \\
\text { Volume, mL }\end{array}$ & $\begin{array}{c}\text { Sludge Gas } \\
\text { Volume Fraction }\end{array}$ \\
\hline 0 & $\overline{0}$ & 13.3 & 67.6 & -0.0152 \\
\hline 3 & $\overline{5}$ & 13.7 & $\overline{69.2}$ & 0.0084 \\
\hline$\overline{7}$ & 10 & $\overline{14.4}$ & 73.2 & 0.0630 \\
\hline 10 & 12.5 & 14.8 & 74.8 & 0.0832 \\
\hline 13 & 14.5 & 15.1 & $\overline{76.4}$ & 0.1025 \\
\hline 21 & 20.5 & 16.0 & 81.3 & 0.1558 \\
\hline 26 & 24 & 16.7 & 84.5 & 0.1879 \\
\hline 30 & 26 & 17.1 & 86.9 & 0.2104 \\
\hline$\overline{34}$ & $\overline{28}$ & 17.6 & 89.3 & 0.2318 \\
\hline 38 & 30.5 & 17.9 & 90.9 & 0.2454 \\
\hline 44 & 34 & 18.9 & 95.7 & 0.2834 \\
\hline 67 & $\overline{44}$ & 20.5 & 103.8 & 0.3390 \\
\hline 80 & 50 & 21.8 & 110.2 & 0.3776 \\
\hline 86 & $\overline{53}$ & $\overline{22.2}$ & 112.6 & 0.3909 \\
\hline 93 & 56 & 22.5 & 114.2 & 0.3995 \\
\hline$\overline{95}$ & 56.5 & $\overline{22.4}$ & 113.4 & 0.3953 \\
\hline 98 & 58 & 22.4 & 113.4 & 0.3953 \\
\hline 102 & 59 & 22.5 & 114.2 & 0.3995 \\
\hline 107 & $\overline{62}$ & $\overline{22.5}$ & 114.2 & 0.3995 \\
\hline 112 & 62.5 & 22.5 & 114.2 & 0.3995 \\
\hline 117 & 64.5 & 22.7 & 115.0 & 0.4037 \\
\hline 118 & 66 & 22.1 & 111.8 & 0.3866 \\
\hline 124 & 67 & 21.9 & 111.0 & 0.3821 \\
\hline 133 & 69.5 & 21.8 & 110.2 & 0.3776 \\
\hline 134 & $\overline{70}$ & 20.6 & 104.6 & 0.3440 \\
\hline$\overline{145}$ & $\overline{72}$ & 20.3 & 103.0 & 0.3338 \\
\hline 175 & 80 & 20.2 & 102.2 & 0.3286 \\
\hline
\end{tabular}


Table A.13. Gas Retention Data for 67-Pa Clay $(29.2-\mathrm{cm}$ initial height and $2.54-\mathrm{cm}$ diameter)

\begin{tabular}{|c|c|c|c|c|}
\hline $\begin{array}{c}\text { Elapsed } \\
\text { Time, min }\end{array}$ & $\begin{array}{l}\text { Volume Gas } \\
\text { Generated, } \mathrm{mL}\end{array}$ & $\begin{array}{l}\text { Sludge } \\
\text { Height, } \mathrm{cm}\end{array}$ & $\begin{array}{l}\text { Sludge } \\
\text { Volume, } \mathrm{mL}\end{array}$ & $\begin{array}{c}\text { Sludge Gas Volume } \\
\text { Fraction }\end{array}$ \\
\hline$\overline{0}$ & 0 & 29.2 & 148.0 & 0.0068 \\
\hline 3 & $\overline{7}$ & $\overline{29.4}$ & 148.8 & 0.0122 \\
\hline 6 & 11.5 & 31.1 & 157.7 & 0.0676 \\
\hline 9 & 15.5 & 31.9 & 161.7 & 0.0908 \\
\hline 12 & 21 & 32.5 & 164.9 & 0.1086 \\
\hline 16 & 25.5 & 33.7 & 170.5 & 0.1380 \\
\hline$\overline{21}$ & $\overline{32}$ & 35.1 & 177.8 & 0.1731 \\
\hline 26 & 38 & 36.0 & 182.6 & 0.1950 \\
\hline 34 & 47 & 37.9 & 192.3 & 0.2354 \\
\hline 39 & 53 & 38.9 & 197.1 & 0.2541 \\
\hline 50 & 65 & 41.3 & 209.1 & 0.2971 \\
\hline 54 & 73 & 43.2 & 218.8 & 0.3281 \\
\hline$\overline{62}$ & 81 & 44.6 & 226.0 & 0.3497 \\
\hline$\overline{70}$ & 87 & 45.7 & 231.7 & 0.3655 \\
\hline$\overline{83}$ & 99.5 & 47.6 & 241.3 & 0.3908 \\
\hline 87 & 103 & 48.3 & 244.5 & 0.3989 \\
\hline$\overline{93}$ & 109 & 47.9 & 242.9 & 0.3949 \\
\hline 100 & 111.5 & 47.3 & 239.7 & 0.3867 \\
\hline 101 & 113 & 41.9 & 212.4 & 0.3078 \\
\hline 117 & 124 & 43.5 & 220.4 & 0.3330 \\
\hline 133 & 135 & 45.4 & 230.1 & 0.3610 \\
\hline 142 & 141 & 46.5 & 235.7 & 0.3763 \\
\hline$\overline{151}$ & $\overline{145}$ & 47.9 & 242.9 & 0.3949 \\
\hline 154 & 147 & 48.6 & 246.1 & 0.4028 \\
\hline 157 & 149 & 48.9 & 247.8 & 0.4067 \\
\hline 160 & $\overline{151}$ & 49.2 & 249.4 & 0.4105 \\
\hline 163 & 153 & 49.4 & 250.2 & 0.4124 \\
\hline 166 & 154 & 49.7 & 251.8 & 0.416 \\
\hline 168 & $\overline{155}$ & 50.0 & 253.4 & 0.420 \\
\hline$\overline{171}$ & 157 & $\overline{50.2}$ & 254.2 & 0.422 \\
\hline 173 & 157.5 & 49.2 & 249.4 & 0.410 \\
\hline 173.5 & 158 & 46.0 & 233.3 & 0.370 \\
\hline 251 & 187 & 44.1 & 223.6 & 0.343 \\
\hline
\end{tabular}


Table A.14. Gas Retention Data for a 67-Pa Clay (46.7-cm initial height and 2.54-cm tube diameter)

\begin{tabular}{|c|c|c|c|c|}
\hline $\begin{array}{l}\text { Elapsed } \\
\text { Time, min }\end{array}$ & $\begin{array}{l}\text { Volume Gas } \\
\text { Generated, } \mathrm{mL} \\
\end{array}$ & $\begin{array}{c}\text { Sludge } \\
\text { Height, } \mathrm{cm}\end{array}$ & $\begin{array}{c}\text { Sludge } \\
\text { Volume, } \mathrm{mL} \\
\end{array}$ & $\begin{array}{c}\text { Sludge Gas Volume } \\
\text { Fraction }\end{array}$ \\
\hline 0 & 0 & 46.7 & 236.5 & 0.0277 \\
\hline 2 & 7 & 47.3 & 239.7 & 0.0407 \\
\hline 5 & 12.5 & 48.4 & 245.3 & 0.0627 \\
\hline 8 & 18 & 49.4 & 250.2 & 0.0808 \\
\hline$\overline{11}$ & 23.5 & 50.5 & 255.8 & 0.1010 \\
\hline 14 & 28.5 & 51.4 & 260.6 & 0.1177 \\
\hline 28 & $\overline{52}$ & 55.9 & 283.1 & 0.1879 \\
\hline 31 & 57.5 & 57.0 & 288.8 & 0.2037 \\
\hline 36 & 65.5 & 58.4 & 296.0 & 0.2232 \\
\hline 39 & 70 & $\overline{59.4}$ & 300.8 & 0.2356 \\
\hline 44 & $\overline{78}$ & 60.8 & 308.1 & 0.2536 \\
\hline 47 & 82.5 & 61.8 & 312.9 & 0.2651 \\
\hline 57 & 90 & 64.6 & $\overline{327.4}$ & 0.2976 \\
\hline$\overline{73}$ & 117.5 & 68.6 & 347.5 & 0.3383 \\
\hline 77 & 123.5 & 69.5 & 352.3 & 0.3473 \\
\hline$\overline{81}$ & 129.5 & 70.5 & 357.2 & 0.3561 \\
\hline 85 & 134 & 71.6 & 362.8 & 0.3662 \\
\hline 90 & 140.5 & 72.6 & 367.6 & 0.3745 \\
\hline 99 & 150 & 73.3 & 371.6 & $\overline{0.3812}$ \\
\hline$\overline{102}$ & 155.5 & 73.7 & 373.2 & 0.3839 \\
\hline 104 & 157.5 & 73.7 & 373.2 & 0.3839 \\
\hline 105 & 158.5 & 73.3 & 371.6 & 0.3812 \\
\hline$\overline{110}$ & 164.5 & 70.0 & 354.7 & 0.3518 \\
\hline 113 & 167.5 & 68.9 & 349.1 & 0.3413 \\
\hline 130 & 185.5 & 68.9 & 349.1 & 0.3413 \\
\hline$\overline{145}$ & 199 & $\overline{70.2}$ & 355.5 & 0.3532 \\
\hline 160 & 210.5 & 73.3 & 371.6 & 0.3812 \\
\hline 168 & $\overline{216}$ & 74.5 & 377.3 & $\overline{0.390}$ \\
\hline 175 & 221.5 & $\overline{75.1}$ & 380.5 & 0.396 \\
\hline 181 & 225.5 & 76.5 & 387.7 & 0.407 \\
\hline 182 & 226.5 & 76.8 & 389.3 & 0.409 \\
\hline 185 & 227.5 & $\overline{77.2}$ & 390.9 & 0.412 \\
\hline 188 & 229.5 & 80.2 & 406.2 & 0.434 \\
\hline
\end{tabular}


Table A.14 (contd)

\begin{tabular}{||c|c|c|c|c|}
\hline $\begin{array}{c}\text { Elapsed } \\
\text { Time, min }\end{array}$ & $\begin{array}{c}\text { Volume Gas } \\
\text { Generated, mL }\end{array}$ & $\begin{array}{c}\text { Sludge } \\
\text { Height, cm }\end{array}$ & $\begin{array}{c}\text { Sludge } \\
\text { Volume, mL }\end{array}$ & $\begin{array}{c}\text { Sludge Gas Volume } \\
\text { Fraction }\end{array}$ \\
\hline \hline 191 & 231.5 & 80.2 & 406.2 & 0.434 \\
\hline 196 & 234 & 81.1 & 411.1 & 0.441 \\
\hline 199 & 236 & 81.4 & 412.7 & 0.443 \\
\hline 202 & 240 & 81.8 & 414.3 & 0.445 \\
\hline 208 & 242 & 82.7 & 419.1 & 0.451 \\
\hline 211 & 245.5 & 77.8 & 394.2 & 0.417 \\
\hline 250 & 264.5 & 74.0 & 374.8 & 0.387 \\
\hline
\end{tabular}


Table A.15. Gas Retention Data for a 67-Pa Clay $(82.7-\mathrm{cm}$ initial height and 2.54-cm tube diameter)

\begin{tabular}{|c|c|c|c|c|}
\hline $\begin{array}{l}\text { Elapsed } \\
\text { Time, } \min \end{array}$ & $\begin{array}{l}\text { Volume Gas } \\
\text { Generated, } \mathrm{mL}\end{array}$ & $\begin{array}{c}\text { Sludge } \\
\text { Height, cm }\end{array}$ & $\begin{array}{c}\text { Sludge } \\
\text { Volume, } \mathrm{mL} \\
\end{array}$ & $\begin{array}{c}\text { Sludge Gas Volume } \\
\text { Fraction }\end{array}$ \\
\hline 0 & 0 & 82.7 & 419.1 & 0.0121 \\
\hline 3 & 14 & 85.3 & 432.0 & 0.0415 \\
\hline$\overline{6}$ & 26 & 87.6 & 444.0 & 0.0675 \\
\hline$\overline{9}$ & 38 & 90.0 & 456.1 & 0.0922 \\
\hline 12 & $\overline{48}$ & 91.9 & 465.8 & 0.1110 \\
\hline 15 & 58.5 & 93.8 & 475.4 & 0.1291 \\
\hline 18 & 70 & 95.7 & 485.1 & 0.1464 \\
\hline 21 & 80.5 & 97.8 & 495.5 & 0.1644 \\
\hline 24 & 92 & 99.9 & 506.0 & 0.1817 \\
\hline 27 & 102 & 101.9 & 516.4 & 0.1983 \\
\hline 30 & 112 & 103.7 & 525.3 & 0.2118 \\
\hline 33 & 122 & 105.7 & 535.7 & 0.2272 \\
\hline 36 & 131 & 107.6 & 545.4 & 0.2408 \\
\hline 39 & 140 & 109.4 & 554.2 & 0.2530 \\
\hline 42 & 150 & 111.3 & 563.9 & 0.2657 \\
\hline 45 & 159 & 112.9 & 571.9 & 0.2761 \\
\hline 48 & 168 & 114.8 & 581.6 & 0.2881 \\
\hline 51 & 177.5 & 116.5 & 590.4 & 0.2988 \\
\hline 54 & 184 & 118.0 & 597.7 & 0.3072 \\
\hline 57 & 192 & 119.5 & 605.7 & 0.3165 \\
\hline 60 & 200 & 121.3 & 614.6 & 0.3263 \\
\hline 63 & 210 & 122.7 & 621.8 & 0.3341 \\
\hline 68 & 222 & 125.7 & 637.1 & 0.3501 \\
\hline 70 & 226 & 126.2 & 639.5 & 0.3526 \\
\hline 76 & 233 & 128.7 & 652.4 & 0.3653 \\
\hline 82 & 256 & 131.3 & 665.2 & 0.3776 \\
\hline 83 & 261 & 130.0 & 658.8 & 0.3715 \\
\hline 90 & 278 & 131.4 & 666.0 & 0.378 \\
\hline 90.5 & 277.5 & 130.0 & 658.8 & 0.372 \\
\hline 105 & 309 & 131.1 & 664.4 & 0.377 \\
\hline 119 & 335 & 135.3 & 685.3 & 0.396 \\
\hline 123 & 341.5 & 130.8 & 662.8 & 0.375 \\
\hline 130 & 353 & 135.7 & 687.8 & 0.398 \\
\hline 135 & 361 & 137.6 & 697.4 & 0.406 \\
\hline 142 & 373 & 139.4 & 706.3 & 0.414 \\
\hline
\end{tabular}


Table A.15 (contd)

\begin{tabular}{|c|c|c|c|c|}
\hline $\begin{array}{l}\text { Elapsed } \\
\text { Time, } \min \end{array}$ & $\begin{array}{l}\text { Volume Gas } \\
\text { Generated, } \mathrm{mL}\end{array}$ & $\begin{array}{c}\text { Sludge } \\
\text { Height, } \mathrm{cm}\end{array}$ & $\begin{array}{c}\text { Sludge } \\
\text { Volume, } \mathrm{mL}\end{array}$ & $\begin{array}{c}\text { Sludge Gas Volume } \\
\text { Fraction }\end{array}$ \\
\hline 148 & 381 & 141.0 & 714.3 & 0.420 \\
\hline 153 & 391.5 & 142.4 & 721.6 & 0.426 \\
\hline 158 & 398 & 143.8 & 728.8 & 0.432 \\
\hline$\overline{163}$ & 403.5 & 145.1 & 735.2 & 0.437 \\
\hline 170 & 413 & 147.2 & 745.7 & 0.445 \\
\hline 175 & 420 & 148.3 & 751.3 & 0.449 \\
\hline 181 & 425 & 147.2 & 745.7 & 0.445 \\
\hline 196 & 443 & 150.3 & 761.8 & 0.456 \\
\hline 201 & 449 & 151.4 & 767.4 & 0.460 \\
\hline 204 & 453 & 152.1 & 770.6 & 0.463 \\
\hline 205 & 454 & 152.4 & 772.2 & 0.464 \\
\hline 209 & 459 & 153.0 & 775.4 & 0.466 \\
\hline 213 & 463 & 152.9 & 774.6 & 0.466 \\
\hline 217 & 466 & 153.7 & 778.7 & 0.468 \\
\hline 218 & 468 & 151.9 & 769.8 & 0.462 \\
\hline 220 & 469 & 152.1 & 770.6 & 0.463 \\
\hline 222 & 472 & 151.1 & 765.8 & 0.459 \\
\hline 224 & 475 & 148.3 & 751.3 & 0.449 \\
\hline 229 & 479 & 149.2 & 756.1 & 0.452 \\
\hline 233 & 482 & 150.3 & 761.8 & 0.456 \\
\hline 245 & $\overline{493}$ & 152.7 & 773.8 & 0.465 \\
\hline 254 & 499 & 154.1 & 781.1 & 0.470 \\
\hline 257 & 501 & 154.9 & 785.1 & 0.473 \\
\hline 260 & 507 & 153.7 & 778.7 & 0.468 \\
\hline 265 & 509 & 154.3 & 781.9 & 0.470 \\
\hline 271 & 515 & 155.3 & 786.7 & 0.474 \\
\hline 274 & 515.5 & 155.6 & 788.3 & 0.475 \\
\hline 276 & 517 & 155.6 & 788.3 & 0.475 \\
\hline 280 & 519 & 156.1 & 790.7 & 0.476 \\
\hline 283 & 521 & 156.7 & 793.9 & 0.479 \\
\hline 299 & 531 & 154.3 & 781.9 & 0.470 \\
\hline
\end{tabular}


Table A.16. Gas Retention Data for a 67-Pa Clay (91-cm initial height and 2.54-cm tube diameter)

\begin{tabular}{|c|c|c|c|c|}
\hline $\begin{array}{c}\text { Elapsed } \\
\text { Time, } \mathbf{m i n}\end{array}$ & $\begin{array}{l}\text { Volume Gas } \\
\text { Generated, } \mathrm{mL}\end{array}$ & $\begin{array}{c}\text { Sludge } \\
\text { Height, cm }\end{array}$ & \begin{tabular}{|c|} 
Sludge \\
Volume, $\mathrm{mL}$ \\
\end{tabular} & $\begin{array}{c}\text { Sludge Gas Volume } \\
\text { Fraction }\end{array}$ \\
\hline 0 & 0 & 91.0 & 460.9 & 0.0141 \\
\hline 3 & $\overline{12}$ & 92.9 & 470.6 & 0.0343 \\
\hline 6 & 30 & 96.4 & 488.3 & 0.0693 \\
\hline 9 & 46 & 99.5 & 504.4 & 0.0990 \\
\hline 12 & 58 & 101.8 & 515.6 & 0.1186 \\
\hline 16 & 74 & 105.1 & 532.5 & 0.1466 \\
\hline 20 & 87 & 107.8 & 546.2 & 0.1680 \\
\hline 23 & 98 & 109.7 & 555.8 & 0.1824 \\
\hline 26 & 109 & 111.8 & 566.3 & 0.1975 \\
\hline 29 & 118.5 & 113.7 & 575.9 & 0.2110 \\
\hline 32 & 129 & 115.7 & 586.4 & 0.2250 \\
\hline 35 & 139 & 118.0 & 597.7 & 0.2396 \\
\hline 38 & 148 & 119.5 & 605.7 & 0.2497 \\
\hline 41 & 158 & 121.4 & 615.4 & 0.2615 \\
\hline 44 & 168.5 & 123.2 & 624.2 & 0.2720 \\
\hline 47 & 175 & 124.8 & 632.3 & 0.2812 \\
\hline 50 & 186 & 126.8 & 642.7 & 0.2929 \\
\hline 53 & 195 & 128.4 & 650.8 & 0.3017 \\
\hline 56 & 204 & 130.3 & 660.4 & 0.3119 \\
\hline 59 & 212 & 131.9 & 668.5 & 0.3202 \\
\hline 62 & 220 & 133.5 & 676.5 & 0.3282 \\
\hline 65 & 228 & 135.6 & 687.0 & 0.3385 \\
\hline 66 & 230.5 & 135.7 & 687.8 & 0.3393 \\
\hline 69 & 240.5 & 137.3 & 695.8 & 0.3469 \\
\hline 72 & 248.5 & 138.7 & 703.0 & 0.3536 \\
\hline 75 & 256.5 & 140.3 & 711.1 & 0.3609 \\
\hline 78 & 264.5 & 143.2 & 725.6 & 0.3737 \\
\hline 81 & 272.5 & 144.6 & 732.8 & 0.380 \\
\hline 84 & 278.5 & 144.6 & 732.8 & 0.380 \\
\hline 87 & 286.5 & 145.9 & 739.2 & 0.385 \\
\hline 90 & 293.5 & 147.3 & 746.5 & 0.391 \\
\hline 93 & 300.5 & 148.6 & 752.9 & 0.396 \\
\hline 96 & 307.5 & 149.9 & 759.4 & 0.402 \\
\hline 101 & 318.5 & 151.9 & 769.8 & 0.410 \\
\hline 106 & 329 & 154.3 & 781.9 & 0.419 \\
\hline 110 & 338.5 & 156.2 & 791.5 & 0.426 \\
\hline
\end{tabular}


Table A.16 (contd)

\begin{tabular}{|c|c|c|c|c|}
\hline $\begin{array}{l}\text { Elapsed } \\
\text { Time, min } \\
\end{array}$ & $\begin{array}{l}\text { Volume Gas } \\
\text { Generated, } \mathrm{mL}\end{array}$ & $\begin{array}{c}\text { Sludge } \\
\text { Height, cm }\end{array}$ & $\begin{array}{c}\text { Sludge } \\
\text { Volume, } \mathrm{mL} \\
\end{array}$ & $\begin{array}{c}\text { Sludge Gas Volume } \\
\text { Fraction }\end{array}$ \\
\hline 114 & 346.5 & 156.8 & 794.7 & 0.428 \\
\hline 120 & 357.5 & 158.8 & 804.4 & 0.435 \\
\hline 125 & 362.5 & 160.3 & 812.4 & 0.441 \\
\hline 135 & 383.5 & 161.9 & 820.5 & 0.446 \\
\hline 138 & 388.5 & 162.9 & 825.3 & 0.449 \\
\hline 139 & 391 & 161.0 & 815.7 & 0.443 \\
\hline 146 & 402.5 & 163.4 & 827.7 & 0.451 \\
\hline 147 & 404.5 & 163.8 & 830.1 & 0.453 \\
\hline 148 & 405.5 & 162.2 & 822.1 & 0.447 \\
\hline 153 & 412.5 & 163.7 & 829.3 & 0.452 \\
\hline 154 & 413.5 & 164.0 & 830.9 & 0.453 \\
\hline 156 & 416.5 & 162.4 & 822.9 & 0.448 \\
\hline 170 & 436.5 & 166.5 & 843.8 & 0.461 \\
\hline 172 & 439 & 167.0 & 846.2 & 0.463 \\
\hline 174 & 442.5 & 167.5 & 848.6 & 0.465 \\
\hline 176 & 444.5 & 168.1 & 851.9 & 0.467 \\
\hline 180 & 450.5 & 169.1 & 856.7 & 0.470 \\
\hline 183 & 452.5 & 169.9 & 860.7 & 0.472 \\
\hline 187 & 456.5 & 170.8 & 865.5 & 0.475 \\
\hline 193 & 464.5 & 172.1 & 872.0 & 0.479 \\
\hline 195 & 466.5 & 172.7 & 875.2 & 0.481 \\
\hline 198 & 470.5 & 173.4 & 878.4 & 0.483 \\
\hline 200 & 473 & 174.3 & 883.2 & 0.485 \\
\hline 203 & 475 & 174.6 & 884.8 & 0.486 \\
\hline 209 & 481 & 175.7 & 890.5 & 0.490 \\
\hline 218 & 491 & 174.9 & 886.4 & 0.487 \\
\hline 225 & 499 & 175.9 & 891.3 & 0.490 \\
\hline 230 & 503.5 & 176.8 & 896.1 & 0.493 \\
\hline 236 & 508 & 177.8 & 900.9 & 0.496 \\
\hline 243 & 514 & 178.9 & 906.6 & 0.499 \\
\hline 248 & 519 & 179.7 & 910.6 & 0.501 \\
\hline 253 & 523 & 180.5 & 914.6 & 0.503 \\
\hline 259 & 529 & 181.6 & 920.2 & 0.506 \\
\hline 264 & 532 & 182.9 & 926.7 & 0.510 \\
\hline 267 & 533.5 & 183.4 & 929.1 & 0.511 \\
\hline$>267$ & $>533.5$ & $>183.4$ & $>929.1$ & $>0.511$ \\
\hline
\end{tabular}


Table A.17. Gas Retention Data for a 67-Pa Clay (41.6- $\mathrm{cm}$ initial height and 2.54-cm tube diameter)

\begin{tabular}{|c|c|c|c|c|c|}
\hline $\begin{array}{c}\begin{array}{c}\text { Elapsed Time, } \\
\min \end{array} \\
\end{array}$ & $\begin{array}{c}\text { Flow Rate, } \\
\mathrm{mL} / \mathrm{min}\end{array}$ & $\begin{array}{c}\text { Volume Gas } \\
\text { Generated, mL }\end{array}$ & $\begin{array}{c}\text { Sludge Height, } \\
\mathrm{cm}\end{array}$ & $\begin{array}{c}\text { Sludge Volume, } \\
\mathrm{mL}\end{array}$ & $\begin{array}{c}\text { Sludge Gas Volume } \\
\text { Fraction }\end{array}$ \\
\hline 0 & 1.05 & 0.00 & 41.59 & 0.00 & 0.031 \\
\hline 2 & 1.31 & 2.36 & 42.23 & 3.14 & 0.046 \\
\hline 4 & 1.16 & 4.83 & 43.18 & 7.84 & 0.068 \\
\hline 6 & 1.06 & 7.05 & 43.82 & 10.98 & 0.082 \\
\hline 8 & 0.98 & 9.09 & 44.45 & 14.12 & 0.095 \\
\hline 10 & 1.10 & 11.17 & 45.40 & $\overline{18.82}$ & 0.115 \\
\hline$\overline{12}$ & 1.04 & 13.31 & 45.72 & 20.39 & 0.121 \\
\hline 15 & 1.10 & 16.52 & 46.67 & 25.10 & 0.140 \\
\hline 17 & 0.90 & 18.52 & 47.47 & 29.02 & 0.155 \\
\hline 19 & 1.03 & 20.45 & 48.10 & 32.15 & 0.166 \\
\hline 21 & 0.94 & 22.42 & 48.74 & 35.29 & 0.178 \\
\hline 23 & 1.00 & 24.36 & 49.37 & 38.43 & 0.189 \\
\hline 25 & 1.00 & 26.36 & 49.85 & 40.78 & 0.197 \\
\hline 27 & 1.00 & 28.36 & 50.48 & 43.92 & 0.207 \\
\hline 29 & 1.00 & 30.36 & 51.12 & 47.05 & 0.217 \\
\hline 31 & 1.04 & 32.40 & 51.75 & 50.19 & 0.227 \\
\hline 33 & 0.90 & 34.34 & 52.23 & 52.54 & 0.235 \\
\hline$\overline{35}$ & 1.10 & 36.34 & 52.86 & 55.68 & 0.244 \\
\hline 37 & 1.00 & 38.44 & 53.50 & 58.82 & 0.254 \\
\hline 39 & 0.95 & 40.39 & 54.13 & 61.95 & 0.263 \\
\hline 41 & 1.10 & 42.44 & 54.61 & 64.31 & 0.269 \\
\hline 43 & 0.95 & 44.49 & 55.09 & 66.66 & 0.276 \\
\hline 45 & 1.00 & 46.44 & 55.72 & 69.80 & 0.285 \\
\hline 47 & 0.95 & 48.39 & 56.20 & 72.15 & 0.291 \\
\hline 49 & 0.95 & 50.29 & 56.67 & 74.50 & 0.297 \\
\hline 51 & 0.90 & 52.14 & 57.15 & 76.85 & 0.303 \\
\hline 53 & 0.95 & 53.99 & 57.79 & 79.99 & 0.311 \\
\hline 57 & 0.85 & 57.59 & 59.06 & 86.26 & 0.327 \\
\hline 61 & 0.85 & 60.99 & 59.85 & 90.19 & 0.336 \\
\hline 64 & 0.85 & 63.54 & 60.64 & 94.11 & 0.345 \\
\hline 67 & 0.80 & 66.02 & 61.75 & 99.60 & 0.357 \\
\hline 70 & 0.75 & 68.34 & 62.07 & 101.17 & 0.361 \\
\hline 73 & 0.80 & 70.67 & 62.71 & 104.30 & 0.368 \\
\hline 76 & 0.75 & 72.99 & 63.34 & 107.44 & 0.374 \\
\hline 79 & 0.80 & 75.32 & 63.98 & 110.58 & 0.381 \\
\hline 82 & 0.80 & $\overline{77.72}$ & 64.77 & 114.50 & 0.389 \\
\hline 85 & 0.75 & 80.04 & 65.56 & 118.42 & 0.397 \\
\hline 88 & 0.70 & 82.22 & 66.36 & 122.34 & 0.404 \\
\hline
\end{tabular}


Table A.17 (contd)

\begin{tabular}{|c|c|c|c|c|c|}
\hline $\begin{array}{c}\text { Elapsed Time, } \\
\text { min }\end{array}$ & $\begin{array}{c}\text { Flow Rate, } \\
\text { mL/min }\end{array}$ & $\begin{array}{c}\text { Volume Gas } \\
\text { Generated, mL }\end{array}$ & $\begin{array}{c}\text { Sludge Height, } \\
\mathrm{cm}\end{array}$ & $\begin{array}{c}\text { Sludge Volume, } \\
\text { mL }\end{array}$ & $\begin{array}{c}\text { Sludge Gas Volume } \\
\text { Fraction }\end{array}$ \\
\hline \hline 91 & 0.70 & 84.32 & 67.15 & 126.26 & 0.412 \\
\hline 94 & 0.75 & 86.49 & 67.79 & 129.40 & 0.417 \\
\hline 97 & 0.80 & 88.82 & 68.58 & 133.32 & 0.425 \\
\hline 100 & 0.65 & 90.99 & 69.37 & 137.24 & 0.431 \\
\hline 102 & 0.65 & 92.29 & 69.85 & 139.59 & 0.436 \\
\hline 105 & 0.65 & 94.24 & 70.33 & 141.94 & 0.440 \\
\hline 106 & 0.70 & 94.92 & 70.33 & 141.94 & 0.440 \\
\hline 108 & 0.75 & 96.37 & 70.33 & 141.94 & 0.440 \\
\hline 110 & 0.80 & 97.92 & 70.33 & 141.94 & 0.440 \\
\hline 111 & 0.60 & 98.62 & 70.33 & 141.94 & 0.440 \\
\hline 113 & 0.50 & 99.72 & 70.49 & 142.73 & 0.441 \\
\hline 115 & 0.50 & 100.72 & 70.64 & 143.51 & 0.442 \\
\hline 117 & 0.65 & 101.87 & 70.01 & 140.38 & 0.437 \\
\hline 120 & 0.50 & 103.59 & 68.74 & 134.10 & 0.426 \\
\hline 122 & 0.50 & 104.59 & 69.22 & 136.46 & 0.430 \\
\hline 125 & 0.50 & 106.09 & 69.37 & 137.24 & 0.431 \\
\hline 130 & 0.50 & 108.59 & 69.37 & 137.24 & 0.431 \\
\hline 135 & 0.50 & 111.09 & 69.85 & 139.59 & 0.436 \\
\hline 136 & 0.50 & 111.59 & 63.50 & 108.22 & 0.376 \\
\hline 140 & 0.50 & 113.59 & 64.29 & 112.14 & 0.384 \\
\hline 145 & 0.55 & 116.22 & 64.61 & 113.71 & 0.387 \\
\hline 150 & 0.50 & 118.84 & 63.18 & 106.65 & 0.373 \\
\hline 155 & 0.50 & 121.34 & 63.50 & 108.22 & 0.376 \\
\hline 160 & 0.50 & 123.84 & 64.14 & 111.36 & 0.382 \\
\hline 165 & 0.50 & 126.34 & 64.77 & 114.50 & 0.389 \\
\hline & & & & & \\
\hline
\end{tabular}


Table A.18. Gas Retention Data for a 67-Pa Clay (35.7-cm initial height and 5.08-cm tube diameter)

\begin{tabular}{|c|c|c|c|c|c|}
\hline $\begin{array}{c}\text { Elapsed } \\
\text { Time, min }\end{array}$ & $\begin{array}{c}\text { Flow Rate, } \\
\mathrm{ml} / \mathrm{min}\end{array}$ & $\begin{array}{c}\text { Volume Gas } \\
\text { Generated, } \mathbf{m L}\end{array}$ & $\begin{array}{c}\text { Sludge } \\
\text { Height, cm } \\
\end{array}$ & $\begin{array}{c}\text { Sludge } \\
\text { Volume, } \mathrm{mL} \\
\end{array}$ & $\begin{array}{c}\text { Sludge Gas } \\
\text { Volume Fraction }\end{array}$ \\
\hline 0 & 5.30 & 0.00 & 35.74 & 0.00 & 0.031 \\
\hline 2 & 8.20 & 13.50 & 36.85 & 23.31 & 0.061 \\
\hline 4 & 5.01 & 26.71 & 37.64 & 39.97 & 0.082 \\
\hline 6 & 4.98 & 36.70 & 38.28 & 53.29 & 0.097 \\
\hline$\overline{8}$ & 4.60 & 46.28 & 38.91 & 66.61 & 0.113 \\
\hline 10 & 4.50 & 55.38 & 39.55 & 79.93 & 0.127 \\
\hline 12 & 4.50 & 64.38 & 40.18 & 93.26 & 0.142 \\
\hline 14 & 4.40 & 73.28 & 40.82 & 106.58 & 0.155 \\
\hline 16 & 4.25 & 81.93 & 41.45 & 119.90 & 0.169 \\
\hline 18 & 4.20 & 90.38 & 41.93 & 129.89 & 0.179 \\
\hline 20 & 4.10 & 98.68 & 42.41 & 139.88 & 0.188 \\
\hline 22 & 4.00 & 106.78 & 42.88 & 149.88 & 0.198 \\
\hline 24 & 4.00 & 114.78 & 43.36 & 159.87 & 0.207 \\
\hline 26 & 3.90 & 122.68 & 43.99 & 173.19 & 0.219 \\
\hline 28 & 3.75 & 130.33 & 44.63 & 186.51 & 0.230 \\
\hline 30 & 3.75 & 137.83 & 45.10 & 196.50 & 0.239 \\
\hline 32 & 3.70 & 145.28 & 45.58 & 206.50 & 0.247 \\
\hline 34 & 3.70 & 152.68 & 45.90 & 213.16 & 0.252 \\
\hline 36 & 3.60 & 159.98 & 46.37 & 223.15 & 0.260 \\
\hline 38 & 3.60 & 167.18 & 47.01 & 236.47 & 0.271 \\
\hline 40 & 3.60 & 174.38 & 47.49 & 246.46 & 0.278 \\
\hline 42 & 3.50 & 181.48 & 47.96 & 256.45 & 0.286 \\
\hline 44 & 3.50 & 188.48 & 48.44 & 266.45 & 0.293 \\
\hline 46 & 3.45 & 195.43 & 48.76 & 273.11 & 0.298 \\
\hline 48 & 3.50 & 202.38 & 49.07 & 279.77 & 0.303 \\
\hline 50 & 3.45 & 209.33 & 49.71 & 293.09 & 0.312 \\
\hline 52 & 3.35 & 216.13 & 50.03 & 299.75 & 0.317 \\
\hline 54 & 3.30 & 222.78 & 50.34 & 306.41 & 0.321 \\
\hline 56 & 3.40 & 229.48 & 50.66 & 313.07 & 0.326 \\
\hline 58 & 3.30 & 236.18 & 51.14 & 323.07 & 0.332 \\
\hline 60 & 3.30 & 242.78 & 51.61 & 333.06 & 0.339 \\
\hline 62 & 3.30 & 249.38 & 52.09 & 343.05 & 0.345 \\
\hline
\end{tabular}


Table A.18 (contd)

\begin{tabular}{||c|c|c|c|c|c||}
\hline $\begin{array}{c}\text { Elapsed } \\
\text { Time, min }\end{array}$ & $\begin{array}{c}\text { Flow Rate, } \\
\text { ml/min }\end{array}$ & $\begin{array}{c}\text { Volume Gas } \\
\text { Generated, mL }\end{array}$ & $\begin{array}{c}\text { Sludge } \\
\text { Height, cm }\end{array}$ & $\begin{array}{c}\text { Sludge } \\
\text { Volume, mL }\end{array}$ & $\begin{array}{c}\text { Sludge Gas } \\
\text { Volume Fraction }\end{array}$ \\
\hline \hline 64 & 3.30 & 255.98 & 52.41 & 349.71 & 0.349 \\
\hline 66 & 3.10 & 262.38 & 52.72 & 356.37 & 0.353 \\
\hline 68 & 3.00 & 268.48 & 53.20 & 366.36 & 0.359 \\
\hline 70 & 2.80 & 274.28 & 53.52 & 373.02 & 0.363 \\
\hline 72 & 2.80 & 279.88 & 53.84 & 379.69 & 0.367 \\
\hline 74 & 2.90 & 285.58 & 53.99 & 383.02 & 0.369 \\
\hline 76 & 2.60 & 291.08 & 54.15 & 386.35 & 0.371 \\
\hline 78 & 2.40 & 296.08 & 54.15 & 386.35 & 0.371 \\
\hline 80 & 2.50 & 300.98 & 53.84 & 379.69 & 0.367 \\
\hline 82 & 2.50 & 305.98 & 53.99 & 383.02 & 0.369 \\
\hline 84 & 2.45 & 310.93 & 53.68 & 376.35 & 0.365 \\
\hline 86 & 2.30 & 315.68 & 53.52 & 373.02 & 0.363 \\
\hline 88 & 3.00 & 320.98 & 53.52 & 373.02 & 0.363 \\
\hline 90 & 2.50 & 326.48 & 51.61 & 333.06 & 0.339 \\
\hline 92 & 2.50 & 331.48 & 51.61 & 333.06 & 0.339 \\
\hline 97 & 3.00 & 345.23 & 50.34 & 306.41 & 0.321 \\
\hline 102 & 3.00 & 360.23 & 50.34 & 306.41 & 0.321 \\
\hline 112 & 2.50 & 387.73 & 50.34 & 306.41 & 0.321 \\
\hline 122 & 2.50 & 412.73 & 49.71 & 293.09 & 0.312 \\
\hline 132 & 2.50 & 437.73 & 49.71 & 293.09 & 0.312 \\
\hline 142 & 2.5 & 462.73 & 49.71 & 293.09 & 0.312 \\
\hline & & & & & \\
\hline
\end{tabular}


Table A.19. Gas Retention Data for a 67-Pa Clay (35.6-cm initial height and 5.08- $\mathrm{cm}$ tube diameter)

\begin{tabular}{|c|c|c|c|c|c|}
\hline $\begin{array}{l}\text { Elapsed } \\
\text { Time, min }\end{array}$ & $\begin{array}{l}\text { Flow Rate, } \\
\mathrm{mL} / \mathrm{min}\end{array}$ & $\begin{array}{l}\text { Volume Gas } \\
\text { Generated, } \mathrm{mL}\end{array}$ & $\begin{array}{c}\text { Sludge } \\
\text { Height, } \mathrm{cm}\end{array}$ & $\begin{array}{c}\text { Sludge } \\
\text { Volume, } \mathrm{mL}\end{array}$ & $\begin{array}{c}\text { Sludge Gas } \\
\text { Volume Fraction }\end{array}$ \\
\hline$\overline{0}$ & 9.5 & 0 & 32.5628 & 0 & 0.032 \\
\hline$\overline{2}$ & 9.5 & 19 & 33.5153 & 19.98345 & 0.061 \\
\hline 4 & 9.25 & 37.75 & 34.4678 & 39.9669 & 0.088 \\
\hline$\overline{6}$ & 9.25 & 56.25 & 35.7378 & 66.6115 & 0.121 \\
\hline 8 & 9.25 & 74.75 & 36.6903 & 86.59495 & 0.145 \\
\hline 10 & 9 & $\overline{93}$ & 37.6428 & 106.5784 & 0.167 \\
\hline$\overline{12}$ & 8.5 & 110.5 & 38.5953 & 126.56185 & 0.189 \\
\hline$\overline{14}$ & $\overline{8}$ & 127 & 39.5478 & 146.5453 & 0.209 \\
\hline$\overline{16}$ & $\overline{7.5}$ & 142.5 & 40.1828 & 159.8676 & 0.222 \\
\hline$\overline{18}$ & 7 & 157 & 41.1353 & 179.85105 & 0.241 \\
\hline 20 & 7 & $\overline{171}$ & 41.7703 & 193.17335 & 0.253 \\
\hline$\overline{25}$ & 7 & 206 & 43.6753 & 233.14025 & 0.287 \\
\hline 30 & 6.75 & 240.375 & 45.2628 & 266.446 & 0.313 \\
\hline 35 & 6.5 & 273.5 & 46.8503 & 299.75175 & 0.337 \\
\hline 40 & 6 & 304.75 & 48.1203 & 326.39635 & 0.356 \\
\hline$\overline{45}$ & 6 & 334.75 & 49.3903 & 353.04095 & 0.373 \\
\hline 50 & 5 & 362.25 & 50.6603 & 379.68555 & 0.390 \\
\hline$\overline{55}$ & $\overline{4.2}$ & 385.25 & 51.2953 & 393.00785 & 0.397 \\
\hline$\overline{60}$ & $\overline{3.5}$ & 404.5 & 51.6128 & 399.669 & 0.401 \\
\hline 65 & 2.8 & 420.25 & 51.9303 & 406.33015 & 0.405 \\
\hline 70 & $\overline{3}$ & 434.75 & 52.2478 & 412.9913 & 0.409 \\
\hline 75 & 3 & 449.75 & 52.2478 & 412.9913 & 0.409 \\
\hline 80 & $\overline{3}$ & 464.75 & 52.2478 & 412.9913 & 0.409 \\
\hline 85 & $\overline{3}$ & 479.75 & 51.9303 & 406.33015 & 0.405 \\
\hline 87 & 3 & 485.75 & 51.2953 & 393.00785 & 0.397 \\
\hline 89 & 2.75 & 491.5 & 51.6128 & 399.669 & 0.401 \\
\hline 90 & 2.75 & 494.25 & 50.3428 & 373.0244 & 0.385 \\
\hline 95 & 2.75 & 508 & 50.3428 & 373.0244 & 0.385 \\
\hline 100 & 2.75 & 521.75 & 49.3903 & 353.04095 & 0.373 \\
\hline 102 & 2.75 & 527.25 & 49.0728 & 346.3798 & 0.369 \\
\hline 105 & 2.5 & 535.125 & 49.3903 & 353.04095 & 0.373 \\
\hline 110 & 2.25 & 547 & 49.0728 & 346.3798 & 0.369 \\
\hline 113 & 2.25 & 553.75 & 48.7553 & 339.71865 & 0.364 \\
\hline
\end{tabular}


Table A.19 (contd)

\begin{tabular}{||c|c|c|c|c|c|}
\hline $\begin{array}{c}\text { Elapsed } \\
\text { Time, min }\end{array}$ & $\begin{array}{c}\text { Flow Rate, } \\
\mathrm{mL} / \mathrm{min}\end{array}$ & $\begin{array}{c}\text { Volume Gas } \\
\text { Generated, mL }\end{array}$ & $\begin{array}{c}\text { Sludge } \\
\text { Height, } \mathrm{cm}\end{array}$ & $\begin{array}{c}\text { Sludge } \\
\text { Volume, mL }\end{array}$ & $\begin{array}{c}\text { Sludge Gas } \\
\text { Volume Fraction }\end{array}$ \\
\hline \hline 115 & 2 & 558 & 47.8028 & 319.7352 & 0.351 \\
\hline 120 & 1.8 & 567.5 & 47.8028 & 319.7352 & 0.351 \\
\hline 125 & 1.8 & 576.5 & 47.1678 & 306.4129 & 0.342 \\
\hline 130 & 1.8 & 585.5 & 47.4853 & 313.07405 & 0.347 \\
\hline 135 & 2 & 595 & 48.1203 & 326.39635 & 0.356 \\
\hline 140 & 2 & 605 & 48.4378 & 333.0575 & 0.360 \\
\hline 150 & 1.8 & 624 & 49.0728 & 346.3798 & 0.369 \\
\hline 210 & 1.8 & 732 & 45.2628 & 266.446 & 0.313 \\
\hline
\end{tabular}


Table A.20. Gas Retention Data for 67:Pa Clay (31.4-cm initial height and 10.16-cm diameter)

\begin{tabular}{|c|c|c|c|c|c|}
\hline $\begin{array}{l}\text { Elapsed } \\
\text { Time, min }\end{array}$ & $\begin{array}{l}\text { Flow Rate, } \\
\mathrm{mL} / \mathrm{min}\end{array}$ & $\begin{array}{l}\text { Volume Gas } \\
\text { Generated, } \mathrm{mL}\end{array}$ & $\begin{array}{l}\text { Sludge } \\
\text { Height, } \mathrm{cm}\end{array}$ & $\begin{array}{c}\text { Sludge } \\
\text { Volume, } \mathrm{mL}\end{array}$ & \begin{tabular}{c|} 
Sludge Gas \\
Volume Fraction
\end{tabular} \\
\hline 0 & 15.50 & 0.00 & $\overline{31.43}$ & 0.00 & $\overline{0.044}$ \\
\hline 2 & 15.50 & 31.00 & 32.07 & 50.01 & 0.064 \\
\hline 4 & 15.00 & 61.50 & 32.54 & 87.52 & 0.078 \\
\hline 6 & 15.20 & 91.70 & 33.18 & 137.53 & 0.097 \\
\hline 8 & 14.90 & 121.80 & 33.50 & 162.54 & 0.106 \\
\hline 10 & 14.90 & 151.60 & 33.97 & 200.05 & 0.119 \\
\hline 12 & 14.80 & 181.30 & 34.45 & 237.56 & 0.132 \\
\hline 14 & 15.00 & 211.10 & 34.93 & 275.07 & 0.144 \\
\hline 16 & 14.70 & 240.80 & 35.56 & 325.08 & 0.160 \\
\hline 18 & 14.80 & 270.30 & 36.04 & 362.59 & 0.172 \\
\hline 20 & 14.50 & 299.60 & 36.51 & 400.10 & 0.183 \\
\hline$\overline{22}$ & 14.40 & 328.50 & 36.99 & 437.61 & 0.194 \\
\hline 24 & 14.60 & 357.50 & 37.62 & 487.62 & 0.209 \\
\hline 26 & 14.50 & 386.60 & 38.10 & 525.13 & 0.219 \\
\hline 28 & 14.50 & 415.60 & 38.58 & 562.64 & 0.229 \\
\hline 30 & 14.30 & 444.40 & 38.89 & 587.65 & 0.236 \\
\hline 32 & 14.30 & 473.00 & 39.37 & 625.16 & 0.246 \\
\hline 34 & 14.00 & 501.30 & 39.85 & 662.67 & 0.255 \\
\hline 36 & 13.50 & 528.80 & 40.32 & 700.18 & 0.264 \\
\hline$\overline{38}$ & 13.50 & 555.80 & 40.64 & 725.18 & 0.271 \\
\hline 40 & 13.50 & 582.80 & 40.96 & 750.19 & 0.277 \\
\hline 42 & 13.50 & 609.80 & 41.28 & 775.20 & 0.282 \\
\hline 44 & 13.50 & 636.80 & 41.75 & 812.70 & 0.291 \\
\hline 46 & 13.50 & 663.80 & 42.07 & 837.71 & 0.297 \\
\hline 48 & 12.90 & 690.20 & 42.55 & 875.22 & 0.305 \\
\hline 50 & 12.00 & 715.10 & 42.86 & 900.23 & 0.311 \\
\hline 52 & 12.20 & 739.30 & 43.18 & 925.23 & 0.316 \\
\hline 54 & 13.00 & 764.50 & 43.66 & 962.74 & 0.324 \\
\hline 60 & 11.90 & 839.20 & 44.77 & 1050.26 & 0.342 \\
\hline 62 & 12.00 & 863.10 & 45.24 & 1087.77 & 0.349 \\
\hline 72 & 12.00 & 983.10 & 46.99 & 1225.31 & 0.375 \\
\hline 76 & 12.00 & 1031.10 & 47.63 & 1275.32 & 0.384 \\
\hline 80 & 11.50 & 1078.10 & 47.94 & 1300.33 & 0.388 \\
\hline$\overline{82}$ & 11.90 & 1101.50 & 48.42 & 1337.84 . & 0.395 \\
\hline$\overline{84}$ & 12.00 & 1125.40 & 48.90 & 1375.35 & 0.401 \\
\hline 86 & 12.00 & 1149.40 & 49.37 & 1412.86 & 0.407 \\
\hline
\end{tabular}


Table A.20 (contd)

\begin{tabular}{|c|c|c|c|c|c|}
\hline $\begin{array}{c}\text { Elapsed } \\
\text { Time, } \mathrm{min}\end{array}$ & $\begin{array}{c}\text { Flow Rate, } \\
\mathrm{mL} / \mathrm{min}\end{array}$ & $\begin{array}{l}\text { Volume Gas } \\
\text { Generated, } \mathrm{mL}\end{array}$ & $\begin{array}{c}\text { Sludge } \\
\text { Height, cm }\end{array}$ & $\begin{array}{c}\text { Sludge } \\
\text { Volume, } \mathrm{mL} \\
\end{array}$ & $\begin{array}{c}\text { Sludge Gas } \\
\text { Volume Fraction }\end{array}$ \\
\hline 88 & 10.50 & 1171.90 & 49.69 & 1437.86 & 0.411 \\
\hline 90 & 10.90 & 1193.30 & 49.85 & 1450.37 & 0.413 \\
\hline 92 & 12.00 & 1216.20 & 50.17 & 1475.37 & 0.417 \\
\hline 94 & 11.50 & 1239.70 & 50.48 & 1500.38 & 0.421 \\
\hline 96 & 11.50 & 1262.70 & 50.80 & 1525.38 & 0.425 \\
\hline 98 & 11.50 & 1285.70 & 51.12 & 1550.39 & 0.429 \\
\hline 100 & 10.90 & 1308.10 & 51.44 & 1575.40 & 0.433 \\
\hline 102 & 10.50 & 1329.50 & 51.59 & 1587.90 & 0.435 \\
\hline 104 & 10.50 & 1350.50 & 51.75 & 1600.40 & 0.437 \\
\hline 106 & 10.50 & 1371.50 & 52.23 & 1637.91 & 0.442 \\
\hline 110 & 10.00 & 1412.50 & 52.71 & 1675.42 & 0.448 \\
\hline 112 & 10.50 & 1433.00 & 53.02 & 1700.43 & 0.451 \\
\hline 114 & 10.00 & 1453.50 & 53.34 & 1725.43 & 0.455 \\
\hline 116 & 9.20 & 1472.70 & 53.66 & 1750.44 & 0.458 \\
\hline 118 & 9.00 & 1490.90 & 53.82 & 1762.94 & 0.460 \\
\hline 120 & 9.00 & 1508.90 & 53.82 & 1762.94 & $0 . \overline{460}$ \\
\hline 122 & 9.00 & 1526.90 & 53.98 & 1775.45 & 0.462 \\
\hline 124 & 9.00 & 1544.90 & 54.13 & 1787.95 & 0.463 \\
\hline 126 & 9.00 & 1562.90 & 54.29 & 1800.45 & 0.465 \\
\hline 128 & 8.75 & 1580.65 & 54.61 & 1825.46 & 0.468 \\
\hline 130 & 9.00 & 1598.40 & 54.77 & 1837.96 & 0.470 \\
\hline 132 & 8.50 & 1615.90 & 54.77 & 1837.96 & 0.470 \\
\hline 134 & 9.00 & 1633.40 & 54.77 & 1837.96 & 0.470 \\
\hline 136 & 8.50 & 1650.90 & 54.77 & 1837.96 & 0.470 \\
\hline 138 & 8.80 & 1668.20 & 54.77 & 1837.96 & 0.470 \\
\hline 140 & 8.50 & 1685.50 & 54.61 & 1825.46 & 0.468 \\
\hline 145 & 8.00 & 1726.75 & 54.77 & 1837.96 & 0.470 \\
\hline 150 & 8.00 & 1766.75 & 54.77 & 1837.96 & 0.470 \\
\hline 155 & 8.00 & 1806.75 & 54.77 & 1837.96 & 0.470 \\
\hline 160 & 7.50 & 1845.50 & 54.45 & 1812.96 & 0.467 \\
\hline 165 & 7.50 & 1883.00 & 54.77 & 1837.96 & 0.470 \\
\hline 170 & 7.50 & 1920.50 & 54.77 & 1837.96 & 0.470 \\
\hline
\end{tabular}


Table A.21. Gas Retention Data for a 67-Pa Clay $(27.0-\mathrm{cm}$ initial height and 10.16- $\mathrm{cm}$ tube diameter)

\begin{tabular}{|c|c|c|c|c|c|}
\hline $\begin{array}{c}\text { Elapsed } \\
\text { Time, min }\end{array}$ & $\begin{array}{c}\text { Flow Rate, } \\
\mathrm{mL} / \mathrm{min}\end{array}$ & $\begin{array}{l}\text { Volume Gas } \\
\text { Generated, } \mathrm{mL}\end{array}$ & $\begin{array}{c}\text { Sludge } \\
\text { Height, cm }\end{array}$ & \begin{tabular}{|c|} 
Sludge \\
Volume, $\mathrm{mL}$ \\
\end{tabular} & $\begin{array}{c}\text { Sludge Gas } \\
\text { Volume Fraction }\end{array}$ \\
\hline 0 & 30.00 & 0.00 & 26.99 & 0.00 & 0.032 \\
\hline 2 & 30.00 & 60.00 & 27.62 & 50.01 & 0.055 \\
\hline 4 & 30.00 & 120.00 & 28.58 & 125.03 & 0.088 \\
\hline$\overline{6}$ & 30.00 & 180.00 & 29.53 & 200.05 & 0.118 \\
\hline$\overline{8}$ & 30.00 & 240.00 & 30.48 & 275.07 & 0.147 \\
\hline 10 & 30.00 & 300.00 & 31.12 & 325.08 & 0.165 \\
\hline 12 & 29.00 & 359.00 & 31.75 & 375.09 & 0.182 \\
\hline 14 & 28.00 & 416.00 & 32.39 & 425.11 & 0.199 \\
\hline 16 & 27.00 & 471.00 & 33.02 & 475.12 & 0.215 \\
\hline 18 & 26.00 & 524.00 & 33.66 & 525.13 & 0.230 \\
\hline 20 & 24.50 & 574.50 & 34.29 & 575.14 & 0.245 \\
\hline 25 & 23.00 & 693.25 & 36.20 & 725.18 & 0.287 \\
\hline 30 & 22.00 & 805.75 & 37.47 & 825.21 & 0.312 \\
\hline 35 & 20.00 & 910.75 & 39.05 & 950.24 & 0.341 \\
\hline 40 & 20.00 & 1010.75 & 40.32 & 1050.26 & 0.363 \\
\hline 45 & 19.00 & 1108.25 & 41.59 & 1150.29 & 0.383 \\
\hline 50 & 19.00 & 1203.25 & 42.86 & 1250.32 & 0.403 \\
\hline 55 & 16.00 & 1290.75 & 43.82 & 1325.33 & 0.416 \\
\hline 60 & 14.50 & 1367.00 & 44.77 & 1400.35 & 0.429 \\
\hline 65 & 13.50 & 1437.00 & 45.40 & 1450.37 & 0.438 \\
\hline 70 & 13.00 & 1503.25 & 46.04 & 1500.38 & 0.446 \\
\hline 75 & 12.50 & 1567.00 & 46.67 & 1550.39 & 0.454 \\
\hline 80 & 12.50 & 1629.50 & 46.67 & 1550.39 & 0.454 \\
\hline 85 & 12.50 & 1692.00 & 46.99 & 1575.40 & 0.458 \\
\hline 87 & 12.00 & 1716.50 & 46.99 & 1575.40 & 0.458 \\
\hline 89 & 11.00 & 1739.50 & 46.99 & 1575.40 & 0.458 \\
\hline 90 & 10.50 & 1750.25 & 46.99 & 1575.40 & 0.458 \\
\hline 95 & 10.00 & 1801.50 & 46.99 & 1575.40 & 0.458 \\
\hline 100 & 10.00 & 1851.50 & 46.67 & 1550.39 & 0.454 \\
\hline 102 & 10.00 & 1871.50 & 45.72 & 1475.37 & 0.442 \\
\hline 105 & 9.50 & 1900.75 & 45.09 & 1425.36 & 0.434 \\
\hline 110 & 9.00 & 1947.00 & 45.09 & 1425.36 & 0.434 \\
\hline 113 & 8.50 & 1973.25 & 44.45 & 1375.35 & 0.425 \\
\hline
\end{tabular}


Table A.21 (contd)

\begin{tabular}{||c|c|c|c|c|c||}
\hline $\begin{array}{c}\text { Elapsed } \\
\text { Time, min }\end{array}$ & $\begin{array}{c}\text { Flow Rate, } \\
\mathrm{mL} / \mathrm{min}\end{array}$ & $\begin{array}{c}\text { Volume Gas } \\
\text { Generated, mL }\end{array}$ & $\begin{array}{c}\text { Sludge } \\
\text { Height, cm }\end{array}$ & $\begin{array}{c}\text { Sludge } \\
\text { Volume, mL }\end{array}$ & $\begin{array}{c}\text { Sludge Gas } \\
\text { Volume Fraction }\end{array}$ \\
\hline \hline 115 & 8.00 & 1989.75 & 44.45 & 1375.35 & 0.425 \\
\hline 120 & 7.50 & 2028.50 & 44.45 & 1375.35 & 0.425 \\
\hline 125 & 7.00 & 2064.75 & 44.45 & 1375.35 & 0.425 \\
\hline 130 & 8.00 & 2102.25 & 43.18 & 1275.32 & 0.407 \\
\hline 135 & 8.00 & 2142.25 & 42.55 & 1225.31 & 0.398 \\
\hline 140 & 7.00 & 2179.75 & 41.91 & 1175.30 & 0.388 \\
\hline 150 & 6.80 & 2248.75 & 41.28 & 1125.28 & 0.378 \\
\hline 210 & 6.80 & 2656.75 & 39.37 & 975.25 & 0.347 \\
\hline
\end{tabular}


Table A.22. Gas Retention Data for a 67-Pa Clay (29.0-cm initial height and 15.24-cm tube diameter)

\begin{tabular}{|c|c|c|c|c|c|}
\hline $\begin{array}{l}\text { Elapsed } \\
\text { Time, min }\end{array}$ & $\begin{array}{c}\text { Flow Rate, } \\
\mathrm{mL} / \mathrm{min}\end{array}$ & $\begin{array}{l}\text { Volume Gas } \\
\text { Generated, } \mathrm{mL}\end{array}$ & $\begin{array}{c}\text { Sludge } \\
\text { Height, } \mathrm{cm}\end{array}$ & $\begin{array}{c}\text { Sludge } \\
\text { Volume, } \mathrm{mL}\end{array}$ & \begin{tabular}{c|} 
Sludge Gas \\
Volume Fraction
\end{tabular} \\
\hline 0 & 60.00 & 0.00 & 29.03 & 0.00 & 0.045 \\
\hline 2 & 57.00 & 117.00 & 29.67 & 125.29 & 0.067 \\
\hline$\overline{4}$ & 55.00 & 229.00 & 30.30 & 250.57 & 0.087 \\
\hline 6 & 54.00 & 338.00 & 30.94 & 375.86 & 0.107 \\
\hline 8 & 51.00 & 443.00 & 31.57 & 501.14 & 0.126 \\
\hline 10 & 49.90 & 543.90 & 32.21 & 626.43 & 0.144 \\
\hline$\overline{12}$ & 48.20 & 642.00 & 32.84 & 751.71 & 0.161 \\
\hline 14 & 46.20 & 736.40 & $\begin{array}{l}33.48 \\
\end{array}$ & 877.00 & 0.178 \\
\hline$\overline{16}$ & 45.00 & 827.60 & 34.11 & 1002.28 & 0.194 \\
\hline 18 & 43.00 & 915.60 & 34.43 & 1064.93 & 0.202 \\
\hline 20 & 42.50 & 1001.10 & 34.75 & 1127.57 & $\overline{0.210}$ \\
\hline 22 & 42.50 & 1086.10 & 35.38 & 1252.86 & 0.225 \\
\hline 24 & 40.00 & 1168.60 & 35.86 & 1346.82 & 0.236 \\
\hline 26 & 41.80 & 1250.40 & 36.33 & 1440.78 & 0.246 \\
\hline 28 & 42.00 & 1334.20 & 36.97 & 1566.07 & 0.260 \\
\hline 30 & 40.00 & 1416.20 & 37.45 & 1660.03 & 0.270 \\
\hline 32 & 38.20 & 1494.40 & 37.92 & 1754.00 & 0.280 \\
\hline$\overline{34}$ & 38.10 & 1570.70 & 38.24 & 1816.64 & $\overline{0.286}$ \\
\hline 36 & 38.10 & 1646.90 & 38.56 & 1879.28 & 0.292 \\
\hline 38 & 37.50 & 1722.50 & 38.87 & 1941.93 & 0.298 \\
\hline$\overline{40}$ & 36.00 & 1796.00 & 39.19 & 2004.57 & 0.305 \\
\hline 42 & 35.50 & 1867.50 & 39.51 & 2067.21 & 0.310 \\
\hline 44 & 36.00 & 1939.00 & 39.83 & 2129.85 & 0.316 \\
\hline 46 & 35.00 & 2010.00 & 40.30 & 2223.82 & 0.325 \\
\hline$\overline{48}$ & 35.00 & 2080.00 & 40.78 & 2317.78 & 0.333 \\
\hline 50 & 35.00 & 2150.00 & 41.10 & 2380.42 & 0.339 \\
\hline 52 & 35.00 & 2220.00 & 41.41 & 2443.07 & 0.344 \\
\hline 54 & 34.50 & 2289.50 & 41.73 & 2505.71 & 0.350 \\
\hline$\overline{62}$ & 30.00 & 2547.50 & 43.48 & 2850.25 & 0.378 \\
\hline 66 & 31.00 & 2669.50 & 44.11 & 2975.53 & 0.387 \\
\hline 68 & 31.00 & 2731.50 & 44.59 & 3069.49 & 0.394 \\
\hline 70 & 30.00 & 2792.50 & 44.75 & 3100.82 & 0.397 \\
\hline 72 & 28.50 & 2851.00 & 44.91 & 3132.14 & 0.399 \\
\hline
\end{tabular}


Table A.22 (contd)

\begin{tabular}{||c|c|c|c|c|c||}
\hline $\begin{array}{c}\text { Elapsed } \\
\text { Time, min }\end{array}$ & $\begin{array}{c}\text { Flow Rate, } \\
\mathrm{mL} / \mathrm{min}\end{array}$ & $\begin{array}{c}\text { Volume Gas } \\
\text { Generated, } \mathrm{mL}\end{array}$ & $\begin{array}{c}\text { Sludge } \\
\text { Height, } \mathrm{cm}\end{array}$ & $\begin{array}{c}\text { Sludge } \\
\text { Volume, mL }\end{array}$ & $\begin{array}{c}\text { Sludge Gas } \\
\text { Volume Fraction }\end{array}$ \\
\hline 76 & 29.00 & 2966.00 & 45.54 & 3257.42 & 0.408 \\
\hline 78 & 28.50 & 3023.50 & 45.70 & 3288.74 & 0.410 \\
\hline 80 & 28.00 & 3080.00 & 45.86 & 3320.07 & 0.412 \\
\hline 82 & 27.50 & 3135.50 & 46.18 & 3382.71 & 0.417 \\
\hline 84 & 26.50 & 3189.50 & 46.49 & 3445.35 & 0.421 \\
\hline 98 & 26.50 & 3560.50 & 47.76 & 3695.92 & 0.437 \\
\hline 100 & 25.50 & 3612.50 & 47.92 & 3727.24 & 0.439 \\
\hline 102 & 25.00 & 3663.00 & 48.08 & 3758.57 & 0.441 \\
\hline 104 & 25.00 & 3713.00 & 48.24 & 3789.89 & 0.443 \\
\hline 106 & 25.00 & 3763.00 & 48.40 & 3821.21 & 0.445 \\
\hline 108 & 25.00 & 3813.00 & 48.72 & 3883.85 & 0.449 \\
\hline 112 & 25.00 & 3913.00 & 48.72 & 3883.85 & 0.449 \\
\hline 114 & 25.00 & 3963.00 & 48.72 & 3883.85 & 0.449 \\
\hline 116 & 24.30 & 4012.30 & 48.72 & 3883.85 & 0.449 \\
\hline 122 & 23.00 & 4154.20 & 48.72 & 3883.85 & 0.449 \\
\hline 126 & 22.50 & 4245.20 & 48.72 & 3883.85 & 0.449 \\
\hline 134 & 22.50 & 4425.20 & 48.72 & 3883.85 & 0.449 \\
\hline 140 & 21.50 & 4557.20 & 48.72 & 3883.85 & 0.449 \\
\hline 140.3 & 35.00 & 4565.68 & 47.76 & 3695.92 & 0.437 \\
\hline 142 & 25.00 & 4616.68 & 47.76 & 3695.92 & 0.437 \\
\hline 142.16 & 122.00 & 4628.44 & 31.57 & 501.14 & 0.126 \\
\hline 144 & 17.50 & 4756.78 & 31.57 & 501.14 & 0.126 \\
\hline 160 & 20.00 & 5056.78 & 32.52 & 689.07 & 0.153 \\
\hline 170 & 18.50 & & 33.48 & 877.00 & 0.178 \\
\hline & & & & & \\
\hline
\end{tabular}


Table A.23. Gas Retention Data for a 67-Pa Clay (30.5-cm initial height and 30.48-cm tube diameter)

\begin{tabular}{||c|c|c|c|c|c||}
\hline $\begin{array}{c}\text { Elapsed } \\
\text { Time, } \mathrm{min}\end{array}$ & $\begin{array}{c}\text { Flow Rate, } \\
\mathrm{mL} / \mathrm{min}\end{array}$ & $\begin{array}{c}\text { Volume Gas } \\
\text { Generated, mL }\end{array}$ & $\begin{array}{c}\text { Sludge } \\
\text { Height, cm }\end{array}$ & $\begin{array}{c}\text { Sludge } \\
\text { Volume, mL }\end{array}$ & $\begin{array}{c}\text { Sludge Gas } \\
\text { Volume Fraction }\end{array}$ \\
\hline \hline 0 & 250.00 & 0.00 & 30.48 & 0.00 & 0.020 \\
\hline 5 & 248.00 & 1245.00 & 32.07 & 1157.75 & 0.069 \\
\hline 10 & 243.00 & 2472.50 & 33.97 & 2547.04 & 0.122 \\
\hline 15 & 235.00 & 3667.50 & 35.24 & 3473.24 & 0.155 \\
\hline 20 & 230.00 & 4830.00 & 36.20 & 4167.89 & 0.177 \\
\hline 25 & 200.00 & 5905.00 & 37.47 & 5094.08 & 0.206 \\
\hline 40 & 212.00 & 8995.00 & 42.23 & 8567.32 & 0.298 \\
\hline 45 & 210.00 & 10050.00 & 43.50 & 9493.52 & 0.319 \\
\hline 50 & 175.00 & 11012.50 & 44.77 & 10419.71 & 0.339 \\
\hline 55 & 180.00 & 11900.00 & 45.72 & 11114.36 & 0.353 \\
\hline 60 & 180.00 & 12800.00 & 46.67 & 11809.01 & 0.366 \\
\hline 65 & 153.00 & 13632.50 & 47.63 & 12503.66 & 0.380 \\
\hline 70 & 130.00 & 14340.00 & 48.58 & 13198.31 & 0.392 \\
\hline 75 & 125.00 & 14977.50 & 49.53 & 13892.95 & 0.404 \\
\hline 80 & 150.00 & 15665.00 & 50.17 & 14356.05 & 0.412 \\
\hline 85 & 160.00 & 16440.00 & 51.44 & 15282.25 & 0.427 \\
\hline 90 & 100.00 & 17090.00 & 52.07 & 15745.35 & 0.434 \\
\hline 95 & 120.00 & 17640.00 & 52.39 & 15976.90 & 0.438 \\
\hline 100 & 120.00 & 18240.00 & 53.02 & 16439.99 & 0.445 \\
\hline 105 & 150.00 & 18915.00 & 53.66 & 16903.09 & 0.451 \\
\hline 110 & 130.00 & 19615.00 & 53.98 & 17134.64 & 0.455 \\
\hline 115 & 150.00 & 20315.00 & 54.61 & 17597.74 & 0.461 \\
\hline 120 & 120.00 & 20990.00 & 55.25 & 18060.84 & 0.468 \\
\hline 125 & 130.00 & 21615.00 & 55.25 & 18060.84 & 0.468 \\
\hline 130 & 130.00 & 22265.00 & 55.56 & 18292.39 & 0.471 \\
\hline 135 & 150.00 & 22965.00 & 55.56 & 18292.39 & 0.471 \\
\hline 140 & 130.00 & 23665.00 & 55.56 & 18292.39 & 0.471 \\
\hline 145 & 134.00 & 24325.00 & 55.56 & 18292.39 & 0.471 \\
\hline 146 & 290.00 & 24537.00 & 34.61 & 3010.14 & 0.139 \\
\hline 150 & 120.00 & 25357.00 & 35.24 & 3473.24 & 0.155 \\
\hline 160 & 120.00 & 26557.00 & 35.88 & 3936.34 & 0.170 \\
\hline & & & & & \\
\hline
\end{tabular}


Table A.24. Gas Retention Data for a 200-PA Clay (12.5 cm Initial Height and $30.5 \mathrm{~cm}$ Tube Diameter)

\begin{tabular}{||c|c|c|c|c||}
\hline $\begin{array}{c}\text { Elapsed } \\
\text { Time, min }\end{array}$ & $\begin{array}{c}\text { Volume Gas } \\
\text { Generated, ml }\end{array}$ & $\begin{array}{c}\text { Sludge } \\
\text { Height, cm }\end{array}$ & $\begin{array}{c}\text { Sludge } \\
\text { Volume, ml }\end{array}$ & $\begin{array}{c}\text { Sludge Gas Volume } \\
\text { Fraction }\end{array}$ \\
\hline \hline 0 & & 12.5 & $9,120.38$ & 0.042 \\
\hline 5 & & 13.2 & $9,631.12$ & 0.095 \\
\hline 10 & 342.50 & 14.4 & $10,506.67$ & 0.174 \\
\hline 15 & 990.00 & 15.2 & $11,090.38$ & 0.220 \\
\hline 20 & $1,577.50$ & 16.2 & $11,820.01$ & 0.270 \\
\hline 25 & $2,127.50$ & 17.1 & $12,476.67$ & 0.311 \\
\hline 30 & $2,635.00$ & 17.4 & $12,695.56$ & 0.324 \\
\hline 35 & $3,100.00$ & 17.9 & $13,060.38$ & 0.344 \\
\hline 40 & $3,537.50$ & 18.4 & $13,425.19$ & 0.363 \\
\hline 45 & $3,950.00$ & 18.9 & $13,790.01$ & 0.381 \\
\hline 50 & $4,342.50$ & 19.2 & $14,008.90$ & 0.391 \\
\hline 55 & $4,717.50$ & 19.2 & $14,008.90$ & 0.391 \\
\hline 61 & $5,134.50$ & 18.9 & $13,790.01$ & 0.381 \\
\hline 67 & $5,518.50$ & 18.8 & $13,717.04$ & 0.377 \\
\hline 72 & $5,816.00$ & 18.8 & $13,717.04$ & 0.377 \\
\hline 88 & $6,680.00$ & 18.4 & $13,425.19$ & 0.363 \\
\hline 95 & $7,033.50$ & 18.4 & $13,425.19$ & 0.363 \\
\hline 102 & $7,369.50$ & 18.4 & $13,425.19$ & 0.363 \\
\hline 108 & $7,633.50$ & 18.4 & $13,425.19$ & 0.363 \\
\hline 115 & $7,917.00$ & 18.4 & $13,425.19$ & 0.363 \\
\hline 200 & & & & \\
\hline 1015 & & 17.9 & $13,060.38$ & 0.344 \\
\hline & & & & \\
\hline
\end{tabular}


Table A.25. Gas Retention Data for a 200-PA Clay (11.4 cm Initial Height and $30.5 \mathrm{~cm}$ Tube Diameter), Duplicate

\begin{tabular}{||c|c|c|c|c||}
\hline $\begin{array}{c}\text { Elapsed } \\
\text { Time, min }\end{array}$ & $\begin{array}{c}\text { Volume Gas } \\
\text { Generated, } \mathrm{ml}\end{array}$ & $\begin{array}{c}\text { Sludge } \\
\text { Height, } \mathrm{cm}\end{array}$ & $\begin{array}{c}\text { Sludge } \\
\text { Volume, } \mathrm{ml}\end{array}$ & $\begin{array}{c}\text { Sludge Gas Volume } \\
\text { Fraction }\end{array}$ \\
\hline \hline 0 & 0.0 & 11.4 & $8,317.8$ & 0.045 \\
\hline 10 & 535.0 & 13.2 & $9,631.1$ & 0.181 \\
\hline 13 & 847.0 & 13.8 & $10,068.9$ & 0.219 \\
\hline 17 & $1,243.0$ & 14.1 & $10,287.8$ & 0.236 \\
\hline 22 & $1,710.5$ & 14.5 & $10,579.6$ & 0.259 \\
\hline 27 & $2,138.0$ & 15.5 & $11,309.3$ & 0.310 \\
\hline 32 & $2,530.5$ & 16.1 & $11,747.0$ & 0.337 \\
\hline 37 & $2,900.5$ & 16.5 & $12,038.9$ & 0.354 \\
\hline 42 & $3,258.0$ & 16.9 & $12,330.7$ & 0.370 \\
\hline 48 & $3,654.0$ & 17.4 & $12,695.6$ & 0.390 \\
\hline 52 & $3,900.0$ & 17.9 & $13,060.4$ & 0.408 \\
\hline 57 & $4,202.5$ & 18.1 & $13,206.3$ & 0.415 \\
\hline 62 & $4,492.5$ & 18.3 & $13,352.2$ & 0.422 \\
\hline 67 & $4,772.5$ & 18.7 & $13,644.1$ & 0.435 \\
\hline 72 & $5,035.0$ & 18.7 & $13,644.1$ & 0.435 \\
\hline 77 & $5,270.0$ & 18.5 & $13,498.2$ & 0.429 \\
\hline 82 & $5,490.0$ & 17.9 & $13,060.4$ & 0.408 \\
\hline 87 & $5,710.0$ & 17.7 & $12,914.5$ & 0.401 \\
\hline 92 & $5,925.0$ & 17.7 & $12,914.5$ & 0.401 \\
\hline 97 & $6,140.0$ & 17.5 & $12,768.5$ & 0.394 \\
\hline 102 & $6,345.0$ & 17.5 & $12,768.5$ & 0.394 \\
\hline 107 & $6,535.0$ & 17.6 & $12,841.5$ & 0.397 \\
\hline 115 & $6,811.0$ & 17.6 & $12,841.5$ & 0.397 \\
\hline 120 & $6,963.5$ & 17.6 & $12,841.5$ & 0.397 \\
\hline 420 & & 17.0 & $12,403.7$ & 0.374 \\
\hline 600 & & & & \\
\hline 1200 & & 16.7 & $12,184.8$ & 0.362 \\
\hline & & & & \\
\hline
\end{tabular}


Table A.26. Gas Retention Data for a 200-PA Clay (17.8 cm Initial Height and $91.4 \mathrm{~cm}$ Tube Diameter)

\begin{tabular}{|c|c|c|c|c|}
\hline $\begin{array}{c}\text { Elapsed } \\
\text { Time, min }\end{array}$ & $\begin{array}{c}\text { Volume Gas } \\
\text { Generated, mL }\end{array}$ & $\begin{array}{c}\text { Sludge } \\
\text { Height, cm }\end{array}$ & $\begin{array}{c}\text { Sludge } \\
\text { Volume, }\end{array}$ & $\begin{array}{c}\text { Sludge Gas Volume } \\
\text { Fraction }\end{array}$ \\
\hline \hline 0 & & 17.8 & 116.76 & 0.030 \\
\hline 5 & & 18.4 & 120.93 & 0.064 \\
\hline 10 & & 19.7 & 129.27 & 0.127 \\
\hline 15 & & 21.0 & 137.61 & 0.182 \\
\hline 20 & & 22.2 & 145.94 & 0.230 \\
\hline 25 & & 23.5 & 154.28 & 0.273 \\
\hline 30 & & 24.8 & 162.62 & 0.312 \\
\hline 35 & & 26.0 & 170.96 & 0.347 \\
\hline 40 & & 27.3 & 179.30 & 0.379 \\
\hline 45 & & 28.6 & 187.64 & 0.408 \\
\hline 50 & & 29.8 & 195.98 & 0.434 \\
\hline 60 & & 31.1 & 204.32 & 0.459 \\
\hline 70 & & 31.8 & 208.49 & 0.470 \\
\hline 110 & & 33.0 & 216.83 & 0.492 \\
\hline 120 & & 33.0 & 216.83 & 0.492 \\
\hline 140 & & 33.0 & 216.83 & 0.492 \\
\hline 200 & & 33.0 & 216.83 & 0.492 \\
\hline 260 & & 33.0 & 216.83 & 0.492 \\
\hline 400 & & & & \\
\hline 1120 & & 31.1 & 204.32 & 0.459 \\
\hline
\end{tabular}




\section{Appendix B}

Actual Waste Gas Retention Data 
Table B.1. Gas Retention Data for the S-102 Salt Cake Composite in Vessel 5

\begin{tabular}{||c|c|c|c|c|c||}
\hline Time & $\begin{array}{c}\text { Solids Layer } \\
\text { Height, cm }\end{array}$ & $\begin{array}{c}\text { Total (Liquid) } \\
\text { Height, cm }\end{array}$ & $\begin{array}{c}\text { Growth } \\
\text { Volume, mL }\end{array}$ & $\begin{array}{c}\text { Growth Void } \\
\text { Fraction }\end{array}$ & $\begin{array}{c}\text { Pressure, } \\
\text { mm Hg }\end{array}$ \\
\hline $9: 35: 00$ & 5.80 & 6.30 & 0.0 & 0.000 & 747 \\
\hline $9: 39: 00$ & 5.80 & 6.30 & 0.0 & 0.000 & 747 \\
\hline $9: 39: 32$ & 6.05 & 6.55 & 1.2 & 0.041 & 531 \\
\hline $9: 39: 42$ & 6.15 & 6.65 & 1.7 & 0.057 & 514 \\
\hline $9: 40: 30$ & 6.20 & 6.70 & 1.9 & 0.064 & 473 \\
\hline $9: 41: 30$ & 6.30 & 6.80 & 2.4 & 0.079 & 434 \\
\hline $9: 44: 45$ & 6.30 & 6.80 & 2.4 & 0.079 & 421 \\
\hline $9: 45: 02$ & 6.45 & 6.95 & 3.1 & 0.101 & 381 \\
\hline $9: 45: 17$ & 6.70 & 7.20 & 4.3 & 0.134 & 301 \\
\hline $9: 46: 22$ & 6.20 & 6.70 & 1.9 & 0.064 & 461 \\
\hline $9: 49: 00$ & 6.65 & 7.15 & 4.1 & 0.128 & 321 \\
\hline $9: 50: 00$ & 6.80 & 7.30 & 4.8 & 0.147 & 289 \\
\hline $9: 52: 30$ & 6.90 & 7.35 & 5.0 & 0.152 & 274 \\
\hline $9: 53: 00$ & 7.15 & 7.60 & 6.2 & 0.181 & 240 \\
\hline $9: 55: 00$ & 7.30 & 7.75 & 6.9 & 0.198 & 222 \\
\hline $9: 57: 00$ & 7.45 & 7.90 & 7.6 & 0.214 & 207 \\
\hline $9: 58: 30$ & 7.60 & 8.05 & 8.3 & 0.230 & 196 \\
\hline $9: 59: 00$ & 7.90 & 8.40 & 10.0 & 0.265 & 175 \\
\hline $10: 01: 00$ & 7.95 & 8.50 & 10.5 & 0.276 & 166 \\
\hline $10: 02: 00$ & 8.25 & 8.75 & 11.7 & 0.296 & 153 \\
\hline $10: 03: 30$ & 8.35 & 8.80 & 11.9 & 0.299 & 151 \\
\hline $10: 06: 00$ & & 9.10 & 13.4 & 0.325 & 141 \\
\hline $10: 08: 45$ & & 9.25 & 14.1 & 0.336 & 135 \\
\hline $10: 09: 00$ & & 9.40 & 14.8 & 0.347 & 131 \\
\hline $10: 13: 00$ & & 9.55 & 15.5 & 0.358 & 123 \\
\hline $10: 15: 00$ & & 9.65 & 16.0 & 0.365 & 121 \\
\hline $10: 17: 00$ & & 9.85 & 16.9 & 0.379 & 116 \\
\hline $10: 18: 30$ & & 9.95 & 17.4 & 0.385 & 115 \\
\hline $10: 24: 30$ & & 10.10 & 18.1 & 0.395 & 109 \\
\hline $10: 27: 00$ & & 10.25 & 18.8 & 0.404 & 105 \\
\hline $10: 27: 30$ & & 10.40 & 19.6 & 0.413 & 103 \\
\hline & & & & & \\
\hline
\end{tabular}

B.1 
Table B.1 (contd)

\begin{tabular}{|c|c|c|c|c|c|}
\hline Time & $\begin{array}{c}\text { Solids Layer } \\
\text { Height, cm }\end{array}$ & $\begin{array}{c}\text { Total (Liquid) } \\
\text { Height, cm }\end{array}$ & $\begin{array}{c}\text { Growth } \\
\text { Volume, mL }\end{array}$ & $\begin{array}{c}\text { Growth Void } \\
\text { Fraction }\end{array}$ & $\begin{array}{c}\text { Pressure, } \\
\mathrm{mm} \mathrm{Hg}\end{array}$ \\
\hline \hline $10: 30: 00$ & & 10.45 & 19.8 & 0.416 & 102 \\
\hline $10: 30: 30$ & & 10.50 & 20.0 & 0.419 & 102 \\
\hline $10: 31: 30$ & & 11.20 & 23.4 & 0.457 & 88 \\
\hline $10: 33: 37$ & & 11.25 & 23.6 & 0.459 & 89 \\
\hline $10: 34: 00$ & & 11.00 & 22.4 & 0.446 & 88 \\
\hline $10: 38: 00$ & & 11.05 & 22.7 & 0.449 & 81 \\
\hline $10: 40: 56$ & & 11.45 & 24.6 & 0.469 & 74 \\
\hline $10: 41: 30$ & & 11.15 & 23.1 & 0.454 & 59 \\
\hline $10: 46: 00$ & & 11.00 & 22.4 & 0.446 & 55 \\
\hline $10: 53: 00$ & & 11.00 & 22.4 & 0.446 & 48 \\
\hline
\end{tabular}


Table B.2. Gas Retention Data for the S-102 Salt Cake Composite in Vessel 6

\begin{tabular}{|c|c|c|c|c|c||}
\hline Time & $\begin{array}{c}\text { Solids Layer } \\
\text { Height, cm }\end{array}$ & $\begin{array}{c}\text { Total (Liquid) } \\
\text { Height, cm }\end{array}$ & $\begin{array}{c}\text { Growth } \\
\text { Volume, } \mathrm{mL}\end{array}$ & $\begin{array}{c}\text { Growth Void } \\
\text { Fraction }\end{array}$ & $\begin{array}{c}\text { Pressure, } \\
\text { mm Hg }\end{array}$ \\
\hline \hline $13: 26: 00$ & 5.05 & 5.30 & 0.0 & 0.000 & 745 \\
\hline $13: 33: 44$ & 5.25 & 5.50 & 1.0 & 0.039 & 516 \\
\hline $13: 34: 24$ & 5.45 & 5.70 & 1.9 & 0.075 & 407 \\
\hline $13: 34: 54$ & 5.6 & 5.80 & 2.4 & 0.091 & 363 \\
\hline $13: 37: 34$ & 5.7 & 5.95 & 3.1 & 0.116 & 331 \\
\hline $13: 38: 49$ & 6 & 6.25 & 4.6 & 0.161 & 273 \\
\hline $13: 42: 54$ & & 6.50 & 5.8 & 0.195 & 244 \\
\hline $13: 44: 02$ & & 6.65 & 6.5 & 0.214 & 219 \\
\hline $13: 48: 24$ & & 6.90 & 7.7 & 0.244 & 203 \\
\hline $13: 50: 59$ & & 7.05 & 8.4 & 0.261 & 191 \\
\hline $13: 55: 04$ & & 7.20 & 9.1 & 0.277 & 182 \\
\hline $13: 56: 04$ & & 6.10 & 3.8 & 0.139 & 350 \\
\hline $13: 56: 59$ & & 7.55 & 10.8 & 0.312 & 163 \\
\hline $13: 57: 24$ & & 8.00 & 13.0 & 0.352 & 140 \\
\hline $13: 58: 14$ & & 8.15 & 13.7 & 0.365 & 133 \\
\hline $14: 03: 19$ & & 8.85 & 17.1 & 0.417 & 113 \\
\hline $14: 03: 34$ & & 9.50 & 20.2 & 0.458 & 96 \\
\hline $14: 04: 02$ & & 9.75 & 21.4 & 0.473 & 91 \\
\hline $14: 09: 34$ & & 9.80 & 21.6 & 0.476 & 89 \\
\hline $14: 12: 09$ & & 9.70 & 21.2 & 0.470 & 89 \\
\hline $14: 12: 54$ & & 10.00 & 22.6 & 0.486 & 79 \\
\hline $14: 13: 09$ & & 10.20 & 23.6 & 0.497 & 76 \\
\hline $14: 16: 54$ & & 9.70 & 21.2 & 0.470 & 73 \\
\hline $14: 18: 24$ & & 10.00 & 22.6 & 0.486 & 73 \\
\hline $14: 20: 29$ & & 9.60 & 20.7 & 0.464 & 57 \\
\hline $14: 23: 19$ & & 9.90 & 22.1 & 0.481 & 51 \\
\hline $14: 43: 19$ & & 8.50 & 15.4 & 0.392 & 9 \\
\hline & & & & & \\
\hline
\end{tabular}


Table B.3. Gas Retention Data for the S-102 Sludge in Vessel 7

\begin{tabular}{|c|c|c|c|c|c||}
\hline Time & $\begin{array}{c}\text { Solids Layer } \\
\text { Height, cm }\end{array}$ & $\begin{array}{c}\text { Total Height, } \\
\mathrm{cm}\end{array}$ & $\begin{array}{c}\text { Growth } \\
\text { Volume, } \mathrm{mL}\end{array}$ & $\begin{array}{c}\text { Growth Void } \\
\text { Fraction }\end{array}$ & $\begin{array}{c}\text { Pressure, } \\
\text { mm Hg }\end{array}$ \\
\hline $10: 12: 00$ & 7.45 & 7.45 & 0.0 & 0.000 & 748 \\
\hline $10: 13: 48$ & 7.60 & 7.60 & 0.7 & 0.020 & 568 \\
\hline $10: 14: 36$ & 7.50 & 7.50 & 0.2 & 0.007 & 683 \\
\hline $10: 15: 45$ & 7.75 & 7.75 & 1.4 & 0.039 & 422 \\
\hline $10: 17: 30$ & 7.80 & 7.80 & 1.7 & 0.045 & 403 \\
\hline $10: 21: 00$ & 8.10 & 8.10 & 3.1 & 0.081 & 301 \\
\hline $10: 24: 30$ & 8.20 & 8.20 & 3.6 & 0.093 & 262 \\
\hline $10: 28: 00$ & 8.25 & 8.25 & 3.9 & 0.098 & 249 \\
\hline $10: 31: 20$ & 8.45 & 8.45 & 4.8 & 0.120 & 190 \\
\hline $10: 40: 00$ & 8.50 & 8.50 & 5.1 & 0.125 & 148 \\
\hline $10: 42: 30$ & 8.55 & 8.55 & 5.3 & 0.130 & 133 \\
\hline $10: 45: 12$ & 8.70 & 8.70 & 6.0 & 0.145 & 116 \\
\hline $10: 46: 00$ & 8.75 & 8.75 & 6.3 & 0.150 & 108 \\
\hline $10: 52: 00$ & 9.00 & 9.00 & 7.5 & 0.174 & 84 \\
\hline $10: 54: 30$ & 9.05 & 9.05 & 7.7 & 0.179 & 83 \\
\hline $10: 57: 00$ & 9.15 & 9.15 & 8.2 & 0.188 & 70 \\
\hline $11: 04: 00$ & 9.20 & 9.20 & 8.4 & 0.192 & 52 \\
\hline $11: 10: 30$ & 9.20 & 9.20 & 8.4 & 0.192 & 23 \\
\hline $11: 15: 30$ & 9.25 & 9.25 & 8.7 & 0.197 & 5 \\
\hline $11: 18: 00$ & 9.10 & 9.10 & 7.9 & 0.183 & 543 \\
\hline & & & & & \\
\hline
\end{tabular}


Table B.4. Gas Retention Data for the S-102 Sludge in Vessel 8

\begin{tabular}{||c|c|c|c|c|c||}
\hline Time & $\begin{array}{c}\text { Solids Layer } \\
\text { Height, cm }\end{array}$ & $\begin{array}{c}\text { Total (Liquid) } \\
\text { Height, cm }\end{array}$ & $\begin{array}{c}\text { Growth } \\
\text { Volume, mL }\end{array}$ & $\begin{array}{c}\text { Growth Void } \\
\text { Fraction }\end{array}$ & $\begin{array}{c}\text { Pressure, } \\
\text { mm Hg }\end{array}$ \\
\hline \hline $13: 26: 37$ & 7.15 & 7.45 & 0.0 & 0.000 & 747 \\
\hline $13: 40: 57$ & 7.20 & 7.50 & 0.2 & 0.007 & 659 \\
\hline $13: 42: 17$ & 7.45 & 7.75 & 1.4 & 0.040 & 396 \\
\hline $13: 43: 17$ & 7.25 & 7.55 & 0.5 & 0.014 & 514 \\
\hline $13: 50: 17$ & 7.30 & 7.60 & 0.7 & 0.021 & 530 \\
\hline $13: 55: 17$ & 7.35 & 7.65 & 1.0 & 0.027 & 458 \\
\hline $13: 58: 17$ & 7.40 & 7.70 & 1.2 & 0.034 & 408 \\
\hline $14: 00: 17$ & 7.45 & 7.75 & 1.4 & 0.040 & 351 \\
\hline $14: 03: 17$ & 7.65 & 7.95 & 2.4 & 0.066 & 268 \\
\hline $14: 07: 17$ & 7.75 & 8.05 & 2.9 & 0.078 & 235 \\
\hline $14: 12: 17$ & 7.90 & 8.20 & 3.6 & 0.095 & 205 \\
\hline $14: 16: 17$ & 8.05 & 8.35 & 4.3 & 0.112 & 180 \\
\hline $14: 20: 17$ & 8.20 & 8.50 & 5.0 & 0.129 & 160 \\
\hline $14: 22: 17$ & 8.45 & 8.70 & 5.9 & 0.149 & 139 \\
\hline $14: 26: 17$ & 8.95 & 9.20 & 8.3 & 0.196 & 104 \\
\hline $14: 30: 17$ & 9.05 & 9.35 & 9.0 & 0.211 & 96 \\
\hline $14: 32: 17$ & 9.25 & 9.50 & 9.7 & 0.223 & 89 \\
\hline $14: 37: 17$ & 9.45 & 9.70 & 10.7 & 0.239 & 84 \\
\hline $14: 43: 37$ & 9.55 & 9.80 & 11.2 & 0.247 & 81 \\
\hline $14: 46: 17$ & 9.75 & 10.00 & 12.1 & 0.263 & 75 \\
\hline $14: 50: 17$ & 10.20 & 10.45 & 14.3 & 0.295 & 70 \\
\hline $14: 56: 17$ & & 10.50 & 14.5 & 0.300 & 66 \\
\hline $14: 56: 37$ & & 10.70 & 15.4 & 0.313 & 64 \\
\hline $14: 58: 17$ & & 10.10 & 12.6 & 0.271 & 63 \\
\hline $15: 00: 32$ & & 10.20 & 13.1 & 0.278 & 59 \\
\hline $15: 02: 17$ & & 10.00 & 12.1 & 0.263 & 59 \\
\hline $15: 03: 17$ & & 10.30 & 13.5 & 0.286 & 50 \\
\hline $15: 04: 17$ & & 10.50 & 14.5 & 0.300 & 50 \\
\hline $15: 05: 32$ & & 10.95 & 16.6 & 0.329 & 45 \\
\hline $15: 07: 12$ & & 10.10 & 12.6 & 0.271 & 45 \\
\hline & & & & & \\
\hline
\end{tabular}


Table B.5. Gas Retention Data for the SY-103 Whole Tank Composite in Vessel 3

\begin{tabular}{|c|c|c|c|c|c|}
\hline Time & $\begin{array}{l}\text { Solids Layer } \\
\text { Height, } \mathrm{cm}\end{array}$ & $\begin{array}{c}\text { Total (Liquid) } \\
\text { Height, cm }\end{array}$ & $\begin{array}{c}\text { Growth } \\
\text { Volume, } \mathrm{mL}\end{array}$ & $\begin{array}{l}\text { Growth Void } \\
\text { Fraction }\end{array}$ & $\begin{array}{l}\text { Pressure, } \\
\mathrm{mm} \mathrm{Hg}\end{array}$ \\
\hline $11: 10: 00$ & 10.45 & 14.00 & 0.0 & 0.000 & 754 \\
\hline $11: 14: 00$ & 10.45 & 14.00 & 0.0 & 0.000 & 606 \\
\hline $11: 16: 30$ & 10.45 & 14.05 & 0.2 & 0.005 & 531 \\
\hline $11: 20: 30$ & 10.50 & 14.10 & 0.5 & 0.010 & 450 \\
\hline $11: 22: 00$ & 10.50 & 14.10 & 0.5 & 0.010 & 422 \\
\hline $11: 25: 30$ & 10.55 & 14.15 & 0.7 & 0.014 & 383 \\
\hline $11: 29: 40$ & 10.55 & 14.20 & 1.0 & 0.019 & 283 \\
\hline $11: 33: 00$ & 10.60 & 14.25 & 1.2 & 0.024 & 230 \\
\hline $11: 35: 30$ & 10.65 & 14.30 & 1.4 & 0.028 & 209 \\
\hline $11: 41: 00$ & 10.65 & 14.30 & 1.4 & 0.028 & 210 \\
\hline $11: 43: 00$ & 10.70 & 14.35 & 1.7 & 0.033 & 176 \\
\hline $11: 45: 30$ & 10.75 & 14.45 & 2.2 & 0.042 & 140 \\
\hline $11: 46: 30$ & 10.85 & 14.60 & 2.9 & 0.055 & 120 \\
\hline $11: 48: 25$ & 11.00 & 14.65 & 3.1 & 0.059 & 101 \\
\hline 11:50:00 & 11.10 & 14.70 & 3.4 & 0.063 & 92 \\
\hline $11: 52: 00$ & 11.20 & 14.85 & 4.1 & 0.076 & 78 \\
\hline 11:53:10 & 11.35 & 15.00 & 4.8 & 0.088 & 68 \\
\hline $11: 54: 00$ & & 15.05 & 5.1 & 0.092 & 66 \\
\hline $11: 56: 00$ & & 14.80 & 3.9 & 0.072 & 66 \\
\hline $11: 56: 45$ & & 15.00 & 4.8 & 0.088 & 55 \\
\hline 11:58:00 & & 14.85 & 4.1 & 0.076 & 48 \\
\hline $12: 00: 30$ & & 15.00 & 4.8 & 0.088 & 37 \\
\hline $12: 01: 30$ & & 14.40 & 1.9 & 0.037 & 32 \\
\hline $12: 04: 00$ & & 14.10 & 0.5 & 0.010 & 31 \\
\hline $12: 06: 00$ & & 14.05 & 0.2 & 0.005 & 26 \\
\hline $12: 07: 00$ & & 14.00 & 0.0 & 0.000 & 22 \\
\hline 12:10:00 & & 14.00 & 0.0 & 0.000 & 18 \\
\hline 12:11:30 & & 14.10 & 0.5 & 0.010 & 14 \\
\hline $12: 12: 30$ & & 14.10 & 0.5 & 0.010 & 13 \\
\hline
\end{tabular}


Table B.6. Gas Retention Data for the SY-103 Nonconvective Composite in Vessel 4

\begin{tabular}{|c|c|c|c|c|c||}
\hline Time & $\begin{array}{c}\text { Solids Layer } \\
\text { Height, cm }\end{array}$ & $\begin{array}{c}\text { Total (Liquid) } \\
\text { Height, cm }\end{array}$ & $\begin{array}{c}\text { Growth } \\
\text { Volume, } \mathrm{mL}\end{array}$ & $\begin{array}{c}\text { Growth Void } \\
\text { Fraction }\end{array}$ & $\begin{array}{c}\text { Pressure, } \\
\text { mm Hg }\end{array}$ \\
\hline \hline $13: 43: 00$ & 5.15 & 5.35 & 0.0 & 0.000 & 756 \\
\hline $13: 45: 00$ & 5.15 & 5.35 & 0.0 & 0.000 & 653 \\
\hline $13: 49: 00$ & 5.15 & 5.35 & 0.0 & 0.000 & 600 \\
\hline $13: 51: 00$ & 5.20 & 5.40 & 0.2 & 0.010 & 568 \\
\hline $13: 53: 30$ & 5.20 & 5.40 & 0.2 & 0.010 & 498 \\
\hline $13: 55: 30$ & 5.20 & 5.40 & 0.2 & 0.010 & 448 \\
\hline $13: 59: 00$ & 5.25 & 5.45 & 0.5 & 0.019 & 357 \\
\hline $14: 01: 30$ & 5.25 & 5.45 & 0.5 & 0.019 & 319 \\
\hline $14: 04: 30$ & 5.25 & 5.45 & 0.5 & 0.019 & 281 \\
\hline $14: 07: 15$ & 5.35 & 5.55 & 0.9 & 0.037 & 234 \\
\hline $14: 09: 45$ & 5.40 & 5.70 & 1.7 & 0.064 & 183 \\
\hline $14: 12: 00$ & 5.45 & 5.70 & 1.7 & 0.064 & 166 \\
\hline $14: 13: 30$ & 5.45 & 5.75 & 1.9 & 0.073 & 153 \\
\hline $14: 16: 00$ & 5.50 & 5.80 & 2.1 & 0.081 & 140 \\
\hline $14: 19: 00$ & 5.55 & 5.85 & 2.4 & 0.089 & 126 \\
\hline $14: 21: 30$ & 5.55 & 5.85 & 2.4 & 0.089 & 114 \\
\hline $14: 23: 00$ & 5.70 & 6.00 & 3.1 & 0.113 & 95 \\
\hline $14: 26: 00$ & 5.75 & 6.05 & 3.3 & 0.121 & 86 \\
\hline $14: 27: 30$ & 6.00 & 6.25 & 4.3 & 0.149 & 70 \\
\hline $14: 30: 30$ & 6.05 & 6.30 & 4.5 & 0.156 & 66 \\
\hline $14: 31: 30$ & 6.25 & 6.50 & 5.4 & 0.183 & 60 \\
\hline $14: 33: 00$ & 6.35 & 6.55 & 5.7 & 0.188 & 56 \\
\hline $14: 36: 00$ & 6.55 & 6.75 & 6.6 & 0.212 & 50 \\
\hline $14: 38: 00$ & 6.65 & 6.80 & 6.9 & 0.217 & 48 \\
\hline $14: 39: 30$ & 6.75 & 6.90 & 7.3 & 0.228 & 46 \\
\hline $14: 42: 00$ & & 7.05 & 8.1 & 0.248 & 43 \\
\hline $14: 44: 00$ & & 7.20 & 8.8 & 0.264 & 41 \\
\hline $14: 47: 00$ & & 7.45 & 9.9 & 0.289 & 39 \\
\hline $14: 49: 00$ & & 7.55 & 10.4 & 0.299 & 37 \\
\hline $14: 50: 30$ & & 7.55 & 10.4 & 0.299 & 33 \\
\hline $14: 54: 00$ & & 6.50 & 5.4 & 0.182 & 30 \\
\hline & & & & & \\
\hline
\end{tabular}

B.7 
Table B.6 (contd)

\begin{tabular}{|c|c|c|c|c|c|}
\hline Time & $\begin{array}{c}\text { Solids Layer } \\
\text { Height, cm }\end{array}$ & $\begin{array}{c}\text { Total (Liquid) } \\
\text { Height, } \mathrm{cm}\end{array}$ & $\begin{array}{c}\text { Growth } \\
\text { Volume, } \mathrm{mL}\end{array}$ & $\begin{array}{c}\text { Growth Void } \\
\text { Fraction }\end{array}$ & $\begin{array}{c}\text { Pressure, } \\
\mathrm{mm} \mathrm{Hg}\end{array}$ \\
\hline $14: 56: 00$ & & 6.00 & 3.1 & 0.112 & 27 \\
\hline $15: 01: 00$ & & 6.00 & 3.1 & 0.112 & 20 \\
\hline $15: 03: 30$ & & 6.00 & 3.1 & 0.112 & 16 \\
\hline $15: 07: 00$ & & 6.00 & 3.1 & 0.112 & 13 \\
\hline
\end{tabular}




\section{Distribution}

No. of

Copies

Offsite

2 Office of Scientific and Technical Information

H. K. Fauske

Fauske and Associates Inc 16W070 W. 83rd Street

Burr Ridge, IL 60521

C. W. Forsberg

P.O. Box 2008

MS 6495

Oak Ridge, TN 37831

B. C. Hudson

P.O. Box 271

Lindsborg, KA 67456

J. L. Kovach

Nuclear Consulting Services Inc.

P.O. Box 29151

Columbus, $\mathrm{OH} \quad 43229-0151$

T. S. Kress

102 B Newridge Road

Oak Ridge, TN 37830-8118

T. E. Larson

2711 Walnut Street

Los Alamos, NM 87544

4 Los Alamos National Laboratory

P.O. Box 1663

Los Alamos, NM 87545

Attn: D. R. Bennett, K575

W. L. Kubic, K575

K. Pasamehmetlogu, K575

J. R. White, K\$575
No. of

Copies

N. G. McDuffie

Civil Engineering Department

Apperson Hall 202

Oregon State University

Corvallis, OR 97331-2302

D. A. Powers

Sandia National Laboratory

7964 Sartan Way NE, MS 0744

Albuquerque, NM 87185-0744

W. Schulz

727 Sweethead Drive

Wilmington, DE 19800

S. E. Slezak

MS 1004

Sandia National Laboratory

P.O. Box 5800

Albuquerque, NM 87110

W. R. Rossen

Dept. of Petroleum/Geosystems

Engineering

The University of Texas at Austin

Austin, TX 78712-3246

Onsite

6 DOE Richland Operations Office

M. H. Campbell

$57-73$

K. O. Chen

S7-54

J. M. Gray

S7-54

C. A. Groendyke

S7-54

W. F. Hendrickson

57-54

G. W. Rosenwald

Distr.1 
No of

Copies

25 Westinghouse Hanford Company

H. Babad

S. A. Barker

W. B. Barton

R. E. Bauer

D. R. Bratzel

R. J. Cash

G. L. Dunford

S. J. Eberlein

R. F. Eggers

L. L. Fritts

R. C. Hill

K. M. Hodgson

G. D. Johnson (5)

N. W. Kirch

C. E. Leach

J. W. Lentsch

D. M. Ogden

D. A. Reynolds

G. R. Sawtelle

E. R. Siciliano

R. J. Van Vleet

Other

L. M. Stock
No of

Copies

47 Pacific Northwest National Laboratory

S. Q. Bennett

K7-90

P. R. Bredt (3)

P7-25

M. E. Brewster

K9-62

J. W. Brothers (5)

K9-20

S. A. Bryan

P7-25

J. L. Buelt

P7-41

S. D. Colson

K2-14

P. A. Gauglitz (15)

P7-41

J. H. Konynenbelt

P7-41

T. E. Michener

K7-15

L. G. Morgan

B. J. Palmer

K6-48

K7-15

L. R. Pederson

M. R. Powell

S. D. Rassat (3)

A. Shekarriz

C. W. Stewart

J. M. Tingey

S. M. Tingey

P. D. Whitney

K2-44

P7-19

P7-41

K7-15

K7-15

P7-25

P7-25

Information Release (5)
K5-12

K1-06 